\title{
Preliminary Analyses of Scenarios for Potential Human Interference for Repositories in Three Salt Formations
}

\section{Technical Report}

October 1985

INTERA Technologies, Inc.

prepared for

Office of Nuclear Waste Isolation Battelle Memorial Institute 505 King Avenue

Columbus, OH 43201-2693

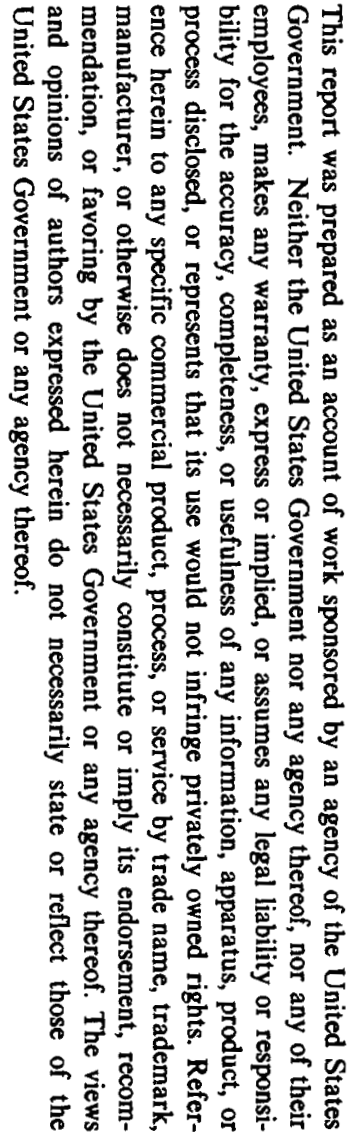

The content of this report was effective as of July 1984. This report was prepared by INTERA Technologies, Inc., for Battelle Project Management Division, Office of Nuclear Waste Isolation under Contract No. DE-AC02-83CH10140 with the U.S. Department of Energy.

This document is 


\section{DISCLAIMER}

This report was prepared as an account of work sponsored by an agency of the United States Government. Neither the United States Government nor any agency Thereof, nor any of their employees, makes any warranty, express or implied, or assumes any legal liability or responsibility for the accuracy, completeness, or usefulness of any information, apparatus, product, or process disclosed, or represents that its use would not infringe privately owned rights. Reference herein to any specific commercial product, process, or service by trade name, trademark, manufacturer, or otherwise does not necessarily constitute or imply its endorsement, recommendation, or favoring by the United States Government or any agency thereof. The views and opinions of authors expressed herein do not necessarily state or reflect those of the United States Government or any agency thereof. 


\section{DISCLAIMER}

Portions of this document may be illegible in electronic image products. Images are produced from the best available original document. 
A-1 Pressure Boundary Conditions for Palo Duro Basin Local

Ground-Water Flow Modeling......................... 172

A-2 Thickness of Layers in Paradox Sice Mode1............. 174

A-3 Pressure Boundary Conditions for Paradox Basin Local

Ground-Water Flow Modeling....................... 176

A-4 Pressure Boundary Conditions for Richton Dome Local Ground-Water Flow Modeling.......................

E-1 Minimum Brine Volumes to Satisfy 1.E-5 per Year Fractional Release Criterion............................... 206

E-2 Minimum Brine Volumes to Satisfy EPA Criterion for Release to Accessible Environment......................... 207 
Preliminary analyses of scenarios for human interference with the performance of a radioactive waste repository in a deep salt formation are presented. The following scenarios are analyzed: (1) the U-Tube Connection Scenario involving multiple connections between the repository and the overlying aquifer system, (2) the Single Borehole Intrusion Scenario involving penetration of the repository by an exploratory borehole that simultaneously connects the repository with overlying and underlying aquifers, and (3) the Pressure Release Scenario involving inflow of water to saturate any void space in the repository prior to creep closure with subsequent release under near lithostatic pressures following creep closure. The methodology to evaluate repository performance in these scenarios is described and this methodology is applied to reference systems in three candidate formations: bedded salt in the Palo Duro Basin, Texas; bedded salt in the Paradox Basin, Utah; and the Richton Salt Dome, Mississippi, of the Gulf Coast Salt Dome Basin. 
FOREWORD

The National Waste Terminal Storage (NWTS) program was established in 1976 by the U.S. Department of Energy's (DOE) predecessor, the Energy Research and Development Administration." In September 1983, this program became the Civilian Radioactive Waste Management (CRWM) Program. Its purpose is to develop technology and provide facilities for safe, environmentally acceptable, permanent disposal of high-level waste (HLW). HLW includes wastes from both commercial and defense sources, such as spent (used) fuel from nuclear power reactors, accumulations of wastes from production of nuclear weapons, and solidified wastes from fuel reprocessing.

The information in this report pertains to the preliminary human interference studies of the Salt Repository Project of the Office of Geologic Repositories in the CRWM Program.

This report was developed by L. D. Rickertsen and M. Reeves of INTERA Technologies, Inc. for the Office of Nuclear Waste Isolation. 
EXECUTIVE SUMMARY............................. 1

ES.1 U-TUBE CONNECTION SCENARIO................... 2

ES.2 SINGLE BOREHOLE INTRUSION SCENARIO.............. 3

ES.3 PRESSURE RELEASE SCENARIO................... 8

HUMAN INTERFERENCE SCENARIOS..................... 15

2.1 SCENARIO DEFInITION........................ 15

2.1.1 Connections with an Overlying Aquifer....... 15

2.1.2 Simultaneous Connections With Overlying and Underlying Aquifers.................. 16

2.1.3 Pressure Release..................... 19

2.2 PERformance meAsUres...................... 20

2.3 PHYSICAL PROCESSES AND EVALUATION OF SCENARIOS....... 22

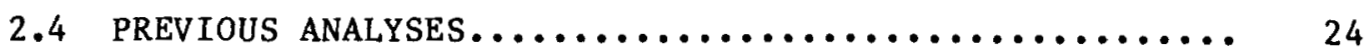

2.4.1 Connections With An Overlying Aquifer........ 24

2.4.2 Simultaneous Connections With Overlying and Underlying Aquifers................ 24

2.4.3 Pressure Release..................... 25

3 DESCRIPTION OF THE REPOSITORY SYSTEM............... 27

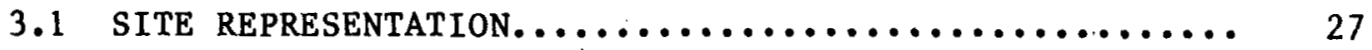

3.1.1 Palo Duro Basin Site................... 27

3.1.2 Paradox Basin Site................... 28

3.1.3 Richton Dome Site.................... 28

3.2 UNDERGROUND FACILITY...................... 29

3.3 WASTE DESCRIPTION...................... 32 
TABLE OF CONTENTS

(Continued)

Section

Page

4 MULTIPLE CONNECTIONS WITH OVERLYING AQUIFER - U-TUBE

CONNECTION SCENARIO......................... 37

4.1 LOCAL FLOW IN THE U-TUBE................... 37

4.1.1 Local Flow in U-Tube at Palo Duro Basin Site.. 38

4.1.2 Local Flow in the U-Tube at the Paradox

Basin Site.......................... 44

4.1.3 Local Flow in U-Tube at Richton Dome Site..... 51

4.1.4 Effects of Temperature and Salinity.......... 56

4.2 RELEASE OF RADIONUCLIDES FROM UNDERGROUND FACILITY

FOR U-TUBE SCENARIO............................ 58

4.3 RELEASE TO THE ACCESSIBLE ENVIRONMENT FOR U-TUBE

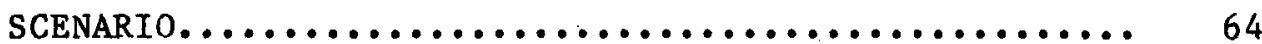

4.4 CONCLUSIONS FROM U-TUBE CONNECTION SCENARIO

ANALYSES................................ 66

5 SIMULTANEOUS CONNECTIONS WITH OVERLYING AND UNDERLYING

AQUIFERS - SINGLE BOREHOLE INTRUSION SCENARIO........... 71

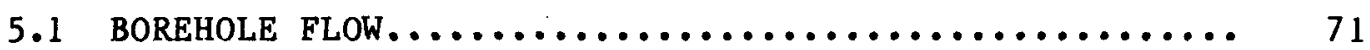

5.1.1 Borehole Flow at the Palo Duro Basin Site..... 72

5.1.2 Borehole Flow at the Paradox Basin Site...... 80

5.2 CREEP AND DISSOLUTION OF SALT IN THE BOREHOLE....... 82

5.2.1 Magnitude of Creep Rate in Borehole.......... 86

5.2.2 Magnitude of Dissolution Rate in Borehole..... 92

5.3 RELEASE OF RADIONUCLIDES FROM UNDERGROUND FACILITY

FOR SINGLE BOREHOLE INTRUSION SCENARIO........... 102

5.3.1 Underground Facility Performance at the

Palo Duro Basin Site................... 102

5.3.2 Underground Facility Performance at the

Paradox Basin Site................... 105 
5.4 RELEASE TO THE ACCESSIBLE ENVIRONMENT FOR SINGLE BOREHOLE INTRUSION SCENARIO................. 107

5.4.1 Palo Duro Basin Site Assessment............ 108

5.4.2 Paradox Basin Site Assessment............. 121

5.4.3 Integrated Release to the Accessible Environment........................ 121

5.5 CONCLUSIONS FROM SINGLE BOREHOLE INTRUSION SCENARIO

ANALYSES..............................

6.1 CREEP CLOSURE OF REPOSITORY OPENINGS............. 131

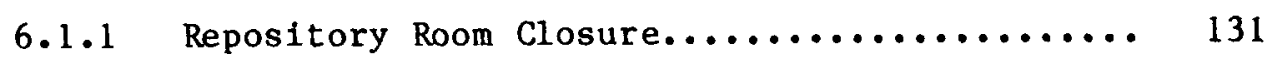

6.1.2 Consolidation of the Crushed Salt Backfi11... 137

6.2 FLOW OF WATER INTO REPOSITORY OPENINGS............ 141

6.2.1 Infiltration Through Shaft Disturbed Zone.... 143

6.2.2 Migration of Brine Inclusions............. 152

6.2 .3 other Sources of Water................ 155

6.3 RELEASE OF BRINE. FROM THE REPOSITORY.............. 156

6.4 CONCLUSIONS FROM PRESSURE-RELEASE ANALYSES......... 156

7 CONCLUSIONS AND RECOMMENDATIONS FROM PRELIMINARY HUMAN INTERFERENCE SCENARIO ANALYSES..................... 159 


\section{APPENDICES}

MINIMUM CONSEQUENTIAL BRINE VOLUMES FOR SALT REPOSITORIES

F

BRINE MIGRATION AT POTENTIAL SALT SITES IN

PALO DURO, PARADOX, AND THE GULF COAST. 


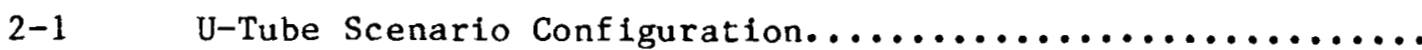

Time Dependence of Water Volume in Pressure Release

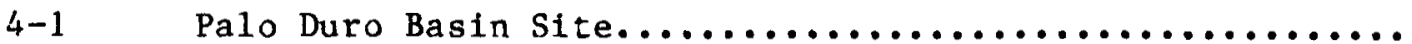

4-2 Horizontal Representation of Palo Duro Site for U-Tube

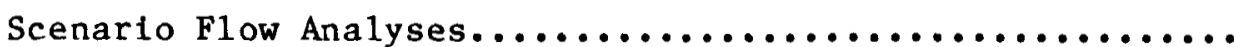

4-3 Vertical Representation of Palo Duro Site for U-Tube

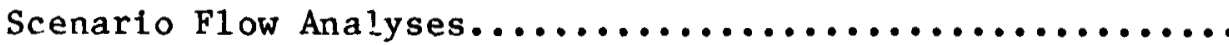

4-4 U-Tube Flow Calculated as a Function of U-Tube Conductivity................................. 46

4-5 Paradox Basin Site........................... 47

4-6 Horizontal Representation of Paradox Site for U-Tube Scenario Flow Analyses........................... 48

4-7 Vertical Representation of Paradox Site for U-Tube Scenario Flow Analyses......................... 50

4-8 Richton Dome Site........................... 52

4-9 Vertical Representation of Richton Site for U-Tube Scenario Flow Analyses........................... 53

4-10 Horizontal Representation of Richton Site for U-Tube Scenario Flow Analyses......................... 55

5-1 Representation of Palo Duro Stratigraphy for Single

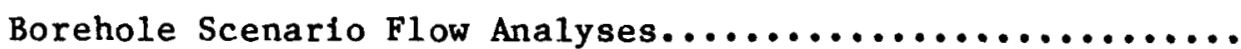

5-2 Horizontal Discretization of Palo Duro Site for Single

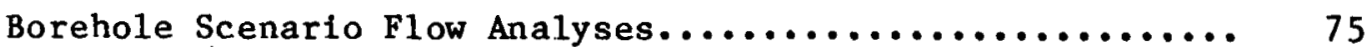

5-3 Calculated Borehole Flow Rate for Palo Duro Basin......... 79

5-4 Representation of Paradox Basin Stratigraphy for Single

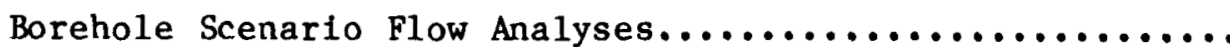


5-5 Horizontal Discretization of Paradox Basin Site for Single Borehole Scenario Flow Analyses................ 84

5-6 Conceptual Model for Evaluation of Thermomechanical Conditions Near Borehole.......................... 88

5-7 Effect of Fluid Pressure on Creep Closure at Depth

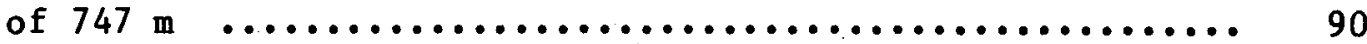

5-8 Comparison of Calculated Asymptotic Closure Rates with Steady-State Creep Parameter......................... 91

5-9 Borehole Radius Calculated at Selected Times............. 93

5-10 Calculated Progressive Salinity of Borehole Flow......... 95

5-11 Calculated Fluid and Rock Temperature with Depth......... 96

5-12 Calculated Radius of Borehole Versus Time............. 97

5-13 Calculated Fluid Velocity in Borehole................. 98

5-14 Calculated Borehole Radius with Depth................. 100

5-15 Calculated Borehole Dissolution as a Function of Salt

Content of Formation............................ 101

5-16 Calculated Fractional Release Rate from Underground Facility for Palo Duro Basin......................... 104

5-17 Calculated Fractional Release Rate from Underground

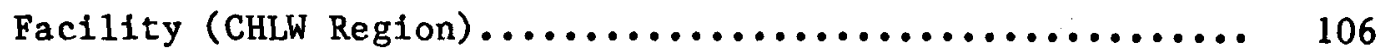

5-18 Calculated Release Rate to Accessible Environment Palo Duro Basin - Granite Wash $\left({ }^{129} \mathrm{I} ;{ }^{14} \mathrm{C}\right) \ldots \ldots \ldots \ldots \ldots \ldots . . .110$

5-19 Calculated Release Rate to Accessible Environment

Palo Duro Basin - Granite Wash $\left({ }^{237} \mathrm{~Np}+{ }^{233_{\mathrm{U}}}+{ }^{229} \mathrm{Th}\right) \ldots \ldots 111$

5-20 Calculated Release Rate to Accessible Environment Palo Duro Basin - Granite Wash $\left({ }^{242} \mathrm{Pu}+{ }^{238} \mathrm{U} \rightarrow\right.$ $\left.234 \mathrm{U}+{ }^{230_{\mathrm{Th}}}+{ }^{226} \mathrm{Ra}\right) \ldots \ldots \ldots \ldots \ldots \ldots \ldots \ldots \ldots \ldots \ldots \ldots \ldots \ldots$

5-21 Calculated Release Rate to Accessible Environment Palo Duro Basin - Granite Wash $\left({ }^{235} \mathrm{U}\right) \ldots \ldots \ldots \ldots \ldots \ldots \ldots \ldots$ 


\section{LIST OF FIGURES}

(Continued)

Figure

Page

5-22 Calculated Release Rate to Accessible Environment Palo Duro Basin - Granite Wash $\left({ }^{236} \mathrm{U}+{ }^{232} \mathrm{Th}\right) \ldots \ldots \ldots \ldots \ldots . . .114$

5-23 Calculated Release Rate to Accessible Environment Palo Duro Basin - Wolf camp $\left({ }^{129} \mathrm{I} ;{ }^{14} \mathrm{C}\right) \ldots \ldots \ldots \ldots \ldots \ldots \ldots . \ldots \ldots$

5-24 Calculated Release Rate to Accessible Environment Palo Duro Basin - Wolfcamp $\left({ }^{237} \mathrm{~Np}+{ }^{233} \mathrm{U} \rightarrow{ }^{229} \mathrm{Th}\right) \ldots \ldots \ldots \ldots 117$

5-25 Calculated Release Rate to Accessible Environment Palo Duro Basin - Wolfcamp $\left({ }^{238_{U}}+{ }^{234} \mathrm{U} \rightarrow{ }^{230_{\mathrm{Th}}}+{ }^{226} \mathrm{Ra}\right) \ldots 118$

5-26 Calculated Release Rate to Accessible Environment Palo Duro Basin - Wolfcamp $\left({ }^{235}\right.$ U).................... 119

5-27 Calculated Release Rate to Accessible Environment Palo Duro Basin - Wolf camp $\left({ }^{236} \mathrm{U}+{ }^{232} \mathrm{Th}\right) \ldots \ldots \ldots \ldots \ldots \ldots \ldots . \ldots 120$

5-28 Calculated Release Rate to Accessible Environment Paradox Basin - Leadville $\left({ }^{129} \mathrm{I} ;{ }^{14} \mathrm{C}\right) \ldots \ldots \ldots \ldots \ldots \ldots \ldots \ldots . \ldots 123$

5-29 Calculated Release Rate to Accessible Environment Paradox Basin - Leadville $\left({ }^{237} \mathrm{~Np} \rightarrow{ }^{233_{\mathrm{U}}} \rightarrow{ }^{229} \mathrm{Th}\right) \ldots \ldots \ldots \ldots . .124$

5-30 Calculated Release Rate to Accessible Environment Paradox Basin - Leadville $\left({ }^{238} \mathrm{U}+{ }^{234} \mathrm{U}+{ }^{230} \mathrm{Th}+{ }^{226} \mathrm{Ra}\right) \ldots$

5-31 Calculated Release Rate to Accessible Environment Paradox Basin - Leadville $\left({ }^{235}\right.$ U)..................... 126

5-32 Calculated Release Rate to Accessible Environment Paradox Basin - Leadville $\left({ }^{236} U+{ }^{232} \mathrm{Th}\right) \ldots \ldots \ldots \ldots \ldots \ldots \ldots$

6-1 Calculated Repository Void Volume at Palo Duro Site....... 134

6-2 Calculated Repository Vold Volume at Paradox Site........ 135

6-3 Calculated Repository Void Volume at Richton Site........ 136

6-4 Comparison of Steady-State Creep Model of Room Closure

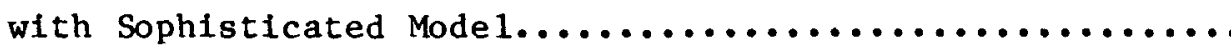


A-1 Phreatic Surface for Local Model of Richton Site.........

B-1 Schematic of Simple U-Tube Flow Model.

C-1 Simple Model of Salt Dissolution by Borehole Flow Based on Uniform Dissolution Versus Depth................ 188

C-2 Improved Model of Salt Dissolution by Borehole Flow Considering Progressive Saturation of Borehole Flow,

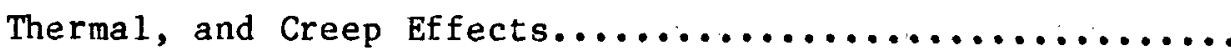

C-3 Conceptual Model for Borehole Dissolution and Creep

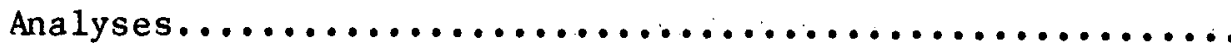


Fis-1 Performance Measures Calculated for U-Tube Connection

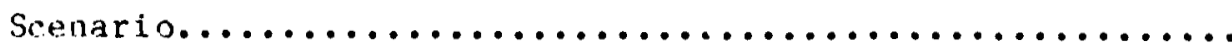

ES-2 Flow Rates Calculated for Single Borehole Intrusion

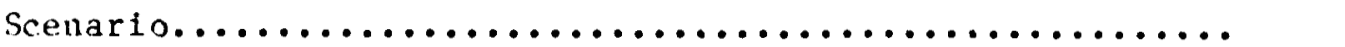

ES-3 Performance Measures Calculated for Single Borehole Intrusion scenario........................... 9

Es-4 Estinate of Total Water Influx to Repository........... 11

3-! Repository Design Parameters..................... 30

3-2 Description of Waste Packages..................... 31

3-3 Important Fission Products in Reference Waste........... 33

3-4 Important Actinides and Daughters in Reference Waste...... 34

3-5 Relative Thermal Decay Rates for Repository Waste........ 35

4-1 Flow Parameters for Reference U-Tube................. 39

4-2 Horizontal Grid Discretization of Palo Duro Site......... 42

4-3 In Situ Temperatures Assumed for Sites............... 45

4-4 Horizontal Grid Discretization for the Paradox Site....... 49

4-5 Horizontal Grid Discretization for the Richton Site...... 54

4-6 Summary of Local Flow Predicted for U-Tube at Three Sites.. 57

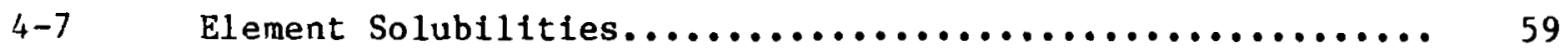

4-8 Effective Concentration of Selected Radionuclides Based on Element Solubility........................... 60

4-9 Waste Form Leach Rates.......................... 62

4-10 Effective Concentration of Radionuclide Based on Dissolution of Waste Form to Solubility Limit............ 63

4-11 Performance Measure for Release From Underground Facility

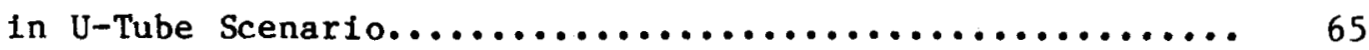

4-12 Integrated 10,000-Year Release From U-Tube Flow Through Spent Fuel Disposal Room....................... 67 
4-13 Integrated 10,000-Year Release From U-Tube Flow Through CHLW Disposal Room............................ 68

5-1 Parameters Assumed for Palo Duro Basin Site............ 74

5-2 Predicted Flow Rate Entering Receiving Units From Borehole in Palo Duro Basin............................. 78

5-3 Parameters Assumed for Paradox Basin Site.............. 83

5-4 Predicted Borehole Flow Rate at Paradox Basin Site....... 85

5-5 Material Properties for Salt Thermomechanical Analysis..... 89

5-6 Performance Measure for Release From Underground

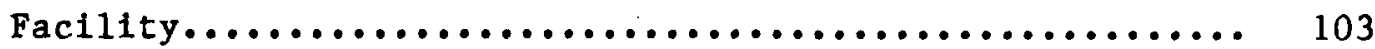

5-7 Radionuclide Transport Parameters.................. 109

5-8 Integrated Releases to Accessible Environment........... 122

6-1 Parameters for Room Closure Analysis................ 133

6-2 Crushed Salt Creep and Consolidation Properties.......... 140

6-3 Model Estimates of Repository Closure Times............ 142

6-4 Hydraulic Properties of Sedimentary Rock From

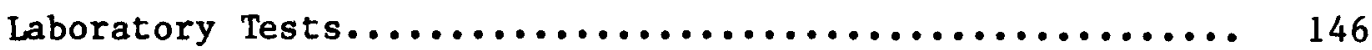

6-5 Hydrogeologic Description of Undisturbed Palo Duro Basin Formation for Infiltration Analysis................. 147

6-6 Hydrogeologic Description of Undisturbed Paradox Basin Formation for Infiltration Analysis.................. 148

6-7 Hydrogeologic Description of Undisturbed Richton Dome Formation for Infiltration Analysis................. 149

6-8 Estimate of Water Influx Through Shaft Disturbed Zone..... 150

6-9 Brine Migration at Salt Sites..................... 153

6-10 Estimate of Total Water Influx to Repository............ 154 
This report discusses potential unexpected human activities that could affect ihe nuclear waste coniainment and isolation in a geologic repository in a salt formation. The scenario assessmenis made are based on preliminary information for bedded salt sites in the Palo Duro Basin, Texas, and the Paradox Basin, Utah, and for the Richton Salt Dome in Perry County, Mississippi.

Initial assessments of reposicory performance considered a broad spectrum of scenarios involving human interference activities (Claiborne, 1974; Bingham and Barr, 1979; Guiftre et al, 1980; Harwe1.l et al, 1982). However, the scenarios which these reports indicate may be important are variations of only a few mata scenarios. Three of these are considered here:

1. Multiple connections of the repository with an overlying aquifer (U-Tube Connection Scenario).

2. Borehole connection of repository with overlying and underlying aquifers (Single Borehole Intrusion Scenario).

3. Pressure release of contaminated brine which, frum creep closure, is near lithostatic pressure (Pressure Release Scenario).

A scenario for salt solution mining (Harwell et al, 1982) has not been considered. Such a scenario does not appear credible given the communication requiremenis of $10 \mathrm{CFK} 60.2$ regarding the placement of markers and the distribution of relevani records, the systematic planning which precedes the relatively long-term (up to 50 years) operacion of a mined storage cavern, and the pasive controls on the site which society, out of self. interest, will likely exercise. 


\section{ES.1 U-TUBE CONNECTION SCENARIO}

This scenario involves diversion of water from the upper aquifer system through the repository by means of connections between the repository and the overlying units. One of these connections is assumed to be an exploratory borehole inadvertently drilled into a repository storage room. The other connection is assumed to be an access shaft which, although backfilled and plugged during permanent closure, still offers potential hydraulic connection between the aquifer and the host rock.

Assumptions to evaluate the flow through the U-Tube include:

- The borehole is assumed to be drilled into the storage room 1,000 years after permanent closure of the repository and connects the repository to the upper aquifer system. This assumption neglects the effect after 1,000 years of passive controls such as widely distributed records and permanent markers constructed at the site.

- The shaft and associated disturbed zone connect the repository to the upper aquifer system with an average conductivity of $1.0 \times 10^{-6} \mathrm{~m} / \mathrm{day}$.

- A pathway exists through the repository to connect the borehole and shaft. This pathway involves the mine tunnels, corridors, and the storage drift. The average conductivity of the crushed salt backfill in these openings and repository seal material is assumed to be $1.0 \times 10^{-6} \mathrm{~m} /$ day.

- Hydraulic properties of the system are assumed to be constant throughout the entire period of interest.

Based on these assumptions, the flow is calculated in a local flow model taking into account density variations due to increased salinity of the water in the salt units and the increased temperature due to the generation of heat by the radioactive waste. Pressure boundary conditions are provided from the regional analysis of the basin. 
To calculate radionuclide releases, a simple conceptual model is used. Important assumptions of this model include:

- Water in the storage room is assumed to be able to seep into the emplacement hole through and around the emplacement hole plug.

- Waste package containment after 1,000 years following permanent closure is neglected and release of radionuclides into the water is assumed to be controlled by leaching from the waste form and the solubility of the radionuclides and the constituents of the waste form.

- The decay in the transport of dissolved radionuclides from the emplacenent hole into the storage room is neglected.

Radionuclide release is evaluated from the radionuclide concentration and the calculated rate of flow in the storage room. The accessible environment in this case is assumed to be all of the upper aquifer system. This assumption is conservative and neglects any decrease in concentration that can occur in transport through the controlled zone.

Table ES-1 summarizes, for the U-Tube Connection Scenario, the maximum predicted fractional releases and the peak predicted integrated releases for any 10,000-year release following closure. The values for these performance measures are negligible relative to the proposed release standards (NRC, 1983, Section 60.112; EPA, 1982, Appendix). These results, although consistent with similar analyses of this scenario for a bedded salt site (Cranwell et al, 1982a; Pepping et al, 1983; DOE, 1983), are preliminary. They are subject to change as supporting data become increasingly more site-specific and as conservative assumptions are replaced by more realistic representations, including uncertainties.

\section{ES.2 SLNGLE BOREHOLE INTRUSION SCENARIO}

The Single Borehole Intrusion Scenario refers to the situation in which a borehole passes through the repository and connects the overlying aquifer system with a hydrostratigraphic unit below the repository horizon. A plezometric potential difference between the overlying and underlying units 
Table ES-1. Performance Measures Calculated for U-Tube Connection Scenario

Engineered Barrier

Performance Measure (a)

Potential Sites (Ci Released/Ci 1000-yr Inventory/Year)
System Performance Measure ${ }^{(b)}$
Palo Duro Basin
$8.3 \times 10^{-13}$
$4.5 \times 10^{-6}$
Paradox Basin
$8.0 \times 10^{-13}$
$4.5 \times 10^{-6}$
Richton Dome
$5.0 \times 10^{-14}$
$2.8 \times 10^{-7}$

(a) Performance measure specified by NRC (1983, Section 60.113). The values are based on the calculated fraction of radionuclides dissolving in water in the repository per year.

(b) Performance measure specifled by EPA (1982, Section 191.13 and Appendix). The measure is defined by:

$$
\text { Measure }=\sum_{1} \frac{\mathrm{Q}_{1}}{\mathrm{RL}_{1}}
$$

where $Q_{1}$ is the integrated release to the accessible environment during the 10,000-year time interval immediately following closure, the sum extends over all radionuclides, and $\mathrm{RL}_{i}$ is the EPA release limit for the $i^{\text {th }}$ radionuclide. In this document, $Q_{i}$ is taken to be the peak integrated release to the accessible environment during any 10,000-year time interval following closure. 
can induce water to flow through the borehole. Depending on the degree of salt saturation of the water, the flow rate, and repository conditions, the water may dissolve salt from the repository host rock. Such dissolution could expose some of the waste emplaced in the host rock and permit leaching of radionuclides from the waste form into the water.

Because no aquifer underlies the Richton Dome, the single borehole analysis was not performed for this case. The analysis of the Single Borehole Intrusion Scenario for bedded salt formations is based on a simple conceptual mode1. The model uses a generic salt repository design and a conservative representation for the radionuclide inventories. Preliminary data are used to represent the properties of the site. Where data are not yet available, conservative rates for processes, consistent with physical constraints on these rates, are utilized to provide the estimates of repository performance. The following assumptions are used to estimate the borehole flow rate:

- The area modeled extends 10 to $20 \mathrm{~km}$ beyond the borehole, depending on the site. Pressure conditions at the outer boundary of this local area are those derived from a regional hydrologic model of the basin and these pressures are assumed to be constant throughout the simulation period. Thus, constraints to the borehole flow due to limited availability of ground water in the aquifer are not taken into account.

- Plugging of the borehole by silt or other material is neglected and the modeled borehole flow is controlled by the hydraulic properties of the transmitting and receiving aquifers. Decreased flow due to insoluble matter released during salt dissolution is neglected.

- The finite-difference grid block representing the borehole is larger than the borehole would actually be; thus, the contact area between the borehole and the aquifer is conservatively large; and the flow rate into the borehole is overestimated, particularly for the case where the hydraulic resistance of the borehole is negligible. 
- Any change in hydraulic conductivity with time is neglected, and a constant driving potential is assumed to be maintained for at least 10,000 years.

The analyses are based on the regional studies of the aquifer units. The local flow model uses the regional information to estimate aquifer properties and flow boundary conditions. Maximum flow is calculated for the range of hydraulic conditions possible in the borehole. The results of these flow rate calculations are summarized in Table ES- 2 .

Dissolution in all salt units intersected by the borehole is calculated taking into account progressive saturation of the flow in these units, effects of temperature variations, both in situ and those induced by the heat production of the emplaced waste, and deformation of the borehole due to creep in the salt units. In particular, dissolution of the repository salt is calculated and used to evaluate the rate of exposure of waste packages to the borehole flow.

The calculation of radionuclide release from the repository is based on several important assumptions:

- The borehole is assumed to be drilled 1,000 years after permanent closure of the repository. Although the passive controls such as the permanent markers constructed at the site are likely to deter such drilling far beyond this time (Berry, 1983), this assumption has been made to provide conservative estimates of release.

- Radionuclide containment by the waste package after this time is neglected and release of radionuclides from waste exposed to the borehole flow is assumed to be controlled by the waste form leach rate and the solubility of the radionuclides and the constituents of the waste form.

The boundary to the accessible environment is considered to be the perimeter in the recelving unit that 1 ies $10 \mathrm{~km}$ from the borehole. The performance measures calculated in this case are the rate of dissolution of radionuclides into the borehole flow (fractional rate of release from the repository) and the integrated 10,000-year discharge of radionuclides across the $10 \mathrm{~km}$ boundary. 


\begin{tabular}{|c|c|c|}
\hline \multirow[t]{2}{*}{ Potential Sites } & \multicolumn{2}{|c|}{ Flow Rate ( $\mathrm{m}^{3} /$ day) } \\
\hline & Silted Borehole $(\mathrm{a})$ & Open Borehole ${ }^{(b)}$ \\
\hline Palo Duro Basin & 0.59 & 3800 \\
\hline Paradox Basin & 0.66 & 270 \\
\hline
\end{tabular}

(a) Conductivity in borehole $=30 \mathrm{~m} /$ day

(b) Resistance of borehole negligible relative to that of transmitting or receiving aquifers. 
The results of the analyses are summarized in Table ES-3. These results are preliminary and are subject to change as supporting data become increasingly more site-specific and as conservative assumptions are replaced by more realistic representations, including uncertainties.

The calculated performance measures, which are negligible relative to the proposed release standards (NRC, 1983, Section 60.112; EPA, 1982, Appendix), are typically much lower than those calculated in other analyses of the Single Borehole Intrusion Scenario (Cranwell et al, 1982a; DOE, 1983; Pepping et al, 1983). However these analyses do not attempt to account for constraints such as the progressive saturation of the flow.

\section{ES.3 PRESSURE RELEASE SCENARIO}

The processes comprising the Pressure Release Scenario may be summarized as follows:

- Water flows into the repository by avallable pathways before salt can creep to close voids remaining after permanent closure of the repository.

- Creep closure compresses fluld in these voids until near-lithostatic flufd pressures are attained.

- Heat generated in the repository due to the radioactive decay of the emplaced waste increases temperatures in the formation and modifies pressures and creep rates in the repository.

- Radionuclides leach into the water in the repository.

- Pressure releases through the shaft-seal system or through an exploratory borehole.

Considerations of the relatively small fluid volume in comparison to the repository volume, distribution of the fluid over the entire repository, and the affect of creep closure in hydraulically isolating a point of intrusion all appear to indicate that it is not possible here to establish a credible scenario for radionuclide release. These evaluations are described below. 
Table ES-3. Performance Measures Calculated for Single Borehole Intrusion Scenario

$\begin{array}{ccc} & \text { Engineered Barrier } & \\ \text { Performance Measure (a) } & \text { System Performance } \\ \text { Potential Sites (Ci Released/Ci 1000-yr Inventory/Year) } & \text { Measure (b) }\end{array}$
Palo Duro Basin
$2.2 \times 10^{-6}$
$6.3 \times 10^{-4}$
Paradox Basin
$2.2 \times 10^{-6}$
$3.8 \times 10^{-7}$

(a) Performance measure specified by NRC (1983, Section 60.113). The values are based on the calculated fraction of radionuclide dissolving in water in the repository per year.

(b) Performance measure specified by EPA (1982, Section 191.13 and Appendix). The measure is defined by:

$$
\text { Measure }=\sum_{i} \frac{Q_{i}}{R L_{i}}
$$

where $Q_{i}$ is the integrated release to the accessible environment during the 10,000-year time interval immediately following closure, the sum extends over all radionuclides, and $\mathrm{RL}_{\mathbf{i}}$ is the EPA release limit for the $i^{\text {th }}$ radionuclide. In this document, $Q_{i}$ is taken to be the peak integrated release to the accessible environment during any 10,000-year time interval following closure. 
Water Flow-Through Shaft Seal System. The shaft seal system is not likely to contribute significant quantities of water to the repository because the shaft seal system will be designed to satisfy objectives (NRC, 1983, Section 60.134) including:
"Seals for shafts and boreholes shall be designed so that following permanent closure they do not become pathways that compromise the geologic repository's ability to meet the performance objectives for the period following permanent closure."

Construction of such seals would be authorized only after reasonable assurance has been given that construction procedures would allow the repository to service its intended function of isolation (NRC. 1983, Section 60.31). Potential flow through the zone of rock disturbed by shaft construction is estimated and the amounts of water are shown to be insignificant. The estimated accumulations are shown in Table ES-4.

Water Flow From Surrounding Formations. Flow of water through intact salt will be limited because the permeability of the salt is very low. For example, the measured permeability is often below the resolution of the testing apparatus (Tien et a1, 1983, p. 209). Transient permeability introduced in the salt in the immediate vicinity of the repository openings due to excavation and to heat would be eliminated rapidly due to the creep consolidation of the salt.

Brine F1ow From Salt Formations. Because of the heat generated by the waste in the repository, brine inclusions in the salt can migrate toward the heat source. The calculated volumes of brine (see Appendix F), that could accumulate have been estimated and these estimates are shown in Table ES-4. Comparison of such analyses with experimental data (Hohlfelder, 1980), Indicates that such calculations predict much larger volumes collecting in the emplacement borehole than would occur in actual repository conditions. However, even considering the volumes in Table ES-4, the calculated accumulations are not large enough to impact repository performance significantly. 


\begin{tabular}{|c|c|c|c|}
\hline \multirow[b]{2}{*}{ Source } & \multicolumn{3}{|c|}{ Estimated Total Inflow $\left(\mathrm{m}^{3}\right)$} \\
\hline & Palo Duro Basin & Paradox Basin & Richton Dome \\
\hline Infiltration from Shat & & & \\
\hline Disturbed Zone & 120 & 310 & 160 \\
\hline (Chapter 6) & & & \\
\hline Hea:-Induced Brine & & & \\
\hline Migration (See & & & \\
\hline Appendix F) & 3,320 & 3,100 & 930 \\
\hline Total & 3,440 & 3,810 & 1,090 \\
\hline
\end{tabular}


Release of Radionuclides. The mechanisms listed above for fluid inflow into the repository also may be considered as possible release mechanisms for removing fluid from the repository. However, several factors arise which limit both inflow and release. Creep closure of the repository allows only 20 to 70 years for inflow and releases through the shaft disturbed zone. For such flows this time period is insufficient to permit degradation of the waste package and contamination of the fluid. Creep closure would hydraulically isolate a possible point of human intrusion. Also, the unmeasurably small permeabllity of the intact salt severely limits inflows and releases through interconnected porosity within the salt.

Further, the movement of brine inclusions toward the repository heat source is insufficient to permit significant amounts of fluid to migrate into the repository prior to creep closure, and the direction of such movement, as determined by the thermal gradient, would not permit contaminated inclusions to leave the repository region. The expected lifetime of the waste package (greater than 10,000 years) provides yet another barrier to the release of radioactive fluid from the repository. Finally, active and passive controls at the site make both inflows prior to creep closure and releases following such closure, which arise from human intrusion, a highly unlikely event. 
1 INTRODUCTION

This report discusses the assessments of the performance of spent fuel and high-level waste repositories in candidate salt sites in the Palo Duro Basin, the Paradox Basin, and the Gulf Coast Salt Dome Basin. They are focused on the impacts associated with any human activities that could potentially interfere with repository performance. These assessments are based on conservative assumptions and show releases significantly below current release standard quantities (EPA, 1982).

Salt formations are being investigated as potential repository sites because they are known to have properties which are favorable for radioactive waste isolation. For example, these formations generally contain little or no circulating ground water because the salt units are essentially impermeable. In many cases, the surrounding rock inhibits ground-water flow as well. The formations presently being considered are very stable and there is 1ittle or no likelihood that these conditions would change significantly during the period that waste isolation would be required.

Because of the isolation of the waste from the accessible environment offered by these natural features of the salt formation, it is important to take into account any potential penetrations of the salt formation that would permit the intrusion of ground water into the repository. This report discusses the preliminary analyses that have been conducted of potential intrusions such as exploratory drilling in the vicinity of the repository.

These analyses are part of an orderly program of human interference scenario performance assessments that is being conducted from two different directions. In the first, the credibility of such scenarios is being examined in terms of probabilities for human activities that could interfere with system performance. In most cases, these probabilities will be very small because of the poor resource potential of the sites. Furthermore, passive controls such as widely distributed records and permanent markers constructed at the site will be used to communicate the existence of the repository and thereby severely limit inadvertent intrusion at the site. On this basis, many of the scenarios being considered will not provide a credible means for significant impact to performance. 
The second thrust of the assessments is to analyze scenarios that have not so far been excluded from consideration. Such evaluations may determine that the consequences of the scenario are insignificant and therefore need not be considered further. Such evaluations also provide a basis to understand the physical processes involved and to identify the data base that must be developed to perform detailed assessments of the site. It is the application of the assessments from this second point of view that is discussed in this report.

The evaluations conducted to the present have been based on generic data and some preliminary site data. Simple models consistent with the level of data available have been developed for the processes involved in the scenarios. Where data are presently lacking or uncertain, conservative parameter values (in the sense of predicting greater consequences) are chosen. The models are then applied to predict repository system performance for the conservative conditions assumed. The reader is therefore cautioned that the assessments at this stage do not constitute predictions of system performance, but only serve to indicate if such analyses need to be carried to the next level of assessment. As the level of data increases and as the repository designs are refined, the scenarios can be considered in greater detail to determine specific expectations of system performance.

To date, the evaluations have been made for three candidate salt formations: the Palo Duro Basin, Texas; the Paradox Basin, Utah; and the Richton Dome, Mississippi. The first two of these represent bedded salt sites while the third is used to examine the scenarios in a diapiric formation. A specific location within any of these formations has not yet been selected and the analyses have relied on general information regarding the formations. Stratigraphic sequence, unit identification, and formation properties are based on representations that have been abstracted from drill stem tests throughout the regions. 


\subsection{SCENARIO DEFINITION}

Although there is a large number of possible scenarios for potential human interference with repository performance, most of these are variations of a few basic scenarios. The basic scenarios considered in this report are:

- scenarios involving connections of the repository with an overlying aquifer

- scenarios involving simultaneous connection of the repository with overlying and underlying aquifers

- scenarios involving inflow to the repository prior to creep closure with subsequent release under near lithostatic pressures after creep closure.

These categories are described in more detail below.

\subsubsection{Connections With an Overlying Aquifer}

If a borehole drilled to the repository horizon penetrates a disposal drift or other opening, a path is created for potential intrusion of water into the repository from an overlying aquifer. Likewise, the shafts excavated as part of the repository access could also provide such a pathway. of course, the shafts will be plugged and sealed as part of the permanent closure of the repository system; however, the potential for such a pathway still may exist if the shaft seals perform poorly or if rock in the vicinity of the shaft which nay be disturbed by the excavation is not effecively sealed. other, much less probable, connections could also be imagined: a fault in the formation could connect the repository to overlying strata for example. The probability of such a fault extending far enough to be significant and being undetected in the course of repository operations is extremely small. Nevertheless, at this point the possibility can still be included in the set of those scenarios involving connections with the overlying aquifer. 
If there are multiple connections of the repository with an overlying aquifer, it is possible for water flowing in the aquifer to be diverted down to the repository through one connection, for this water to dissolve radionuclides in the repository, and for the water to return to the aquifer through another connection, transporting radionuclides to the accessible environment. The basic configuration considered here is illustrated in Figure 2-1. In this configuration, one connection is provided by such a borehole and the other is provided by one of the shafts and the corresponding access tunnel excavated during repository construction. The probability for such a scenario is likely to be small since it involves a combination of lowprobability factors; however, quantitative assessment of the probability is not made here.

The connection in the repository between the two vertical legs would involve the repository tunnel and storage room network. These excavations are expected to be closed because of backfilling and sealing during the engineered closure operations. In addition, the host salt will creep to substantially reduce the vold space remaining in the repository following engineered closure. Under expected conditions, the permeability of the repository openings should therefore approximate in situ conditions in the salt.

\subsubsection{Simultaneous Connections With Overlying and Underlying Aquifers}

A possibility in this case is a borehole drilled through the candidate salt layer to a depth sufficient to connect aquifers that underlie and overlie the repository. Under normal drilling practice, the borehole would be cased at least through the upper aquifer. However, it is possible for the borehole to be 1mproperly cased or that the casing fails or is removed. In this case, pressure differences between the aquifers could induce flow through the borehole and affect the performance of the repository. For example, the flow could dissolve salt at the repository horizon; and, if waste packages were to be exposed to the flow as a result of the dissolution, the processes that determine waste package integrity and radionuclide containment could be affected. Radionuclides released to the flow could then be transported to the recelving aquifer and migrate to the accessible environment. This scenario is suggested in Figure 2-2. 


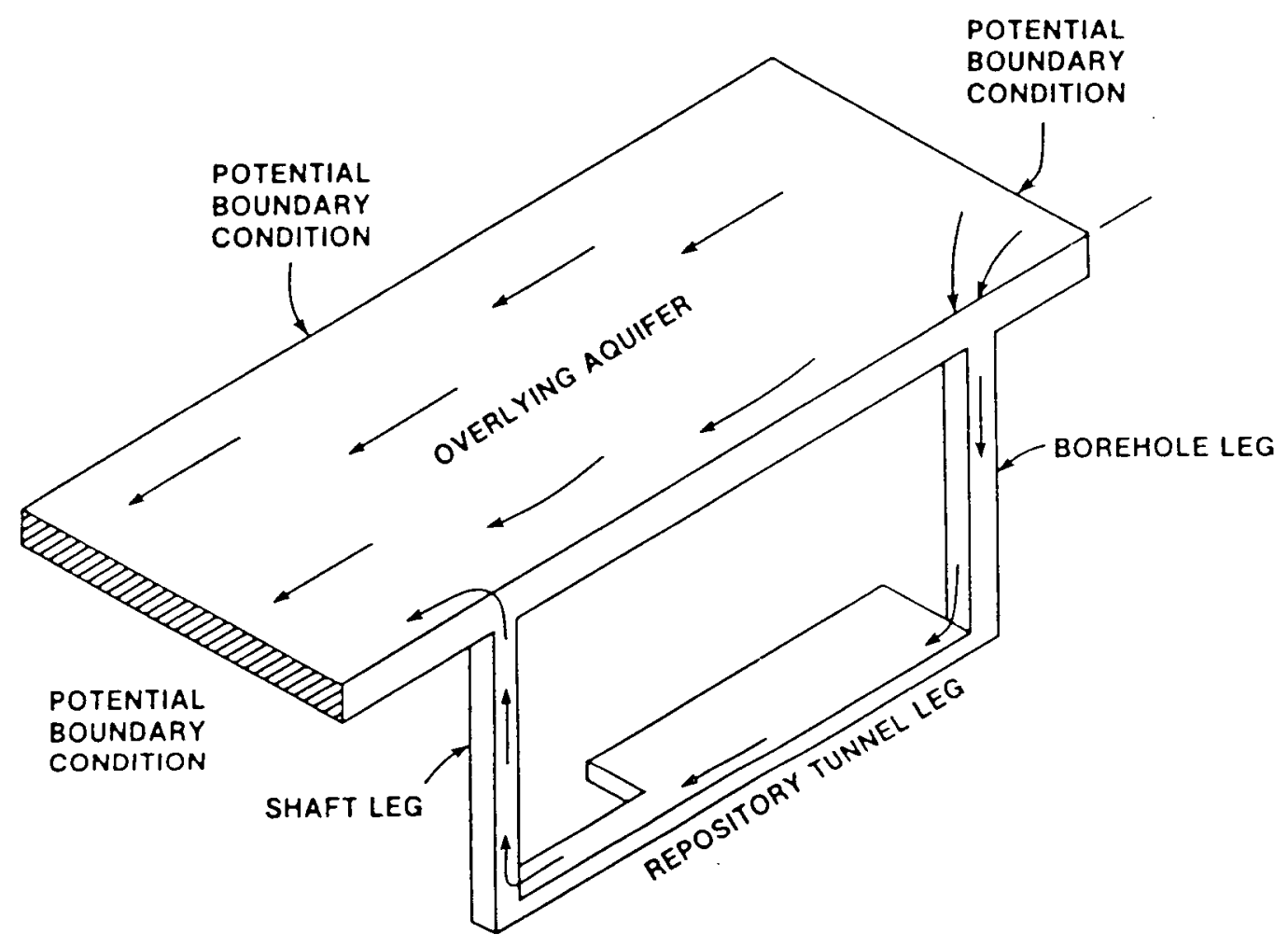

Figure 2-1. U-Tube Scenario Configuration 


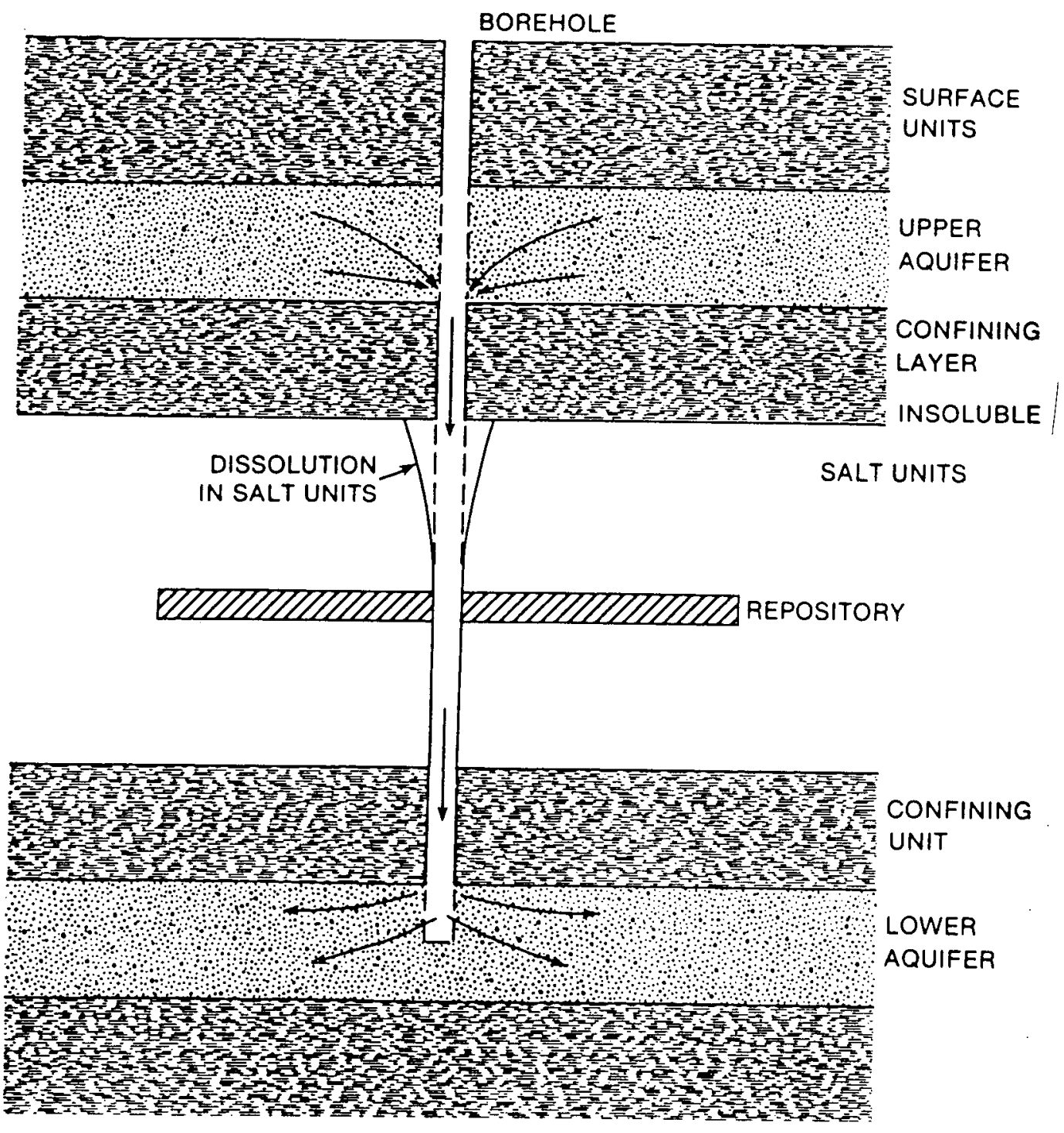

Figure 2-2. Single Borehole Intrusion Scenario 
Such a scenario may not be applicable to all sites, requiring as it does both the existence of overlying and underlying aquifers and some likelihood of drilling through the repository and connecting them. For example, this description does not fit the Richton Dome site since there is no underlying aquifer.

\subsubsection{Pressure Release}

This scenario consists of the following processes:

- Water flows into the repository by available pathways before salt can creep to close voids remaining after permanent closure of the repository.

- Creep closure compresses fluid in these voids until near lithostatic fluid pressures are attained.

- Heat generated in the repository due to the radioactive decay of the emplaced waste increases temperatures in the formation and modifies pressures and creep rates in the repository.

- Radionuclides leach into the water in the repository.

- A pressure release occurs.

Water-inflow mechanisms include flow through the shaft-seal system and the movement of brine inclusions into the repository. Release modes include the pressurized release of contaminated water through an exploratory borehole or through the shaft-seal system.

Two points are noteworthy in the above scenario definition. First, the salt is assumed to be effectively impermeable during the time period preceding release. Otherwise, pressurization to a near lithostatic pressure would not occur, and fluid pressures would rather approach hydrostatic equilibrium with the resident formation water. Second, there is the crucial importance of salt creep. It is during creep closure that any repository fluid is pressurized. 
Furthermore, it is creep closure which limits the time period during which this scenario may occur. Figure 2-3 typifies the process. As shown there, the repository volume decreases relatively rapidly until the fluidsaturated volume is reached at time $t_{S A T}$. For times greater than $t_{S A T}$, the repository response is dependent upon the compressibility of the fluid and the mode of release, if any. The time period $\mathrm{T}_{\text {CLOSE, of Figure 2-3, corresponds }}$ to the case of no fluid inflow. Since $\mathrm{T}_{\mathrm{SAT}}<\mathrm{T}_{\text {CLOSE }} \lesssim 100$ years (Chapter 6), the time available for fluid inflow into the repository is limited. In Chapter 6, the shaft-seal system and the creep process are examined formally, and the question of scenario credibility is considered.

\subsection{PERFORMANCE MEASURES}

The performance measures for the scenarios are those related to the prediction of release from the total repository system. Two performance measures are considered. The first refers to release from the engineered barrier system. The quantitative statement of the proposed criterion for the performance of the repository engineered barrier system is (NRC, 1983, Section 60.113):

"The engineered barrier system shall be designed, assuming anticipated processes and events, so that...the release rate of any radionuclide from the engineered barrier system following the containment period shall not exceed one part in 100,000 per year of the inventory of that radionuclide calculated to be present at 1,000 years following permanent closure, or such other fraction of the inventory as may be approved or specified by the Commission; provided, that this requirement does not apply to any radionuclide which is released at a rate less than $0.1 \%$ of the calculated total release rate 1imit. The calculated total release rate limit shall be taken to be one part in 100,000 per year of the inventory of radioactive waste, originally emplaced in the underground facility, that remains after 1,000 years of radioactive decay." 


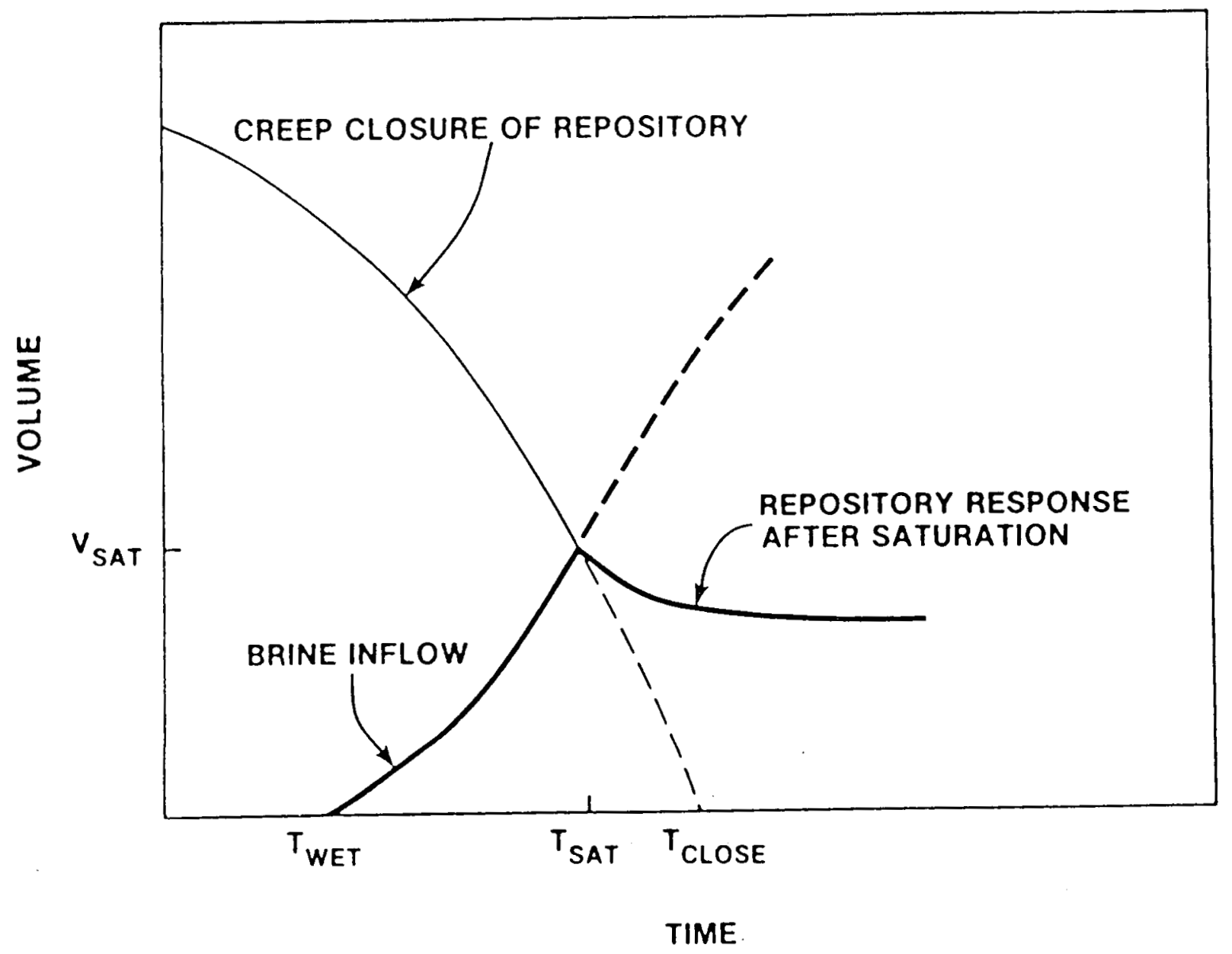

Figure 2-3. Time Dependence of Water Volume in Pressure Release Scenario 
Because of the qualification of "anticipated processes and events", it is not clear at this point how this criterion would be applied to particular human interference scenarios without a detailed probability assessment. Nevertheless the release of radionuclides from the underground facility can be predicted within the specific conceptual models and compared to the above performance measure for the sake of gaining perspective regarding the scenario. The procedure that is used in the preliminary assessments is to evaluate the fractional release rate defined as the fraction of the total system inventory for a specific radionuclide released from the confines of the underground facility each year. The regulatory performance measure can then be directly calculated from this fractional release rate. It is assumed that release from the engineered barrier system and release from the underground facility defined in this way are the same.

The second type of release measure is the total integrated release from the repository system to the accessible environment. The accessible environment as defined by the U.S. Environmental Protection Agency (EPA) includes all primary ground-water formations and secondary ground-water formations more than 10 kilometers from the location of emplacement of the wastes (EPA, 1982, Section 191.13). The EPA has also established criteria for total release of radionuclides to the accessible environment for the 10,000year period following permanent closure of the repository (EPA, 1982, Appendix). An upper bound to this performance measure is the integrated release during any 10,000-year time interval following permanent closure. For the purpose of these analyses, this latter, upper-bound estimate is evaluated.

\subsection{PHYSICAL PROCESSES AND EVALUATION OF SCENARIOS}

At the present level of understanding of the conditions in the repository system, the approach to the evaluation of these human intrusion scenarios is similar in all cases. The first step is to evaluate the thermal and thermomechanical environments in the system. These conditions determine the displacement rates within the repository and help to determine hydraulic properties.

The next step is to evaluate local flow conditions in the system. For those scenarios in which the flow is determined by the regional hydrologic system, the regional flow is evaluated first. The regional flow provides 
boundary conditions for the local flow evaluations. For those scenarios in which the local flows are not determined by regional recharge and discharge conditions, such as for brine migration in salt, local phenomenological models must be evaluated. Effects of temperature and salinity may affect the flow rates and need to be taken into account.

Then, the performance of the underground facility is evaluated in terms of the fractional rate of release of radionuclides. This performance measure is assumed to correspond to the rate of dissolution of radionuclides into the water in the repository. This rate will depend on the rate of exposure of waste packages to the water, the performance of the waste packages, and the chemical conditions in the repository. These factors are all defined in the conceptual model.

A simplification in the present assessments is that the containment of radionuclides in the waste packages is neglected altogether in these analyses because performance of the waste package under the unexpected conditions associated with the scenario has not yet been evaluated. In future assessments, detalled evaluations of waste package performance will be performed and integrated into the scenario model to provide more realistic evaluations.

In addition, because the chemical conditions anticipated for the repository are not precisely known at the present level of data and because the behavior of radionuclides and other constituents of the waste form are not well-understood in all cases, conservative values (in the sense of predicting greater concentrations) are used for solubilities and waste form leach rates.

Finally, the release to the accessible environment is evaluated. This evaluation is a transport calculation using the calculated release from the underground facility as a source term. Transport is calculated to the boundary that defines the accessible environment, a specified distance from the repository in the receiving aquifer. Specification of this distance will depend, in part, upon the scenario model. 


\subsection{PREVIOUS ANALYSES}

\section{4:1 Connections With An Overlying Aquifer}

The scenario described in Section 2.1.1 has been analyzed in the Waste Isolation Pilot Plant (WIPP) Safety Analysis Report (DOE, 1983, Section 8.1.2.2). These investigations predict low releases for a repository at the WIPP site in southeastern New Mexico. The approach used in the assessment of the WIPP site differs from that in this analysis. In the former analysis, constraints to release imposed by waste form and radionuclide solubility limits are not taken into account; but it is assumed that release is 1imited by the solubility of the salt host rock. Consequently, the predictions in the WIPP assessments are expected to exceed any actual conditions by a wide margin.

This scenario has also been investigated by the U.S. Nuclear Regulatory Commission (NRC) using an approach similar to that for the WIPP study (Cranwe11 et a1, 1982a; Pepping et a1, 1983). The approach and conclusions of the NRC studies are similar to those of the WIPP analysis.

\subsubsection{Simultaneous Connections With Overlying and Underlying Aquifers}

Repository performance assessment for this case has been investigated by the NRC for a bedded salt site (Cranwell et al, 1982a, Pepping et al, 1983). In addition, this scenario has been investigated in the WIPP Safety Analysis Report (DOE, 1983, Section 8.1.2.1). These investigations have used simple models for the repository release rates. For example, the increased salinity of water reaching the repository horizon due to dissolution in preceding salt units is not taken into account in the estimate of dissolution at the repository horizon. Parametric performance assessments of the scenario have been conducted (Cloninger et a1, 1980; Cloninger and Cole, 1981; Burkholder, 1982) to provide insight regarding the proposed NRC standards. However, these analyses have not attempted to model the processes that physically constrain the releases in detail.

A method to evaluate the borehole dissolution rate and the subsequent release has been described by Cranwell et al (1982b). An investigation of borehole growth by dissolution utilizing a realistic model was initiated by 
The repository system includes the site, the host rock formation, the underground facility at the site, and the waste. Each of these must be specified in sufficlent detail to permit analyses. Although candidate areas are being investigated, specific sites within these areas have not yet been selected. Consequently, the specification of the system cannot be very precise at present. Nevertheless, general data for the sites and preliminary repository designs are avallable on which the analyses can be conducted. Therefore, repository systems are defined herein consistent with the current level of information and to the level necessary to conduct the preliminary analyses.

\subsection{SITE REPRESENTATION}

Candidate sites are befing considered in the Palo Duro Basin, Texas, the Paradox Basin, Utah, and the Gulf Coast Salt Dome Basin. As a result of the preliminary investigations, data are available to crudely specify representative sites from these areas for the analyses.

\subsubsection{Palo Duro Basin Site}

A site typical of that which might be found in Deaf Smith or Swisher Counties in West Texas is used as the basis for the preliminary Palo Duro Basin analyses. The stratigraphic representation assumed here is based on the Stone \& Webster (1983) analysis.

The Permian rocks in the Palo Duro Basin include bedded salts that may serve as satisfactory candidate repository host strata. A prospective repository host layer is the Cycle 4 salt unit in the Lower San Andres Formation. A repository horizon in this unit about $725 \mathrm{~m}$ below the surface is assumed. The Lower San Andres includes a sequence of salt beds, several of which (including Cycle 4) are thick. Salt also occurs in other portions of the geology both above and below the Lower San Andres. The Upper Seven Rivers Formation in the Upper Permian layers, for example, is a thick salt bed. 
The Ogallala aquifer overlies the system and the Dockum is also relatively transmissive. These units are considered to make up the upper aquifer in the analyses. The repository host salt formation is separated from this aquifer by the sedimentary confining layers of the Upper Permian.

The Permian layers extend well below the assumed repository horizon as we11. Below these layers is the Wolfcamp which includes impermeable shales and more transmissive carbonate rocks. Deeper, the Pennsylvanian rocks also contain relatively permeable limestones, as well as arkosic sandstones, collectively referred to in the representation as the "granite wash."

\subsubsection{Paradox Basin Site}

The representation assumed for the Paradox Basin site is based on the analysis by Woodward-Clyde Consultants (1982) of the GD-1 well. In this case, the repository host is considered to be the Cycle 6 salt unit of the Paradox Formation. The representation given here is probably applicable to a location in either Davis Canyon or Lavender Canyon.

The repository horizon is assumed to be about $910 \mathrm{~m}$ below the surface. Overlying the Paradox Formation are relatively transmissive units composed largely of sandstone and limestone including the Cutler Formation rocks, the Cedar Mesa and the Elephant Canyon Formations, and the upper portion of the Honaker Trail Formation. Collectively, these are referred to here as the upper aquifer. Separating the repository host layer from these relatively transmissive zones are several hundred feet of sedimentary, confining rock in the Honaker Trail Formation.

The Paradox Formation, itself, is an extensive sequence of thick salt beds and interbeds. Below the Paradox are more permeable rocks of the Pinkerton Trail, Molas, Leadville and other formations. These units are referred to here as lower aquifer units.

\subsubsection{Richton Dome Site}

The Richton Salt Dome in Perry County, Mississippi, is one of the largest diapiric salt domes in the United States. The stratigraphic sequence assumed is based on the analysis of Law Engineering Testing Company (1982). The 
repository horizon is assumed to be $605 \mathrm{~m}$ below the surface and $355 \mathrm{~m}$ below the top of the salt dome.

The site is characterized by an overlying aquifer that represents the Hattiesburg and Catahoula Formations and by other strata adjacent to the dome.

\subsection{UNDERGROUND FACILITY}

The underground facility concept considered here consists of an excavation of room and pillar construction within the host salt unit. The repository consists of a network of disposal drifts and connecting tunnels. Vertical waste emplacement holes are drilled in the floors of these rooms; and, after emplacement of waste packages, the holes are plugged with crushed salt and concrete and the storage room is backfilled with crushed salt and sealed with salt blocks.

Table 3-1 defines the repository parameters used in these preliminary analyses. The repository is assumed to accommodate both spent fuel (SF) and comercial high-level waste (CHLW) packages as well as other wastes. The areas allocated to these packages will be contiguous and the distribution of packages in these areas can be inferred from Table 3-1. The designed distribution of the packages is based on considerations of temperature conditions that would be generated in the repository by the radioactive decay of the SF and CHLW and, therefore, depends on the heat generation rates of individual waste packages. The loadings assumed for this report are given in Table 3-2.

The parameters specified in Tables 3-1 and 3-2 describe the underground facility for the two bedded salt site representations. Special characteristics of the Richton Dome site dictate some minor variations in this description. 
Table $3 \cdots 1 . \quad$ Repository Design Parameters $(a)$

\begin{tabular}{|c|c|c|c|}
\hline & SF Region & \multicolumn{2}{|c|}{ CHLW Region } \\
\hline \multicolumn{4}{|l|}{ Waste Region } \\
\hline Width (m) & 3,100 & \multicolumn{2}{|c|}{3,100} \\
\hline Length $(\mathrm{m})$ & 1,145 & \multicolumn{2}{|c|}{470} \\
\hline Load (MTHM) (a) & 36,000 & \multicolumn{2}{|c|}{36,000} \\
\hline Load Density $\left(\mathrm{YTHM} / \mathrm{m}^{2}\right)$ & $0.010^{(\mathrm{b})}$ & \multicolumn{2}{|c|}{0.025} \\
\hline Thermal Density $\left(\mathrm{W} / \mathrm{m}^{2}\right)$ & $15^{(c)}$ & \multirow{2}{*}{\multicolumn{2}{|c|}{$\begin{array}{l}30(\mathrm{c}) \\
1.5 \mathrm{E}+6\end{array}$}} \\
\hline Excavated Void Space $\left(\mathrm{m}^{3}\right)$ & $3.9 E+6$ & & \\
\hline \multicolumn{4}{|l|}{ Disposal Rooms } \\
\hline Witth (m) & 6.4 & \multicolumn{2}{|c|}{5.8} \\
\hline Height $(m)$ & 4.6 & \multicolumn{2}{|c|}{4.6} \\
\hline Length (m) & 150 & \multicolumn{2}{|c|}{150} \\
\hline Number & 880 & \multicolumn{2}{|c|}{280} \\
\hline Extraction Ratio & 0.32 & \multicolumn{2}{|c|}{0.22} \\
\hline \multirow[t]{2}{*}{ Porosity After Backfill } & 0.3 & \multicolumn{2}{|c|}{0.3} \\
\hline & Palo Duro & Paradox & Richton \\
\hline Approximate Repository Depth (m) & 730 & 910 & 610 \\
\hline Thickness of Host Salt $(\mathrm{m})$ & 34 & 74 & -- \\
\hline Shaft Pillar Width (m) & 730 & 910 & 610 \\
\hline Shaft Diameter (m) & 6.4 & 6.4 & 6.4 \\
\hline Tunnel width (m) & 6.4 & 6.4 & 6.0 \\
\hline Tunnel Height (m) & 4.6 & 4.6 & 4.1 \\
\hline
\end{tabular}

(a) MTHM = metric tons of heavy metals.

(b) Based on pressurized water reactor (PWR) SF.

(c) At waste emplacement, based on 10-year-old waste. 
Table 3-2. Description of Waste Packages ${ }^{(a)}$

$\mathrm{SF}(\mathrm{PWR}) \quad \mathrm{SF}(\mathrm{BWR})^{(\mathrm{b})} \quad \mathrm{CHLW}$

$\begin{array}{llll}\mathrm{kW} / \mathrm{pkg}(\mathrm{c}) & 5.5 & 5.5 & 9.5 \\ \mathrm{MTHM} / \mathrm{pkg} & 4.2 & 5.3 & 9.8 \\ \text { \#Pkgs } & 5,259 & 2,640 & 3,673 \\ \text { Total MTHM } & 22,000 & 14,000 & 36,000\end{array}$

(a) Other wastes will also be emplaced but radionuclides are substantially reduced and these are not considered here.

(b) BWR = bolling water reactor.

(c) At waste emplacement, based on 10-year-old waste. 


\subsection{WASTE DESCRIPTION}

The two types of waste explicitly considered in the analyses are SF and CHLW from a reprocessing fuel cycle. Other wastes would also be included in an actual repository. However, the radionuclide inventories associated with these other wastes would not be significant relative to those contained in the $\mathrm{SF}$ or CHLW and are not considered further.

The reference radionuclide inventories approximately 1000 years after emplacement in the repository used in the analyses are given in Tables 3-3 and 3-4. These inventories are based upon the generic inventories given by the U.S. Department of Energy (1980) in the Final Environmental Impact Statement, Management of Commercially Generated Nuclear Waste.

The SF and CHLW will generate heat in the repository due to radioactive decay. The heat generation rate at emplacement depends on the repository and waste package thermal loadings which are specified in Tables 3-1 and 3-2. The heat generation rate also depends on the decay characteristics, and the relative heat generation rates are given in Table 3-5. 
Table 3-3. Important Fission Products in Reference Waste ${ }^{(a)}$

\begin{tabular}{|c|c|c|}
\hline \multirow[b]{2}{*}{ Isotope } & Ci/MTHM 1000 Years & After Reactor Discharge \\
\hline & $\mathrm{SF}^{(\mathrm{b})}$ & $\mathrm{CHLW}^{(\mathrm{c})}$ \\
\hline${ }^{14} \mathrm{C}$ & $6.5 \mathrm{E}-1$ & 0 \\
\hline${ }^{79} \mathrm{Se}$ & $3.5 E-1$ & $3.5 \mathrm{E}-1$ \\
\hline${ }^{90} \mathrm{Sr}$ & $1 \cdot 3 E-6$ & $1 \cdot 3 \mathrm{E}-6$ \\
\hline${ }^{93} \mathrm{Zr}$ & $1.7 \mathrm{E}+0$ & $1.7 \mathrm{E}+0$ \\
\hline $93 m_{\mathrm{Nb}}$ & $1.7 \mathrm{E}+0$ & $1.7 \mathrm{E}+0$ \\
\hline${ }^{99} \mathrm{Tc}$ & $1.3 E+1$ & $1 \cdot 3 E+1$ \\
\hline${ }^{126} \mathrm{Sn}$ & $4.8 \mathrm{E}-1$ & $4.8 \mathrm{E}-1$ \\
\hline $126 \mathrm{~m}_{\mathrm{Sb}}$ & $4.8 E-1$ & $4.8 E-1$ \\
\hline${ }^{126} \mathrm{Sb}$ & $4.8 \mathrm{E}-1$ & $4.8 E-1$ \\
\hline${ }^{135} \mathrm{Cs}$ & $2.7 E-1$ & $2.7 E-1$ \\
\hline${ }^{137} \mathrm{Cs}$ & $8.8 \mathrm{E}-6$ & $8.8 E-6$ \\
\hline${ }^{151} \mathrm{Sm}$ & $4.0 \mathrm{E}-1$ & $4.0 \mathrm{E}-1$ \\
\hline
\end{tabular}

(a) Radionuclides not listed constitute less than 0.1 percent of the total inventory. Inventories for ${ }^{90} \mathrm{Sr}$ and ${ }^{137} \mathrm{Cs}$ are listed to illustrate their sma11 contribution.

(b) From Battelle's Pacific Northwest Laboratories (1979), Table 3.3.8.

(c) Uranium-only recycle, plutonium stored separately. From Battelle's Pacific Northwest Laboratories (1979), Table 3.3.8. 
Table 3-4. Important Actinides and Daughters in Reference Waste (a)

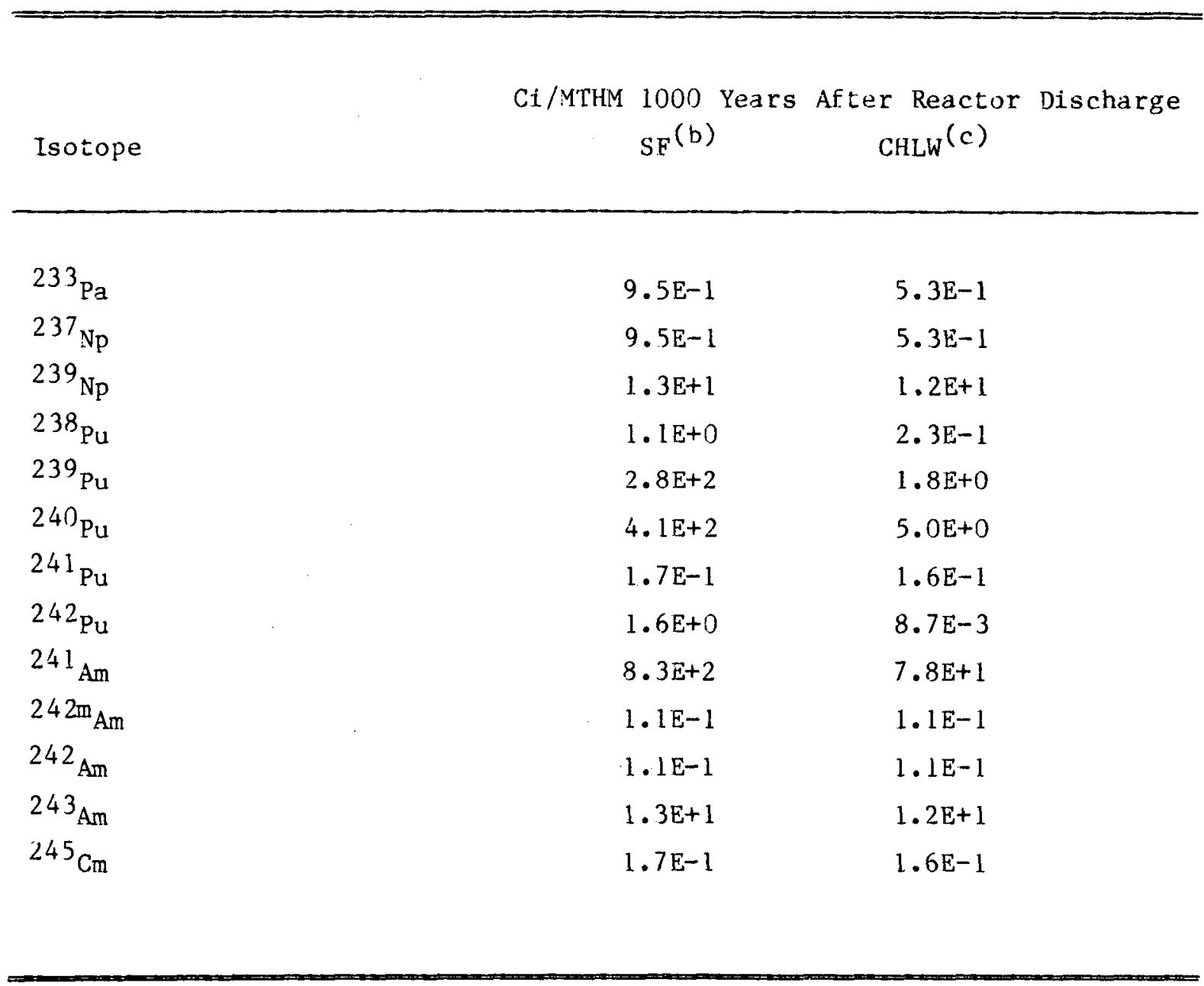

(a) Radionuclides not 1 isted constitute less than 0.1 percent of the total inventory.

(b) From Battelle's Pacific Northwest Laboratories (1979), Table 3.3.10.

(c) Uranium-only recycle, plutonium stored separately. Chemical separation assumed to remove 99.5 percent of uranium and plutonium, but no other activities. From Battelle's Pacific Northwest Laboratories (1979), Table 3.3 .12 . 
Table 3-5. Relative Thermal Decay Rates for Repository Waste ${ }^{(a)}$

Age of Waste $(y r)^{(b)}$

SF

CHLW

$\begin{array}{lll}1.0 \mathrm{E}+1 & 1.0 \mathrm{E}+0 & 1.0 \mathrm{E}+0 \\ 1.0 \mathrm{E}+2 & 2.4 \mathrm{E}-1 & 1.1 \mathrm{E}-1 \\ 1.0 \mathrm{E}+3 & 4.7 \mathrm{E}-2 & 3.6 \mathrm{E}-3 \\ 1.0 \mathrm{E}+4 & 1.1 \mathrm{E}-2 & 4.4 \mathrm{E}-4 \\ 1.0 \mathrm{E}+5 & 7.9 \mathrm{E}-4 & 9.1 \mathrm{E}-5 \\ 1.0 \mathrm{E}+6 & 3.3 \mathrm{E}-4 & 1.2 \mathrm{E}-4\end{array}$

(a) Battelle's Pacific Northwest Laboratories (1979).

(b) Age of waste at emplacement in repository is assumed to be 10 years. 
Snow and Chang (1975), but not completed. Other analyses of cavity dissolution rates performed for the salt industry have a bearing (for example, see Saberian and Podio, 1976). However, these are sufficiently different from the calculations needed for evaluation of repository performance (e.g., neglecting temperature and creep effects), that new analyses are necessary.

\subsubsection{Pressure Release}

Other analyses of pressure release scenarios have not been reported. However, Lanner (1983), p. 19, has identified such a scenario. 
4 MULTiPLE CONNECTIONS WITH OVERLYING AQUIFER U-TUBE CONNECTION SCENARIO

This scenario was introduced in Section 2.1.1. The scenario involves two connections between the repository and the upper aquifer, one an exploratory borehole drilled into a repository disposal drift and the other an access shaft. In this chapter, the configuration composed of the two vertical legs and the horizontal leg involving the repository room and tunnel network is referred to as a U-Tube. The analysis of the scenario involves evaluation of the local flow in the U-Tube, release of radionuclides from the waste to the flow, and transport of radionuclides to the upper aquifer.

\subsection{LOCAL FLOW IN THE U-TUBE}

The rate of flow of the water locally is determined by solving for the steady-state pressure distribution in a local representation of the site that includes the U-Tube. This representation involves discretization of the system into a three-dimensional grid suitable for solution by a finitedifference approach. The vertical discretization represents the upper aquifer, the repository, and confining layers between the aquifer and the repository host rock. The horizontal representation includes the borehole, the access shaft, and the pathway through the repository. The model extends far enough laterally so that pressures at the boundarles are not significantly affected by the diversion of flow in the U-Tube. Pressures obtalned from regional modeling are used as fixed-pressure (Dirichlet) boundary conditions for the model. The SWENT code (INTERA, 1983b) is used for the simulation of the flow in this local system.

The geometry of the system is suggested in Figure 2-1. The shaft is assumed to have a diameter of $6.6 \mathrm{~m}$ and extends from the upper aquifer down to the repository horizon. It is assumed to be backfilled and sealed. The borehole is assumed to be a 0.23-m-diameter drillhole (a typical size) extending through the aquifer and the confining layers to the repository, penetrating one of the repository disposal drifts. The pathway through the repository is represented by a tunnel extending from the shaft through the shaft pillar and the repository to the location of the borehole. 
The calculation of the local flow requires flow properties of the aquifers and the other units. The aquifer properties used in this local flow evaluation are assumed to be the sane as those in the regional analyses of the basin, ignoring heterogeneity in these units. The conductance for the separate legs of the U-Tube configuration depends on the geometry. This geometry varies somewhat from site to site. The hydrallic conductivities assumed for these nembers are given in Table 4-1. The shaft and the repository tunnels are assumed to have a conductivity of $1.0 \mathrm{E}-6 \mathrm{~m} / \mathrm{day}$. The value of $1.0 \mathrm{E}-6 \mathrm{in} /$ day was used by Gureghian et al (1983) to characterize the properties of the shaft seal system for a repository in salt.

The borehole is asslgned a perneability of $30.5 \mathrm{~m} /$ day appropriate for a coarse sand (Means and Parcher, 1963) as if the borehole were silted froin loose soils in the overburten. However, the resistance to the flow of the borehole is essentially negligible compared to that in the shaft or the tunnels and the results are not sensitive to the particular choice of the borehole properties given in Table $4-1$.

\subsubsection{Local Flow in U-Tube at Palo Duro Basin Site}

The area modeled in the Palo Duro site analysis is shown in Figure 4-1. The local model extends over an area 19.3 by $19.3 \mathrm{~km}$. Figure $4-2$ gives the 14 by 13 horizontal finite-difference grid utilized in the analysis. The details of this grid are given in Table 4-2. A four-layer system is used to describe the verical section. The details of this discretization are given in Figure 4-3. Hydraulic properties for the strata are also given in this figure. These properiies are based on the regional modeling analyses (INTERA, 1984a).

The elevation of the layers is essentially constant throughout the local representation. The orientation and location of the U-Tube at the site can be readily inferred from Figure 4-2. In the local model the cross-sectional areas of the various nembers of the U-Tube have been increased somewhat to facilitate the numerical ireatment. Accordingly, the conductivities have also been modified appropriately so that the effective conductance of each member is unchanged. 
Table 4-1. Flow Parameters for Reference U-Tube

Palo Duro Paradox Richton

Shaft

Cross-sectional area $\left(\mathrm{m}^{2}\right)$

32

32

32

Length (m) (a)

390

480

450

Conductivity (m/day)

$1.0 \mathrm{E}-6$

$1.0 \mathrm{E}-6$

$1.0 \mathrm{E}-6$

Conductance $\left(\mathrm{m}^{2} /\right.$ day $)$

$8.2 \mathrm{E}-8$

$6.7 \mathrm{E}-8$

$7.1 \mathrm{E}-8$

Borehole

$\begin{array}{llll}\text { Cross-sectional area }\left(\mathrm{m}^{2}\right) & 0.04 & 0.04 & 0.04 \\ \text { Length }(\mathrm{m})(\mathrm{a}) & 390 & 465 & 465 \\ \text { Conductivity (m/day) } & 30 & 30 & 30\end{array}$

Tunne 1

$\begin{array}{llll}\text { Cross-sectional area }\left(\mathrm{m}^{2}\right) & 29 & 29 & 25 \\ \text { Length }(\mathrm{m}) & 2,880 & 2,870 & 4,990 \\ \text { Conductivity }(\mathrm{m} / \text { day }) & 1.0 \mathrm{E}-6 & 1.0 \mathrm{E}-6 & 1.0 \mathrm{E}-6 \\ \text { Conductance }\left(\mathrm{m}^{2} / \text { day }\right) & 1.0 \mathrm{E}-9 & 1.0 \mathrm{E}-9 & 4.9 \mathrm{E}-9\end{array}$

(a) Length is distance from upper aquifer to repository horizon. 


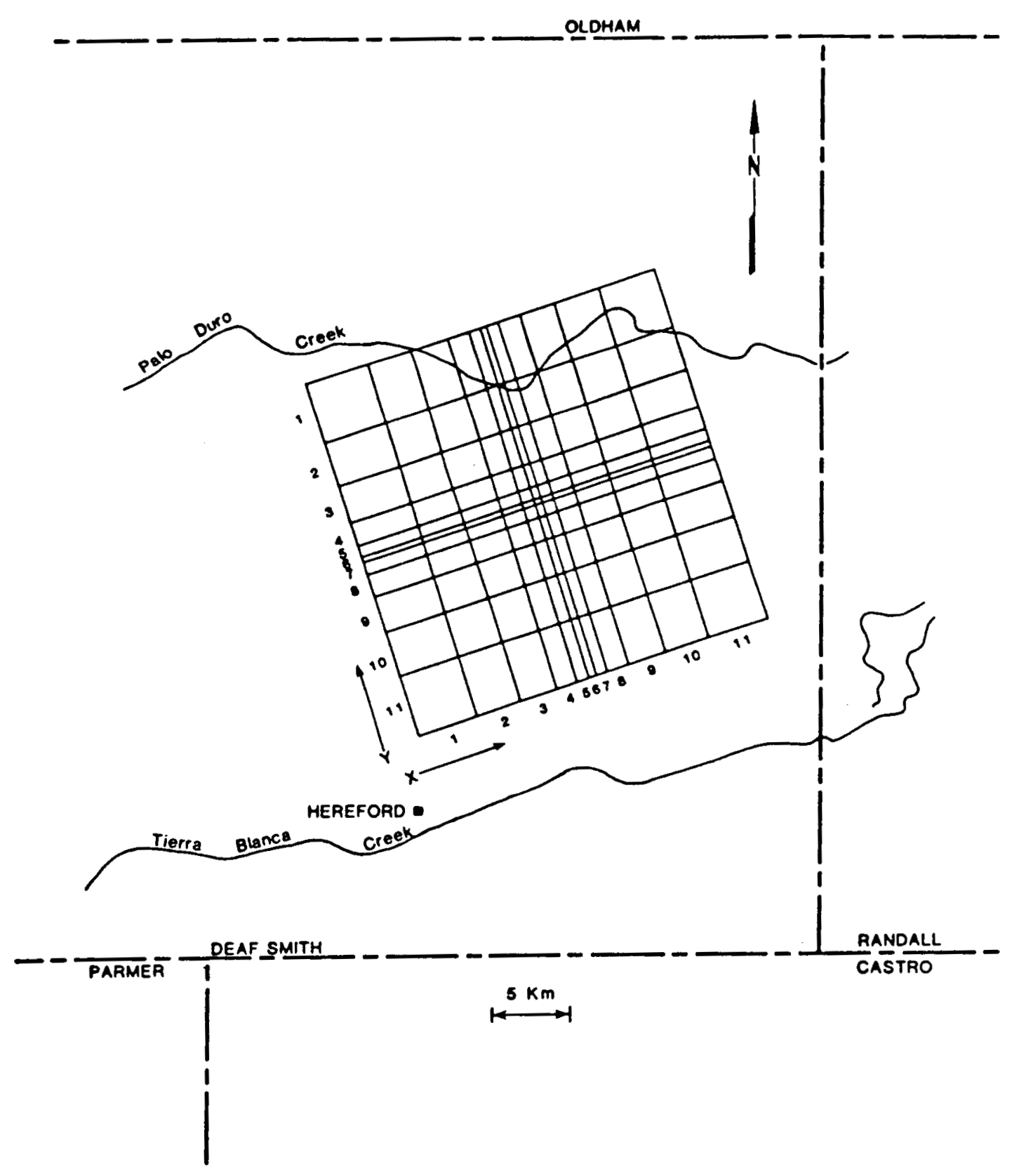

Figure 4-1. Palo Duro Basin Site 


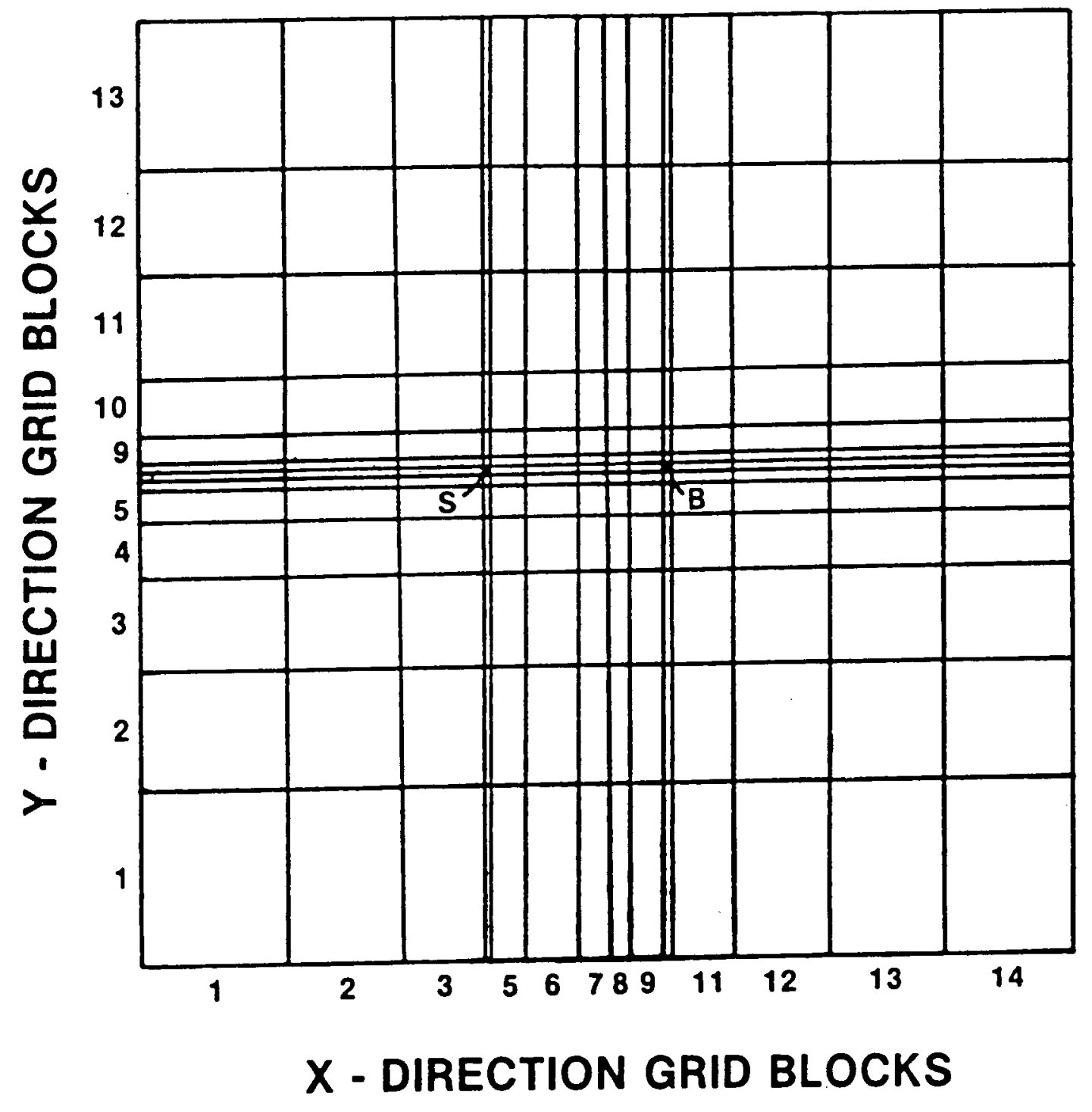

NOT TO SCALE $B=B O R E H O L E$ $S=$ SHAFT

Figure 4-2. Horizontal Representation of Palo Duro Site for U-Tube Scenario Flow Analyses 
Table 4-2. Horizontal Grid Discretization of Palo Duro Site

\begin{tabular}{|c|c|c|c|}
\hline $\begin{array}{l}\text { X-Direction } \\
\text { Block }\end{array}$ & $\begin{array}{l}\text { Grid Block } \\
\text { Width (m) }\end{array}$ & $\begin{array}{c}\text { Y-Direction } \\
\text { Block }\end{array}$ & $\begin{array}{l}\text { Grid Block } \\
\text { Length (m) }\end{array}$ \\
\hline 1 & 3,220 & 1 & 3,220 \\
\hline 2 & 2,410 & 2 & 2,410 \\
\hline 3 & 1,950 & 3 & 2,010 \\
\hline 4 & 6.40 & 4 & 1,210 \\
\hline 5 & 445.0 & 5 & 604.0 \\
\hline 6 & 823.0 & 6 & 199.0 \\
\hline 7 & 604.0 & 7 & 4.57 \\
\hline 8 & 402.0 & 8 & 199.0 \\
\hline 9 & 604.0 & 9 & 604.0 \\
\hline 10 & 0.01 & 10 & 1,210 \\
\hline 11 & 1,210 & 11 & 2,010 \\
\hline 12 & 2,010 & 12 & 2,410 \\
\hline 13 & 2,410 & 13 & 3,220 \\
\hline 14 & 3,220 & & \\
\hline
\end{tabular}


CONDUCTIVITY (METERS/DAY)

OGALLALA

DOCKUM

UPPER PERMIAN

TO SAN ANDRES

CYCLE 4 SALT

REPOSITORY

UNDERLYING LAYERS

NEGLECTED

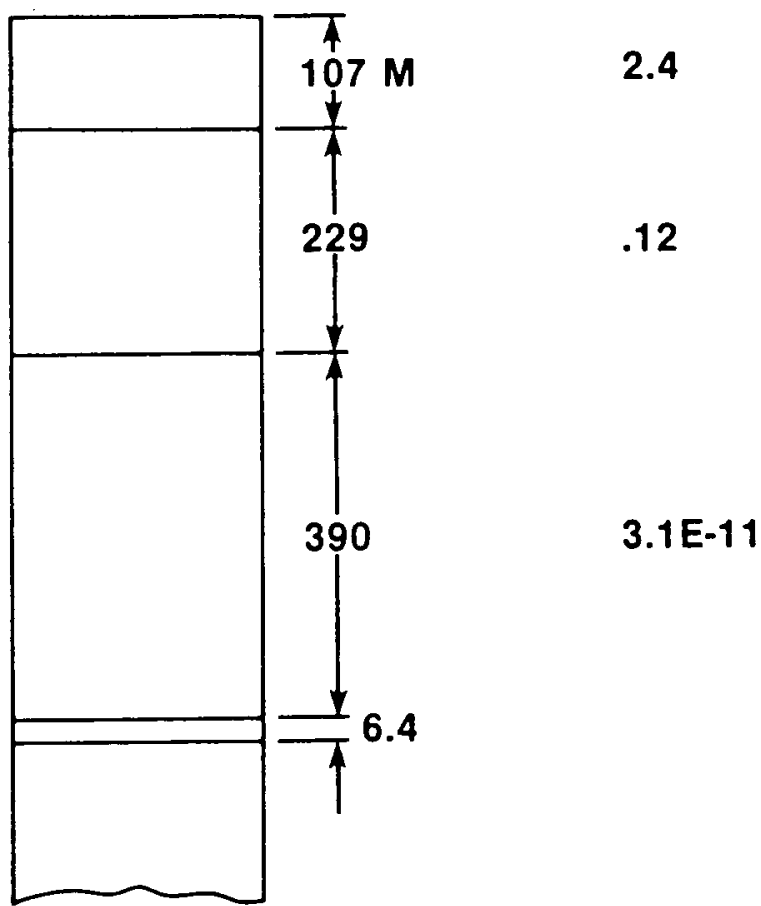

Figure 4-3. Vertical Representation of Palo Duro Site for U-Tube Scenario Flow Analyses 
The flow in this system is evaluated by application of the SWENT code (INTERA, 1983b). The pressure boundary conditions obtained from the regional analysis of the Palo Duro Basin (INTERA, 1984a) are given in Appendix A.

The flow through the U-Tube is predicted to be $3.0 \mathrm{E}-7 \mathrm{~m}^{3} /$ day. Salinity of the fluid in the U-Tube has been neglected and the fluid temperatures are assumed to be the same as the rock. In this case, in situ temperatures have been used and the assumed values are given in Table 4-3. The low value for the flow rate is a reflection of the hydraulic resistance of the shaft and the repository tunnel.

The variation of the flow rate with the conductivity of the U-Tube is shown in Figure 4-4. For this evaluation, the conductivity given is the value averaged over the entire U-Tube. The calculated flow rates increase as the conductivity is increased. For a very large conductivity, the resistance in the $U$-Tube becomes negligible relative to the flow resistance in the upper aquifer and the flow reaches a limiting value. For the boundary conditions and flow properties in the upper aquifer that have been assumed, this limiting flow is $83 \mathrm{~m}^{3} /$ day. This limiting flow occurs for an average conductivity greater than $3.0 \mathrm{E} 5 \mathrm{~m} / \mathrm{day}$; and, since the flow properties will lie well below this value, the expected flow rate is expected to be less than this limit.

\subsubsection{Local Flow in the U-Tube at the Paradox Basin Site}

The area modeled for the Paradox Basin analysis is indicated in Figure 4-5. The local model extends over a $10.7 \mathrm{~km}$ by $10.7 \mathrm{~km}$ area. The horizonta1 finite-difference grid used in this case is shown in Figure 4-6 and is detailed in Table 4-4.

The treatment of the vertical section in this case is conceptually the same as in the Palo Duro site analysis. Seven layers are used to represent this system and these are shown in Figure 4-7. The hydraulic properties assumed for this system are also given in the figure. These values are based upon the regional modeling of the Paradox Basin (INTERA, 1984b).

Figure 4-7 indicates that, unlike the Palo Duro site, the elevation of the surface and the thickness of the subsurface units are not uniform throughout the local regime. The specification of the vertical discretization 
Table 4-3. In Situ Temperatures Assumed for Sites (a)

\begin{tabular}{llll} 
& \multicolumn{3}{c}{ Temperature ( $\left.{ }^{\circ} \mathrm{C}\right)$} \\
\cline { 2 - 4 } Horizon (a) & Palo Duro Paradox & Richton \\
\hline Surface & 20 & 18 & 20 \\
Repository & 70 & 33 & 31 \\
& & & \\
\hline
\end{tabular}

(a) Temperatures at other horizons found by linear interpolation. 


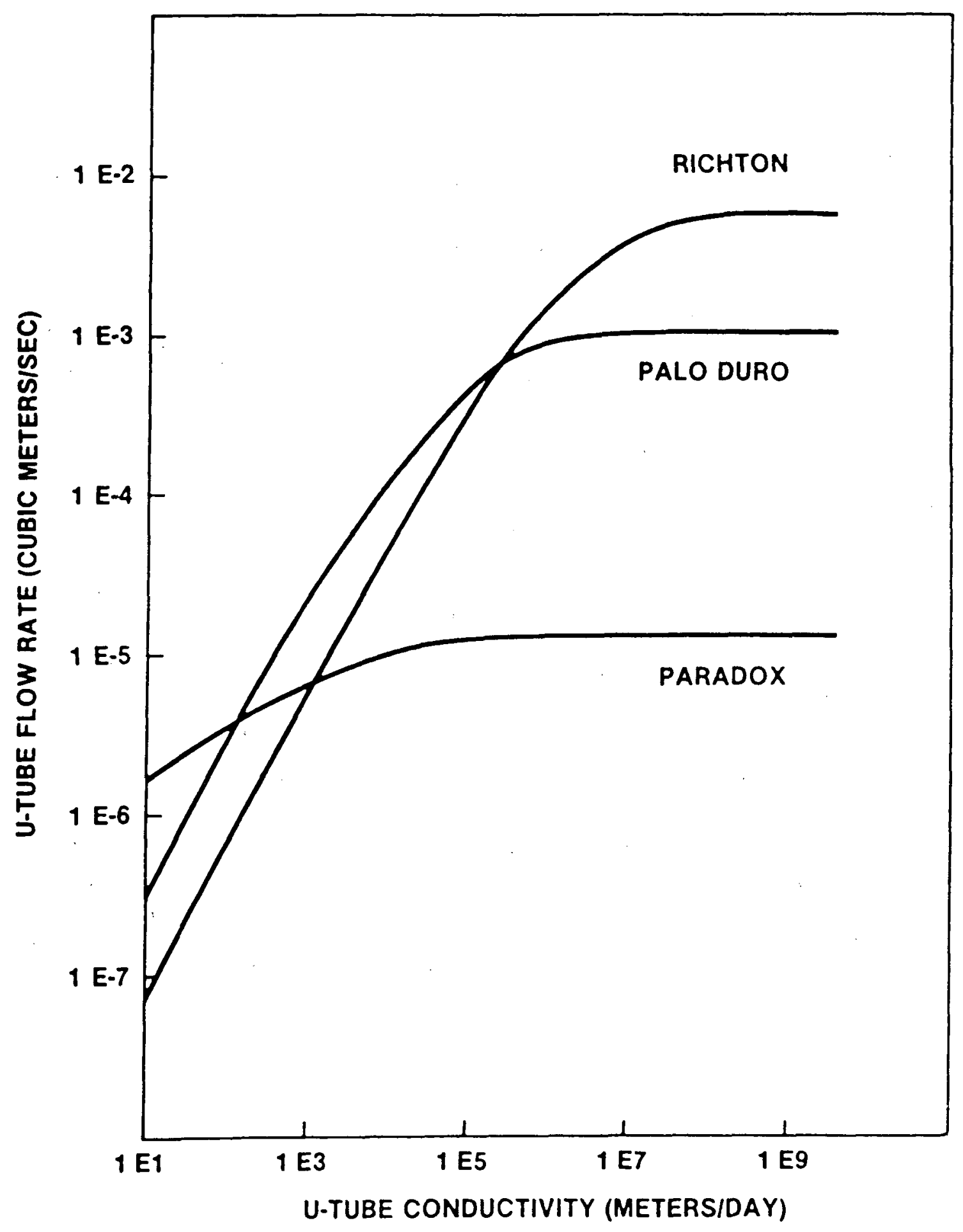

F1gure 4-4. U-Tube Flow Calculated as a Function of U-Tube Conductivity 




F1gure 4-5. Paradox Basin S1te 


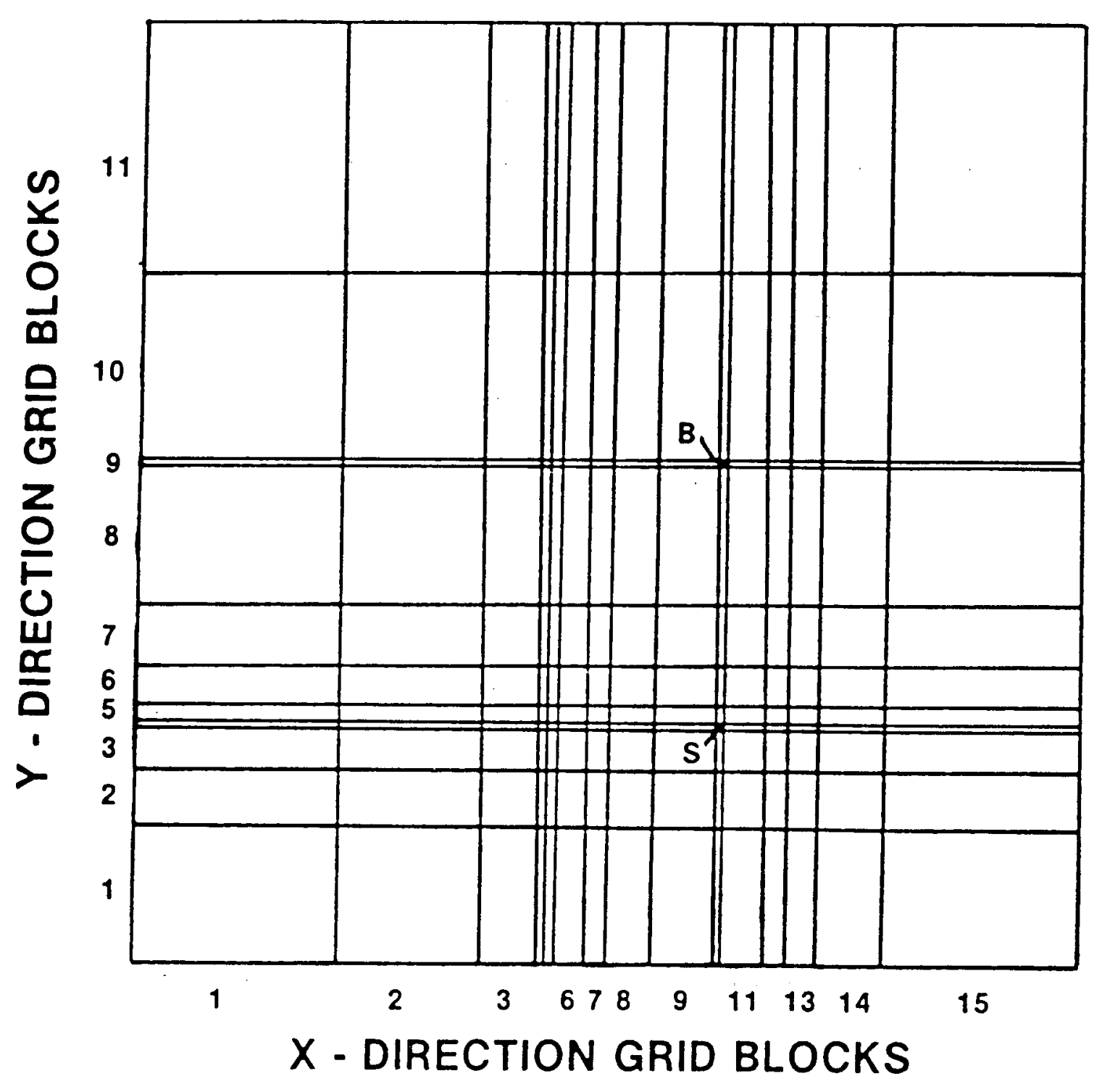

NOT TO SCALE
S = SHAFT
$B=$ BOREHOLE

F1gure 4-6. Horizontal Representation of Paradox Site for U-Tube Scenario Flow Analyses 
Table 4-4. Horizontal Grid Discretization for the Paradox Site

\begin{tabular}{cccc}
\hline $\begin{array}{c}\text { X-Direction } \\
\text { Block }\end{array}$ & $\begin{array}{c}\text { Grid Block } \\
\text { Width (m) }\end{array}$ & $\begin{array}{c}\text { Y-Direction } \\
\text { Block }\end{array}$ & $\begin{array}{c}\text { Grid Block } \\
\text { Length (m) }\end{array}$ \\
\hline 1 & 2,360 & 1 & 1,520 \\
2 & 1,830 & 2 & 762.0 \\
3 & 914.0 & 3 & 366.0 \\
4 & 91.4 & 4 & 6.40 \\
5 & 91.4 & 5 & 207.0 \\
6 & 274.0 & 6 & 366.0 \\
7 & 244.0 & 7 & 762.0 \\
8 & 488.0 & 8 & 1,520 \\
9 & 971.0 & 9 & 0.010 \\
10 & 4.57 & 10 & 2,130 \\
11 & 488.0 & 11 & 3,050 \\
12 & 244.0 & & \\
13 & 381.0 & & \\
14 & 762.0 & & \\
15 & 1,520 & & \\
\hline & & & \\
\hline
\end{tabular}


VARIABLE SURFACE ELEVATION

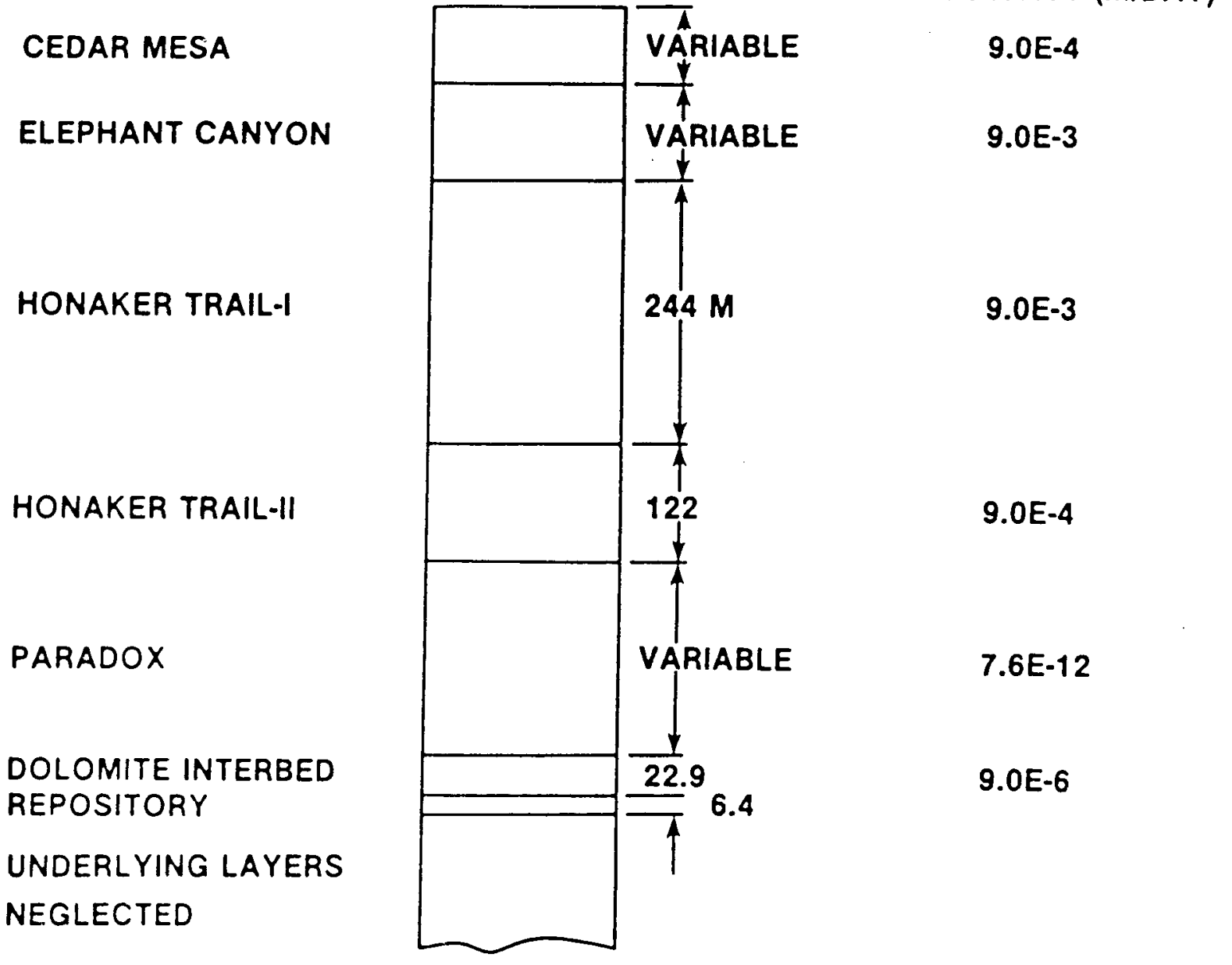

CONDUCTIVITY (MIDAY)

9.OE-4

9.0E-3

9.0E-3

9.0E-4

7.6E-12

9.0E-6

Figure 4-7. Vertical Representation of Paradox Site for U-Tube Scenario Flow Analyses 
is therefore somewhat more complex than in the previous case. The details of this vertical discretization are given in Appendix A.

Otherwise, the treatment of the U-Tube is, in principle, the same as for the Palo Duro case. The orientation and location of the U-Tube can be inferred from Figure 4-6. Because of the variable elevations of the upper aquifer, the lengths of the legs of the $U$-Tube are different from one another in the way indicated in Table 4-1.

The pressure boundary conditions utilized are taken from regional modeling of the Paradox Basin as given by INTERA (1984b). The specific fixed boundary pressures used are given in Appendix A. The calculated flow rate for this case is $2.9 \mathrm{E}-7 \mathrm{~m}^{3} /$ day. Coincidentally, this flow rate is not significantly different from that for the Palo Duro case.

The variation in the flow with the assumed permeability of the U-Tube is shown in Figure 4-4. The limiting flow rate for infinite U-Tube conduction is $1.2 \mathrm{~m}^{3} /$ day, almost two orders of magnitude below the limit for the Palo Duro case, reflecting the lower conductivity of the Elephant Canyon in the Paradox Basin relative to the Ogallala and Dockum units in the Palo Duro Basin.

\subsubsection{Loca1 Flow in U-Tube at Richton Dome Site}

The local model in this case is based on that given by INTERA (1984c). The region modeled is $25.8 \mathrm{~km}$ by $22.7 \mathrm{~km}$ and is shown in Figure 4-8. The 16 by 16 horizontal finite-difference grid used to model this region is shown in Figure 4-9 and the details are given in Table 4-5.

The eight-layer vertical section modeled is shown in Figure 4-10. The thicknesses of the subsurface units are essentially uniform throughout the local regime. However, the elevations of the layers vary over the representation. The surface elevation is based on the elevation of the phreatic surface and this variation is discussed in Appendix A.

The repository design for the Richton Dome is slightly different than at the bedded salt sites given in Table 3-1. The tunnel is somewhat smaller $(4.1 \mathrm{~m}$ by $6.0 \mathrm{~m})$. The geometry and flow parameters in this case are given in Tab1e 4-1.

The pressure boundary conditions are the same as those used in INTERA (1984c) and are described in Appendix A. The resulting flow rate is $1.8 \mathrm{E}-8$ $\mathrm{m}^{3} /$ day about a factor of 16 below the result for the bedded salt sites. 


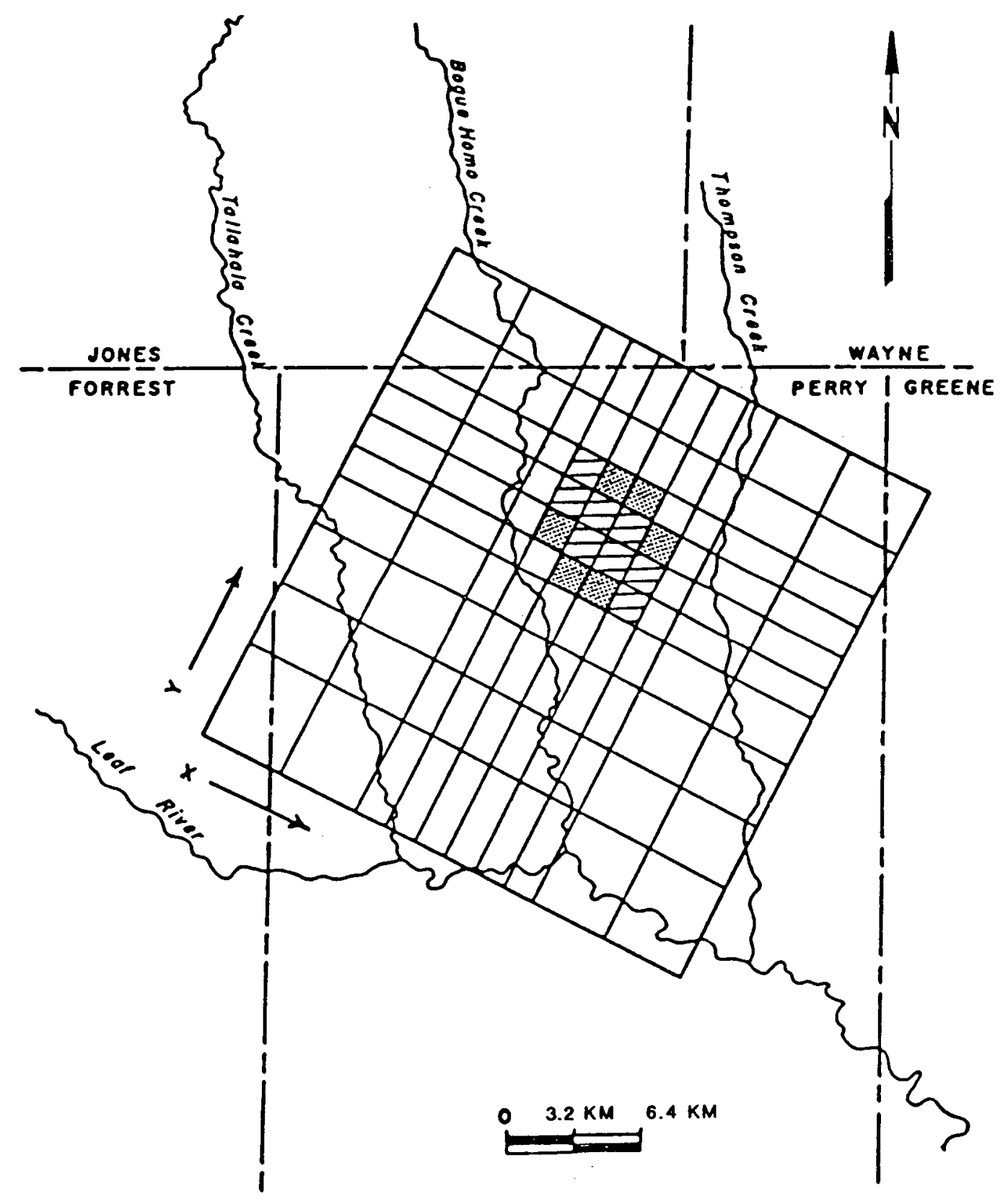

Figure 4-8. Richton Dome Site 


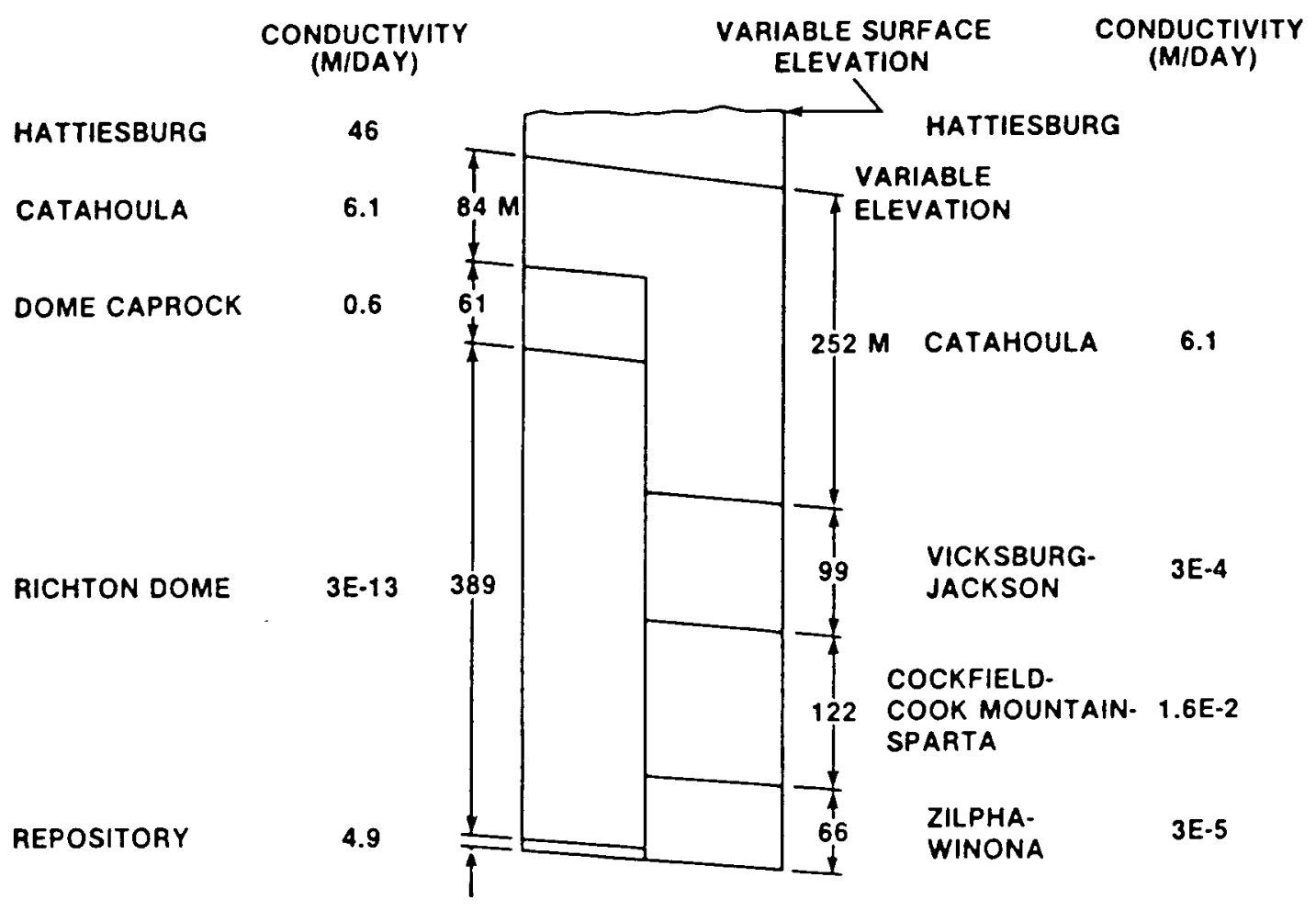

Figure 4-9. Vertical Representation of Richton Site for U-Tube Scenario Flow Analyses 
Table 4-5. Horizontal Grid Discretization for the Richton Site

\begin{tabular}{cccc}
\hline \hline & & & \\
X-Direction & Grid Block & Y-Direction & Grid Block \\
Block & Width (m) & Block & Length (m) \\
& & & \\
1 & 4,830 & 1 & 4,020 \\
2 & 3,220 & 2 & 4,020 \\
3 & 3,220 & 3 & 1,610 \\
4 & 2,910 & 4 & 1,520 \\
5 & 1,610 & 5 & 9.14 \\
6 & 796.0 & 6 & 887.0 \\
7 & 9.14 & 7 & 805.0 \\
8 & 805.0 & 8 & 805.0 \\
9 & 805.0 & 9 & 3.96 \\
10 & 895.0 & 10 & 801.0 \\
11 & 3.96 & 11 & 1,610 \\
12 & 1,530 & 12 & 1,610 \\
13 & 2,410 & 13 & 4,020 \\
14 & 3,220 & 14 & 4,020 \\
\hline \hline
\end{tabular}




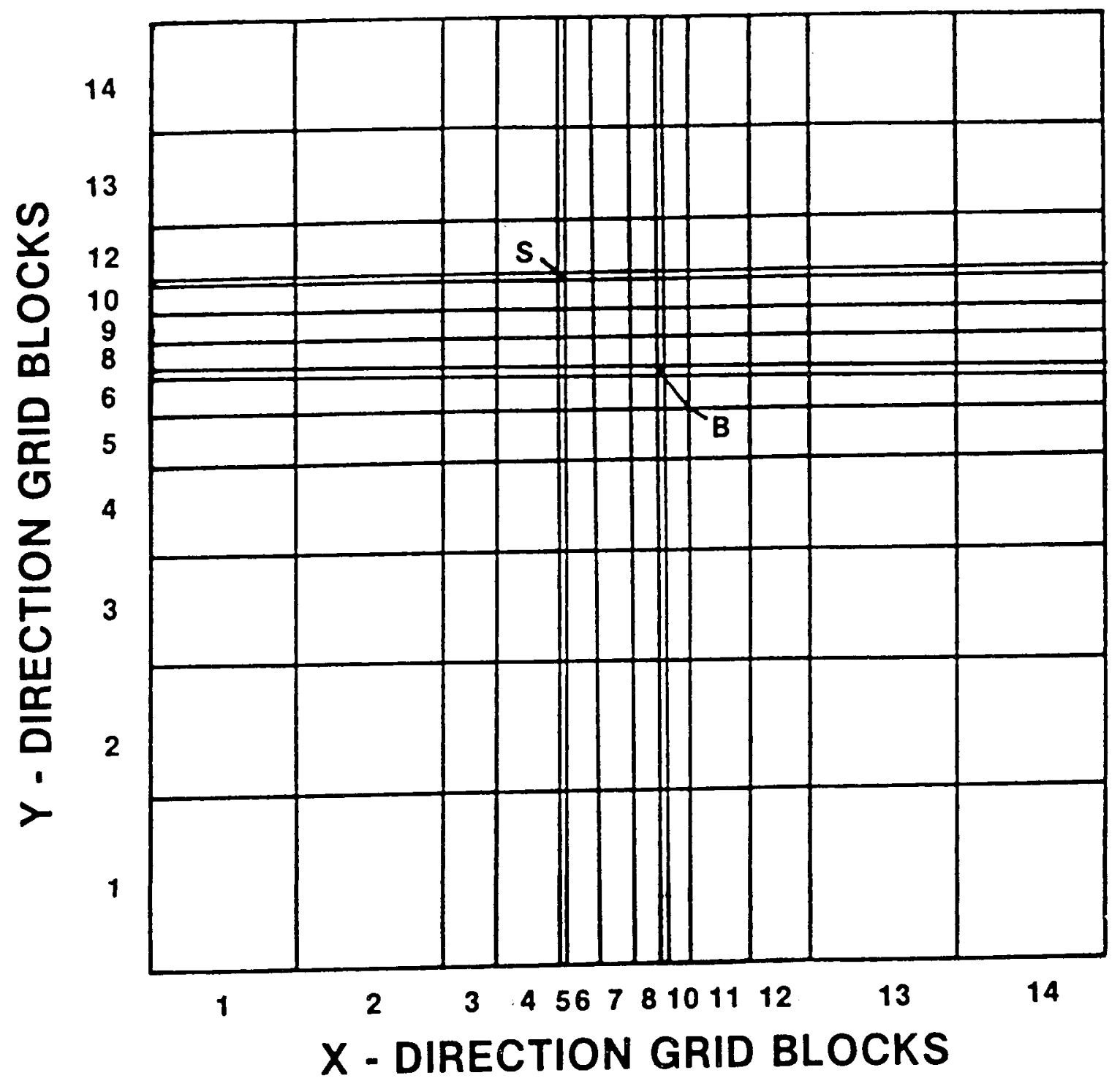

NOT TO SCALE
S = SHAFT
$\mathbf{B}=$ BOREHOLE

Figure 4-10. Horizontal Representation of Richton Site for U-Tube Scenario Flow Analyses 
The flow for an open U-Tube, however, is higher at the Richton site than at the bedded salt sites as shown for the limiting flow rates in Figure 4-4. The limiting flow is about $460 \mathrm{~m}^{3} /$ day, reflecting the relatively conductive nature of the upper aquifer in this case.

\section{1 .4 Ef fects of Temperature and Salinity}

The results of these analyses are summarized in Table 4-6. The first row in this table gives the calculated flow rates for the reference cases. The limiting flows for the specified aquifer conditions are also given in this table. The U-Tube configuration is termed an "open" $U$-Tube in this case because the resistance of the $U$-Tube is negligible compared to that encountered by the flow in the upper aquffer.

These results have been calculated by assuming natural geothermal conditions in the rock and fresh-water density (salinity $=0$ ) in the U-Tube. In fact, however, these conditions could be different. Temperature increases in the vicinity of the repository could occur due to the heat generated by the radioactive waste. The temperature of the water could therefore be affected. The salinity of the water would be expected to increase due to the dissolution of the halite in the salt units that the U-Tube intersects. These effects can influence the density of the water and, therefore, the flow rate. These cases are therefore recalculated taking into account modifications in the U-Tube flow density.

The third and fourth rows of Table 4-6 give the results for a fully saturated flow (salinity $=1$ ) analogous to those in the first two rows for $s=0$. Ambient temperature conditions are assumed. These calculations have been made assuming that the salt dissolution occurs near the entrance of the U-Tube (i.e., at the top of the downward leg) and that the flow discharged into the aquifer is immediately diluted to the in situ aquifer density. A more realistic model of the salt dissolution could be used (INTERA, 1984d) but the present approach serves to provide a maximum density change and thus the largest impact on the flow.

The results in the third row of Table 4-5 show that the volumetric flow rate is not very sensitive to the density of the U-Tube water for the reference case. On the other hand the values for the open U-Tube (i.e., the limiting flow rates) shown in the fourth row display a stronger dependence on 
Table 4-6. Summary of Loca1 Flow Predicted for U-Tube at Three Sites

\begin{tabular}{|c|c|c|c|c|c|c|}
\hline \multirow[b]{3}{*}{ Case } & \multirow[b]{3}{*}{ Configuration } & \multirow[b]{3}{*}{ Salinity } & \multirow{3}{*}{$\begin{array}{l}\text { Temperature } \\
\text { Above Ambient } \\
\text { (C) }\end{array}$} & \multirow[b]{2}{*}{ Volumetric } & \multirow[b]{2}{*}{ Flow Rate } & \multirow[b]{2}{*}{$\left(m^{3} /\right.$ day $)$} \\
\hline & & & & & & \\
\hline & & & & Palo Duro & Paradox & Richton \\
\hline 1 & Reference Case ${ }^{(a)}$ & 0.0 & 0 & $3.0 \mathrm{E}-7$ & $2 \cdot 9 \mathrm{E}-7$ & $1.8 \mathrm{E}-8$ \\
\hline 2 & Open U-Tube ${ }^{(b)}$ & 0.0 & 0 & $8.3 \mathrm{E}+1$ & $1.2 \mathrm{E}+0$ & $4.6 E+2$ \\
\hline 3 & Reference Case ${ }^{(a)}$ & 1.0 & 0 & $2.9 E-7$ & $2.9 E-7$ & $1.8 \mathrm{E}-8$ \\
\hline 4 & Open U-Tube ${ }^{(b)}$ & 1.0 & 0 & $9.2 \mathrm{E}+1$ & $1.3 E+0$ & $5.1 E+2$ \\
\hline 5 & Open U-Tube (b) & 0.0 & 20 & $8 \cdot 3 E+1$ & $1.2 \mathrm{E}+0$ & $4 \cdot 6 \mathrm{E}+2$ \\
\hline
\end{tabular}

(a) Hydraulic conductivity of shaft and repository legs $=1.0 \mathrm{E}-6 \mathrm{~m} /$ day.

(b) Resistance of U-Tube negligible relative to that in aquifer. 
the density; the increase in density to full saturation results in about a 10-percent increase in the volumetric flow rate. The increase in density in this case is about 20 percent so that the corresponding mass flow rate increases by about 30 percent. These results are consistent with a simple model for the U-Tube flow discussed in the Appendix $B$.

The effect of temperature variation is essentially negligible. For example, elevating the temperature of all the water in the U-Tube $20^{\circ} \mathrm{C}$ results in about a 1-percent decrease in density throughout the U-Tube but essentially no detectable change in the limiting flow rate as shown in the fifth row of Table 4-6.

\subsection{RELEASE OF RADIONUCLIDES FROM UNDERGROUND FACILITY FOR U-TUBE SCENARIO}

The flow rates through the U-Tube serve as the basis for the calculation of radionuclide release from the repository. For waste exposed to this flow, radionuclides can be leached from the waste form and dissolved into the flow. Radionuclides can then be transported by the flow to the accessible environment.

There are a number of physical constraints to release of radionuclides to the U-Tube flow, however. For example, the waste will be distributed throughout the repository in disposal rooms that are backfilled and sealed. Most of the waste therefore will not be readily accessible to the flow.

Secondly, in a disposal room in which there is flow, release will be limited by the solubility of the radionuclides. Muller et al (1981) have provided evaluations of upper bounds for these solubilities, and those used in the present analyses are given in Table 4-7. If the release of radionuclides were determined by the radionuclide solubilities alone, the concentrations would be less than or equal to those given in Table 4-8. These values have been calculated from the element solubilities and the radionuclide mass fractions of the 1,000-year inventory. These mass fractions are different for SF and CHLW, and the concentrations in Table 4-8 reflect either possibility. Radionuclides not listed in the table are assumed, for the sake of conservative analysis, to be highly soluble. 
Table 4-7. Element Solubilities

\begin{tabular}{ll}
\hline Element & Solubility (ppm) (a) \\
Strontium & 80 \\
Zircontum & $2.5 \mathrm{E}-5$ \\
Technetium & $(\mathrm{b})$ \\
Palladium & $(\mathrm{b})$ \\
Antimony & $1.0 \mathrm{E}-3$ \\
Tin & $1.0 \mathrm{E}-4$ \\
Radium & $1.0 \mathrm{E}-2$ \\
Thorium & $8.0 \mathrm{E}-2$ \\
Uranium & 20 \\
Neptunium & $6.0 \mathrm{E}-8$ \\
& \\
\hline \hline
\end{tabular}

(a) Muller et al (1981). Solubilities of elements not listed are known or assumed to be high.

(b) Solubility is low but not known. 
Table 4-8. Effective Concentration of Selected Radionuclides Based on Element Solubility

\begin{tabular}{|c|c|c|}
\hline \multirow[b]{2}{*}{ Radionuclide ${ }^{(a)}$} & \multicolumn{2}{|c|}{ Concentration $\left(\mathrm{Ci} / \mathrm{m}^{3}\right)$} \\
\hline & SF Inventory & CHLW Inventory \\
\hline${ }^{93} \mathrm{Zr}$ & $5.4 E-13$ & $5.4 E-13$ \\
\hline${ }^{99} \mathrm{Tc}$ & $2.9 E-1(b)$ & $2.9 E-1(b)$ \\
\hline $126_{\mathrm{Sn}}$ & $2.4 \mathrm{E}-6$ & $2.4 E-6$ \\
\hline${ }^{126} \mathrm{Sb}$ & $7.1 \mathrm{E}-5$ & $7.1 E-5$ \\
\hline $237 \mathrm{~Np}$ & $3.4 \mathrm{E}-11$ & $1.8 \mathrm{E}-10$ \\
\hline${ }^{238} \mathrm{Pu}$ & $3.6 E-3$ & $9.4 \mathrm{E}-2$ \\
\hline${ }^{239} \mathrm{Pu}$ & $6.5 \mathrm{E}-2$ & $7.4 \mathrm{E}-1$ \\
\hline${ }^{240} \mathrm{Pu}$ & $1.3 E+0$ & $2.1 \mathrm{E}+0$ \\
\hline $241_{\mathrm{Pu}}$ & $5.5 \mathrm{E}-4$ & $6.6 \mathrm{E}-2$ \\
\hline $242 \mathrm{Pu}$ & $5.2 E-3$ & $3.6 \mathrm{E}-3$ \\
\hline
\end{tabular}

(a) Radionuclides not listed are assumed to have unlimited solubility.

(b) Solubility of technetium is low. A value of $20 \mathrm{ppm}$ has been used in this evaluation. 
The release of the radionuclides may be limfted by the processes that control leaching from the waste form. Leach rates for both SF and for CHLW glass have been measured in a number of laboratory tests. Spent fuel leach rates for brine solutions were measured by Katayama et al (1980) to be less than $4.0 \mathrm{E}-6 \mathrm{gm} / \mathrm{cm}^{2}$-day for strontium, cesium, plutonium, curium, and other elements and it is believed (Mendel, 1978) that a rate of $1.0 \mathrm{E}-5 \mathrm{gm} / \mathrm{cm}^{2}$-day provides an upper bound to the leach rate for repository conditions. This latter value results in a fractional congruent leach rate of $2.2 \mathrm{E}-3 \mathrm{yr}^{-1}$ when the surface-to-mass ratio of the $S F$ is $0.61 \mathrm{~cm}^{2} / \mathrm{gm}$.

Wiley (1979) has measured the leach rates for borosilicate glass. His measurements gave a leach rate of 1 ess than $1.0 \mathrm{E}-8 \mathrm{gm} / \mathrm{cm}^{2}$-day and a value of $1.0 \mathrm{E}-7 \mathrm{gm} / \mathrm{cm}^{2}$-day is used in this analysis to account for variation in the leaching conditions. If the glass is sufficiently fractured to provide a surface-to-mass ratio of $0.62 \mathrm{~cm}^{2} / \mathrm{gm}$, the fractional leach rate $1 \mathrm{~s} 2.2 \mathrm{E}-5$ $\mathrm{yr}^{-1}$. The leach rate parameters used in the analysis are summarized in Table 4-9.

The leaching of radionuclides may be affected by the solubility of the constituents of the waste form. The concentration of radionuclides in the water based only upon dissolution of the waste matrix can be estimated from:

$$
C_{i}=\rho C_{s} I_{i} / M_{s}
$$

where:

$$
\begin{aligned}
& C_{1}=\text { concentration }\left(\mathrm{Ci} / \mathrm{m}^{3}\right) \\
& \rho=\text { density of water }\left(\mathrm{kg} \mathrm{H}_{2} \mathrm{O} / \mathrm{m}^{3} \text { brine }\right) \\
& C_{S}=\text { waste form solubility }\left(\mathrm{kg} \text { waste form } / \mathrm{kg} \mathrm{H} \mathrm{H}_{2} \mathrm{O}\right) \\
& \mathrm{I}_{1}=\text { radionuclide inventory }(\mathrm{Ci} / \mathrm{MTHM}) \\
& \left.M_{S}=\text { mass of the waste matrix ( } \mathrm{kg} \text { waste form } / \mathrm{MTHM}\right)
\end{aligned}
$$

Table 4-10 gives the limiting concentrations based on this expression. For dissolution of SF, the solubility of the matrix is assumed to be $20 \mathrm{ppm}$ corresponding to a value for uranium oxide, which forms the bulk of the SF. The mass loading is about $960 \mathrm{~kg}$ of uranium oxide per MTHM of original fuel charged. For the CHLW glass, the limit is assumed to be about $50 \mathrm{ppm}$ corresponding to the solubility of silica (Fournier and Rowe, 1977). A value of $160 \mathrm{~kg}$ of glass per MTHM of original fuel is used based on an estimate of 
Table 4-9. Waste Form Leach Rates

\begin{tabular}{lll}
\hline Waste Form & $\mathrm{SF}^{(\mathrm{a})}$ & $\mathrm{CHLW}(\mathrm{b})$ \\
\hline & & \\
Leach rate (gm/ $\mathrm{cm}^{2}$-day) & $1.0 \mathrm{E}-5$ & $1.0 \mathrm{E}-7$ \\
Surface-to-volune ratio $\left(\mathrm{cm}^{2} / \mathrm{gm}\right)$ & 0.61 & 0.62 \\
Fractional leach rate $\left(\mathrm{yr}^{-1}\right)$ & $2.2 \mathrm{E}-3$ & $2.2 \mathrm{E}-5$ \\
Leach duration $(\mathrm{yr})$ & $4.5 \mathrm{E}+2$ & $4.5 \mathrm{E}+4$ \\
& & \\
\hline
\end{tabular}

(a) Based on data for uranium oxide (Katayama, et a1, 1980).

(b) Based on data for borosilicate glass (Wiley, 1979). 
Table 4-10. Effective Concentration of Radionuclide Based on Dissolution of Waste Form to Solubility Limit

\begin{tabular}{|c|c|c|}
\hline \multirow[b]{2}{*}{ Radionuclide(a) } & \multicolumn{2}{|c|}{ Concentration $\left(\mathrm{Ci} / \mathrm{m}^{3}\right)$} \\
\hline & $S F^{(b)}$ & $\mathrm{CHLW}^{(\mathrm{c})}$ \\
\hline${ }^{79} \mathrm{Se}$ & -- & $9.5 \mathrm{E}-5$ \\
\hline $93_{\mathrm{Zr}}$ & 3. $1 E-5$ & $4.6 \mathrm{E}-4$ \\
\hline $93 m_{N b}$ & 3. $1 E-5$ & $4.6 E-4$ \\
\hline $99_{\mathrm{TC}}$ & 2. $3 E-4$ & 3. $5 E-3$ \\
\hline${ }^{126} \mathrm{Sn}$ & -- & 1. $3 \mathrm{E}-4$ \\
\hline${ }^{126} \mathrm{Sb}$ & -- & 1. $3 \mathrm{E}-4$ \\
\hline${ }^{135} \mathrm{Cs}$ & -- & 7. $3 E-5$ \\
\hline${ }^{151_{\mathrm{Sm}}}$ & -- & $1.1 \mathrm{E}-4$ \\
\hline${ }^{233} \mathrm{~Pa}$ & -- & $1.4 E-4$ \\
\hline${ }^{237} \mathrm{~Np}$ & - & $1.4 \mathrm{E}-4$ \\
\hline${ }^{238} \mathrm{Pu}$ & -- & $6.3 \mathrm{E}-5$ \\
\hline $239 \mathrm{Pu}$ & $5.0 E-3$ & $4.9 E-4$ \\
\hline $240 \mathrm{Pu}$ & $7.4 \mathrm{E}-3$ & $1.4 \mathrm{E}-3$ \\
\hline $241_{\mathrm{Pu}}$ & -- & $4.4 E-5$ \\
\hline${ }^{242} \mathrm{Pu}$ & $2.9 E-5$ & -- \\
\hline $241_{\mathrm{Am}}$ & $1.5 \mathrm{E}-2$ & $2.1 \mathrm{E}-2$ \\
\hline${ }^{242} \mathrm{Am}$ & - & $3.0 \mathrm{E}-5$ \\
\hline${ }^{243} \mathrm{Am}$ & 2. $3 E-4$ & 3. $3 E-3$ \\
\hline${ }^{245} \mathrm{Cm}$ & -- & $4.4 E-5$ \\
\hline
\end{tabular}

(a) Where no value is 1isted, radionuclide contributes less than 0.1 percent of the total concentration.

(b) Based on uranium oxide dissolution to a concentration of $20 \mathrm{ppm}$.

(c) Based on CHLW glass dissolution to a concentration of $50 \mathrm{ppm}$. 
$1,500 \mathrm{~kg}$ of glass per CHLW waste package. Comparison of Tables 4-8 and 4-10 Indicates that, with the exception of ${ }^{93} \mathrm{Zr}$ and ${ }^{237} \mathrm{NP}$ the concentration of radionuclides is limited by the dissolution of the waste form.

A very simple, conservative model is used to estimate an upper bound to the rate of release of radionuclides from the underground facility: any containment of the waste package is ignored and radionuclides are assumed to dissolve into the flow of water at a rate consistent with both the leach rate from the waste form and the maximum concentration of radionuclides in the water based on solubility of the radionuclides and the waste form constituents. The performance measure is the ratio of the maximum value of the rate of dissolution into the flow $(\mathrm{Cl} / \mathrm{yr}$ ) to the 1,000 -year system inventory $(C 1)$ for the repository. The calculated values of this performance measure are given in Table 4-11. Because the dissolution of the radionuclides that contribute more than 0.1 percent of the release is controlled by the waste form dissolution, the performance measure is the same for each radionuclide as well.

The release fractions in Table 4-11 are well below the release criterion of one part in 100,000 per year because of the low flow rates predicted. A higher flow rate would result in a correspondingly higher annual release fraction. A theoretical maximum to the flow rate can be determined from the release criterion: the flow rate that would result in an annual release fraction of $1.0 \mathrm{E}-5$ per year from exposed $S F$ is $6.3 E-4 \mathrm{~m}^{3} / \mathrm{sec}$ and the flow for exposed CHLW would be $4.2 \mathrm{E}-5 \mathrm{~m}^{3} / \mathrm{sec}$. According to Figure 4-4, such flows can not be attained at all in the Paradox Basin flow model and would require an average $U$-Tube conductivity of more than $1.0 \mathrm{E}+3 \mathrm{~m} /$ day at the other two sites. An average conductivity of this size is not realistic for the U-Tube; therefore, it is expected that release from the underground facility would satisfy the criterion for release from the engineered barrier system.

\subsection{RELEASE TO THE ACCESSIBLE ENVIRONMENT FOR U-TUBE SCENARIO}

Radionuclides leaving the repository are transported to the upper aquifer by the U-Tube flow. To provide a conservative estimate, transport of radionuclides in the aquifer to the boundary that constitutes the accessible environment is neglected. 
Table 4-11. Performance Measure for Release From Underground Facility in U-Tube Scenario

Limit to Performance Measure $(a)$

Palo Duro Paradox Richton

$\begin{array}{llll}\text { Ratio for exposure of SF } & 5.5 E-14 & 5.3 E-14 & 3.3 E-15\end{array}$

Ratio for Exposure of

$\begin{array}{llll}\text { CHLW } & 8.3 \mathrm{E}-13 & 8.0 \mathrm{E}-13 & 5.0 \mathrm{E}-14\end{array}$

(a) Maximum fraction of 1,000-year inventory of the radionuclide released per year. The performance measure is controlled by the dissolution rate of the waste form and is the same for each radionuclide that contributes more than 0.1 percent of the release. 
The discharge to the upper aquifer over a 10,000 -year period in this case is evaluated by integrating the release rate from the underground facility discussed in the previous section. This release rate depends on time because of radioactive decay and generation of the radionuclides. Taking into account this radioactivity, the maximum values of the calculated integrated releases are given in Tables 4-12 and 4-13 for exposure of SF and CHLW, respectively.

For the sake of comparison the standards for likely release to the accessible environment (EPA, 1982) are also given in these tables. The U-Tube Scenario may not fall into the category of reasonably foreseeable release; however, they are used here to provide perspective. Because of the low flow rate, the predicted releases are well below even these standards.

The maximum allowable flow rate can be determined from the release standards. That is, the flow rate, Q, must satisfy the inequality (EPA, 1982, Appendix)

$$
\sum_{\mathbf{i}} Q \mathrm{QC}_{\mathbf{i}} / \mathrm{RL}_{\mathbf{i}} \leqslant 1
$$

where $C_{i}$ is the effective concentration of the radionuclide integrated over 10,000 years and $\mathrm{RL}_{i}$ is the appropriate EPA release standard for the radionuclide. As an example, using the EPA standards for reasonably foreseeable release, the maximum U-Tube flow rate through a SF disposal room must be less than $24 \mathrm{~m}^{3} / \mathrm{y}$ and the rate through a CHLW disposal room must be less than $41 \mathrm{~m}^{3} / \mathrm{y}$. Using instead the standards for very unlikely release, the flow rate would be a factor of 10 higher. These flow rates are more than six orders greater than those calculated in the reference cases. The average conductivity through the repository and the shaft would have to be greater than $0.1 \mathrm{~m} /$ day before the criterion could be exceeded for the specified conditions in the upper aquifer in this simple model.

\subsection{CONCLUSIONS FROM U-TUBE CONNECTION SCENARIO ANALYSES}

For the three sites considered, the predicted releases are below regulatory criteria by more than five orders of magnitude. The releases predicted for the Richton Dome are slightly below those predicted for the two bedded salt sites. 
Table 4-12. Integrated 10,000-Year Release From U-Tube Flow

Through Spent Fuel Disposal Room

\begin{tabular}{lllcc} 
& \multicolumn{2}{c}{ Limit to Performance Measure } & EPA \\
\cline { 2 - 3 } Radionuclide & Palo Duro & Paradox & Richton & Standard $(c)$ \\
\hline & $2.5 \mathrm{E}-4$ & $2.5 \mathrm{E}-4$ & $1.5 \mathrm{E}-5$ & $7.2 \mathrm{E}+5$ \\
${ }^{99} \mathrm{Tc}$ & $5.0 \mathrm{E}-3$ & $5.0 \mathrm{E}-3$ & $3.0 \mathrm{E}-4$ & $7.2 \mathrm{E}+3$ \\
$239 \mathrm{Pu}$ & $5.1 \mathrm{E}-3$ & $5.1 \mathrm{E}-3$ & $3.1 \mathrm{E}-4$ & $7.2 \mathrm{E}+3$ \\
$240 \mathrm{Pu}$ & $3.5 \mathrm{E}-5$ & $3.5 \mathrm{E}-5$ & $2.1 \mathrm{E}-6$ & $7.2 \mathrm{E}+3$ \\
$242 \mathrm{Pu}$ & $1.8 \mathrm{E}-3$ & $1.8 \mathrm{E}-3$ & $1.1 \mathrm{E}-4$ & $7.2 \mathrm{E}+2$ \\
$241 \mathrm{Am}$ & $1.8 \mathrm{E}-4$ & $1.8 \mathrm{E}-4$ & $1.1 \mathrm{E}-5$ & $2.9 \mathrm{E}+2$ \\
$243 \mathrm{Am}$ & & & &
\end{tabular}

(a) Radionuclides contributing more than 0.1 percent of the total release.

(b) Maximum 10,000-year release from underground facility (Ci). Transport in upper aquifer is neglected.

(c) Standards for 1ikely release to accessible environment based on waste from 72,000 MTHM in the repository (EPA, 1982, Appendix). These standards may not be applicable to U-Tube Scenario but have been included for comparison. 
Table 4-13. Integrated 10,000-Year Release From U-Tube Flow Through CHLW Disposal Room

Limit to Performance Measure ${ }^{(b)}$

Radionuclide (a)

Palo Duro Paradox Richton

EPA

Standard (c)

$\begin{array}{lllll}{ }^{79} \mathrm{Se} & 1.1 \mathrm{E}-4 & 1.1 \mathrm{E}-4 & 6.5 \mathrm{E}-6 & 3.6 \mathrm{E}+4 \\ { }^{93 \mathrm{~m}_{\mathrm{Nb}}} & 5.0 \mathrm{E}-4 & 5.0 \mathrm{E}-4 & 3.1 \mathrm{E}-5 & 3.6 \mathrm{E}+4 \\ { }^{99} \mathrm{Tc} & 3.8 \mathrm{E}-3 & 3.8 \mathrm{E}-3 & 2.3 \mathrm{E}-4 & 7.2 \mathrm{E}+5 \\ { }^{126} \mathrm{Sn} & 1.5 \mathrm{E}-4 & 1.5 \mathrm{E}-4 & 9.0 \mathrm{E}-6 & 5.8 \mathrm{E}+3 \\ { }^{126} \mathrm{Sb} & 1.5 \mathrm{E}-4 & 1.5 \mathrm{E}-4 & 9.0 \mathrm{E}-6 & 3.6 \mathrm{E}+4 \\ { }^{135} \mathrm{Cs} & 8.5 \mathrm{E}-5 & 8.5 \mathrm{E}-5 & 5.0 \mathrm{E}-6 & 1.4 \mathrm{E}+5 \\ { }^{233} \mathrm{~Pa} & 1.6 \mathrm{E}-4 & 1.6 \mathrm{E}-4 & 9.5 \mathrm{E}-6 & 7.2 \mathrm{E}+2 \\ { }^{239} \mathrm{Pu} & 4.9 \mathrm{E}-4 & 4.9 \mathrm{E}-4 & 3.0 \mathrm{E}-5 & 7.2 \mathrm{E}+3 \\ { }^{240} \mathrm{Pu} & 9.5 \mathrm{E}-4 & 9.5 \mathrm{E}-4 & 5.5 \mathrm{E}-5 & 7.2 \mathrm{E}+3 \\ { }^{241} \mathrm{Pu} & 3.3 \mathrm{E}-5 & 3.3 \mathrm{E}-5 & 2.0 \mathrm{E}-7 & 7.2 \mathrm{E}+2 \\ 241 \mathrm{Am} & 2.6 \mathrm{E}-3 & 2.6 \mathrm{E}-3 & 1.6 \mathrm{E}-4 & 7.2 \mathrm{E}+2 \\ 243 \mathrm{Am} & 2.7 \mathrm{E}-3 & 2.7 \mathrm{E}-3 & 1.6 \mathrm{E}-4 & 2.9 \mathrm{E}+2 \\ 245 \mathrm{Cm} & 3.3 \mathrm{E}-5 & 3.3 \mathrm{E}-5 & 2.0 \mathrm{E}-7 & 7.2 \mathrm{E}+2\end{array}$

(a) Radionuclides contributing more than 0.1 percent of the total release.

(b) Maximum 10,000-year release from underground facility (Ci). Transport in upper aquifer is neglected.

(c) Standards for likely release to accessible environment based on waste from 72,000 MTHM in the repository (EPA, 1982, Appendix). These standards may not be applicable to U-Tube Scenario but have been Included for comparison. 
5 SIMULTANEOUS CONNECTIONS WITH OVERLYING AND UNDERLYING AQUIFERS SINGLE BOREHOLE INTRUSION SCENARIO

The scenario was described in Section 2.1.2. The conceptual model involves a borehole drilled through the repository which connects aquifers above and below the repository. The assessment of repository system performance in this scenario requires evaluation of the flow in the borehole, the dissolution of salt from the borehole walls in the salt units, the mechanical deformation of the borehole due to creep in the salt units, associated release processes in the underground facility, and transport of radionuclides released from the underground facility. Evaluation of these factors is discussed in this section.

The analyses are applied only to the bedded salt sites. The domed salt site does not feature an applicable lower aquifer necessary for the scenario. Angled drilling near the flank of the dome could conceivably connect the surface units with an aquifer abutting the dome below the repository horizon. Later assessments may therefore consider the possibility of such drilling once detailed characterization of the dome and the specific repository configuration within the dome have been established.

\subsection{BOREHOLE FLOW}

The prediction of flow in the borehole depends, in part, on the geohydrology that prevalls throughout the region. As in the evaluation of the U-Tube flow discussed in Section 4.1, the boundary conditions for the local flow modeling are derived from the regional conceptualization of the flow field. The regional modeling efforts for the Palo Duro and Paradox Basins are discussed in INTERA (1984a and 1984b). These reports summarize the hydrologic properties in the region, the expected flow in the transmissive units, and the potential travel pathways in these units.

For a given description of the regional flow-field, the detailed representation of the various units at the site and the connections between them plus the flow in the borehole can be predicted. The approach is to assume appropriate hydraulic properties for material in the borehole and to evaluate the flow rate and direction through the borehole from Darcy's law. 
The extension to the estimate of bounding flow rates is addressed indirectly. The same porous media approach is applied, but for an increased conductivity of the borehole. For a sufficiently high conductivity, the borehole flow will be controlled by the properties of the transmitting and receiving units and maximum flow rates will be achieved. This latter situation is referred to here as the "open borehole" condition since the resistance of the borehole is negligible relative to that in ihe transmitting and receiving aquifers.

\subsubsection{Borehole Flow at the Palo Duro Basin Site}

The domain modeled for the local flow at the Palo Duro Site is described In Section 4.1.1 and shown in Figure 4-1. The representation of the hydrostratigraphic units extends deeper than in the case of the U-Tube analysis and the representation is shown in Figure 5-1. The unit groupings in this figure are used to address the features of the local flow. The Ogallala and Dockum units (Layers 1 and 2 in Figure 4-2) represent the transmissive groups near the surface. Similarly, the Wolfcamp carbonate (Layer 7), the Pennsylvanian carbonate, and the Pennsylvanian granite wash represent collections of the more transmissive portions of the Wolfcamp and Pennsylvanian sections.

Layers 3 and 4 are confining layers and include the salt host rock. The interbed in Layer 5 is specifically taken into account in the analysis to evaluate the potential impacts it may impose on the local flow. The continuity of this interbed throughout the region is not known but it is assumed to be continuous in the present analysis. Layer 8 represents the lowconductivity shales in the Wolfcamp and upper Pennsylvanian.

The properties assumed for these units are given in Table 5-1. The flow parameter values for the relatively transmissive units are based on the analyses of the regional assessments (INTERA, 1984a).

The areal discretization for the analysis is shown in Figure 5-2. This discretization is chosen so that the repository is located in the nine blocks in the center of this grid: that is, defined by the 5, 6, and 7 blocks in the $y$ (northwest) direction and by the 5, 6, and 7 blocks in the $x$ (southeast) direction. The borehole is assumed to be drilled in the center of the grid in block $(6,6)$. 


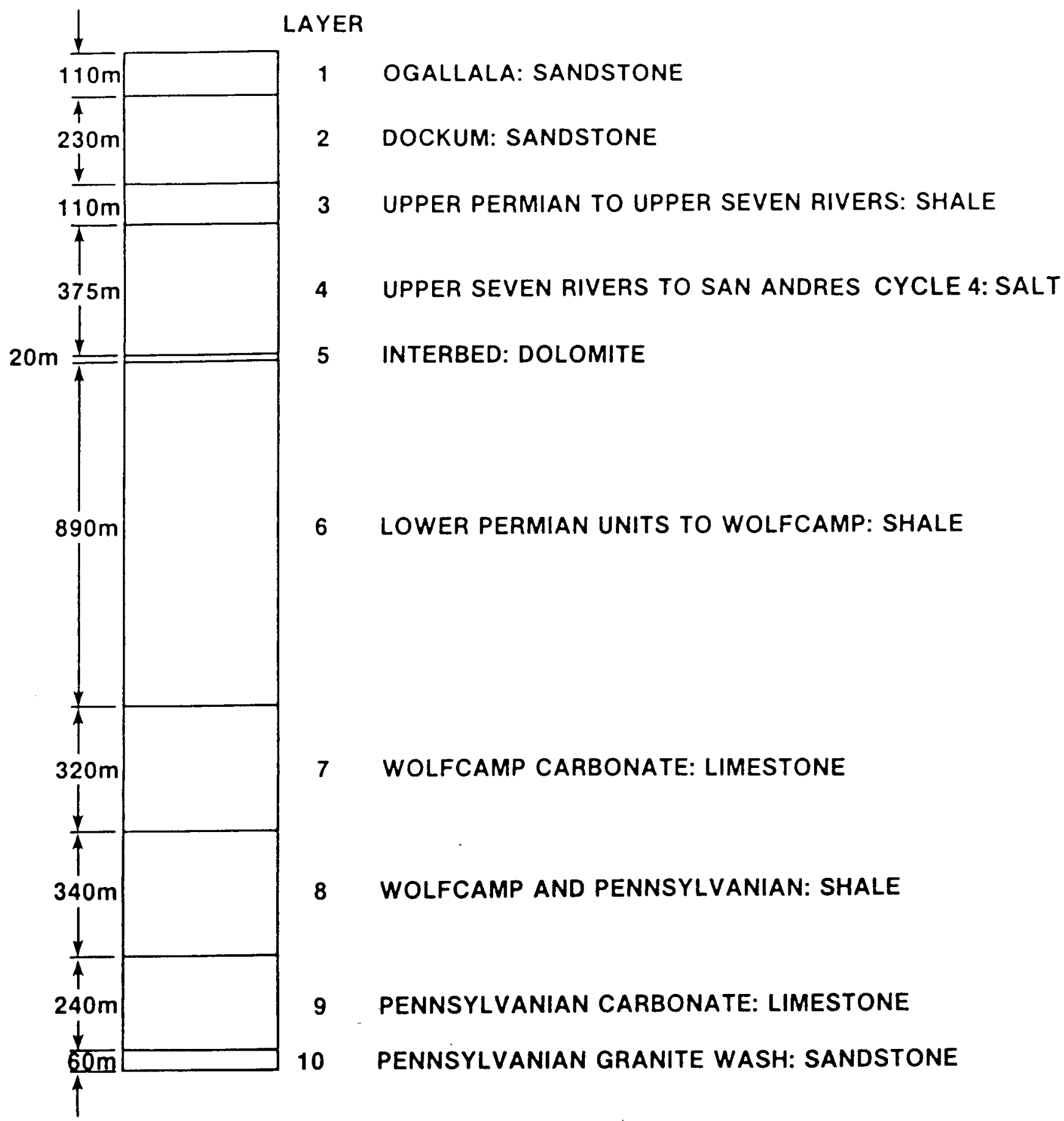

\footnotetext{
Figure 5-1. Representation of Palo Duro Stratigraphy for Single Borehole Scenario Flow Analyses
} 
Table 5-1. Parameters Assumed for Palo Duro Basin Site

\begin{tabular}{|c|c|c|c|c|c|}
\hline Unit & $\begin{array}{l}\text { Thickness } \\
\text { (m) }\end{array}$ & $\begin{array}{l}\text { Conductivity }(\mathrm{a}) \\
(\mathrm{m} / \text { day })\end{array}$ & Porosity & Fraction Salt & Salt Purity \\
\hline Oga11ala & 110 & $8.0 \mathrm{E}+0$ & 0.15 & 0 & -- \\
\hline Dockum & 230 & $4.0 E-1$ & 0.05 & 0 & -- \\
\hline $\begin{array}{l}\text { Upper Permian Including } \\
\text { Upper San Andres }\end{array}$ & 370 & $8.0 \mathrm{E}-12$ & -- & $0^{(b)}$ & $-\infty$ \\
\hline Lower San Andres & 210 & $8.0 \mathrm{E}-12$ & -- & 0.45 & 0.87 \\
\hline Lower Permian to Wolfcamp & 760 & $8.0 \mathrm{E}-12$ & -- & $0^{(b)}$ & -- \\
\hline Wolfcamp Carbonate & 320 & $8.0 \mathrm{E}-4$ & 0.1 & 0 & $\cdots$ \\
\hline $\begin{array}{l}\text { Wolfcamp and Pennsylvanian } \\
\text { Shale }\end{array}$ & 340 & $8.0 \mathrm{E}-8$ & 0.1 & 0 & - \\
\hline Pennsylvanian Carbonate & 240 & $8.0 \mathrm{E}-4$ & 0.1 & 0 & - \\
\hline Granite Wash & 60 & $8.0 \mathrm{E}-2$ & 0.05 & 0 & - \\
\hline
\end{tabular}

(a) Approximate horizontal conductivity. Vertical conductivity is a factor of 10 smaller.

(b) Salt in these units neglected except for Upper Seven Rivers which is represented as a section of 100 percent salt of $20 \mathrm{~m}$ thickness located at a depth of $450 \mathrm{~m}$. 

The evaluation of the steady-state flow for this system is performed with the finite-difference code SWENT (INTERA, 1983b). For the boundary conditions, a vertical recharge of $0.76 \mathrm{~cm} / \mathrm{y}$ is applied at the top of the model corresponding to the expected regional recharge (INTERA, 1984a). The pressure conditions maintained at the lateral boundaries of the upper aquifer and of the Wolfcamp are the same as those described in Appendix A.

A borehole is assumed to connect the upper and lower aquifer systems. Such a borehole would be of small dimension relative to the other characteristic sizes that must be modeled in the local-scale simulation. Including both scales in the model presents numerical difficulties and a simplification is made. The block containing the borehole is modeled as a homogeneous medium with properties determined by the volume average of the borehole properties and those for the rock in the block. This approach will provide only an approximate pressure distribution in the vicinity of the borehole; however, if the flow in the borehole does not significantly perturb the flow field in the aquifers, these pressures will provide an adequate representation for the flow field. In this case, the calculated borehole discharge will be approximately correct even though the flow velocity will only represent the average velocity throughout the block. The borehole velocity must be estimated from this average.

If the borehole flow strongly disturbs the aquifer flow in the vicinity of the borehole, the flow rate through the borehole can be overestimated if the size of the borehole block is much larger than the borehole itself.

In the calculation of the borehole flow rate, the salinity of the water in the borehole is taken into account by assuming that the water is fully saturated in the salt units. Therefore, the fluid density in the borehole is chosen to be $1,250 \mathrm{~kg} / \mathrm{m}^{3}$ with appropriate modification to account for variation with temperature. In the Wolfcamp and the units below, a density of $1,080 \mathrm{~kg} / \mathrm{m}^{3}$ is assumed.

For the initial calculations, it is assumed that the borehole is filled with loose material with a conductivity of $30 \mathrm{~m} /$ day, approximately the conductivity of a coarse-grained sand (Means and Parcher, 1963).

Since the pressure conditions in the Pennsylvanian units are not well known, two cases are considered. In the first case, the Pennsylvanian carbonate and the granite wash are assumed to be connected hydrostatically to the Wolfcamp. In the second case, the Pennsylvanian units are assumed to be 
underpressured with respect to the Wolfcamp and a 60 m potential head difference is arbitrarily imposed between these units and the Wolfcamp to investigate the effect.

The results of the calculations are summarized in Table 5-2. The flow in the borehole is downward from the Ogallala and Dockum units to the lower units and has a magnitude in the borehole of about $0.59 \mathrm{~m}^{3} /$ day. More than 92 percent of this flow goes into the Wolfcamp when the lower units are at the same potential. This division of the flow can be understood from the hydraulic properties. Although the transmissivity of the granite wash is about a factor of 19 greater than that of the Wolfcamp, there is sufficient resistance in the borehole between these units to inhibit the flow to the lower unit in this case.

For the case where the potential in the Pennsylvanian untts is lowered by $60 \mathrm{~m}$, the relative flow into these units is quite different. In this case more than 96 percent of the borehole flow goes into the Pennsylvanian carbonate. In fact, water is drawn out of the Wolfcamp to the lower units by the imposed potential difference. The total borehole flow from the upper aquifer, however, is virtually unchanged from the previous case because this change in the potential is much smaller than the head between the upper and lower units.

As the borehole resistance is decreased, the flow in the borehole should increase. This trend should continue until the resistance in the borehole becomes negligible relative to that in the transmitting and receiving units. For large enough borehole conductivity, the flow into the lower units should be independent of the borehole resistance. This result represents an upper bound to the rate of flow in the borehole and can be used to estimate extreme conditions. These conditions are investigated by calculations for increased borehole conductivity. The results are shown in Figure 5-3 where the flows Into the various units and the total flow in the borehole are shown as a function of the borehole conductivity. The lower units are all assumed to be hydrostatically connected at the boundaries. As can be seen in Figure 5-3, the borehole flow increases with borehole conductivity until the borehole resistance becomes unimportant and the calculated flows are indistinguishable from those for an open borehole. In this case, the flow rate is divided among the various receiving units roughly in proportion to their relative 
Table 5-2. Tredicted Flow Rate Entering Receiving Units From Borehole in Palo Duro Basin (a)

Unit

Flow Rate into Unit $\left(\mathrm{m}^{3} /\right.$ day)

(b)

(c)

$\begin{array}{llr}\text { Wolfcamp } & 0.55 & -0.07 \\ \text { Pennsylvanian carbonate } & 0.01 & 0.58 \\ \text { Pennsylvanian granite wash } & 0.03 & 0.09\end{array}$

(a) Conductivity of borehole is $30 \mathrm{~m} /$ day, and borehole diameter is 9 inches $(0.23 \mathrm{~m})$.

(b) Pressure in Pennsylvantan units = pressure in Wolfcamp + $\rho$ gh.

(c) Pressure in Pennsylvanian units = pressure in Wolfcamp $+\rho g(h-60 \mathrm{~m})$.

The negative flow indicates that flow is from the Wolfcamp into the borehole. 


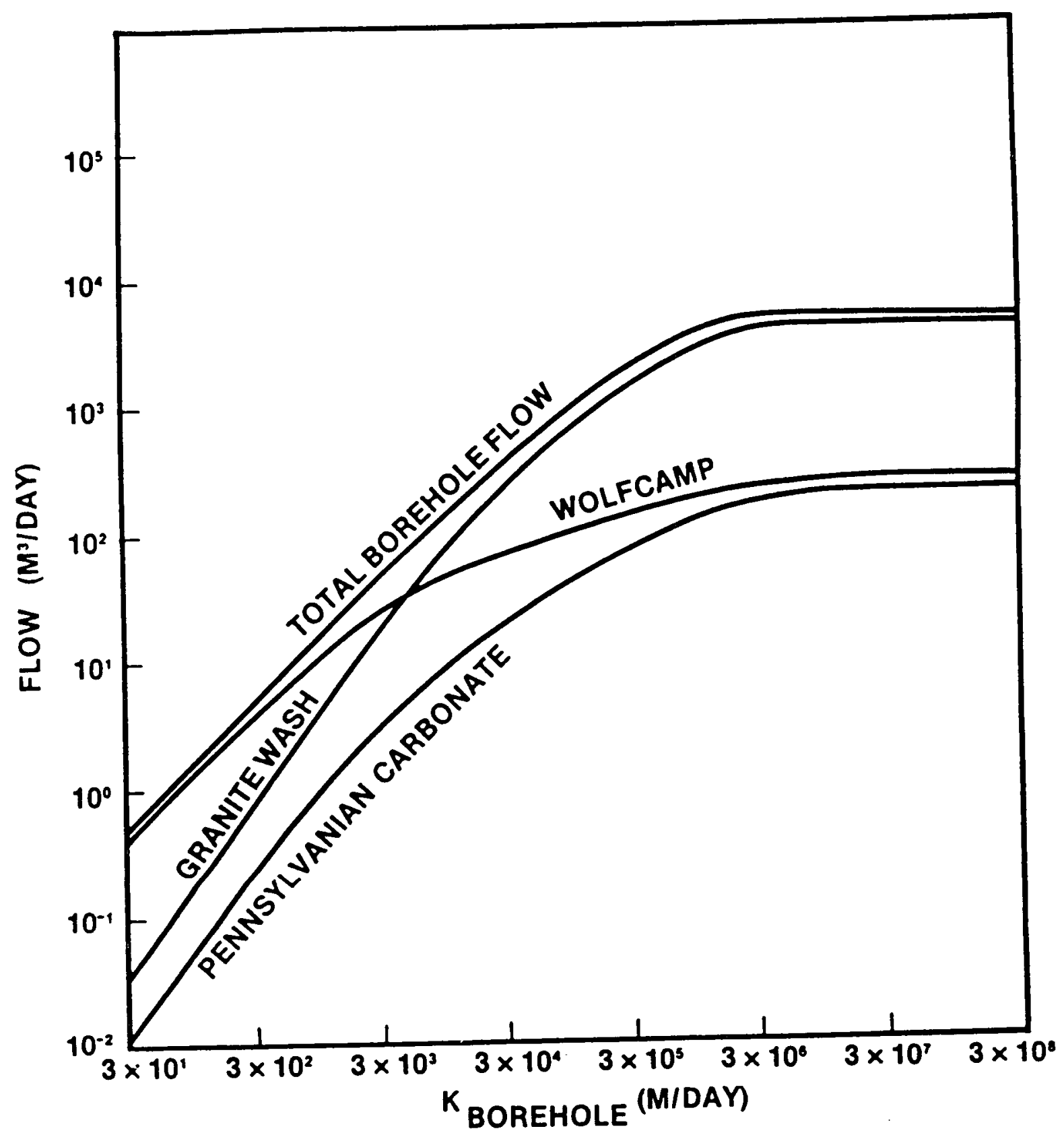

F1gure 5-3. Calculated Borehole Flow Rate for Palo Duro Basin 
transmissivities. The maximum borehole flow rate is predicted to be about $3,800 \mathrm{~m}^{3} /$ day with 5 percent going into the Wolfcamp and 92 percent going into the Pennsylvanian granite wash.

These results represent upper bounds to the borehole flow rate and not necessarily the flow rate that would occur in any actual conditions. For example, the flow rate is affected by using a large grid block to represent the borehole. When the resistance of the borehole is decreased to negligible values, the pressure distribution is determined in part by the size of this block. For radial flow in the vicinity of the borehole, the flow rate calculated for a borehole block of about a $200-\mathrm{m}$ radius will be about a factor of three greater than that calculated for a borehole block of about $0.1 \mathrm{~m}$ radius which is typical of actual borehole sizes.

A second assumption made in the local flow modeling is that the pressures from the regional modeling (which does not include the effects of flow in the borehole) are not changed significantly at the boundaries of the model even when flow occurs through the borehole. This assumption would be appropriate if the boundaries are removed far enough from the borehole so that drawdown effects would not be detectable at the boundaries. If the boundaries were too close or if there were insufficient water available in the transmitting units to maintain the flow in the borehole, the borehole flow could be substantially overestimated. However, for the flows calculated, this problem does not appear to be significant. For example, for the case of an "open" borehole to the granite wash, the drawdown reduces the calculated pressure in the Ogallala and the Dockum by less than 20 percent in the vicinity of the borehole from the undisturbed, in situ value and reduces the pressure in these units by less than 2 percent $3 \mathrm{~km}$ from the borehole. For smaller flow rates, the effect would be even less. Since the boundaries are more than $10 \mathrm{~km}$ from the borehole, it appears that any error in the calcuation due to fixed pressures at this distance would not be important.

\subsubsection{Borehole Flow at the Paradox Basin Site}

The local domain modeled for the Paradox Basin site is shown in Figure 4-5.

The vertical hydrogeological model of the site for this calculation is shown in Figure 5-4. The Cedar Mesa (Layer 1), Elephant Canyon (Layer 2), and 


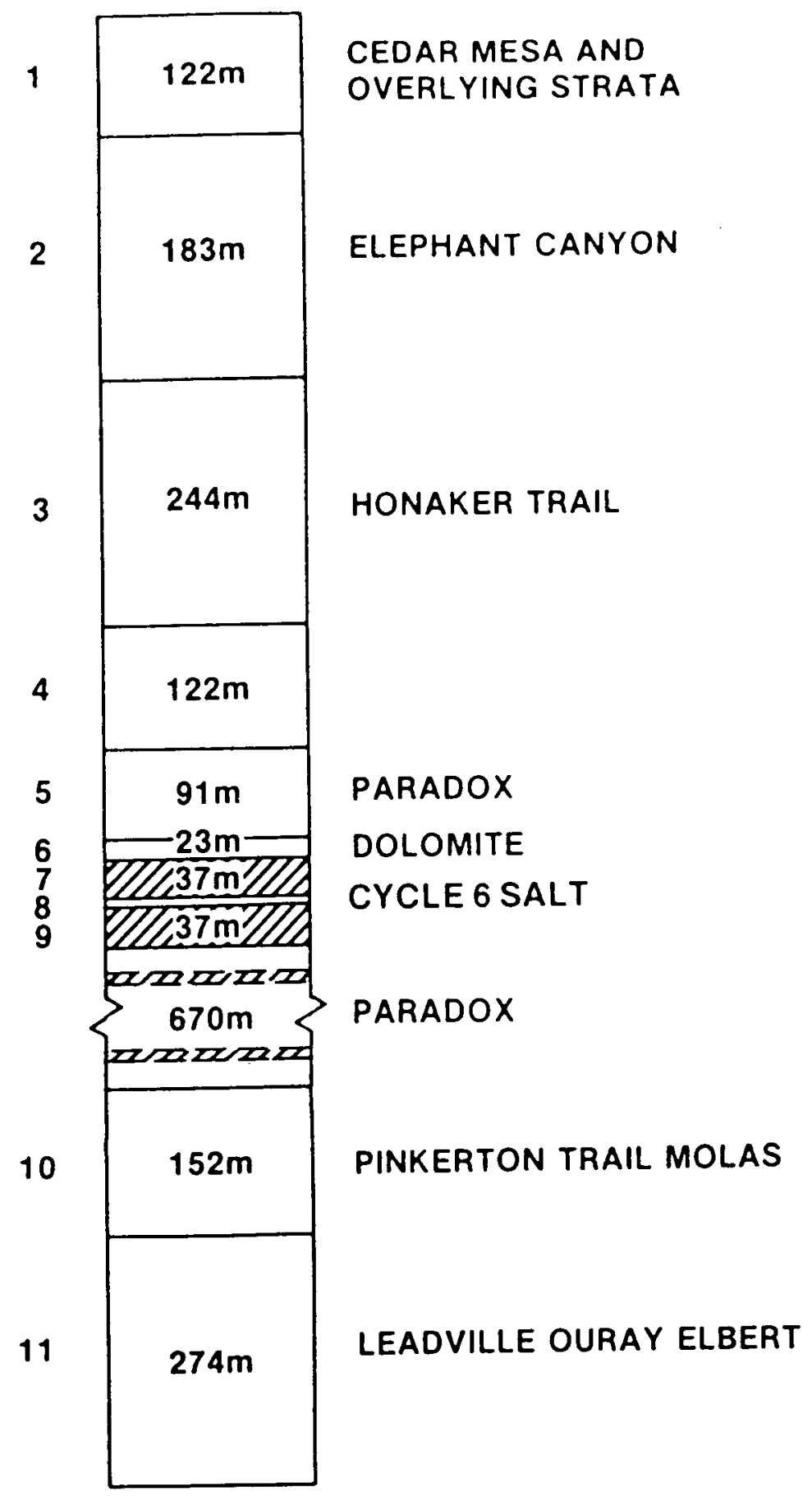

Figure 5-4. Representation of Paradox Basin Stratigraphy for Single Borehole Scenario Flow Analyses 
Honaker Trail units (Layers 3, and 4) in this figure represent the transmissive groups near the surface. Similarly the Pinkerton Trai1-Molas (Layer 10) and the Leadville-Ouray-Elbert (Layer 11) represent collections of the more transmissive units at depth. Layers $5,7,8$ and 9 represent salt units and Layer 6 is a dolomite interbed. The lowest unit labeled "Paradox" in Figure 5-4 between Layers 9 and 10 is a thick, 1mpermeable sequence and is modeled here as a gap in the reglonal flow regime.

The properties assumed for these units are given in Table 5-3. The flow parameter values for the relatively transmissive units are based on the analyses of the regional assessments.

The horizontal discretization is shown in Figure 5-5. The borehole is assumed to be drilled in the center of the grid block defined by block 7 in the $x$ (east) direction and block 4 in the $y$ (north) direction.

The approach used in the Palo Duro Basin analysis (Section 5.1.1) is followed here. The pressures in the hydrostratigraphic units derived from the reglonal modeling and used as the boundary conditions for the local flow modeling are given in Appendix A.

The predicted borehole flow rate in this case $1 \mathrm{~s} 0.66 \mathrm{~m}^{3} /$ day and the flow is vertically down from the Elephant Canyon to the Leadville. Increasing the conductivity increases the flow rate until the receiving and transmitting units control the flow. The results are 1isted in Table 5-4. As can be seen, the bounding flow rate is about $270 \mathrm{~m}^{3} /$ day, more than an order of magnitude less than that for the Palo Duro Basin case. As in the Palo Duro case, the assumption of a large block to represent the borehole leads to an overestimate of the borehole flow when the borehole resistance becomes negligible. In this case, the flow rate calculated is about a factor of three larger than for the case that would be calculated using the smaller block size.

\subsection{CREEP AND DISSOLUTION OF SALT IN THE BOREHOLE}

Creep and dissolution can be evaluated with the BORHOL code (INTERA, 1984d) which has been specifically developed for this scenario and which calculates dissolution, precipitation, creep, and temperature effects in the borehole. The approach used by BORHOL in these calculations is discussed in Appendix $\mathrm{C}$. 
Table 5-3. Parameters Assumed for Paradox Basin Site

\begin{tabular}{|c|c|c|c|c|c|}
\hline Unit & $\begin{array}{l}\text { Thickness } \\
\text { (m) }\end{array}$ & $\begin{array}{c}\text { Conductivity } \\
(\mathrm{a}) \\
(\mathrm{d} / \mathrm{day})\end{array}$ & Porosity & Fraction Salt & Salt Purity \\
\hline $\begin{array}{l}\text { Cedar Mesa and } \\
\text { Overlying Strata }\end{array}$ & -- & $3.0 \mathrm{E}-3$ & 0.1 & 0 & -- \\
\hline Elephant Canyon & 170 & $3.0 \mathrm{E}-3$ & 0.1 & 0 & -- \\
\hline Honaker Trail & 590 & $3.0 \mathrm{E}-3$ & 0.1 & 0 & -- \\
\hline Paradox & 880 & $2.5 E-11$ & -- & 0.74 & 0.84 \\
\hline Pinkerton Trail/Molas & 150 & $3.0 \mathrm{E}-5$ & 0.1 & 0 & - \\
\hline Leadville/Ouray/E1bert & 280 & $3.0 E-2$ & 0.1 & 0 & -- \\
\hline
\end{tabular}

(a) Approximate horizontal conductivity. Vertical conductivity is a factor of 10 smaller. 


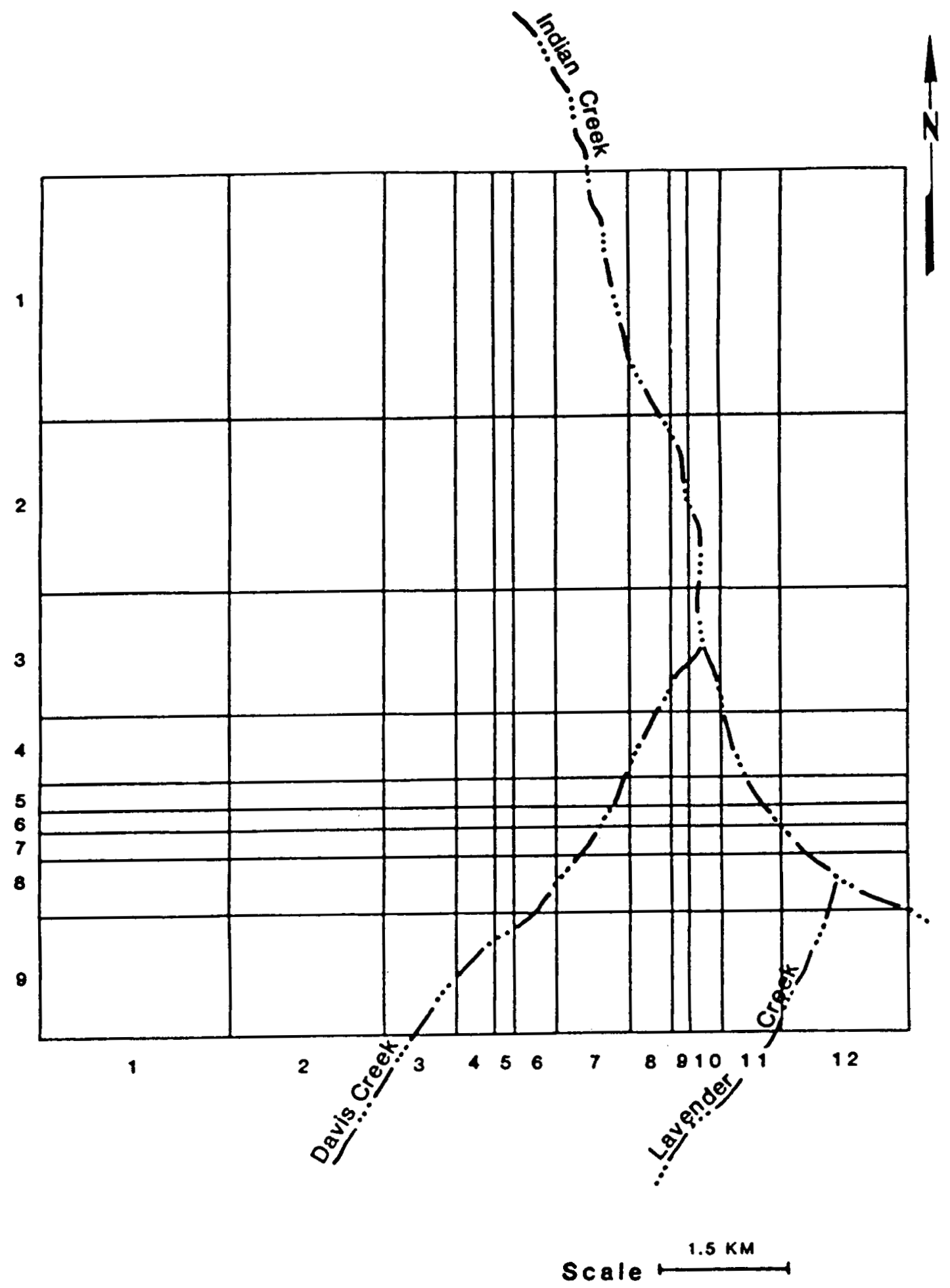

Figure 5-5. Horizontal Discretization of Paradox Basin Site for Stingle Borehole Scenario Flow Analyses 
Table 5-4. Predicted Borehole F1ow Rate at Paradox Basin Site

\begin{tabular}{|c|c|}
\hline $\begin{array}{l}\text { Conductivity } \\
\text { (m/day) }\end{array}$ & $\begin{array}{l}\text { Flow Rate } \\
\left(\mathrm{m}^{3} / \text { day }\right)\end{array}$ \\
\hline $3.0 \mathrm{E}+1$ & $6.6 E-1$ \\
\hline $3.0 \mathrm{E}+2$ & $5.9 E+0$ \\
\hline $3.0 \mathrm{E}+3$ & 4. $3 E+1$ \\
\hline $3.0 \mathrm{E}+4$ & $1.6 \mathrm{E}+2$ \\
\hline $3.0 \mathrm{E}+5$ & $2.5 E+2$ \\
\hline $3.0 \mathrm{E}+6$ & $2.7 E+2$ \\
\hline $3.0 \mathrm{E}+7$ & $2.7 \mathrm{E}+2$ \\
\hline
\end{tabular}


Specific, detailed phenomenological laws governing these processes are not yet known so that it is not yet possible to perform precise analyses. However, some preliminary site data and relevant information from other sources are available so that scoping analyses can be conducted. Results of such calculations are given here to estimate order-of-magnitude effects and then specific analyses using the preliminary site data are described and evaluated to estimate waste exposure rates at the repository horizon for the two sites.

\section{2 .1 Magnitude of Creep Rate in Borehole}

The magnitude of the creep displacement of the borehole walls in the salt units is estimated using a simple representation for the creep response of the salt. The creep strain rate $\dot{\varepsilon}_{c}$ is assumed to follow a viscoelastic constitutive relation:

$$
\dot{\varepsilon}_{c}=\dot{\varepsilon}_{s s}\left(1+B \varepsilon_{a} \exp (-\xi t)\right)
$$

where $\dot{\varepsilon}_{\text {ss }}$ is the steady-state strain rate given by:

$$
\dot{\varepsilon}_{s s}=A \exp (-\gamma / T)(\Delta \sigma)^{n}
$$

and the relaxation frequency $\xi$ is given by:

$$
\xi=\begin{array}{ll}
B A \exp (-Q / R T)(\Delta \sigma)^{\mathrm{n}} & \dot{\varepsilon}_{\mathrm{ss}}>\dot{\varepsilon}_{\mathrm{sS}}^{*} \\
\dot{B}_{\mathrm{ss}}^{*} & \dot{\varepsilon}_{\mathrm{ss}} \leqslant \dot{\varepsilon}_{\mathrm{ss}}^{*}
\end{array}
$$

The parameters in the creep law include:

$$
\begin{aligned}
\varepsilon_{\mathrm{a}} & = \\
\dot{\varepsilon}_{\mathrm{sS}}^{*} & \text { asymptotic transient strain } \\
& \text { critical strain rate dividing the high and low } \\
& \text { regimes }
\end{aligned}
$$

$A, B, n$, and $\gamma=$ empirical parameters

$\mathrm{T} \quad=$ absolute temperature

$\Delta \sigma \quad=$ deviatoric stress. 
The displacement is calculated using the finite-element code, VISCOT (INTERA, 1983a). The conceptual model and boundary and initial conditions assumed are illustrated in Figure 5-6. The borehole and adjacent rock are modeled in an axisymmetric geometry, and the model extends from the borehole radius $r_{0}$ out to a radius of $4 \mathrm{~m}$ to assure that in situ stresses prevail at the boundary.

The calculations are performed in two steps. First, the geostatic stresses are modeled. These stresses are the sum of two terms. The first is evaluated from the upper diagram in Figure 5-6. The section of salt is modeled with a roller boundary at the bottom and zero normal stress at the top and at the outer radius of the cylinder of salt. The second term is evaluated by imposing the virgin overburden stresses on all boundaries. The sum of these two provides the initial state of stress for the evaluations.

In the second step, the transient stress and deformation is evaluated. A roller boundary condition at the bottom and zero vertical stress deviation at the top are imposed. The in situ (geostatic) stresses are assumed to hold at the outer boundary. The inner radius is a free surface with zero radial stress.

The parameters used are given in Table 5-5. These values are typical for Cycle 4 of the Palo Duro salt (Pfeifle et a1, 1981, Table 4.3). Using the in situ temperatures defined in Table 5-5, the borehole wall displacement is predicted for a depth of $750 \mathrm{~m}$. The results are shown in Figure 5-7. The VISCOT calculation gives an inftial transient that quickly reaches a steadystate rate. This calculation is repeated using the BORHOL code (INTERA, 1984d). BORHOL assumes only a secondary creep law so that only the parameters for the steady-state rate are used. The results are compared in Figure 5-7 with those obtained using both the primary and secondary creep components. In this case the latter part of the creep law appears to provide a reasonable estimate of the creep rate.

The estimate of the dependence of the displacement rate on depth is indicated in Figure 5-8. The calculation has been made for depths of 560, 750 , and $970 \mathrm{~m}$. Of course, the creep law may also depend on depth but the single parameter set in Table 5-5 has been used in this case. The results are compared with the steady-state creep rate. This evaluation also suggests that the BORHOL calculations are adequate to estimate the creep effects. 

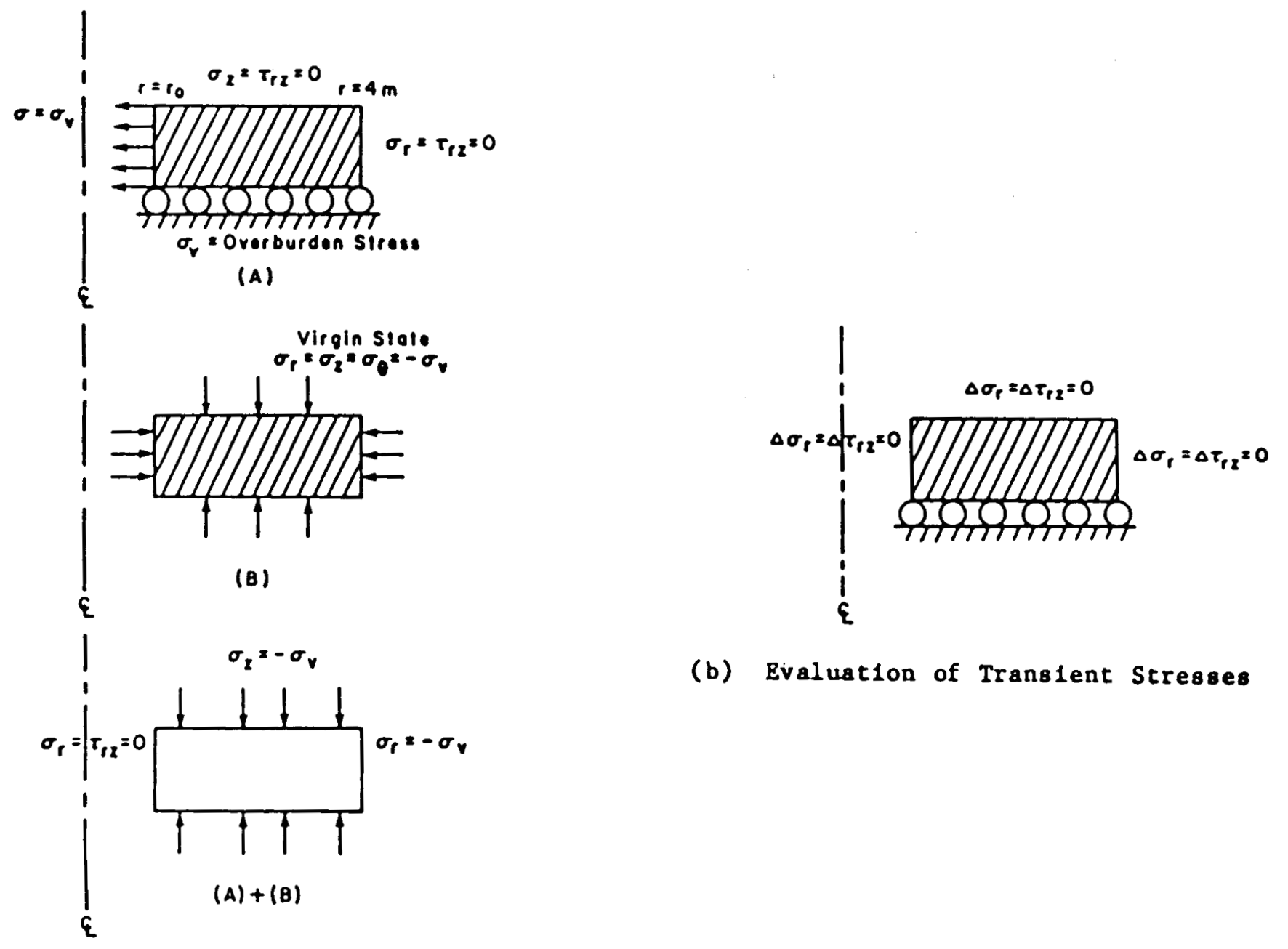

(b) Evaluation of Transient Stresses

a) Evaluation of Geostatic Condition.

$\frac{\text { Figure 5-6. Conceptual Model for Evaluation of Thermomechanical Conditions }}{\text { Near Borehole }}$ 
Table 5-5. Material Properties for Salt Thermomechanical Analysis

\section{Stress Parameters}

Young's Modulus (GPa)

Poisson's Ratio

Coefficient of Thermal Expansion $\left(\mathrm{K}^{-1}\right)$

Average Overburden Density $\left(\mathrm{kg} / \mathrm{m}^{3}\right)$

$\overline{\mathrm{A}}\left(\mathrm{MPa}^{-\mathrm{n}}-\mathrm{sec}\right)$

$\mathrm{n}$

$\gamma(\mathrm{K})$

$\dot{\varepsilon} \operatorname{ss}^{\star}\left(\sec ^{-1}\right)$

$\varepsilon$ a

B
26.6

0.33

4. $1 \mathrm{E}-5$

2500

$4.66 \mathrm{E}-3$

4.6

8660

$5.0 \mathrm{E}-8$

$3.97 \mathrm{E}-2$

82

Thermal Parameters

$\rho \mathrm{Cp}$, Volumetric heat capacity of rock $\left(\mathrm{MJ} / \mathrm{m}^{3}\right) \quad 1.6$

$\alpha$, Thermal Diffusivity $\left(\mathrm{m}^{2} / \mathrm{sec}\right) \quad 1.9 \mathrm{E}-6$

$\mathrm{T}_{0}$, Temperature at Surface $(\mathrm{C}) \quad 15.6$

$\mathrm{g}$, Geothermal Gradient $(\mathrm{C} / \mathrm{m}) \quad 1.83 \mathrm{E}-2$ 


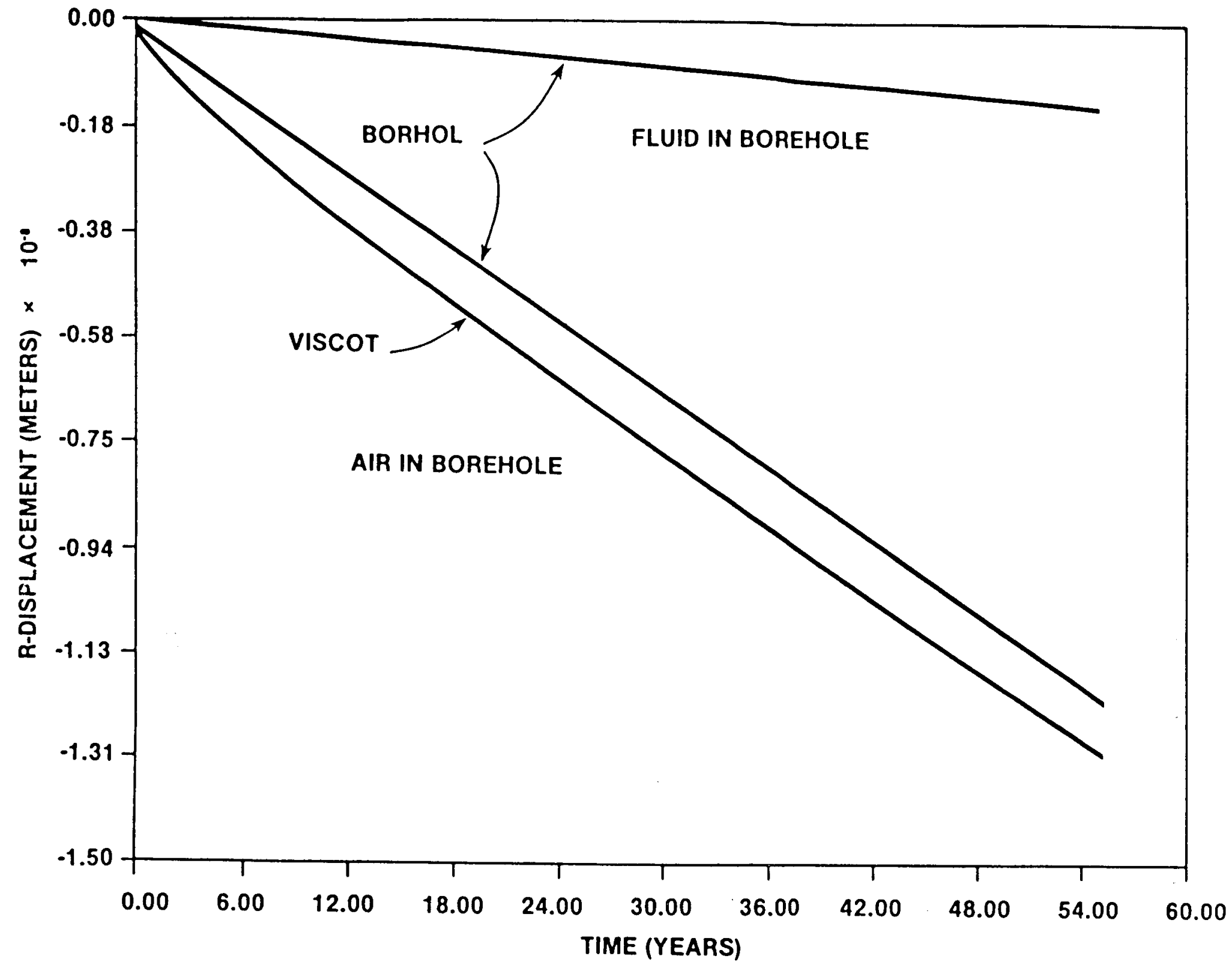

Figure 5-7. Effect of Fluid Pressure on Creep Closure at Depth of $747 \mathrm{~m}$ (No Repository Heat) 


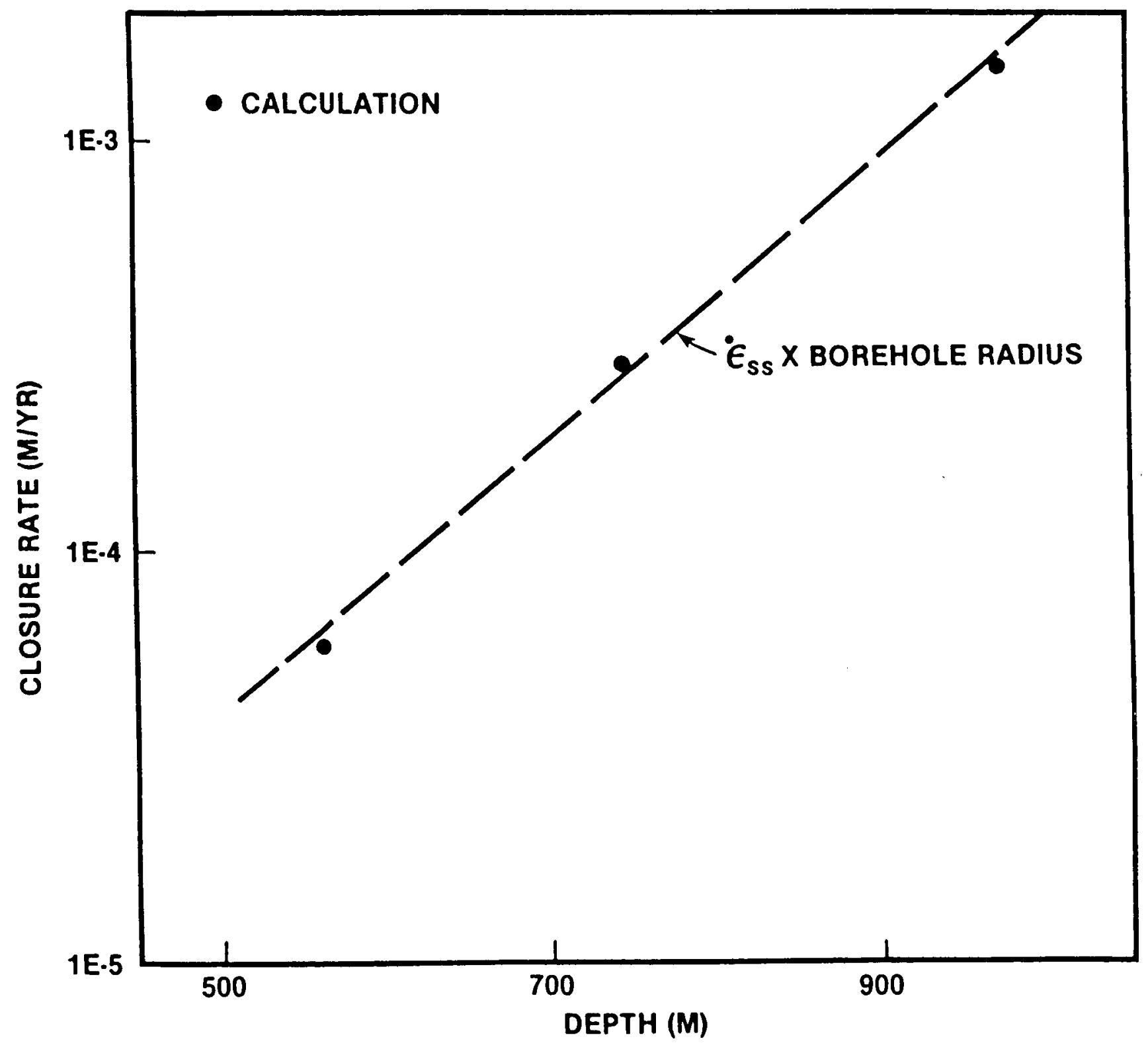


The creep will be affected by the elevated temperatures induced by the heat generated in the repository. This effect is estimated by calculating the displacement of the borehole taking into account both depth and temperature using the BORHOL code. For this evaluation it is assumed that CHLW is emplaced in the repository at an areal thermal loading density of $25 \mathrm{~W} / \mathrm{m}^{2}$. The repository is assumed to be at a depth of $750 \mathrm{~m}$ in the formation and the borehole is assumed to have a radius of $0.1 \mathrm{~m}$ at the time of emplacement. The effect of temperature is shown in Figure 5-9. The increased displacement rate at the repository horizon is dramatic and the borehole is nearly closed after about 75 years in this case. At in situ temperatures; the closure would occur in about 300 years.

These calculations have been made for a borehole which is open and which contains no water. The presence of water would be expected to decrease the displacement rate due to the reduction in the deviatoric stress. The effect calculated using the BORHOL code is shown in Figure 5-7. No dissolution effects are taken into account in this case.

\subsubsection{Magnitude of Dissolution Rate in Borehole}

The dissolution occurring in the salt units due to the flow in the borehole can be estimated using the BORHOL code. Specific dissolution rate parameters for the various units and flow conditions are not yet known in detail. The literature regarding these parameters has been reviewed by $H . C$. Claiborne and R. J. Vedder (see Appendix G) of Oak Ridge National Laboratory under contract to the office of Nuclear Waste Isolation. A condensation of their review is included here in Appendix D. Generic dissolution rates based on their review are also given in Appendix D. These parameters have been used to estimate dissolution rates at a site typical of that in the Palo Duro Basin.

As the water flows down from the Ogallala and Dockum units, it dissolves halite in the salt units encountered. In the evaluation, the salt units are located in two groups. The first group is the Upper Seven Rivers Formation which is assumed to be a thick bed that is pure salt. The second group is the Lower San Andres Formation which is modeled as containing salt distributed uniformly, through the formation. It is assumed that the salt units in the San Andres compose 45 percent of the rock based on the Stone \& Webster (1983) 


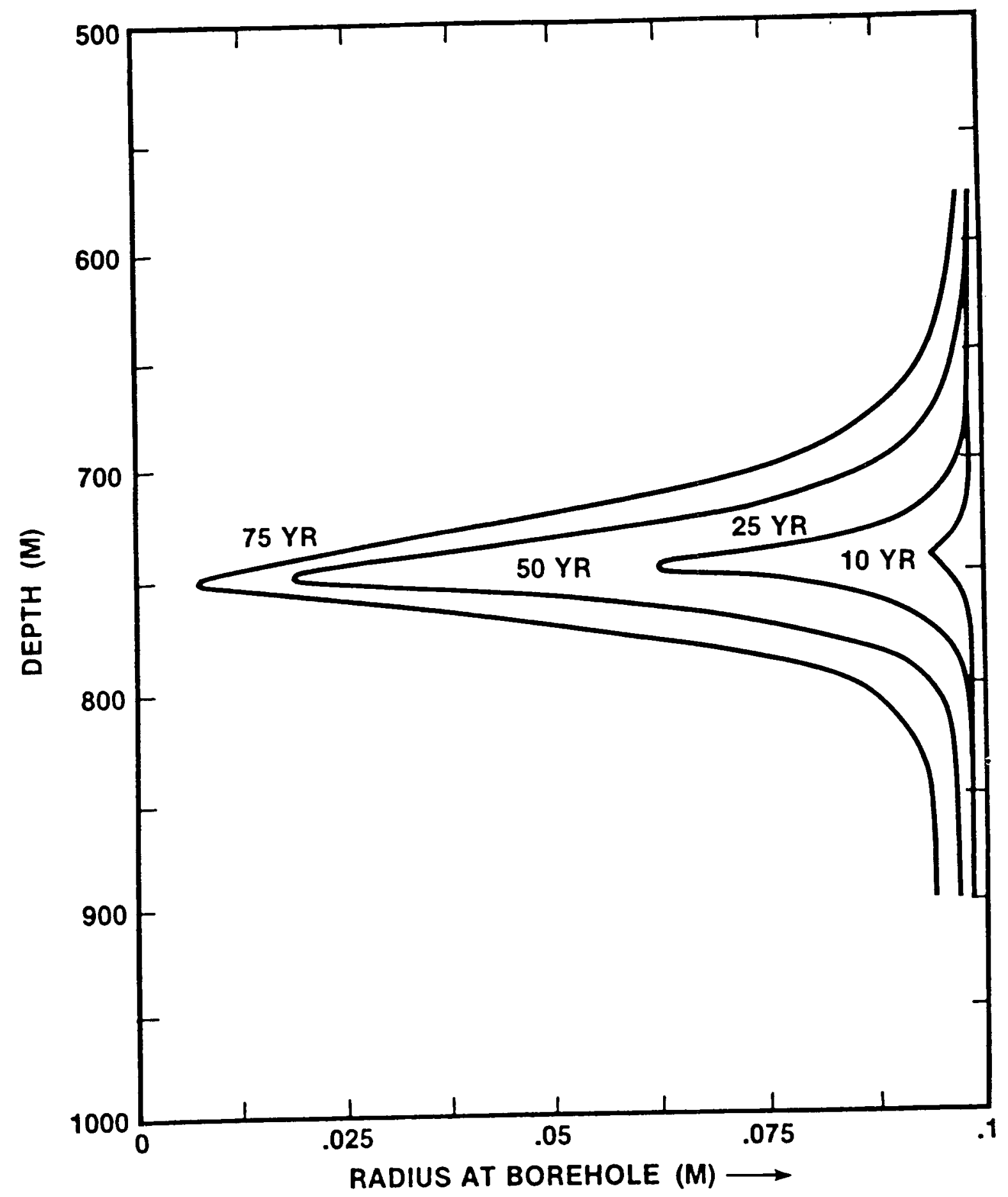

Figure 5-9. Borehole Radius Calculated at Selected Times 
analysis of the Friemel and Detten Well tests. Stone \& Webster (1983) also indicate that impurities in each salt bed constitute about 13 percent of the volume of the salt on the average.

The calculations are made for flow in an open borehole. For a borehole that is partially plugged or filled with loose material or silt, the flow rate will be much smaller. Therefore, the water will saturate with salt much sooner and further upstream than in the open borehole case. The predicted salinity of the open borehole flow is shown in Figure 5-10. In this figure, the top of the salt refers to the dissolution occurring in the Lower Seven Rivers salt. The flow there is more than 90 percent saturated within 10 years after the borehole is drilled. The repository horizon in this case is assumed to be at $725 \mathrm{~m}$. At this horizon, the flow is nearly saturated after only 1 year. Deeper in the salt, at a depth of $900 \mathrm{~m}$ (referred to here as the bottom of the salt although there are other salt layers below this depth), saturation occurs after only a few months of flow. Thus, the salinity of the flow at the lower depths is high due to the dissolution occurring in the upper salt layers.

The temperature in the rock and in the fluid has also been analyzed. The in situ rock temperatures tend to increase with depth. In addition, these temperatures are modified by the heat generated by the radioactive waste. This modification is expected to be most important in the vicinity of the repository and could affect the temperature of the fluid in the borehole passing through the repository. Figure 5-11 shows the predicted temperatures 1,000 years after waste emplacement. Although the fluid temperature does reflect some dependence on the rock temperature, this dependence is weak and the temperatures are largely determined by the thermal conditions in the transmitting aquifer. Because of this weak dependence, transient effects due to the decrease in the waste heat generation rate with time will not have a strong impact and the fluid temperatures in Figure 5-11 are essentially constant during the calculational period.

The calculated borehole radius is shown as a function of time in Figure 5-12. In the deeper layers, the hole grows until dissolution ceases because of salt saturation. At liser times, the hole even begins to close due to salt creep. At the top of the salt, the hole continues to grow in the model in the time frame shown. The impact of the increased borehole radius upon the borehole fluid velocity is shown in Figure 5-13. 


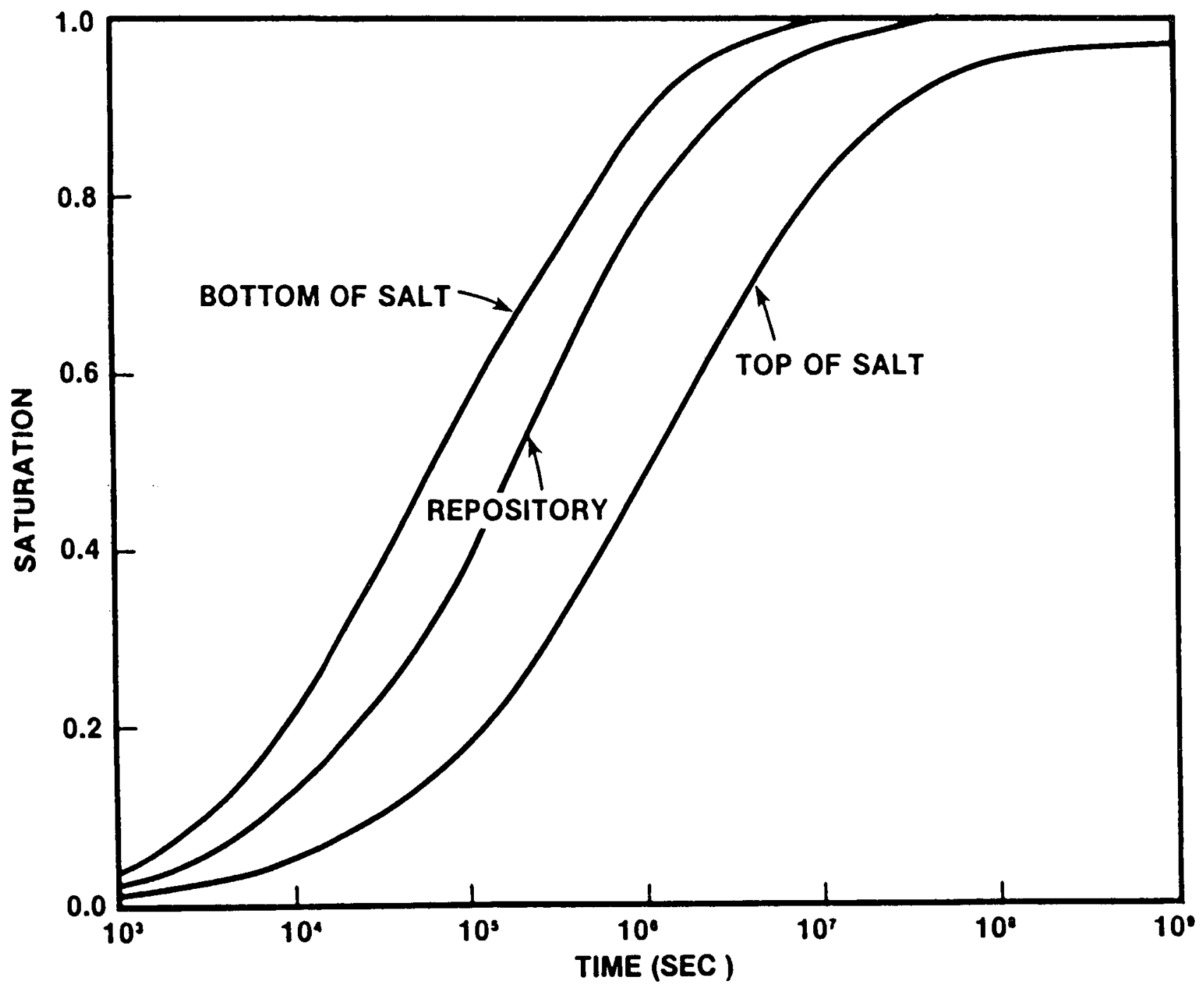

Figure 5-10. Calculated Progressive Salinity of Borehole Flow 


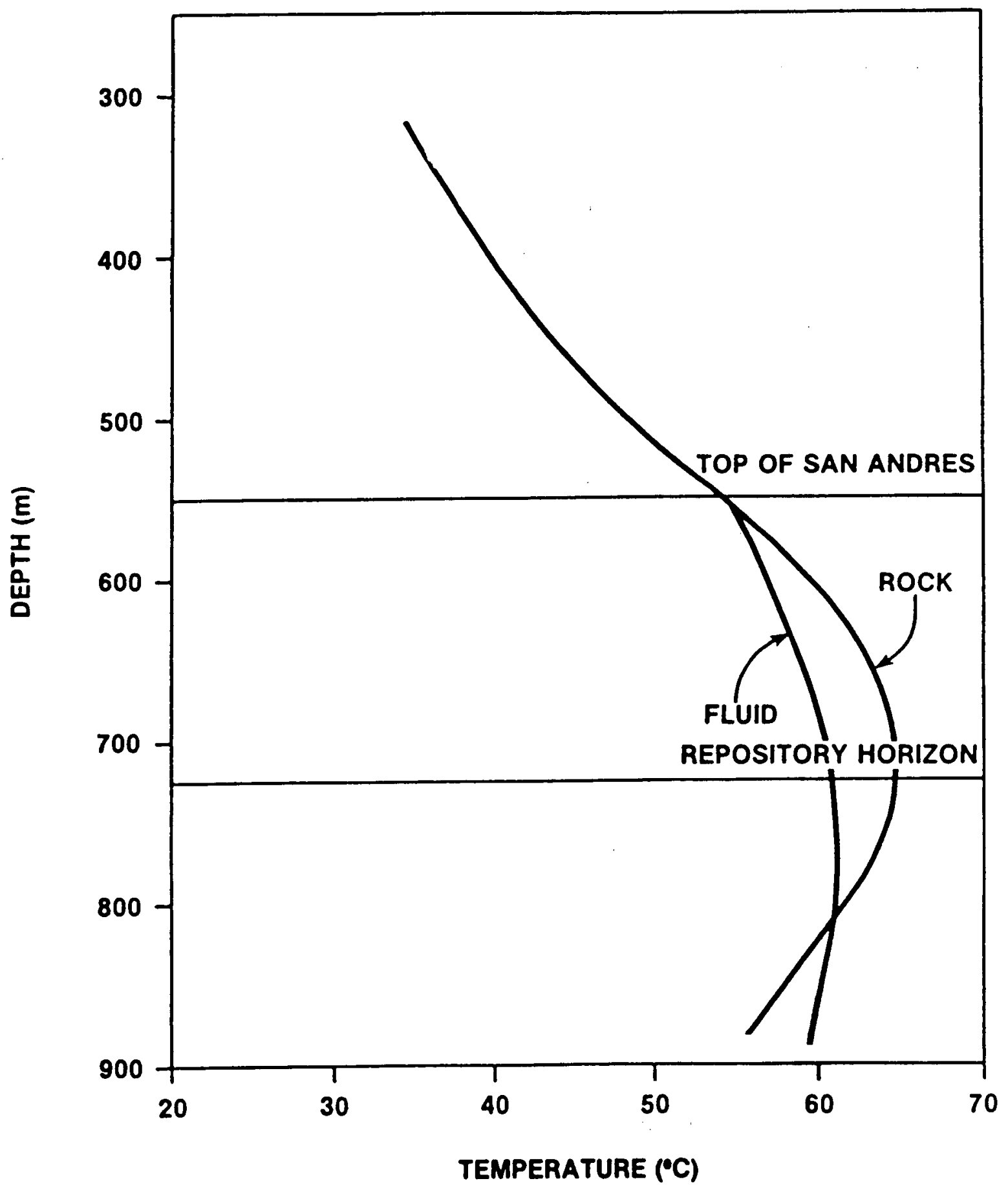

Figure 5-11. Calculated Fluid and Rock Temperature with Depth 


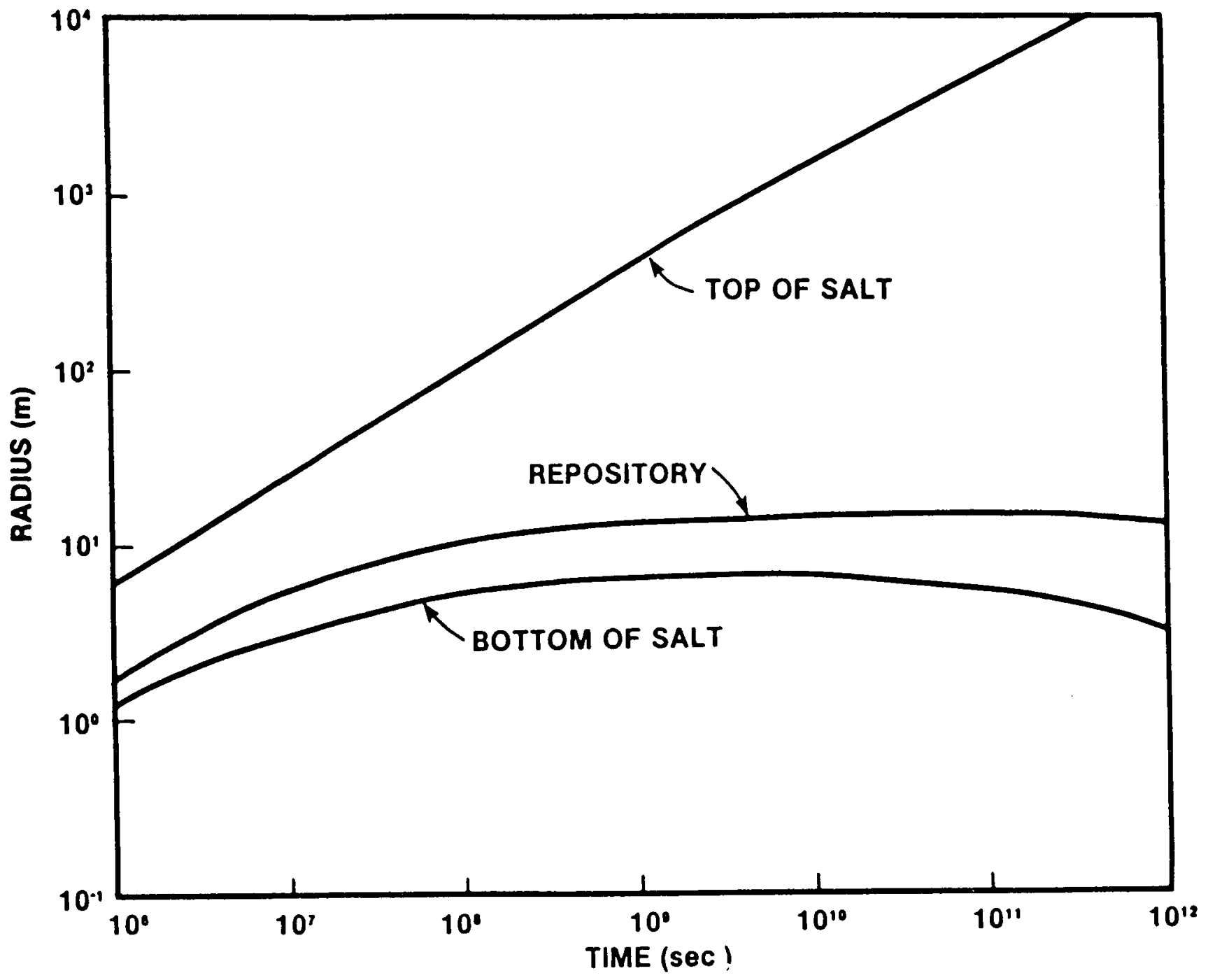

Figure 5-12. Calculated Radius of Borehole Versus Time 


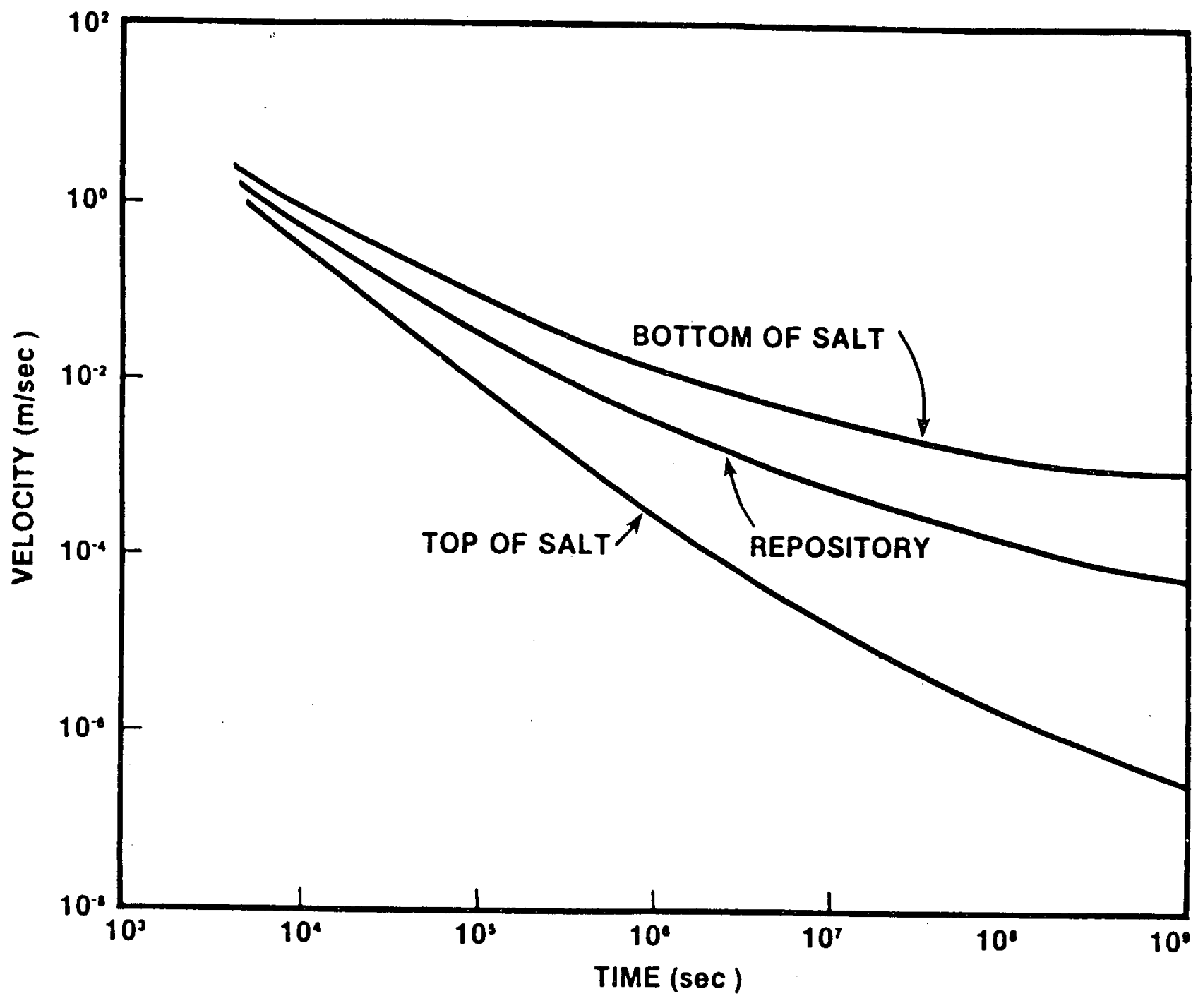

F1gure 5-13. Calculated Fluid Velocity in Borehole 
The shape of the borehole in this idealized model is shown for selected times in Figure 5-14. The "morning glory" shape of the hole, characteristic of the progressive saturation effect, is evident. At the repository horizon, the maximum size of the borehole is predicted to be about $10 \mathrm{~m}$ for the dissolution parameters utilized. For variations in the dissolution rate parameters or other material properties, this maximum size could very well be different.

The peak radius is sensitive to the borehole flow rate and the amount of salt reached by the flow prior to the repository horizon. If the flow were to be larger than the value used $\left(3,800 \mathrm{~m}^{3} / \mathrm{day}\right)$, the repository dissolution could be greater. As explained in section 5.1, the calculated flow rate used is almost certainly an upper bound to the flow rate. For lower flow rates, the dissolution would be greater in the upstream reaches of the borehole so that the repository dissolution would be correspondingly less.

The effect of the quantity of salt intercepted by the borehole flow before reaching the repository horizon is illustrated in Figure 5-15. The upper curve is the result assuming that the overlying San Andres Formation is only 45 percent salt. The lower curve shows the effect when all the rock is assumed to be halite. Because greater dissolution can occur at the upstream horizons in the latter case, saturation can occur sooner. Indeed, significant saturation of the flow at the repository horizon occurs within about one month.

Comparing Figure 5-15 and Figure 5-7, it is evident that the rate of expansion of the borehole due to salt dissolution is many orders of magnitude larger than the creep closure rate for the parameters that have been used in these evaluations. This large difference suggests that for realistic values of these parameters, creep closure will not be an important factor at the repository horizon as long as salt dissolution is occurring. Even so, the creep process cannot be Ignored since at the greatest depths, the dissolution rate is diminished and the creep rate is increased. 


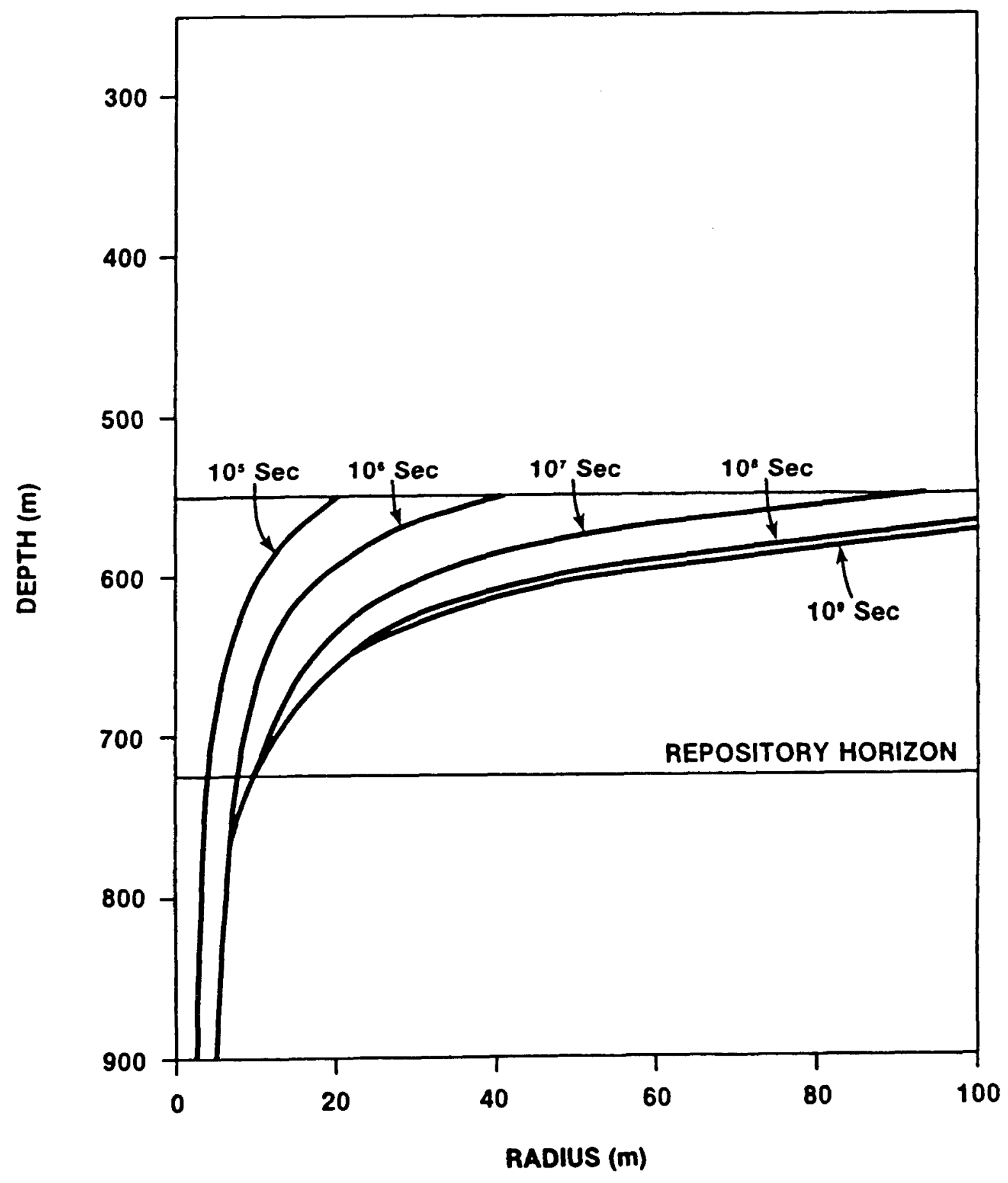

Figure 5-14. Calculated Borehole Radius with Depth 


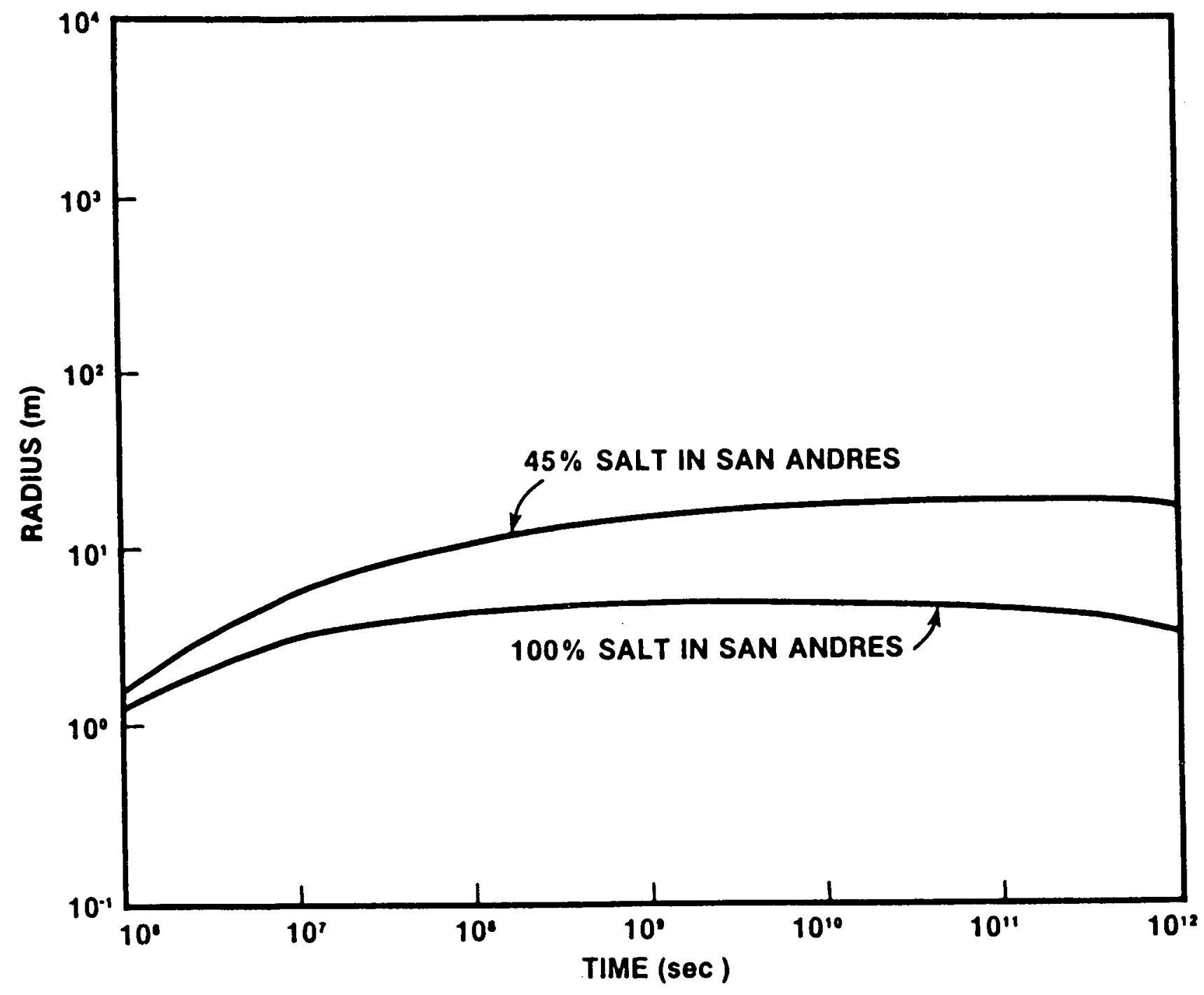




\subsection{RELEASE OF RADIONUCLIDES FROM UNDERGROUND FACILITY FOR SINGLE BOREHOLE INTRUSION SCENARIO}

The dissolution rate of salt at the repository horizon serves as the basis for the evaluation of the rate of exposure of the waste to the borehole flow. The release of radionuclides to this flow then depends on the waste package and the waste form performance as well as the solubility of the radionuclides. In this scenario, the waste package containment is ignored because the performance of the waste package under these conditions has not yet been evaluated. Future assessments will take the waste package integrity and degradation rate into account. The parameters assumed for the waste form leach rates and the solubilities of the radionuclides and waste form constituents are assumed to be the same as those discussed in Section 4.2.

\subsubsection{Underground Facility Performance at the Palo Duro Basin Site}

It is assumed that the dissolution rates of salt at the repository horizon are those described in Section 5.2.2. The peak rate of dissolution of the borehole wall occurs in the first year because the salinity of the water reaching the repository horizon is lowest then. The fraction of the repository host rock dissolved in the first year, based on computed dissolution rate and the total repository area in Table 3-1 is given in Table 5-6. As suggested in Figure 5-14, the dissolution rate rapidly decreases from this peak value and soon became negligible. Thus, total release of radionuclides from the host salt is expected to be limited to the first few years after drilling the borehole.

The release of radionuclides depends on the distribution of waste throughout the repository; for example, a borehole drilled in midpillar or in the passive regions of the repository would not permit release because of the limited size of the dissolution front associated with the borehole. The fractional release also varies depending on whether the borehole intercepts the SF or CHLW regions. The largest value is predicted to occur if the borehole is drilled in the vicinity of the CHLW packages because the radionuclide loading of the CHLW packages is larger than for the packages in the SF region. The results predicted for the maximum exposure rate case are plotted in Figure 5-16. The upper curve shows the fractional release rate 
Table 5-6. Performance Measure for Release From Underground Facility (a)

\begin{tabular}{|c|c|c|c|}
\hline Performance Measure & $\begin{array}{l}\text { Palo Duro Basin } \\
\text { (borehole only } \\
\text { to Wolfcamp) }\end{array}$ & $\begin{array}{l}\text { Palo Duro Basin } \\
\text { (borehole to } \\
\text { granite wash) }\end{array}$ & $\begin{array}{c}\text { Paradox Basin } \\
\text { (borehole to } \\
\text { Leadville) }\end{array}$ \\
\hline $\begin{array}{l}\text { Maximum fraction of } \\
\text { repository area } \\
\text { dissolved per year }\end{array}$ & $7.9 \mathrm{E}-7$ & $1.1 \mathrm{E}-5$ & $2.7 \mathrm{E}-6$ \\
\hline $\begin{array}{l}\text { Maximum fraction of } \\
\text { radionuclides released } \\
\text { per year due to } \\
\text { dissolution on } 1 y\end{array}$ & $1.9 E-6$ & $2.6 \mathrm{E}-5$ & $6.5 E-6$ \\
\hline $\begin{array}{l}\text { Maximum fraction of } \\
\text { radionuclides released } \\
\text { per year due to salt } \\
\text { dissolution and waste } \\
\text { form leaching }\end{array}$ & d & 2. $2 \mathrm{E}-6$ & $2.2 E-6$ \\
\hline
\end{tabular}

(a) Values are for CHLW portion of repository since the values for the SF region are lower. 


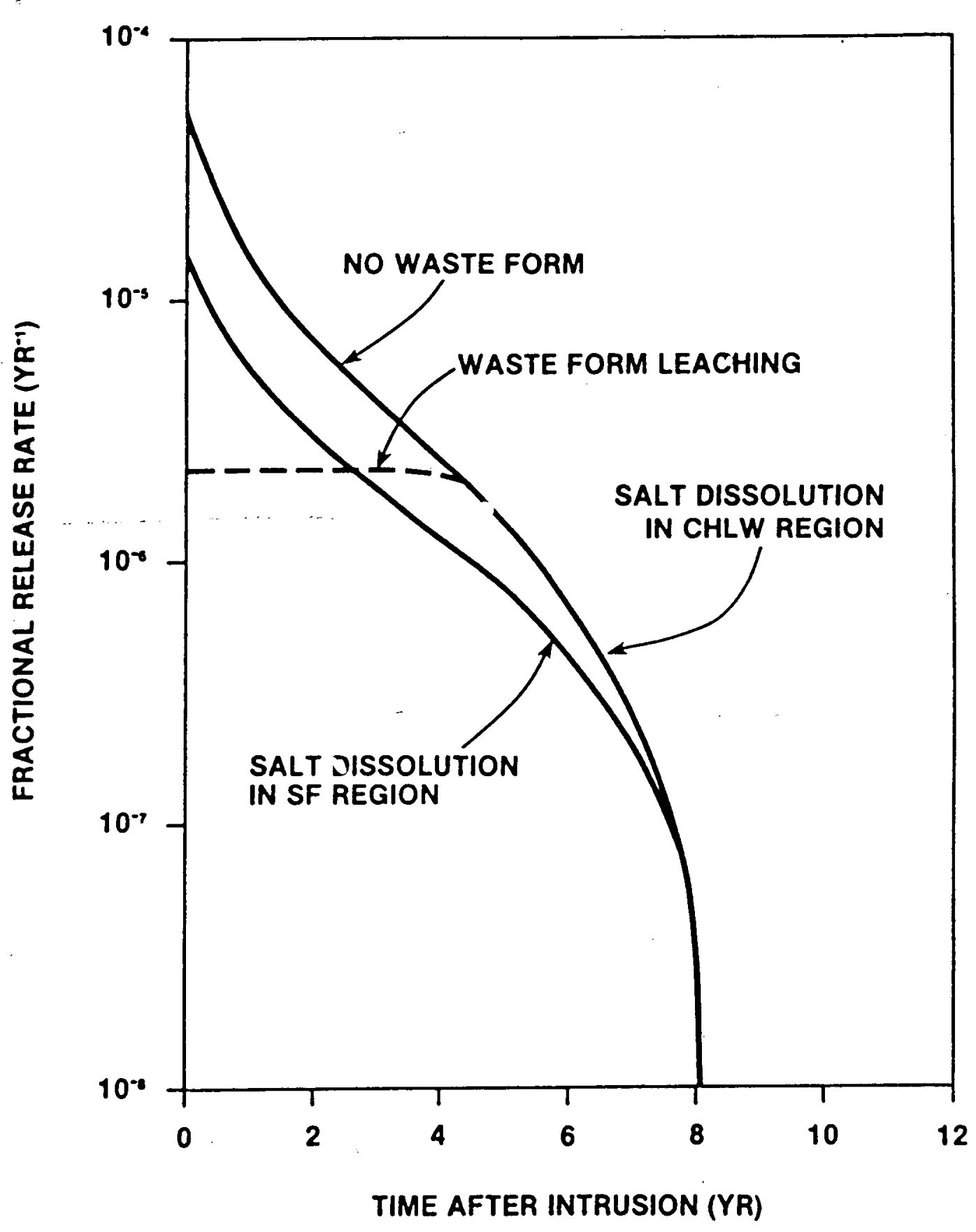

$\frac{\text { F1gure 5-16. Calculated Fractional Release Rate from Underground Fac1lity }}{\text { for Palo Duro Basin }}$ 
considering only the dissolution of salt as a control to release. The annual release is the area under this curve in a l-year interval and the annual release based only on salt dissolution is on the order of one part per 100,000 or less per year.

The release of radionuclides from exposed waste will be limited by the waste form leach rate. The leach rates have been discussed in Section 4.2. The effect of including the glass waste form leach rate in the evaluation is also shown in Figure 5-16. When the finite leach rate of the glass is included, the annual release from the underground facility is nearly an order of magnitude smaller than when the salt alone provides the radionuclide retention.

If the borehole penetrates the SF region, the leach rate used is so conservatively large that the calculations do not reflect any significant limitation by the SF matrix. However, as shown in Figure 5-16, in this case, the fractional release rate due to salt dissolution alone is small anyway because of the lower density of waste in this region. The peak values for this performance measure are listed in Table 5-6. The values in this table correspond to the rates for the borehole in the CHLW portion of the repository since these are larger than those in the SF region.

The above results are for a borehole drilled to the granite wash. If the borehole penetrates only to the Wolfcamp, the flow rate is reduced by about a factor of about 20 because the total transmissivity of the recelving units is reduced by this amount. The lower flow rate means that the fractional release rate from the repository will be lower due to lower dissolution rates. This fact is borne out in the fractional release rate for this case shown in Figure 5-17 shown for the CHLW region of the repository. In this case, both the magnitude and the duration of the release are reduced from that where the flow is a factor of 20 larger. The predicted peak annual release fraction is given in Table 5-6.

\subsubsection{Underground Faclitty Performance at the Paradox Basin Site}

The fractional release rate for the Paradox Basin case is given in Figure 5-17, where it can be compared readily with those for the Palo Duro Basin. Because the flow rate is so low relative to that for the open borehole 


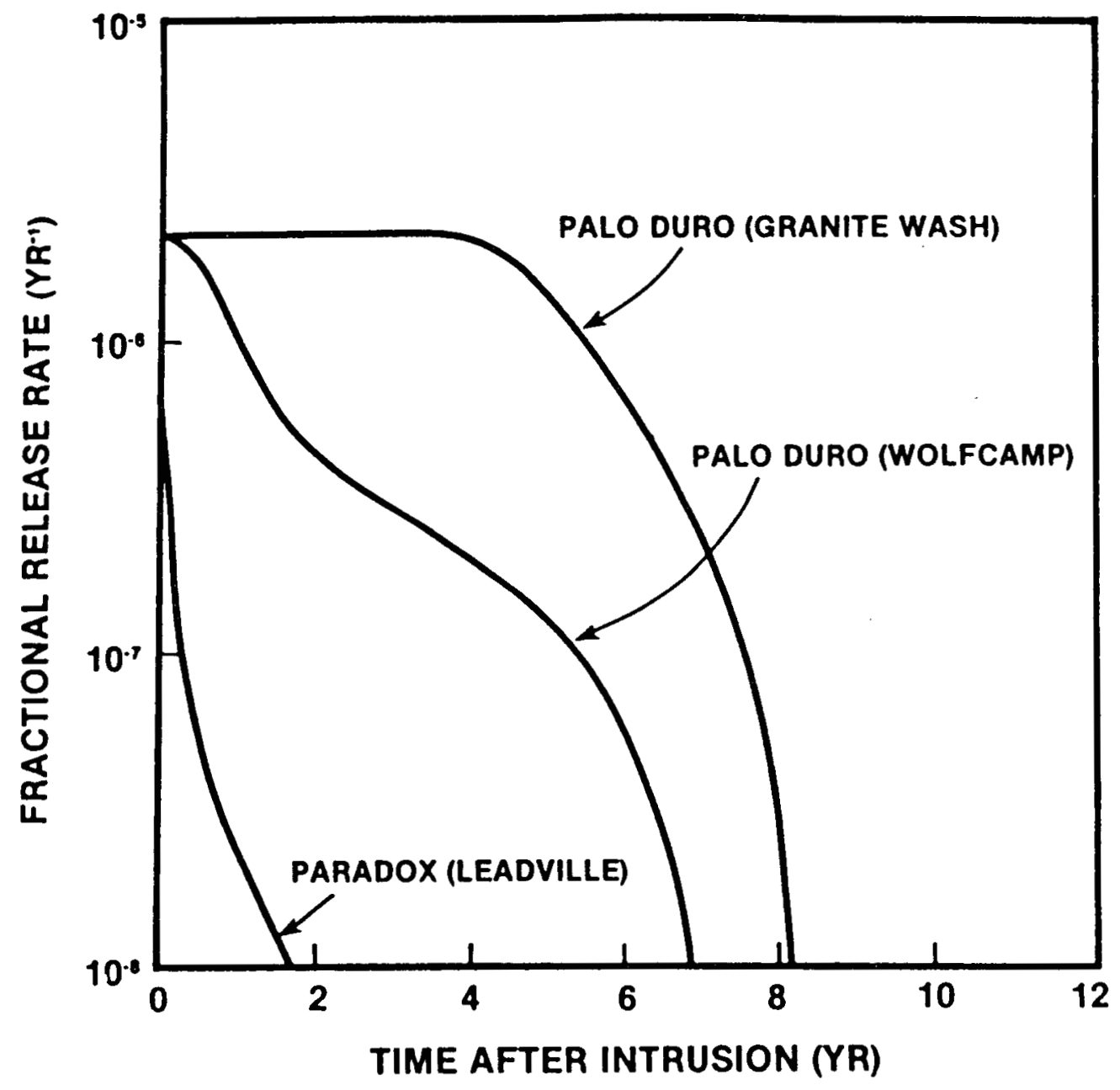

Figure 5-17. Calculated Fractional Release Rate from Underground Fac1lity (CHLW Reg1on) 
down to the granite wash in the Palo Duro Basin, the release rate is smaller and the peak fractional release rate is less than $3 \mathrm{ppm}$ per year, even ignoring the effect of the glass waste form.

The small release rate relative to the Palo Duro case is due to the low salt dissolution rate predicted for the repository horizon. In the evaluation of the salt dissolution, it is assumed that the repository is situated $106 \mathrm{~m}$ below the top of the Paradox. It is also assumed that no major interbeds occur between the repository horizon and the top of the Paradox. The salt is assumed to be 84 percent pure. This representation is consistent with the Woodward-Clyde Consultants (1982) analysis of the GD-1 Well test.

In this representation, the dissolution rates would be comparable between the Palo Duro case and the Paradox case for the same flow rate since the effective columns of salt above the repository are similar in the two cases-about $90 \mathrm{~m}$ in each case. However, the maximum flow rate calculated in Section 5.1.2 for the Paradox Basin case is about a factor of 14 lower than that in the Palo Duro case. Thus, the dissolution is expected to be decreased by an order of magnitude or more.

The resulting fractional release rate due to dissolution alone is shown in Figure 5-17. The release rate in this case is lower than those predicted for the Palo Duro site, even taking the waste form leach rate into account. The performance of the underground facility for the Paradox Basin site is summarized in Table 5-6.

\subsection{RELEASE TO THE ACCESSIBLE ENVIRONMENT FOR SINGLE BOREHOLE INTRUSION SCENARIO}

The radionuclide migration model assumes that radionuclides released from the repository to the borehole flow are transported instantaneously to the receiving unit. No retardation of this transport in the borehole itself is taken into account. It is assumed that the total borehole flow is added to the ambient flow in the receiving unit. Therefore the radionuclides are transported in the ground-water flow in this unit and the flow is determined from the local modeling of the system including the borehole.

As discussed in Section 5.1, for a silted borehole with a conductivity of $30 \mathrm{~m} /$ day or less, the borehole flow rate is expected to be very small with respect to the flow in the receiving units in the Palo Duro Basin or the 
Paradox Basin. The local flow patterns in these units would be virtually unchanged from the amblent flow where no borehole has been drilled. In this case a one-dimensional transport model can be used with the radionuclide source corresponding to the discharge from the borehole and the system release evaluated $10 \mathrm{~km}$ from the repository.

For an open borehole, the flow is calculated to be much larger than for the silted borehole. In this case, the local flow patterns in the receiving units could be strongly influenced by the borehole flow. In fact, the flow in these units is calculated to be essentially radial out to a distance of at least $10 \mathrm{~km}$ in each case. In this circumstance, the transport is calculated for a one-dimensional, radial flow field and is evaluated using an axially symmetric discharge velocity that varies as the inverse of the distance from the borehole. The releases are calculated at the $10-\mathrm{km}$ radius and are the sum of all those around the $62 \mathrm{~km}$ perimeter at the time of interest. The sma11 amount of mechanical dispersion due to the ambient flow field is neglected. This transport problem can be modeled directly with standard migration codes. The code used here is SWENT (INTERA, 1983b) in which radionuclide chain decay and daughter production can be taken into account. Hydrodynamic dispersion and radionuclide retardation can also be included in the calculations using this code. In the one-dimensional model, hydrodynamic, azimuthal dispersion transverse to the direction of flow is not taken into account consistent with the evaluation of total flow across the $10 \mathrm{~km}$ boundary. Longitudinal (radial) dispersion is taken into account with a dispersivity of $100 \mathrm{~m}$. Retardation factors appropriate for the flow in recelving units are not well known at present. However, bounding values have been determined for the salt sites by Muller et al (1981) and these are used here. The values are summarized in Table 5-7.

\subsubsection{Palo Duro Basin Site Assessment}

These evaluations are for the case of a source term due to flow in an open borehole. Typical results are shown for release to the granite wash in Figures 5-18 to 5-22. The radionuclides evaluated in these figures have the largest predicted releases, all others having curie release rates at the $10-\mathrm{km}$ boundary less than $1.0 \mathrm{E}-30 \mathrm{Ci} / \mathrm{yr}$. 
Table 5-7. Radionuclide Transport Parameters ${ }^{(a)}$

\begin{tabular}{lc} 
Element & $\begin{array}{c}\text { Retardation Factor, Rd } \\
(\mathrm{m} 1 / \mathrm{gm})\end{array}$ \\
& 10 \\
Americium & 10 \\
Neptunium & 50 \\
Plutonium & 10 \\
Radium & 5 \\
Tin & 5 \\
Technetium & 50 \\
Thorium & 10 \\
Uranium & \\
& \\
\hline
\end{tabular}

(a) After Muller et a1 (1981). The value for elements not listed is assumed to be zero. 


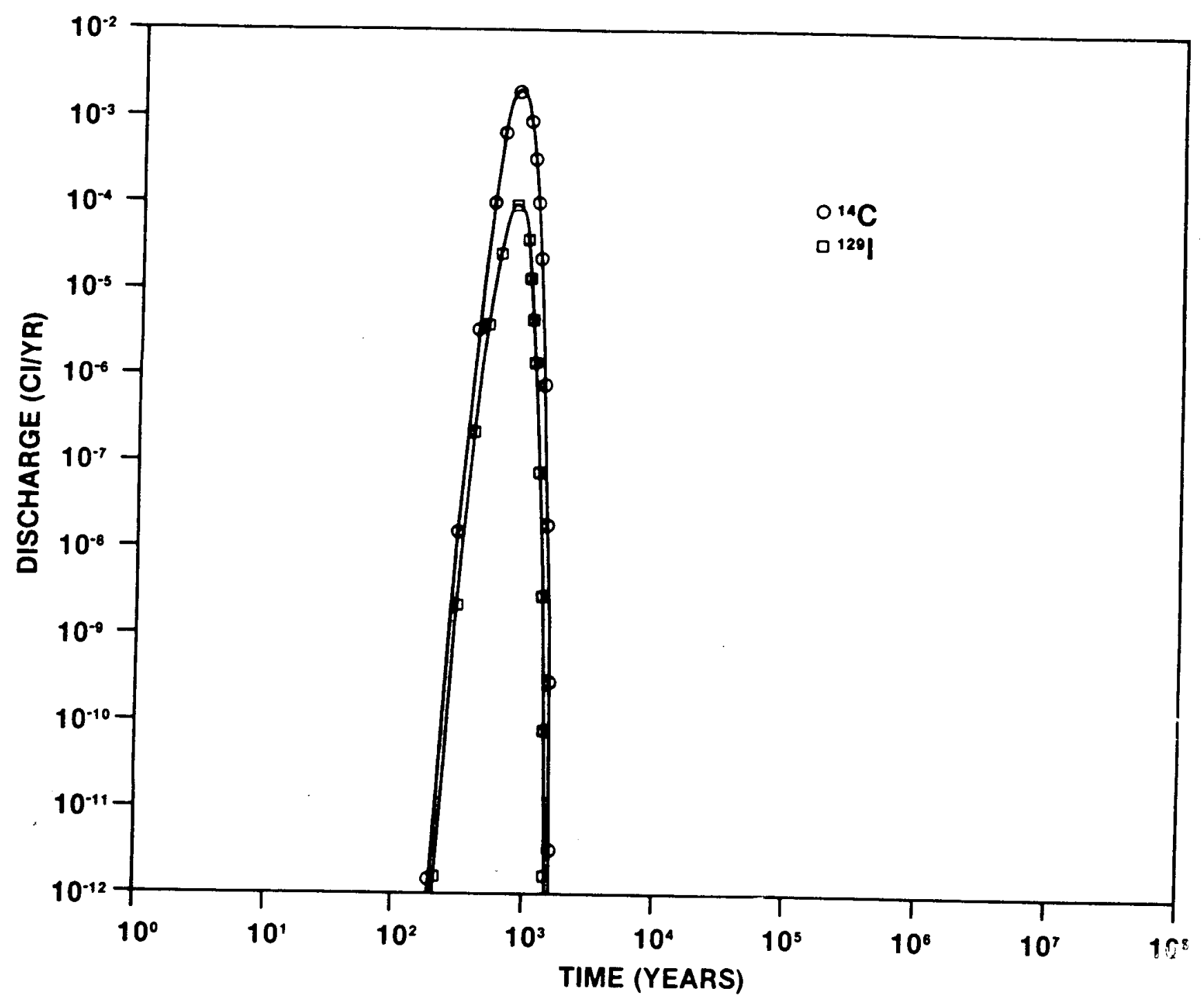

Figure 5-18. Calculated Release Rate to Accessible Envirorrarl ralo Durs pisin Granite Wash $\left({ }^{129} \mathrm{I} ;{ }^{14} \mathrm{C}\right)$ 


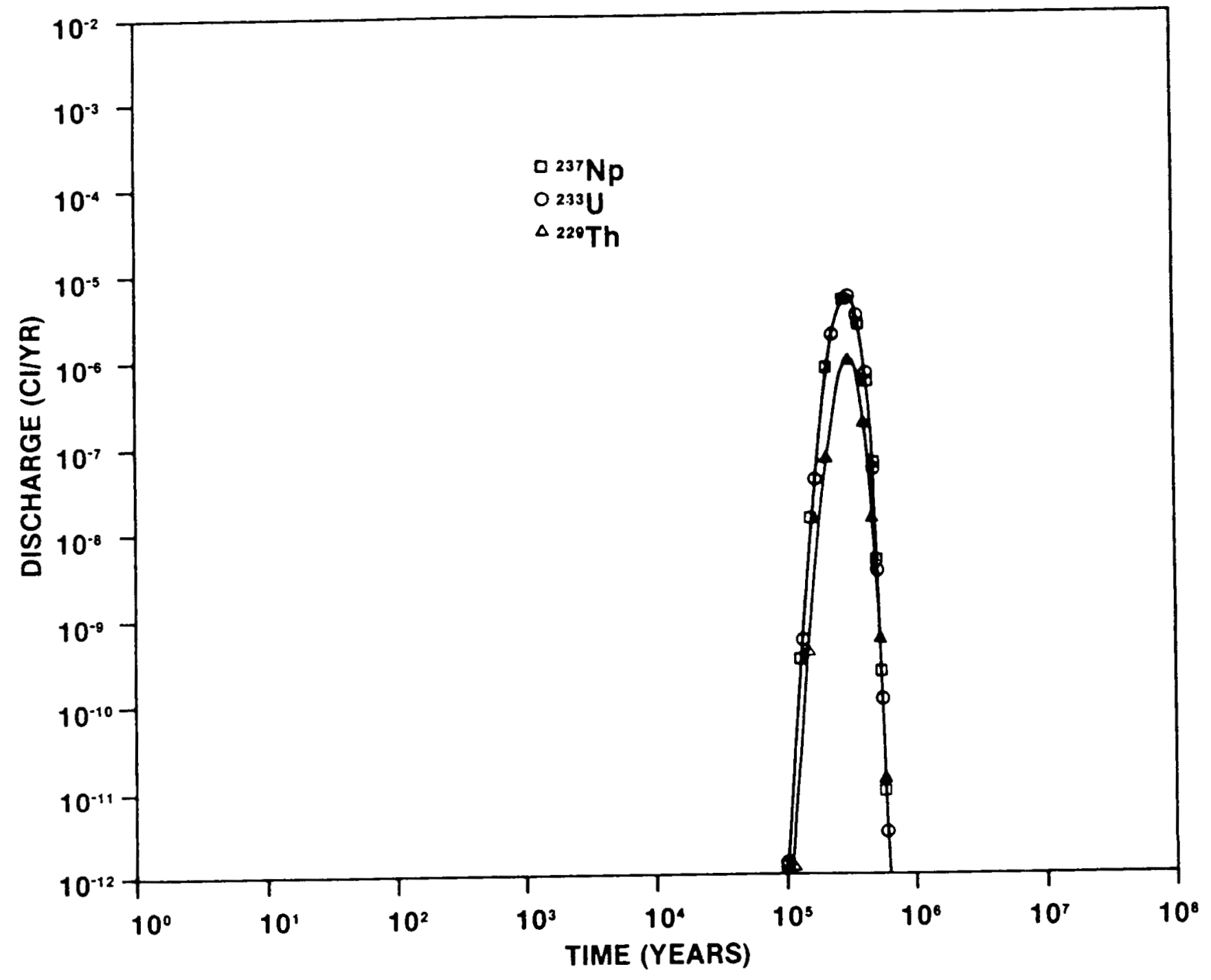

Figure 5-19. Calculated Release Rate to Accessible Environment Palo Duro Basin Granite Wash $\left({ }^{237} \mathrm{NP} \rightarrow 233_{\mathrm{U}}+229 \mathrm{Th}\right)$ 


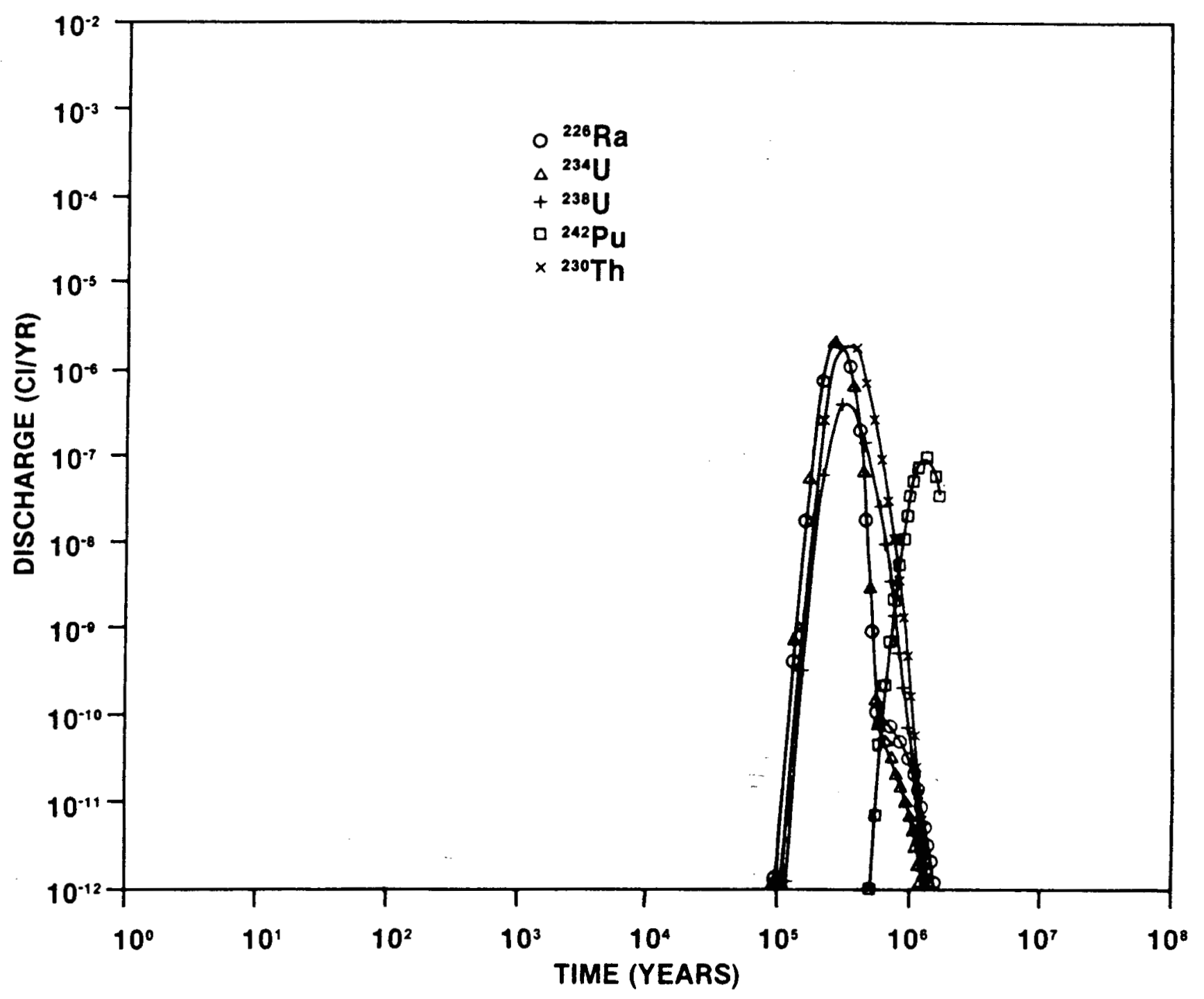

Figure 5-20. Calculated Release Rate to Accessible Environment Palo Duro Basin Granite Wash $\left({ }^{242} \mathrm{Pu} \rightarrow 238_{\mathrm{U}} \rightarrow 234_{\mathrm{U}} \rightarrow 230_{\mathrm{Th}}+226_{\mathrm{Ra}}\right)$ 


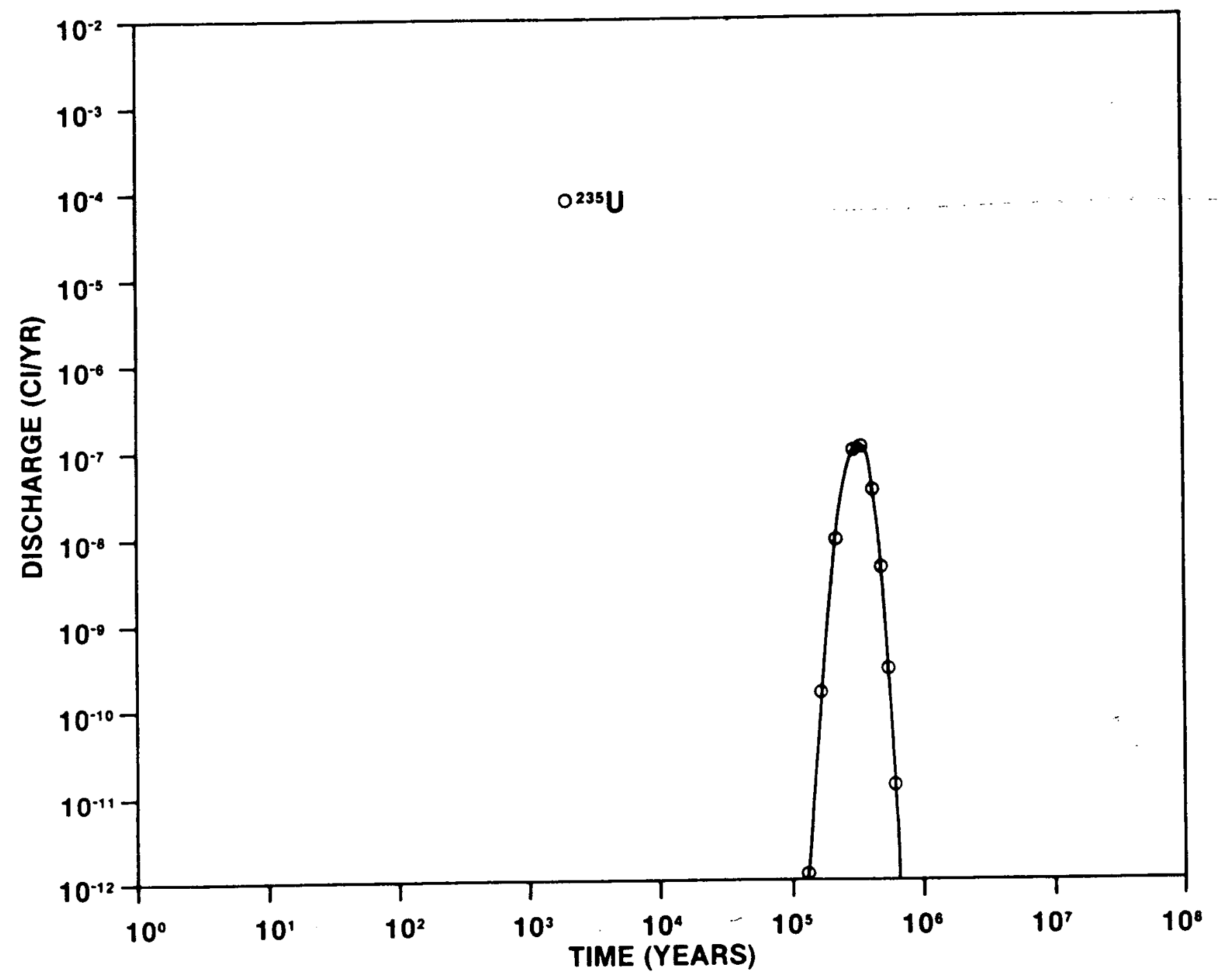

Figure 5-21. Calculated Release Rate to Accessible Environment Palo Duro Basin Granite Wash $\left({ }^{235_{U}}\right)$ 


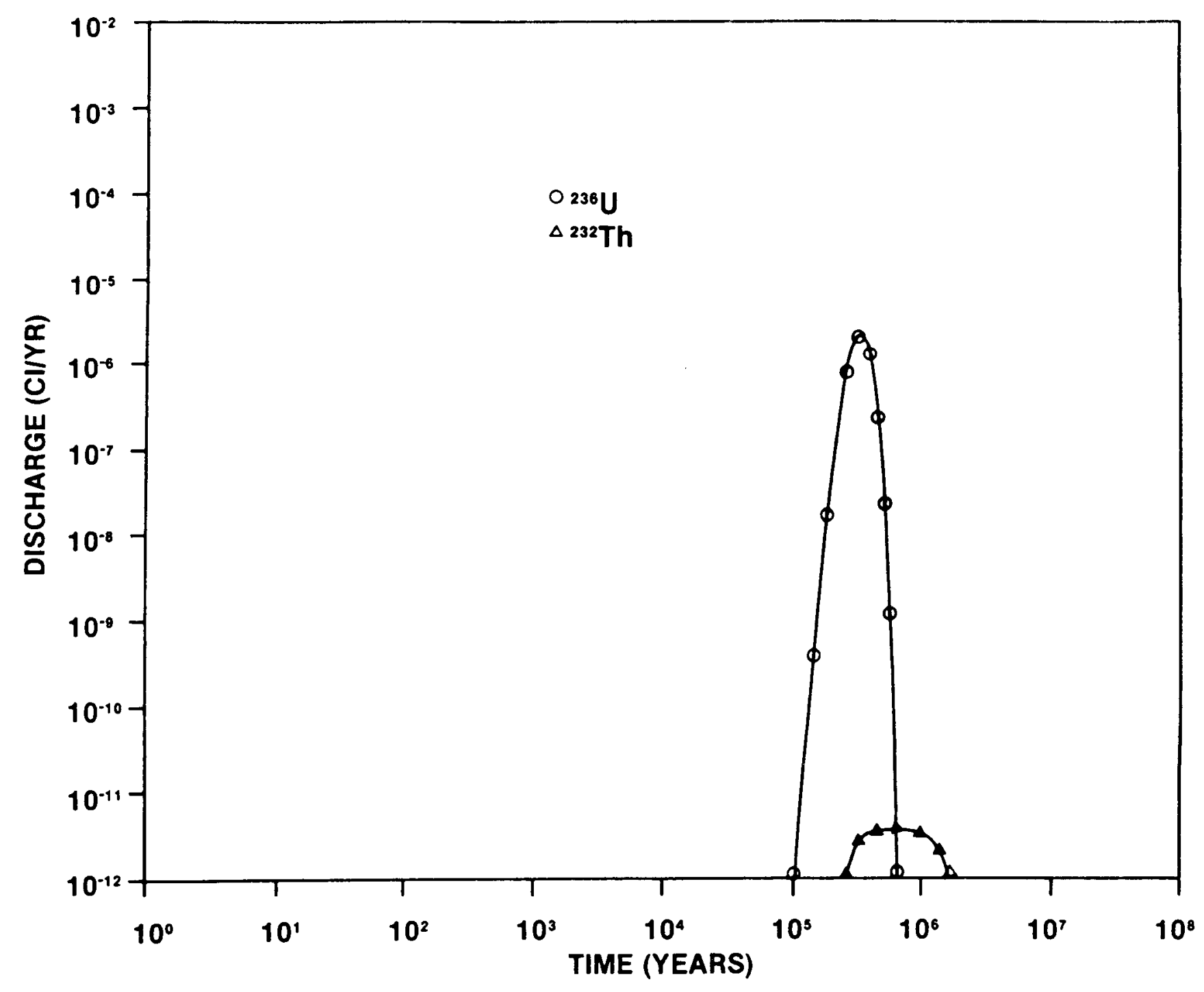

Figure 5-22. Calculated Release Rate to Accessible Environment Palo Duro Basin Granite Wash $\left({ }^{236_{\mathrm{U}}} \rightarrow{ }^{232} \mathrm{Th}\right)$ 
A number of approximations have been used to make these calculations. First, rather than using the fractional radionuclide release rate from the underground facility as the source term, the fractional dissolution rate of the salt is used. This would be a valid assumption if the waste were homogeneously distributed through the salt rather than in discrete packages. As it 1s, the source represents an average over the repository and this term is low (about a factor of 0.42 ) for the CHLW region and a bit high (about a factor of 1.1) for the SF region. The second approximation is that the radionuclide inventories entering the transport calculation are assumed to be those in the SF region. This assumption makes very little difference in the results (less than a factor of three in system release rates), particularly when the area-averaged source rate is used.

The predicted curie release rates are small, all being less than (and usually much less than) $1.0 \mathrm{E}-3 \mathrm{Ci} / \mathrm{yr}$. About 5 percent of the radionuclides are expected to go into the Wolfcamp for the division of flow calculated. This small fraction would travel at a much different (slower) velocity and would not add to the peak arrival rates at the boundary. Therefore, for the purpose of conservative estimates, it is assumed that all of the radionuclides go into the granite wash.

Analogous results for a borehole drilled only down to the Wolfcamp are shown in Figures 5-23 to 5-27. In this case, not only is the transport velocity much smaller than in the previous case (about a factor of 100 smaller due to the lower transmissivity of the Wolfcamp relative to the granite wash), but the source rate is very much reduced because the borehole flow rate is also much smaller. As a result, the releases are substantially reduced relative to those for the case of drilling to the granite wash.

Approximations similar to those made for the granite wash calculation are made for the Wolfcamp modeling. In addition, because the source term has such a small duration, a further approximation is necessary. Because the source term is small, the time step should be small enough to resolve the transported radionuclide pulse; however, a small time step severely affects the calculation. The compromise made is to arbitrarily increase the duration of the leaching process by a factor of $1.0 \mathrm{E}+4$ and reduce the magnitude of the leach rate correspondingly so that the integrated release of radionuclides is unchanged. The effect is to produce an artifical dispersion but releases integrated over 10,000 years are essentially unchanged. It is recognized that 


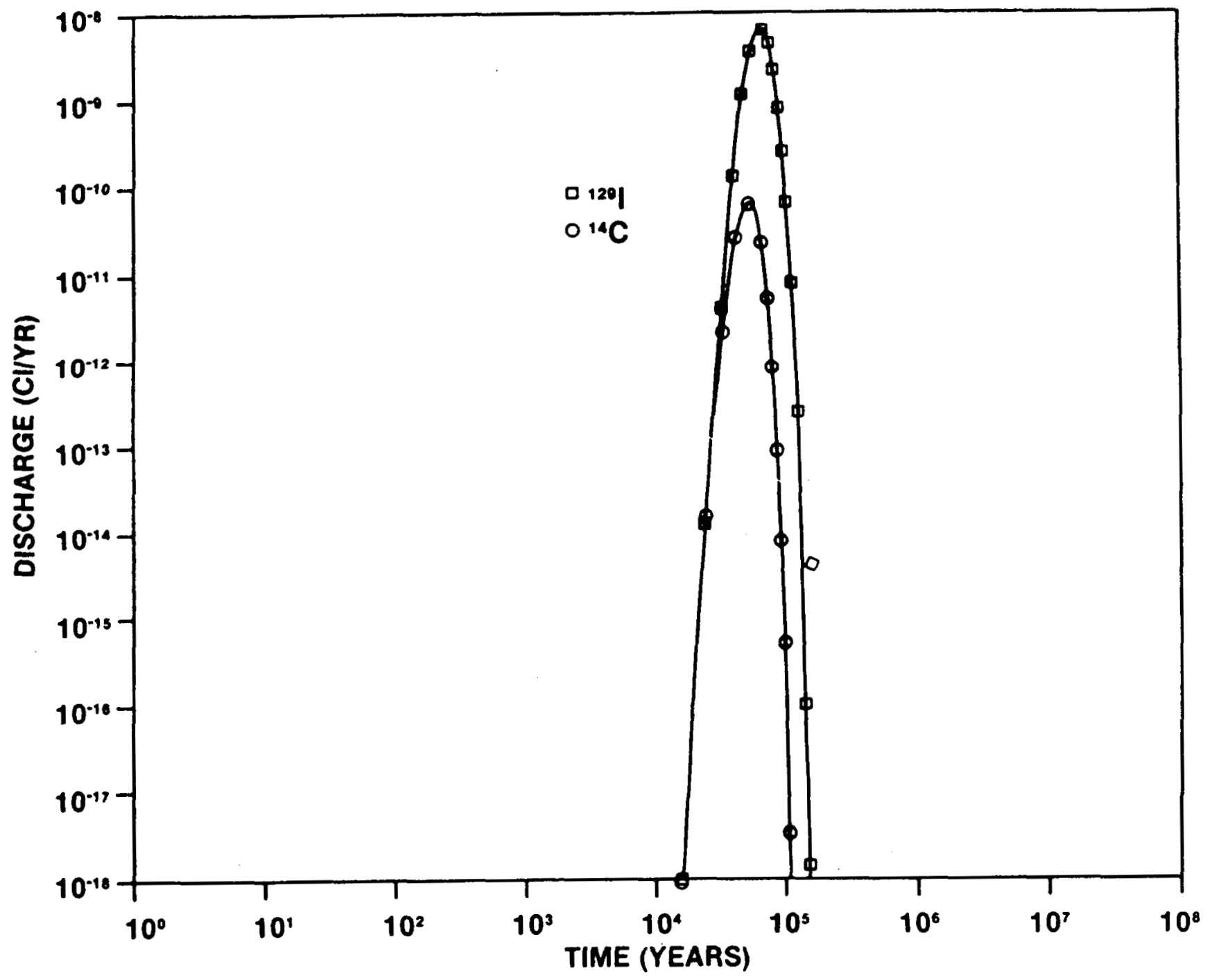

Figure 5-23. Calculated Release Rate to Accessible Environment Palo Duro Basin Wolfcamp $\left({ }^{129} \mathrm{I} ;{ }^{14} \mathrm{C}\right)$ 


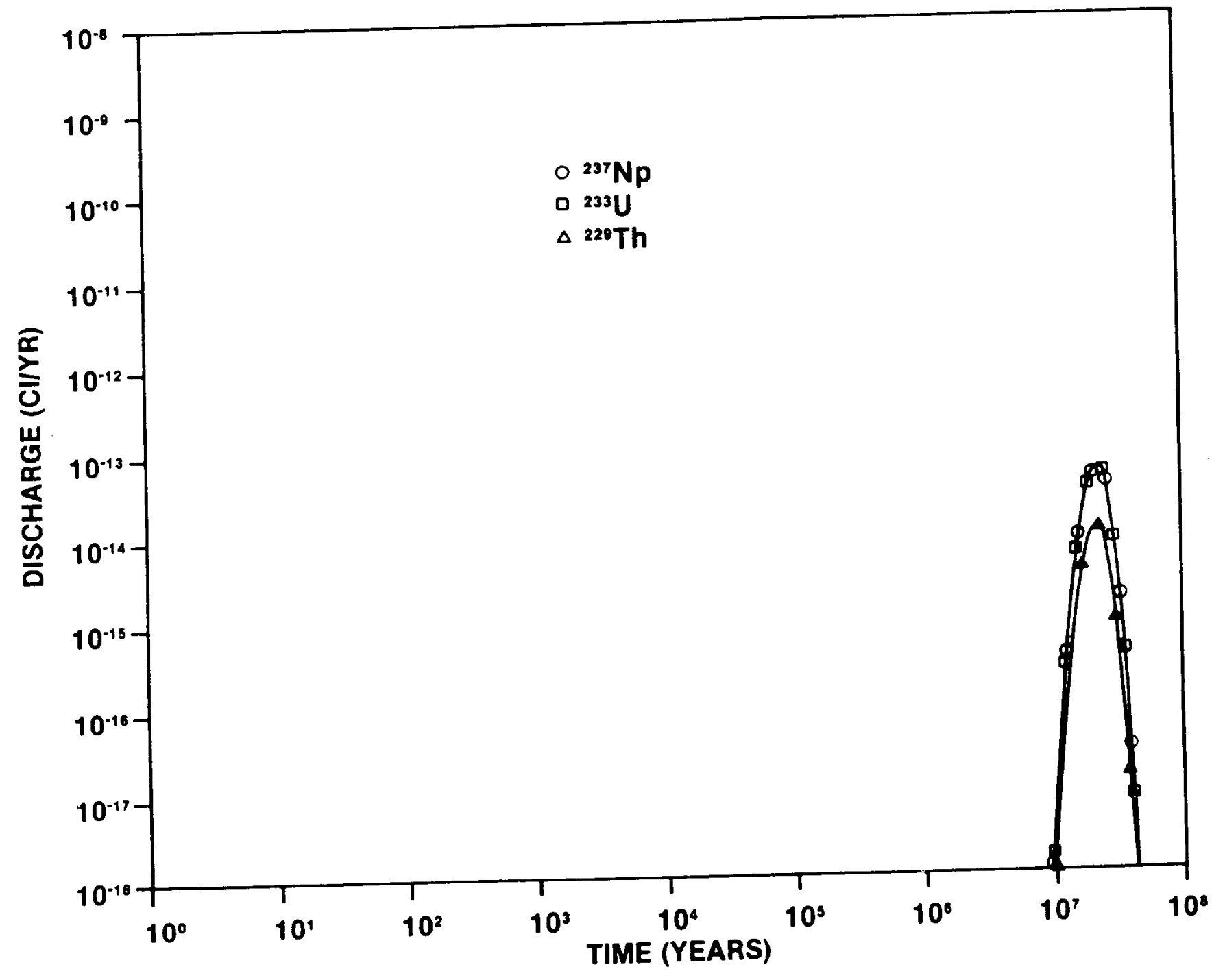

Figure 5-24. Calculated Release Rate to Accessible Environment Palo Duro Basin Wolfcamp $\left(237 \mathrm{~Np}+233_{\mathrm{U}}+{ }^{229} \mathrm{Th}\right)$ 


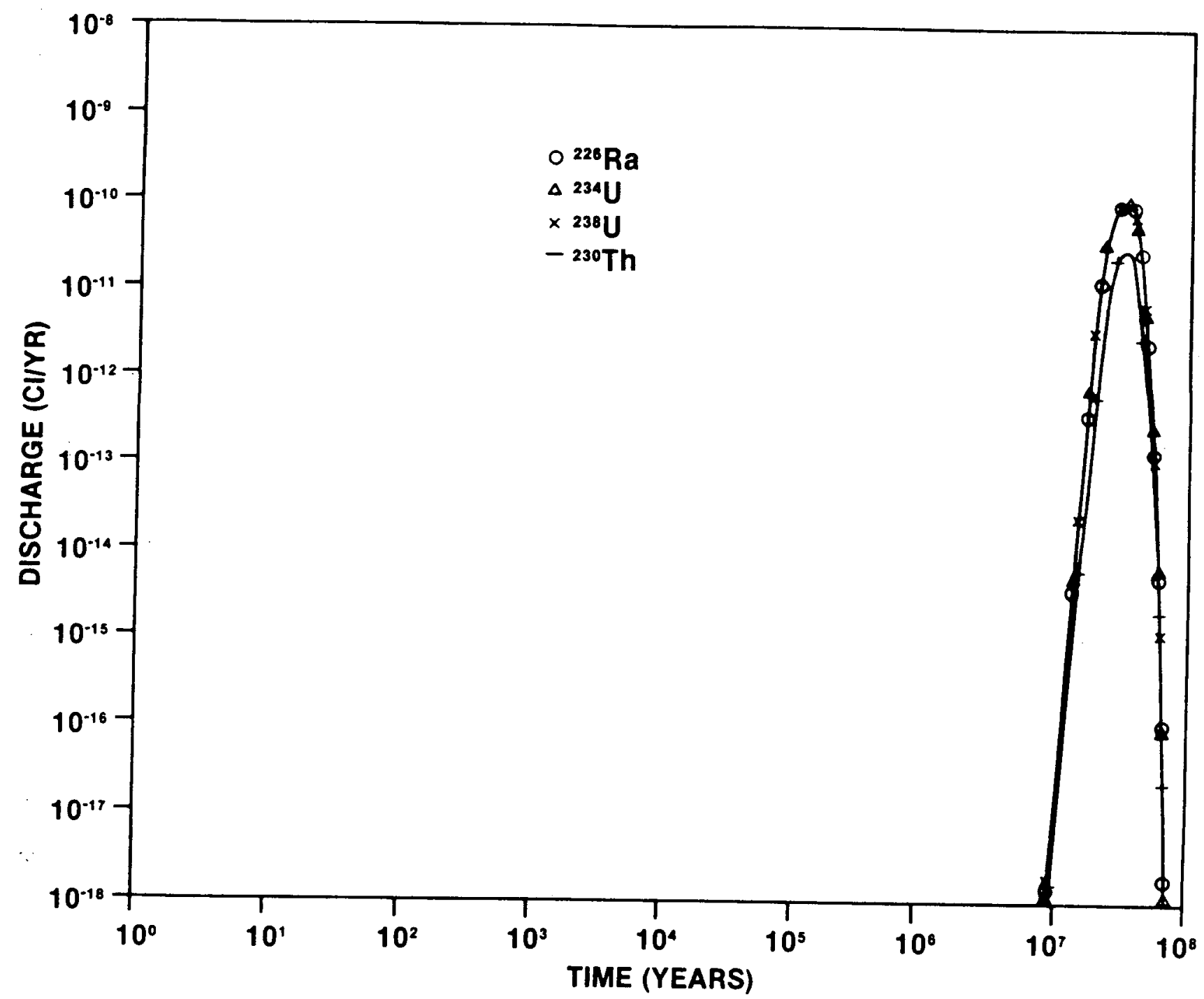

Figure 5-25. Calculated Release Rate to Accessible Environment Palo Duro Basin Wolfcamp $\left(238_{\mathrm{U}} \rightarrow 234_{\mathrm{U}} \rightarrow 230_{\mathrm{Th}}+226_{\mathrm{Ra}}\right)$ 


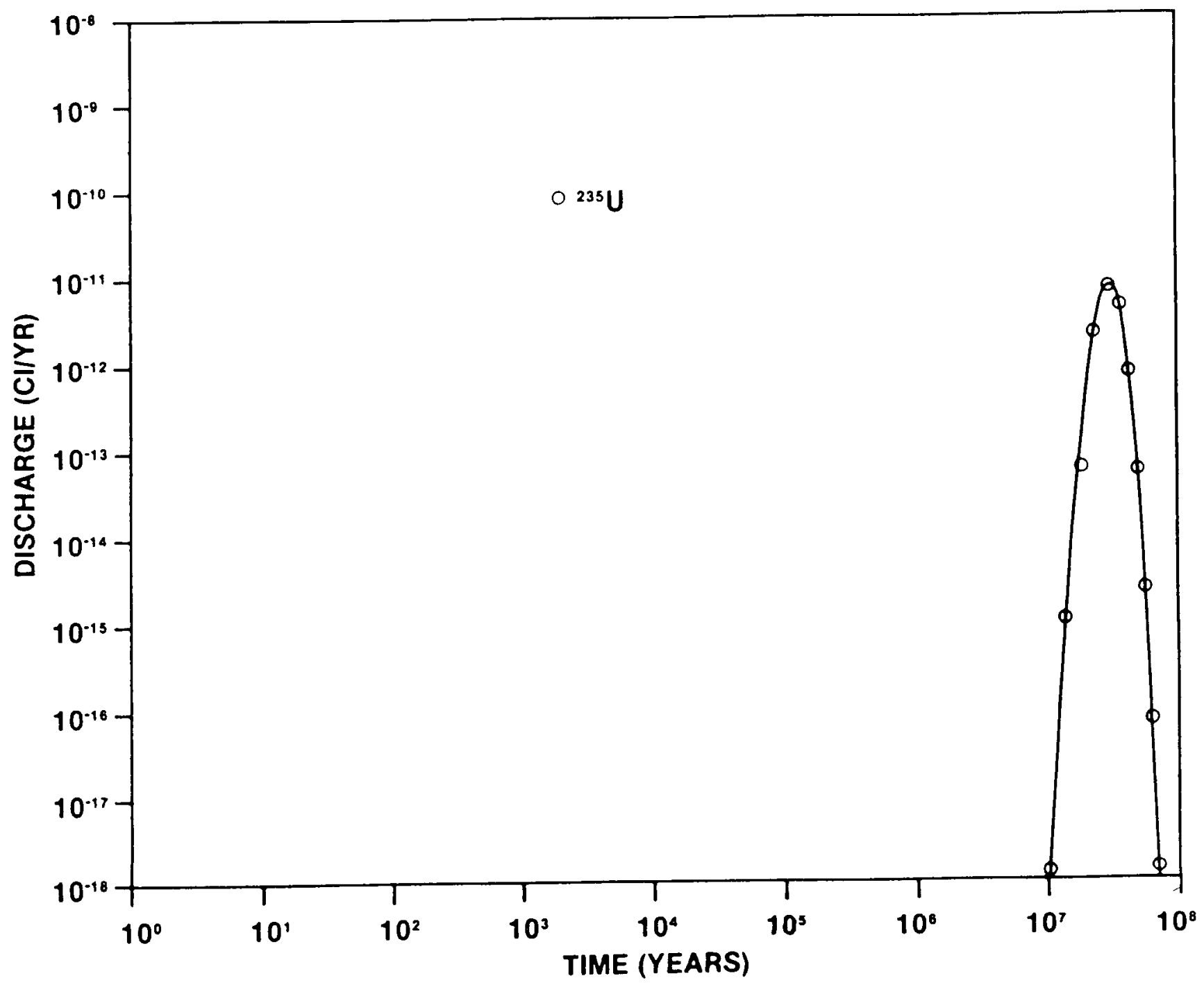

Figure 5-26. Calculated Release Rate to Accessible Environment Palo Duro Basin Wolf camp $\left({ }^{235} \mathrm{U}\right)$ 


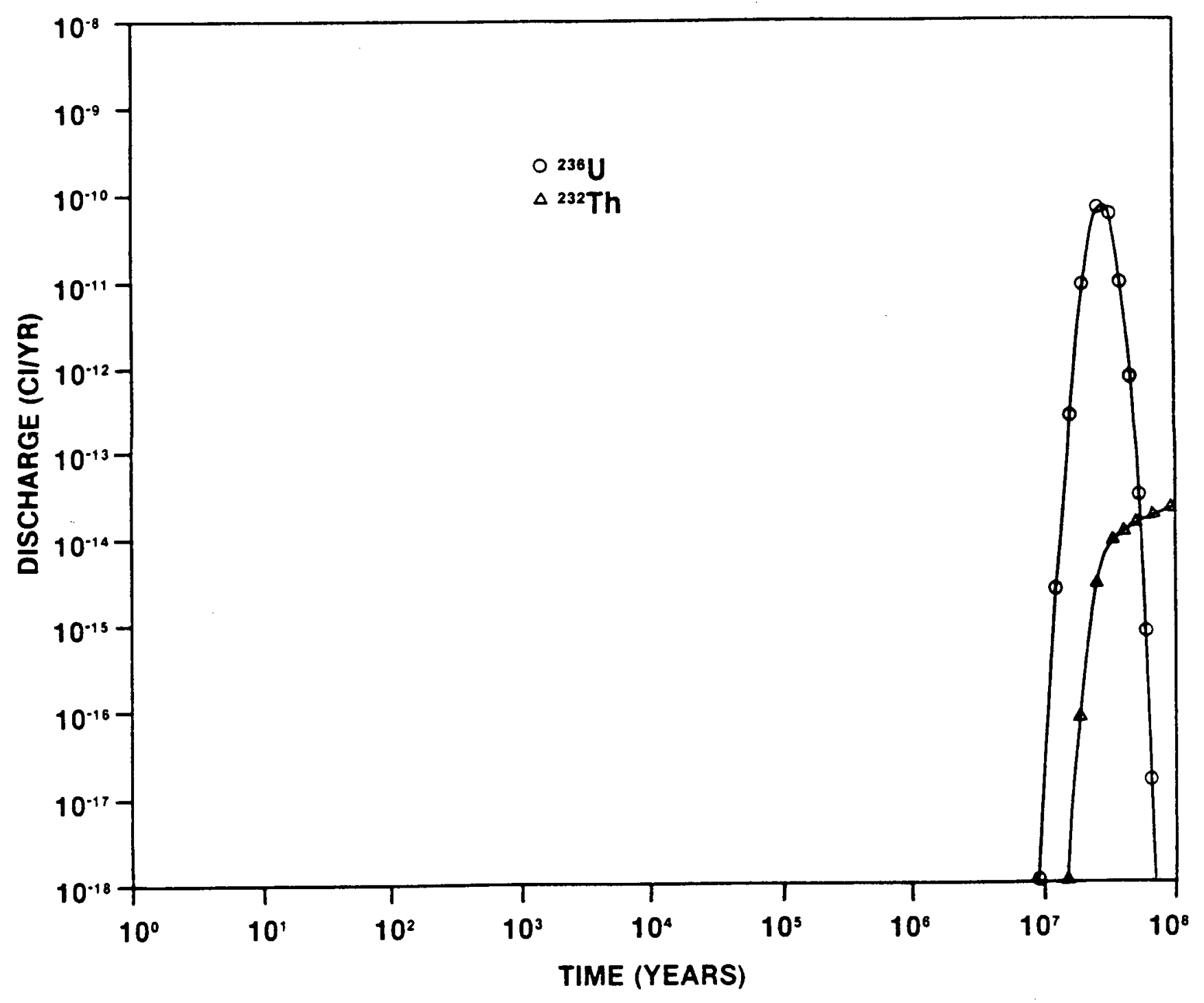

Figure 5-27. Calculated Release Rate to Accessible Environment Palo Duro Basin Wolfcamp $\left(236_{\mathrm{U}} \rightarrow 232_{\mathrm{Th}}\right)$ 
this approach can introduce some inaccuracy and if radionuclide releases appear to be marginally significant, more accurate calculations could be performed. As can be seen in the figures, all releases are quite low and even a factor of $1.0 \mathrm{E}+4$ increase would not produce a significant result. The results are summarized in Table 5-8.

\subsubsection{Paradox Basin Site Assessment}

The results of the analogous calculations for transport in the Leadville unit of the Paradox Basin are shown in Figures 5-28 to 5-32. All approximations made for the Wolfcamp analyses have been made here and, as in the case of the Wolfcamp in the Palo Duro, the release rates are very small.

\subsubsection{Integrated Release to the Accessible Environment}

As described, the accessible environment is defined for these analyses by the boundary $10 \mathrm{~km}$ from the repository in the lower aquifer. The calculated performance measures in this case are the 10,000-year integrated releases at this radius. Table 5-8 gives the peak values predicted at any time. Also given in this table are the EPA proposed criterla for release to the accessible environment (EPA, 1982, Appendix). These standards are currently expressed in terms of the total release only in the first 10,000 years. From the curves in Figures $5-28$ to $5-32$, it is clear that there is virtually no release in the first 10,000 years.

\subsection{CONCLUSIONS FROM SINGLE BOREHOLE INTRUSION SCENARIO ANALYSES}

These evaluations have been, made for the releases associated with drilling at the repository site through the repository. If the borehole connects aquifers above and below the repository, flow may be induced through the borehole that can affect the isolation of the wastes. If such a borehole could be drilled at the site, this scenario would be possible. In a review of 22,000 holes drilled through bedded salt in four counties in Kansas, although 95 percent of the holes displayed no dissolution beyond that associated with drilling fluids, 5 percent of these displayed some degree of post-drilling dissolution (Walters, 1975). In all of these cases but one, the dissolution 
Table 5-8. Integrated Releases to Accessible Environment ${ }^{(a)}$

Radionuclide Palo Duro Basin Palo Duro Basin Paradox Basin

EPA

(Granite Wash)

(Wolfcamp) (Leadville)

Standards $(b)$

(EPA, 1982)

\begin{tabular}{lllll}
\hline $14 \mathrm{C}$ & $1.0 \mathrm{E}+0$ & $7.2 \mathrm{E}-5$ & $7.0 \mathrm{E}-4$ & $1.4 \mathrm{E}+4$ \\
${ }^{99} \mathrm{Tc}$ & $2.1 \mathrm{E}+1$ & $6.7 \mathrm{E}-7$ & $1.1 \mathrm{E}-6$ & $1.4 \mathrm{E}+5$ \\
${ }^{126} \mathrm{Sn}$ & $1.9 \mathrm{E}-2$ & $2.6 \mathrm{E}-29$ & $3.8 \mathrm{E}-21$ & $5.8 \mathrm{E}+3$ \\
${ }^{129} \mathrm{I}$ & $9.8 \mathrm{E}-1$ & $4.2 \mathrm{E}-19$ & $7.4 \mathrm{E}-13$ & $3.6 \mathrm{E}+4$
\end{tabular}

\begin{tabular}{lllll}
\hline $239 \mathrm{Pu}$ & $6.5 \mathrm{E}-14$ & 0 & 0 & $7.2 \mathrm{E}+3$ \\
$235_{\mathrm{U}}$ & $1.1 \mathrm{E}-3$ & $7.8 \mathrm{E}-8$ & $2.0 \mathrm{E}-6$ & $7.2 \mathrm{E}+2$
\end{tabular}

\begin{tabular}{lllll}
\hline${ }^{237} \mathrm{~Np}$ & $6.5 \mathrm{E}-2$ & $5.2 \mathrm{E}-10$ & $5.3 \mathrm{E}-7$ & $1.4 \mathrm{E}+3$ \\
${ }^{233_{\mathrm{U}}}$ & $5.4 \mathrm{E}-2$ & $5.6 \mathrm{E}-10$ & $5.7 \mathrm{E}-7$ & $7.2 \mathrm{E}+2$ \\
${ }^{229} \mathrm{Th}$ & $1.1 \mathrm{E}-2$ & $1.1 \mathrm{E}-10$ & $1.2 \mathrm{E}-7$ & $7.2 \mathrm{E}+2$
\end{tabular}

\begin{tabular}{lllll}
\hline $240 \mathrm{Pu}$ & $3.5 \mathrm{E}-30$ & 0 & 0 & $7.2 \mathrm{E}+3$ \\
$236 \mathrm{U}$ & $2.3 \mathrm{E}-2$ & $6.5 \mathrm{E}-7$ & $2.5 \mathrm{E}-5$ & $7.2 \mathrm{E}+2$ \\
$232_{\mathrm{Th}}$ & $4.1 \mathrm{E}-8$ & $2.0 \mathrm{E}-10$ & $3.3 \mathrm{E}-9$ & $7.2 \mathrm{E}+2$
\end{tabular}

\begin{tabular}{|c|c|c|c|c|}
\hline $242 \mathrm{Pu}$ & $1.1 \mathrm{E}-3$ & $4.0 E-44$ & $9.1 \mathrm{E}-34$ & $7.2 \mathrm{E}+3$ \\
\hline${ }^{238}{ }_{\mathrm{U}}$ & $2.1 \mathrm{E}-2$ & $1.5 E-6$ & $3.8 \mathrm{E}-5$ & 7. $2 \mathrm{E}+2$ \\
\hline${ }^{234} \mathrm{U}$ & 3. $3 E-2$ & $1.5 \mathrm{E}-6$ & $3.8 \mathrm{E}-5$ & 7. $2 E+2$ \\
\hline $230 \mathrm{Th}$ & $4.4 \mathrm{E}-3$ & $3.0 \mathrm{E}-7$ & $7.7 \mathrm{E}-6$ & 7. $2 \mathrm{E}+2$ \\
\hline $226 \mathrm{Ra}$ & $2.2 \mathrm{E}-2$ & $1.5 E-6$ & $3.8 \mathrm{E}-5$ & 2. $2 \mathrm{E}+2$ \\
\hline
\end{tabular}

(a) Maximum 10,000-year release $10 \mathrm{~km}$ from repository.

(b) Standards for foreseeable releases based on waste from 72,000 MTHM emplaced in repository. These standards are listed only to give perspective to the calculated values. 


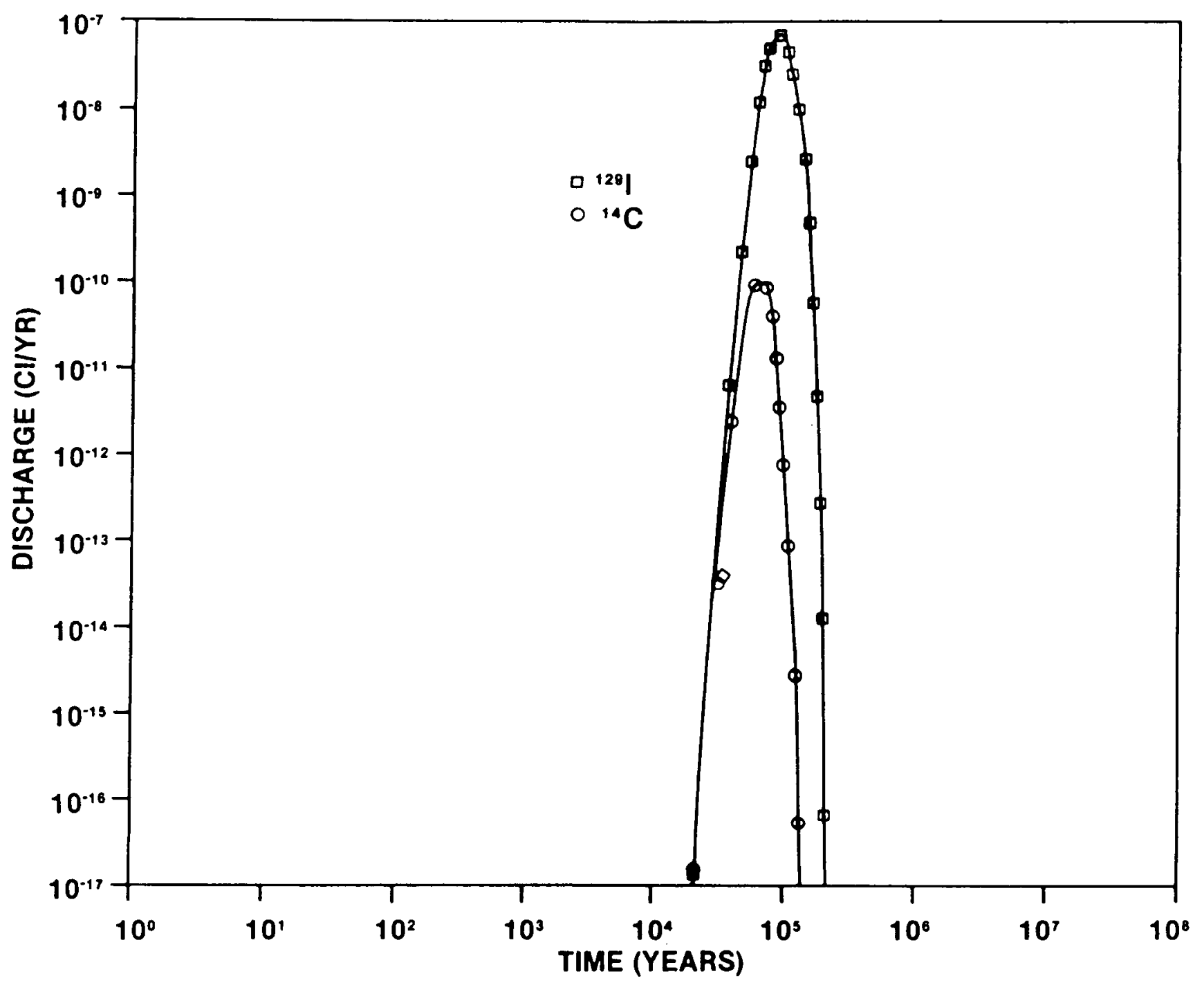

Figure 5-28. Calculated Release Rate to Accessible Environment Paradox Basin Leadville $\left({ }^{129} \mathrm{I} ;{ }^{14} \mathrm{C}\right)$ 


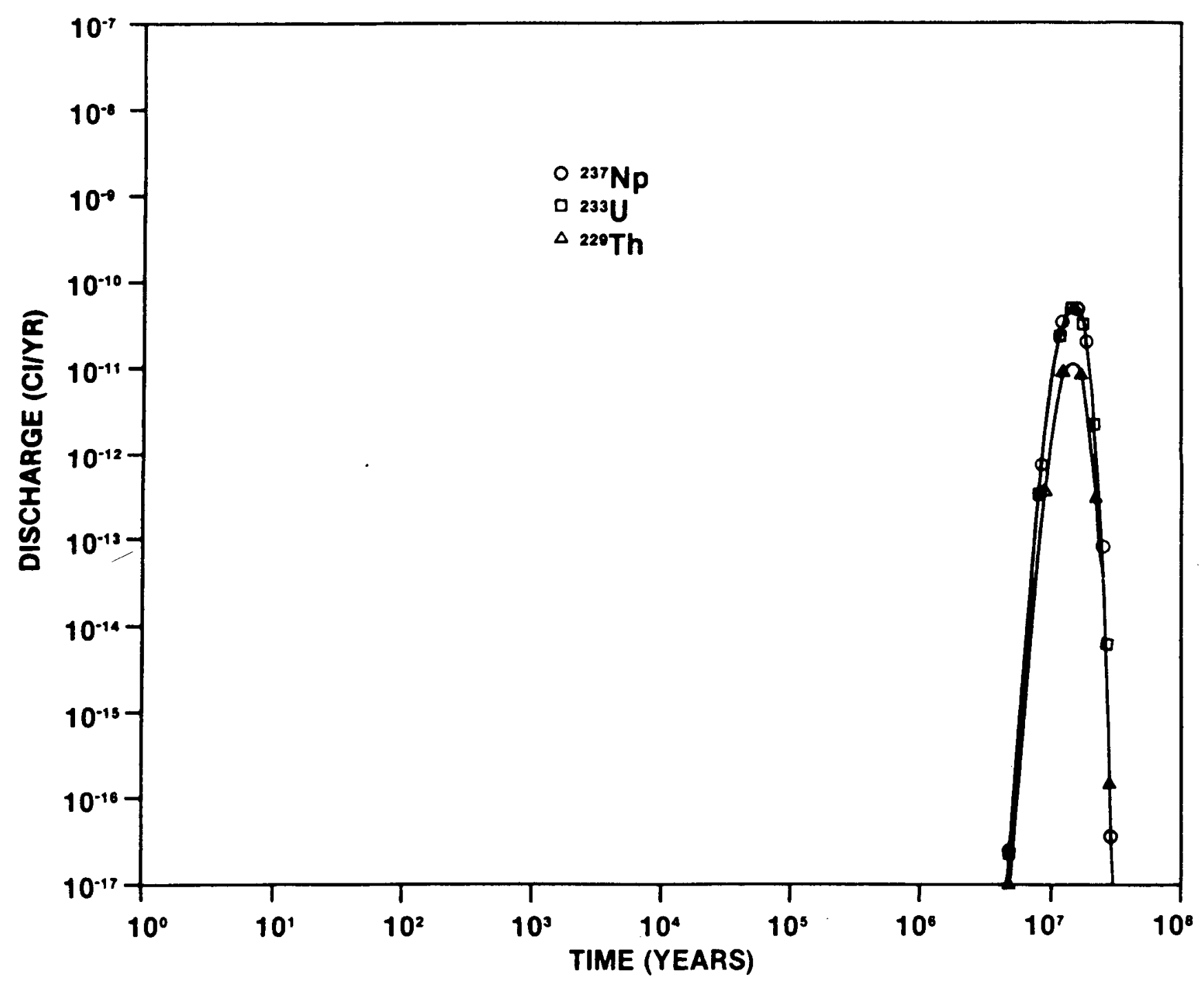

Figure 5-29. Calculated Release Rate to Accessible Environment Paradox Basin Leadville $\left({ }^{237} \mathrm{~Np} \rightarrow 233_{\mathrm{U}} \rightarrow{ }^{229} \mathrm{Th}\right)$ 


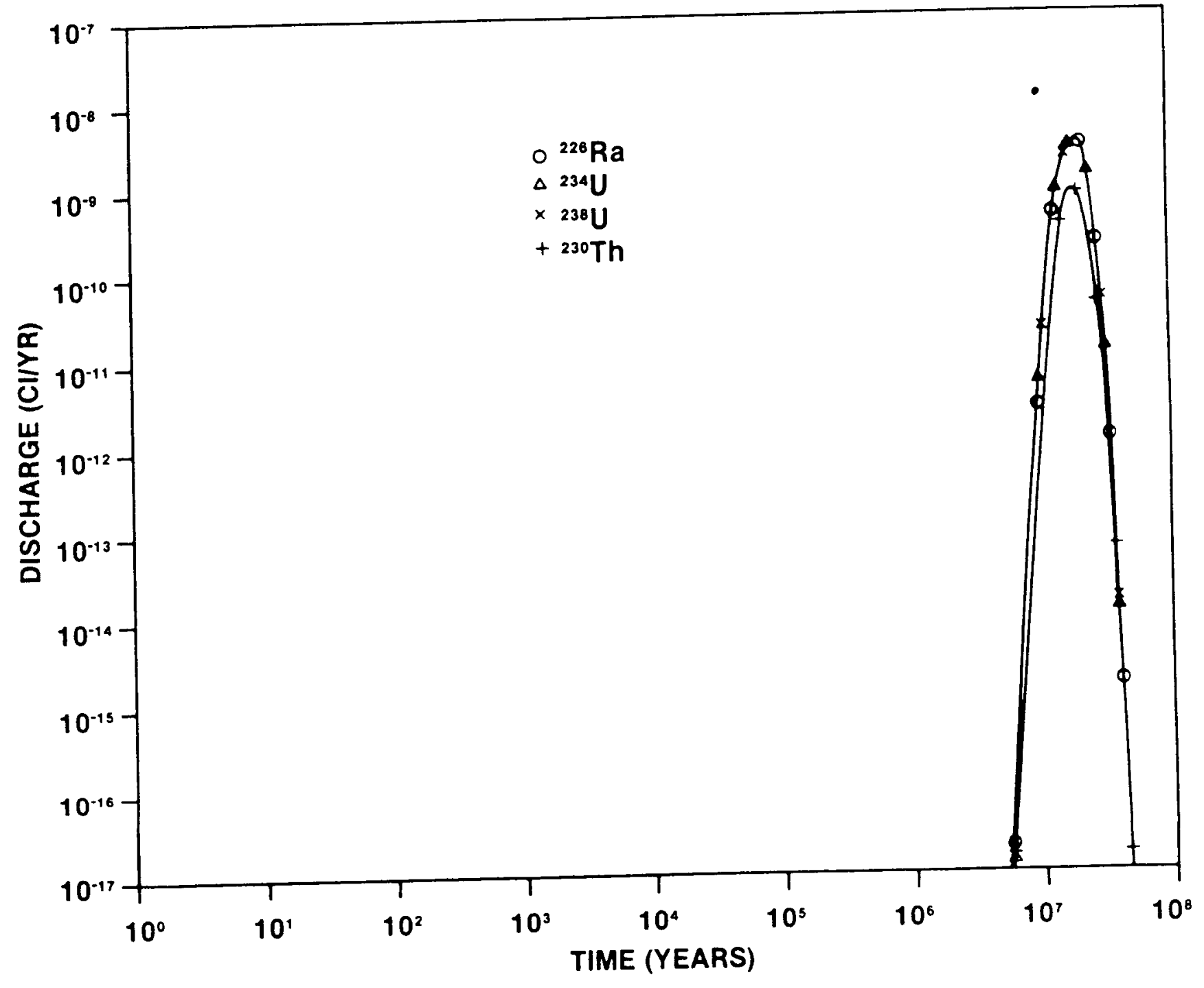

Figure 5-30. Calculated Release Rate to Accessible Environment Paradox Basin Leadville $\left({ }^{238} \mathrm{U} \rightarrow 234_{\mathrm{U}} \rightarrow 230_{\mathrm{Th}} \rightarrow 226_{\mathrm{Ra}}\right)$ 


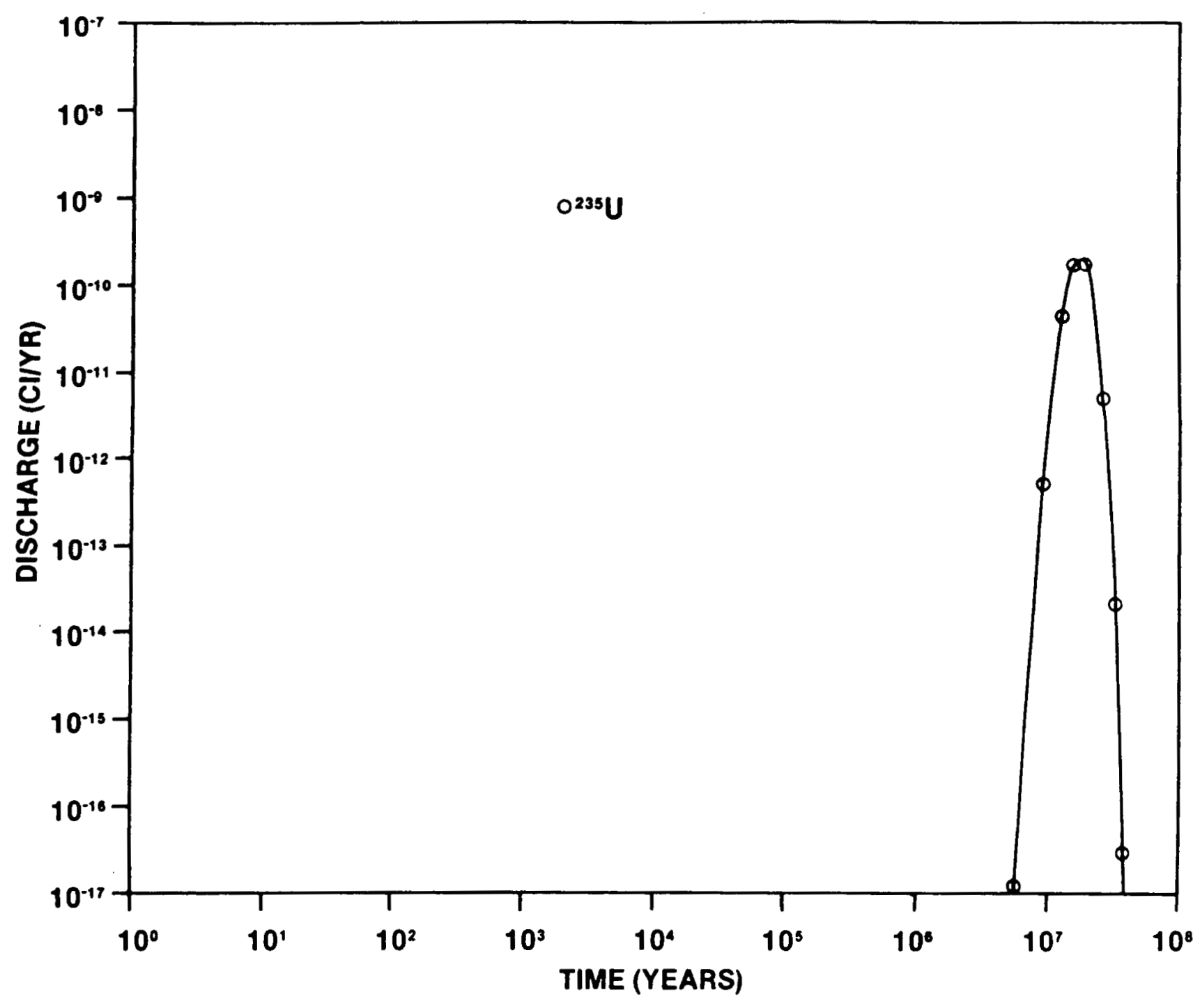

Figure 5-31. Calculated Release Rate to Accessible Environment Paradox Basin Leadville $\left({ }^{235} \mathrm{U}\right)$ 


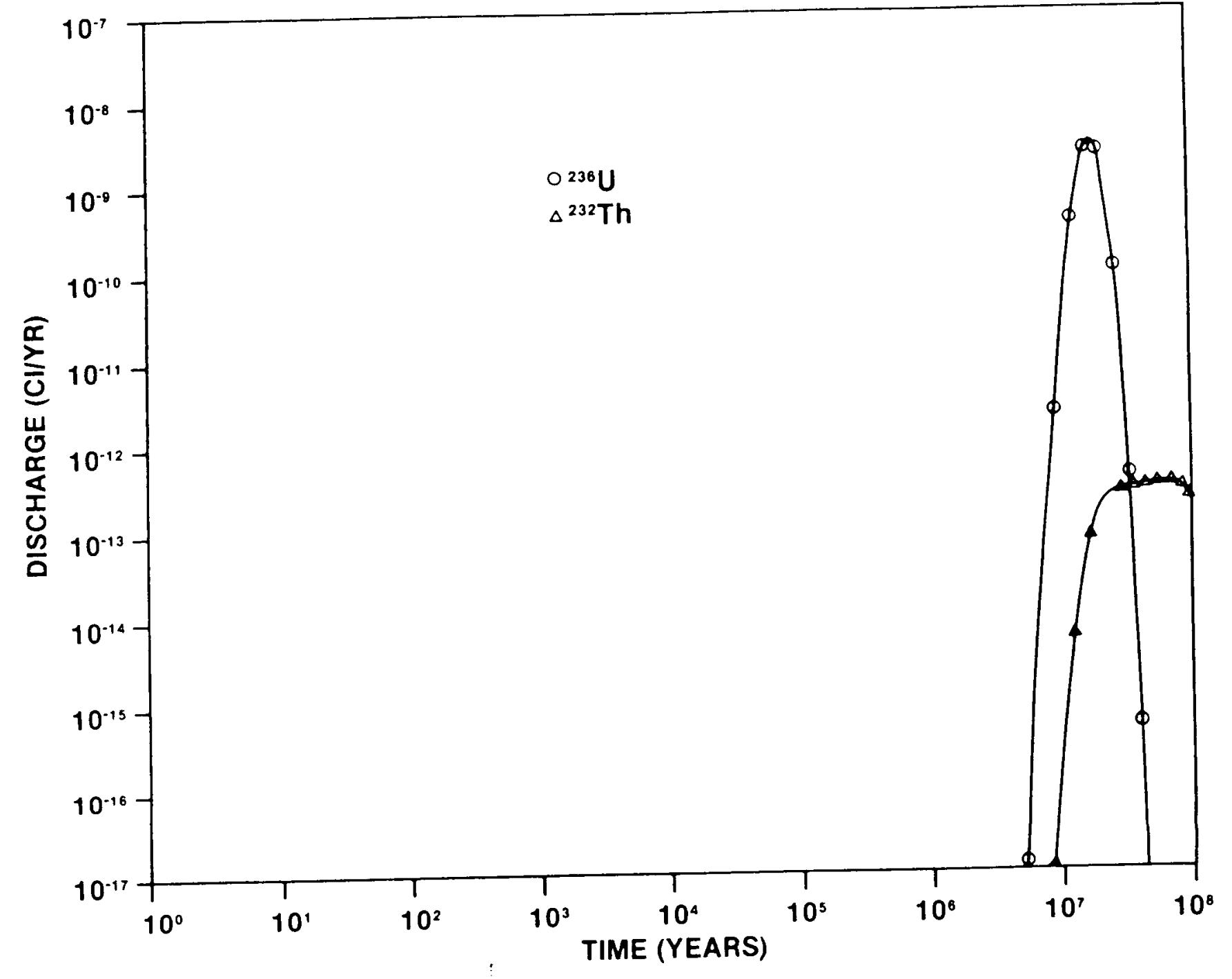

$\frac{\text { Figure 5-32. Calculated Release Rate to Accessible Environment Paradox Basin - }}{\text { Leadville }\left({ }^{236} \mathrm{U} \rightarrow{ }^{232} \mathrm{Th}\right)}$ 
was limited with the borehole opening retreating not more than $3 \mathrm{~m}$ in 30 years. This finding is consistent with the calculated result presented here that dissolution occurs only over a short time producing some borehole growth until the flow becomes saturated. Limiting borehole radii are on the order of $10 \mathrm{~m}$ or less in the calculations presented here.

In one case associated with a cavern solutioning operation, the dissolution associated with the solutioning operations and possibly subsequent natural solutioning resulted in a large cavity and collapse at the surface. The present analysis does not analyze cavity collapse. However, the flow rates considered are the maximum possible, whether for a borehole of small diameter or a larger opening. Any cavity collapse or subsidence would act to fill the cavity and reduce the flow.

The calculated release rates for the open borehole flow situation are quite small and below currently proposed regulatory standards. It may be argued that the criteria may not be applicable to the scenario in the way presented. For example, the EPA criteria for system release may not be applicable to the radial flow problem since the release evaluation involves contributions as far as $20 \mathrm{~km}$ from each other. Likewise, it may not be appropriate to compare the fractional release rates from the repository horizon due to the dissolution with the criteria for release from the engineered barrier subsystem. Nevertheless, the comparison is made here. Based on this comparison, the repository is predicted to perform satisfactorily.

The results can be used to compare the sites. For the case where the borehole extends down to the Wolfcamp in the Palo Duro site, the performance measures are similar for the two sites considered. There are a number of measures to Improve the performance of each. Locating the repository in deeper salt strata will result in lower dissolution rates at the repository horizon. Likewise, more dispersed distribution of waste packages in the salt will also decrease the predicted releases. These improvements have the same effect at both sites. If the borehole extends down to the granite wash and if the granite wash is continuous and capable of receiving much water, however, the predicted releases for the Palo Duro Basin become much larger.

Analyses for this scenario have been conducted for a bedded salt site (NRC, 1983; Pepping et a1 1983; Cranwe11, et al, 1982b) and the predicted releases are somewhat larger than those given here. However, these analyses 
used simple models for the salt dissolution and did not attempt to take into account the physical constraints to the release due to the dissolutioning occurring in salt layers upstream of the repository nor were realistic salt dissolution rates used in these analyses. Therefore, the present study provides a useful contrast to the earlier work and demonstrates the constralnt due to well-understood physical phenomena on the release rate in this case. Several refinements to the analysis should be made for future assessments. For example, preferential dissolution at the respository horizon has not been analyzed. It has been assumed that by 1,000 years after waste emplacement, crushed salt backfill in the repository has recgnsolidated and that creep closure of the rooms has occurred. Because detalled studies of the host salt have not yet verifled that the consolidation and closure will have reached completion by this time, the possibility that these processes have not been completed must be considered. In this case, the Increased surface area at the repository horizon and possible increased circulation through the incompletely closed openings and increased residency time for the flow due to the porosity could increase the dissolution rate at the repository horizon. This possibility should be taken Into account.

A detalled sensitivity analysis has not yet been performed. The impact of model parameters and assumptions that determine the borehole flow and dissolution rate needs to be evaluated to complete the analysis. 
The approach in previous analyses (Pepping et al, 1983; Cranwell et al, 1982a; DOE, 1983) was to assume that exposure of the waste occurred as a result of dissolution of salt in the repository. This effect would not change the conclusions stated above since the releases are limited by the solubility of the waste forms in elther case. Effects of the salinity of the water on these results are essentially negligible.

A rigorous sensitivity analysis has not been conducted. The predicted releases are directly proportional to the U-Tube flow rates and these have been evaluated for a fixed set of conditions in the upper aquifer. In addition, possible variations in repository design have not been investigated. The orientation of the repository was chosen to attempt to maximize the flow through the U-Tube for the bedded salt cases. At the Richton Dome, the orientation is essentially dictated by the shape of the salt dome and the configuration of the repository within the dome. Because of the extremely low releases predicted for the reference cases, it is not expected that variations in these parameters consistent with expected conditions would alter the above conclusions relating to the repository performance. 
The scenario was described in Section 2.1.3. The conceptual model involves an inflow of water prior to creep closure of the repository. The salt-creep process then pressurizes the entrapped water to near-lithostatic pressures. After contamination, the fluid is then released either through an exploratory borehole or through the shaft disturbed zone. In this chapter, two of the most important aspects of the conceptual model are examined in detail. Salt creep is discussed first. Flow through the shaft disturbed zone is then considered. Other inflow and release mechanisms are also considered. In light of these analyses, the scenario does not appear to be credible, and, consequently, no radionuclide discharge rates are computed.

\subsection{CREEP CLOSURE OF REPOSITOKY OPENINGS}

In this section, the time of closure is estimated based on an approach used by Kelsall et al (1985), which is similar to that used in Section 5.2 to evaluate creep closure of boreholes. Calculation of repository closure rates is based on the deformations predicted for a typical repository drift. This repository drift is treated as a cylindrical opening subject to an axially symmetric lithostatic stress. Creep closure is evaluated from the deviatoric stress and the secondary creep law appropriate for each site. Both the temperature and the depth of the repository are taken into account.

Crushed salt used to backfill the drift is taken into account in a simple model. The closure rates would also be affected by the presence of water in the room but all the evaluations are for pre-saturated conditions and the effect of water is ignored.

\subsubsection{Repository Room Closure}

The creep rate assumed for a storage room is based on the solution for steady-state creep of a cylindrical opening. The solution used by Kelsall et al (1985) is:

$$
\frac{d r}{d t}=-A \sqrt{3} \exp (-\gamma / T)(\sqrt{3} \Delta \sigma / n)^{n} \cdot r / 2
$$


where:

$$
\begin{aligned}
\frac{\mathrm{d} r}{\mathrm{~d} t}= & \text { rate of radial displacement of the wall } \\
\mathrm{A}, \mathrm{\gamma}, \mathrm{n}= & \text { secondary creep law parameters } \\
\mathrm{T}= & \text { absolute temperature } \\
\Delta \sigma \quad & \text { deviatoric stress which in this case is the difference } \\
& \text { between the in situ lithostatic stress, } P_{0} \text {, and the } \\
& \text { radial stress applied at the room wall, } P_{1} \\
= & \text { radius of the opening. }
\end{aligned}
$$

The closure of storage rooms in this model is evaluated by integrating the closure rate. The model parameters assumed are given in Table 6-1. The storage room parameters are based on the repository description in Section 3.2, and the creep law parameters are those for the host salt units from Pfeifle et al (1981). The temperature in the repository depends on both the in situ temperature and the temperature rise caused by the heat generated from the radioactive decay of the emplaced waste. The temperatures for the repository design and waste distribution described in Section 3 have been calculated by Wagner et al (1985) for the Palo Duro and Paradox sites. These have been used in the present analysis. The temperature rise in the Richton Dome repository is assumed to be the same as that at the Paradox Basin site. The difference in ambient temperature in the two cases is taken into ascount by adding $8^{\circ} \mathrm{C}$ to the Paradox Basin site temperature history.

The results for an unbackfilled, empty storage room, (i.e., $P_{1}=0$ and $\Delta \sigma=$ in situ lithostatic stress) are shown in Figures 6-1 through 6-3. The upper curve in these three figures indicates the calculated relative void space in the storage rooms as a function of time. It has been assumed that this closure applies to all openings and the results are scaled so that the ordinate gives the total void space in the repository. Discounting the effects of the backfill, the repository is predicted to close in about 100 years at both the Palo Duro site and the Paradox site. According to this prediction the Richton Dome does not close completely but stabilizes at a porosity of about 10 percent in about 600 years.

These predictions are based on a simple model using only the secondary creep response of the salt. Primary creep has not been taken into account. A more sophisticated analysis of the creep closure of the storage room has been 
Table 6-1. Parameters for Room Closure Analysis

Units Palo Duro Paradox Richton

Repository depth

m $\quad 730 \quad 910 \quad 610$

Lithostatic pressure $\left(\mathrm{P}_{\mathrm{o}}\right)^{(\mathrm{a})}$

Average rock density (a)

$\mathrm{MPa}$

$\mathrm{kg} / \mathrm{m}^{3}$

15.3

21.5

13.1

Initial room cross section

$\mathrm{m} \times \mathrm{m}$

2140

2420

2200

Equivalent radius

m

$4.6 \times 6.1$

$4.6 \times 6.1$

$4.6 \times 6.1$

Equivalent radius

3.0

3.0

3.0

Intact salt creep parameters $(b)$

A

$\gamma$

$\mathrm{n}$

$\begin{array}{llll}\mathrm{MPa}^{-\mathrm{n}} \sec ^{-1} & 1.9 \mathrm{E}-4 & 6.5 \mathrm{E}-4 & 2.6 \mathrm{E}-2 \\ { }^{\circ} \mathrm{K}^{-1} & 7154 & 6835 & 9885 \\ -- & 4.15 & 1.88 & 5.01\end{array}$

(a) Assumed values, from Kelsall et al (1985).

(b) Assumed values, from Pfeifle et al (1981). 


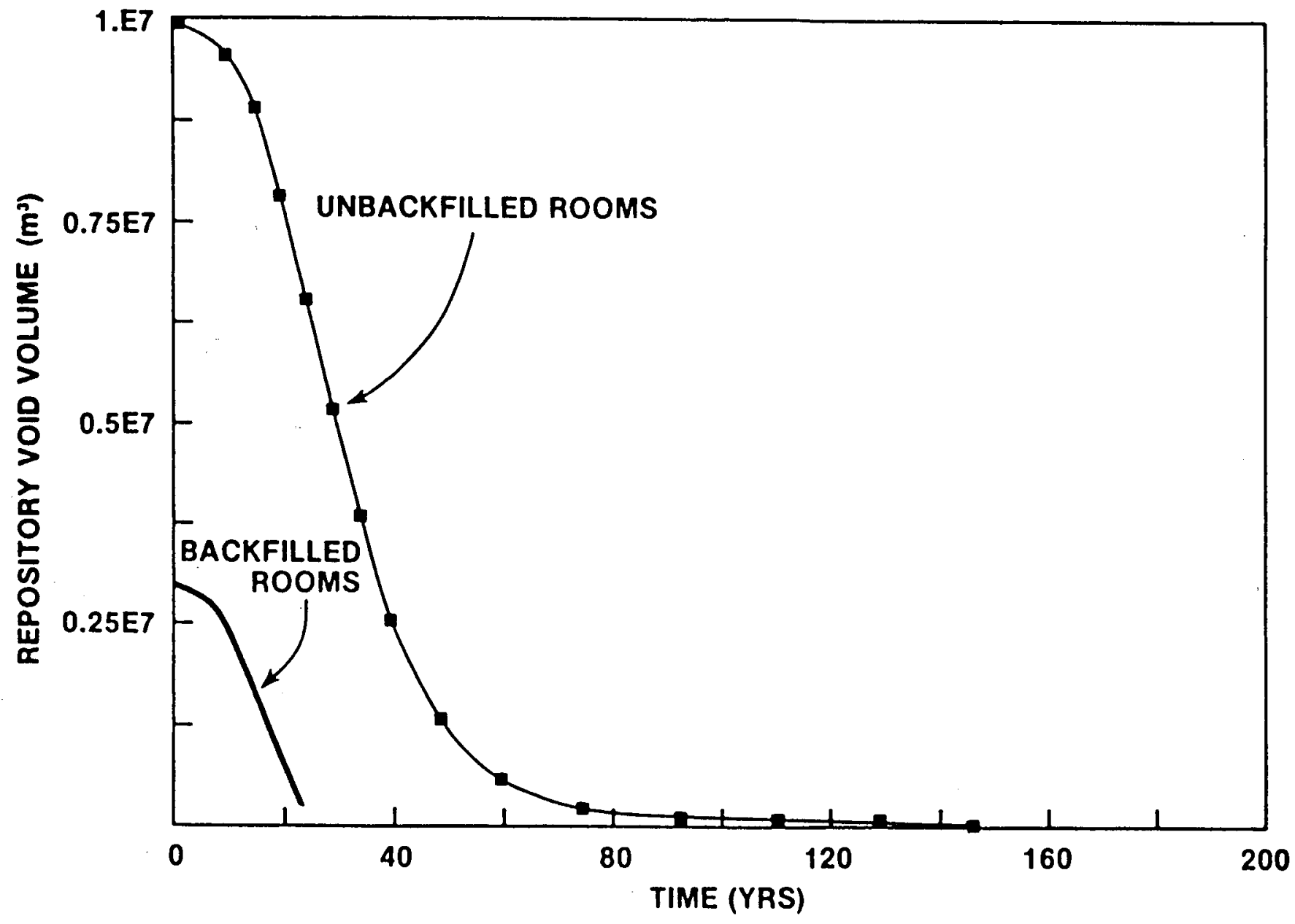

$\underset{\ddagger}{\mathfrak{w}}$

Figure 6-1. Calculated Repository Vold Volume at Palo Duro S1te 


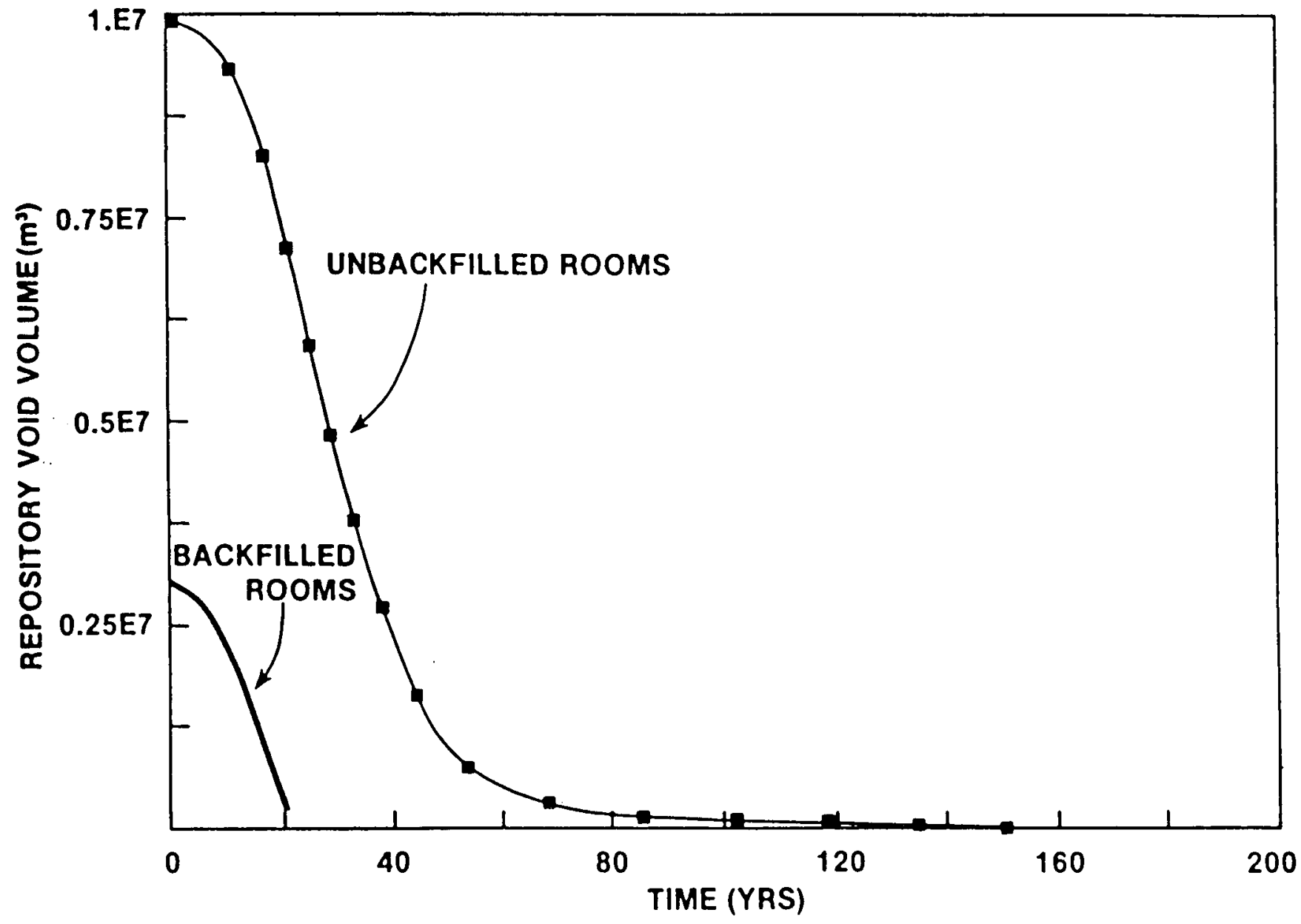




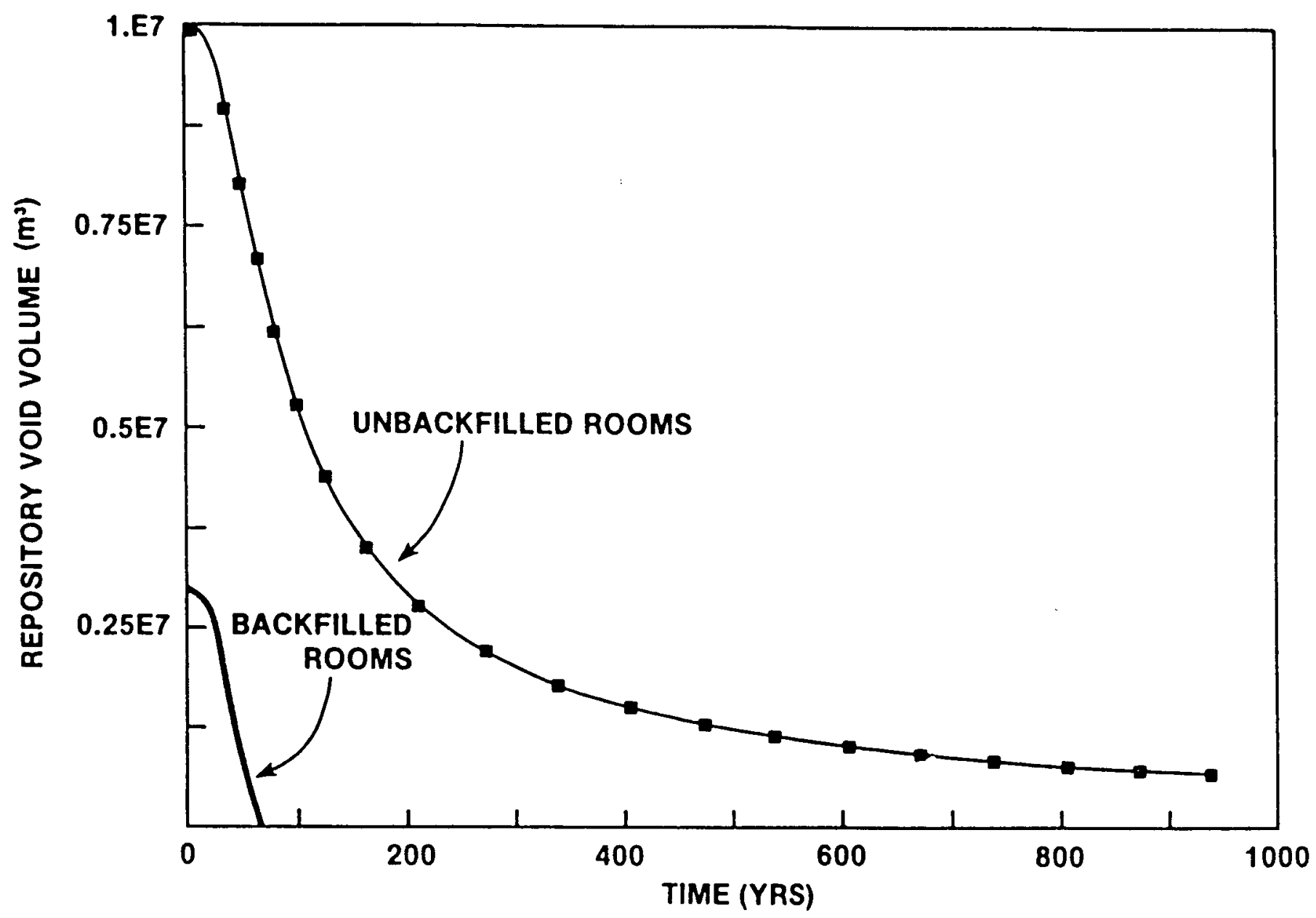

$\stackrel{\varpi}{\omega}$

Figure 6-3. Calculated Repository Void Volume at Richton Site 
conducted by Wagner et al (1985) for the Palo Duro and Paradox sites. This analysis has utilized a more detailed representation of the storage room geometry and the more complete creep law. Their simulations were made only for an initial 5-year period and the analysis for the Palo Duro Basin was made for the Cycle 5 salt in the San Andres rather than the deeper Cycle 4 salt assumed here. Nevertheless, the comparison in Figure 6-4 suggests a rather strong geometrical effect with the cylindrical shape corresponding to a slower rate of creep than the design geometry. The comparison also suggests that the simple model used here is conservative in that it underestimates creep closure.

\subsubsection{Consolidation of the Crushed Salt Backfill}

The backfill in the storage rooms will modify the predicted closure rates and times because of the resistance pressure, $P_{i}$, offered by the backfill as the room closes. The response of the backfill is complicater. by the fact that the crushed salt can consolidate under stress. The treatment of the backfill in this analysis is also adopted from the approach of Kelsall et al (1985).

The creep law assumed for the backfill is given by:

$$
\sigma_{\mathrm{m}}=C\left[\exp \left(D \varepsilon_{\mathrm{v}}\right)-1\right]
$$

where:

$$
\begin{array}{ll}
\sigma_{\mathrm{m}} & =\text { mean backfill stress } \\
\varepsilon_{\mathrm{v}} & =\text { total volumetric strain } \\
\mathrm{C,D} & =\text { empirical creep law parameters. }
\end{array}
$$

The bulk modulus, $\mathrm{B}_{\mathrm{T}}$, of the backfill is therefore:

$$
\begin{array}{ll}
\mathrm{B}_{\mathrm{T}}=\mathrm{CD} \exp \left(\mathrm{D} \varepsilon_{\mathrm{v}}\right) & \varepsilon_{\mathrm{v}}<\varepsilon_{\mathrm{I}} \\
\mathrm{B}_{\mathrm{T}}=\mathrm{B}_{\mathrm{I}} & \varepsilon_{\mathrm{v}}>\varepsilon_{\mathrm{I}}
\end{array}
$$




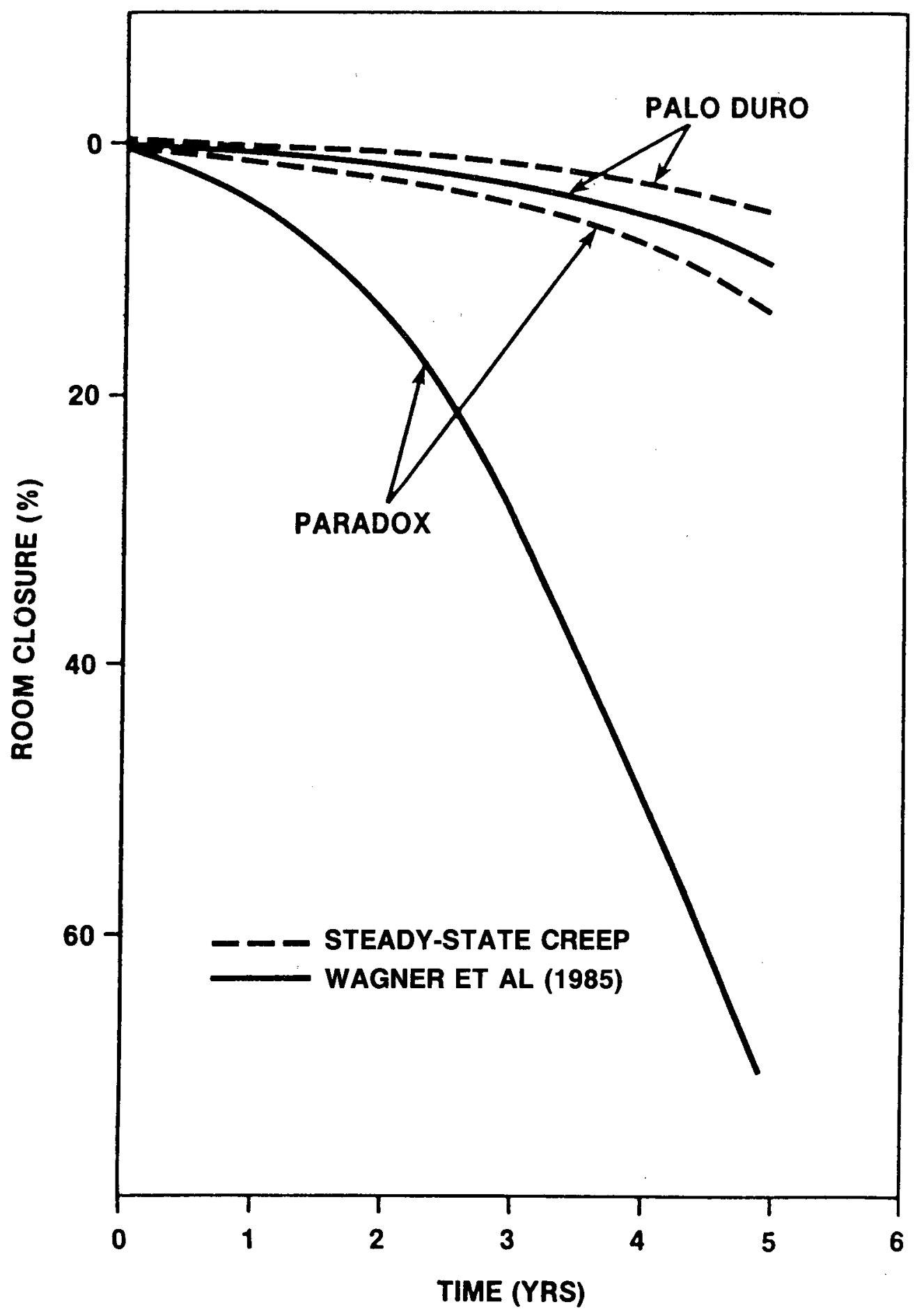

Figure 6-4. Comparison of Steady-State Creep Model of Room Closure with Sophisticated Model 
where:

$$
\begin{aligned}
& { }^{B_{I}}=\text { bulk modulus of intact salt } \\
& \varepsilon_{I}=\text { total volumetric strain when intact conditions are } \\
& \quad \text { obtained. }
\end{aligned}
$$

The consolidation of the backfill is assumed to satisfy:

where:

$$
\dot{\varepsilon}_{c}=E\left(\frac{\sigma_{0}}{\sigma_{0}}\right)^{\alpha}\left(\frac{T-T_{0}}{T_{1}}\right)^{\beta} / \varepsilon_{v} \delta
$$

$$
\begin{aligned}
& \dot{\varepsilon}_{\mathrm{c}} \quad=\text { consolidation strain rate } \\
& { }_{0}, \mathrm{~T}_{0}, \mathrm{~T}_{1}=\text { normalization parameters } \\
& \mathrm{E}, \alpha, \beta, \delta=\text { phenomenological parameters. }
\end{aligned}
$$

Kelsall et al (1985) solved these equations self-consistently to determine the response of the backf111 and the deformation of the room wa11s. Th1s approach is briefly sketched below.

The change in the volumetric strain due to creep in a time step $\Delta t$ is approximately:

$$
\Delta \varepsilon_{\mathbf{v}} \simeq \frac{2}{\mathrm{r}} \frac{\mathrm{dr}}{\mathrm{d} t} \Delta t
$$

The change in the volumetric strain due to consolidation is approximately:

$$
\Delta \varepsilon_{c} \simeq \dot{\varepsilon}_{c} \Delta t
$$

These changes can be integrated to determine the total deformation at a specified time. The internal stress applied on the room wall, $P_{1}$, is determined by integrating the change in $P_{1}$ with time.

$$
\Delta P_{1}=B_{T}\left(\Delta \varepsilon_{v}-\Delta \varepsilon_{c}\right)
$$

This approach has been applied to the evaluation of the salt sites to estimate the impact on the repository closure predictions. The parameters used for the backf111 material are given in Table 6-2. These parameters are based on the properties of crushed salt from the Avery Island salt dome (Wagner, 1980). 
Table 6-2. Crushed Salt Creep and Consolidation Properties

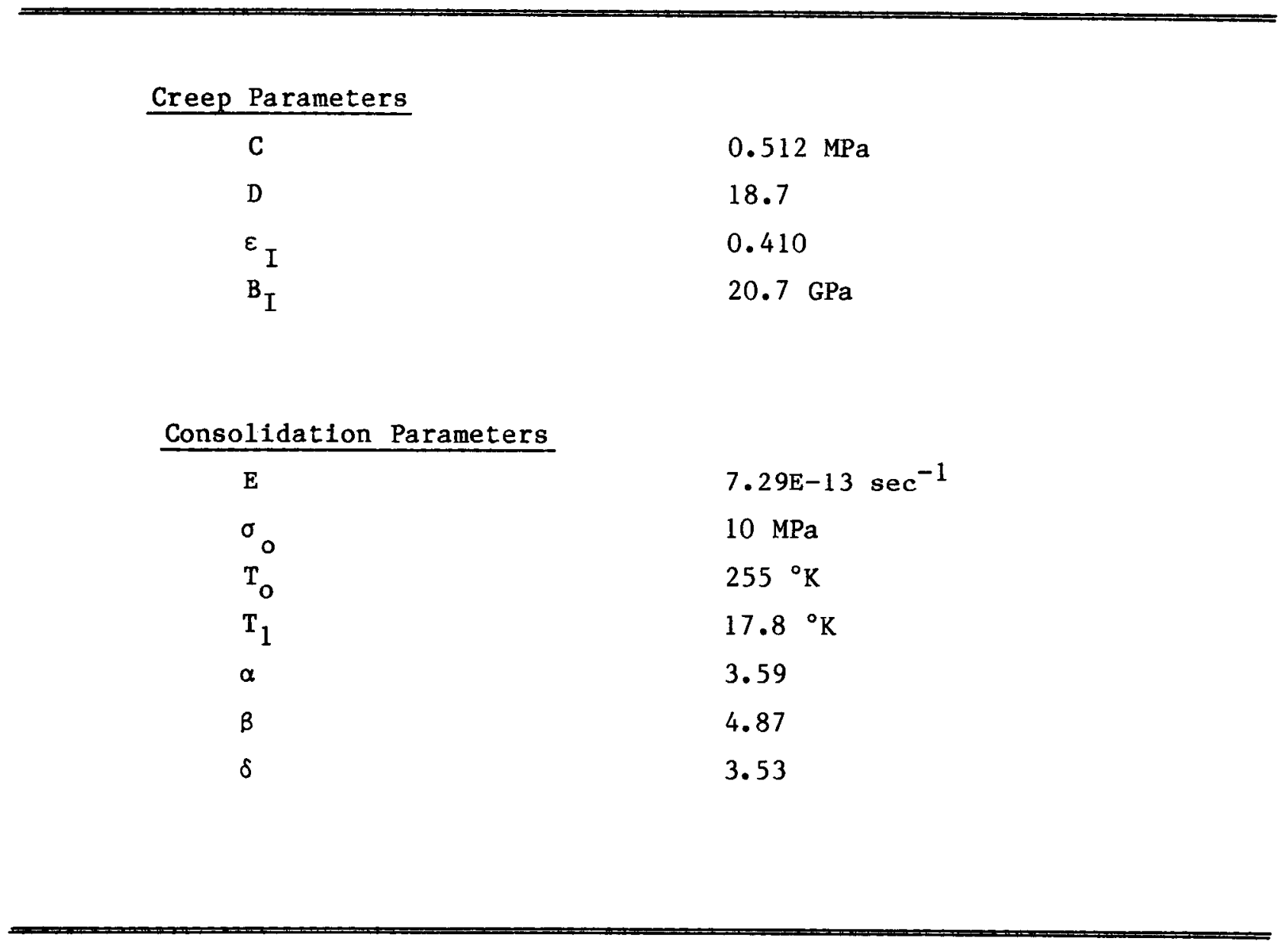


The calculated effect of the backfill in this model is shown in the lower curves in Figures 6-1 through 6-3 for each of the three sites. Evidently the backfill does not significantly modify the closure rate. The most important effect appears to be that the presence of the backfill reduces the void space in the repository and therefore reduces the time needed to close the repository. The closure times for both unbackfilled and backfilled repositories based on these estimates are summarized in Table 6-3. These calculations indicate that the effect of the backfill is to reduce the predicted closure times to about 20 years for the bedded salt sites and about 70 years for the Richton Dome site.

These rates have been predicted for no water in the repository. If water is present in the repository, the closure rates will decrease and the calculations of closure times will need to reflect this change.

\subsection{FLOW OF WATER INTO REPOSITORY OPENINGS}

One of the possibilities for flow into the repository includes flow through interconnected porosity in the salt induced by the fluid pressure gradients that may exist. Such flow depends on the permeability of the salt. While there is some uncertainty regarding this permeability, it is known to be very low (Tien et a1, 1983; DOE, 1983). This permeability is sufficiently low that this possibility is not evaluated further in the preliminary analyses.

Another possibility involves inadvertent human intrusion into the repository. Examples that could occur include exploratory drilling or a solution mining operation in the vicinity of the repository. However, because of the active and passive controls at the site, such inadvertent penetration would be very unlikely for a very long time (Berry, 1983). Because the natural creep closure of the repository certainly will be complete well before 500 to 1,000 years, 1ikely after only 20 to 70 years, the ingress of water by this mechanism will therefore not be significant; and, this mode is also not considered further at this stage of the analyses.

Another possibility is that there will be leakage into the repository from an overlying aquifer by way of boreholes and shafts at the site. These openings would be sealed as a part of the engineered closure of the repository but some leakage could occur through the seal materials. Leakage could also 
Table 6-3. Model Estimates of Reposttory Closure Times

Repository

Closure Time (yrs)

No Backfill(a) Crushed Salt Backfill (b)

$\begin{array}{lcc}\text { Palo Duro } & 100 & 23.6 \\ \text { Paradox } & 100 & 22.1 \\ \text { Richton } & -- & 69.3\end{array}$

(a) Initial porosity of repository openings $=1.0$.

(b) Initial porosity of repository openings $=0.3$. 
occur through the rock inmediately around these openings that has been disturbed by the drilling or excavation process. Such leakage could commence early and ingress could occur before salt creep has closed the repository. The total amount of inflow will depend on the water infiltration rate and the rate of creep closure of the repository.

Brine influx could occur from migration of natural brine inclusions in the salt induced by the heat generated in the radioactive waste. Such brine migration has been observed in heater tests in salt (Bradshaw and McClain, 1971 ).

These latter two modes of inflow are considered in the following sections.

\subsubsection{Infiltration Through Shaft Disturbed Zone}

This section explores the possible effects of seepage through the shaft seal system and through rock adjacent to the shafts that has been disturbed as a result of excavation of the shafts. A study of the infiltration through the shaft seals has been conducted by Gureghian et al (1983) for a shaft seal system at a Paradox Basin site. The calculations in that study predicted that it would require more than 300,000 years for a wetting front to move down to the repository horizon from the overlying Elephant Canyon Formation (Paradox Basin site). This time is much longer than the time required for creep closure of the repository void space; and, consequently, inflow is not expected to be significant. The long delay is due to the low permeability that characterizes the shaft backfill and seal materials. Since materials with similar characteristics would probably be used at any salt site, the shaft system is expected to significantly limit water influx into the repository.

The technique to estimate the time of transit to the repository is similar to that employed by Gureghian et a1 (1983) for the analysis of the shaft seals. This approach is to assume an initial water content in a specified layer and to evaluate the flow in that layer by integrating the equation for total mass conservation in the layer. Assuming unsaturated, onedimensional vertical flow in layer $\mathrm{m}$, the equation for the transit time given by Gureghian et al (1983) is: 


$$
\Delta t_{m}=\left(\frac{n_{m}-\theta_{m}}{K_{m}}\right)\left\{d_{m}+\left(K_{m} R_{m}-H_{m}+h_{c m}\right) \ln \left(\frac{d_{m}+H_{m}-h_{c m}}{H_{m}-h_{c m}}\right)\right\}
$$

where $\Delta t_{m}$ is the transit time through layer $m$, the layer of interest, and where

$$
\mathrm{H}_{\mathrm{m}}=\mathrm{h}_{0}+\sum_{i=1}^{\mathrm{m}-1} \mathrm{~d}_{i}
$$

and

$$
\mathrm{R}_{\mathrm{m}}=\sum_{i=1}^{\mathrm{m}-1} \frac{\mathrm{d}_{i}}{\mathrm{k}_{i}}
$$

The sums are over the layers above the layer $\mathrm{m}$, and these layers are all assumed to be saturated. The parameters in the above equations are:

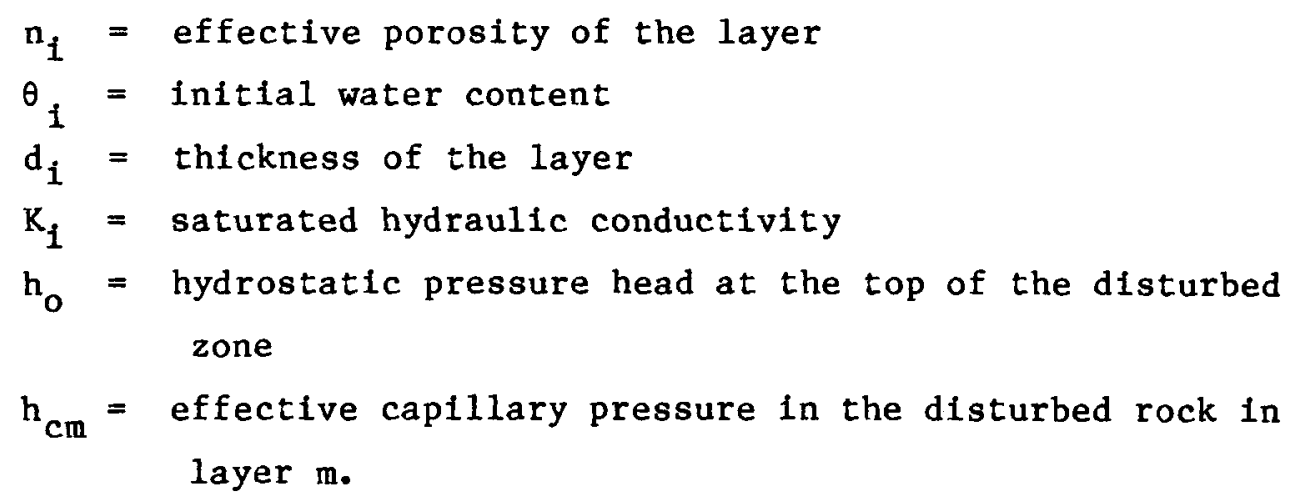

The capillary pressure (Richards, 1931) is on the order of a meter or less for this case and is therefore negligible when compared to the dimensions of the layer. The procedure is to evaluate $\Delta t_{\mathrm{m}}$ for each successive layer in the disturbed zone annulus and to sum them to determine the total time of transit. 
The hydraulic properties for the rock in the disturbed zone will contain uncertainty because of the heterogenity of the rock and because of the disturbance caused by shaft construction. The assessments which will use measured values will therefore need to take into account these uncertainties appropriately. At this preliminary stage of the analyses, however, the selection of hydraulic properties is based on a different approach. Laboratory values for rocks characteristic of the units at the site are used on the grounds that laboratory samples will have experienced stress relief and other effects of the type to which the disturbed zone will be subjected. Hydraulic properties for relevant sedimentary rocks evaluated in laboratory testing have been summarized by Touloukian et al (1981) and the values used here are summarized in Table 6-4.

The representation of the rocks used in this analysis are given in Tables 6-5, 6-6, and 6-7 for the Palo Duro, Paradox, and Richton Dome sites, respectively. The units specified are for the layers below the upper aquifer systems and the unit thicknesses are based on the characterizations referenced in the site descriptions in Section 3.1. The flow properties in these tables are based on Table 6-4.

The calculated transit times through the shaft disturbed zone are summarized in Table 6-8. The traversal from the shaft zone to the repository through the shaft pillar tunnel is ignored. The transit times predicted for the shaft disturbed zone are considerably lower than those calculated through shaft seals and are on the order of the time calculated for creep closure of the repository. Therefore, it may be possible that some influx of water into the repository could occur before the repository is closed.

The flow of water into the repository depends on the time of initial wetting of the repository and the influx rate thereafter. The influx rate can be estimated from the properties of the shaft disturbed zone. To make this estimate, it is assumed that once the wetting front reaches the repository, Darcy flow occurs in the shaft disturbed zone. Therefore the specific influx is represented by:

$$
q=\frac{h_{0}+\sum_{i=1}^{m} d_{i}}{\sum_{i=1}^{m} d_{i} / k_{i}}=H_{m} / R_{m}
$$


Table 6-4. Hydraulic Properties of Sedimentary Rock From Laboratory Tests (a)

\begin{tabular}{lcc}
\hline Rock & Conductivity $(\mathrm{m} / \mathrm{sec})$ & Porosity \\
\hline & & \\
Anhydrite & $5 . \mathrm{E}-8$ & 0.10 \\
Dolomite & $5 . \mathrm{E}-8$ & 0.01 \\
Halite & $2 . \mathrm{E}-9$ & 0.02 \\
Limestone & $5 . \mathrm{E}-8$ & 0.025 \\
Shale & $5 . \mathrm{E}-9$ & 0.02 \\
Siltstone & $5 . \mathrm{E}-9$ & 0.10 \\
& & \\
\hline
\end{tabular}

(a) Based on data given in Touloukian et a1 (1981). 
Table 6-5. Hydrogeologic Description of Undisturbed Palo Duro Basin Formation for Infiltration Analysis ${ }^{(a)}$

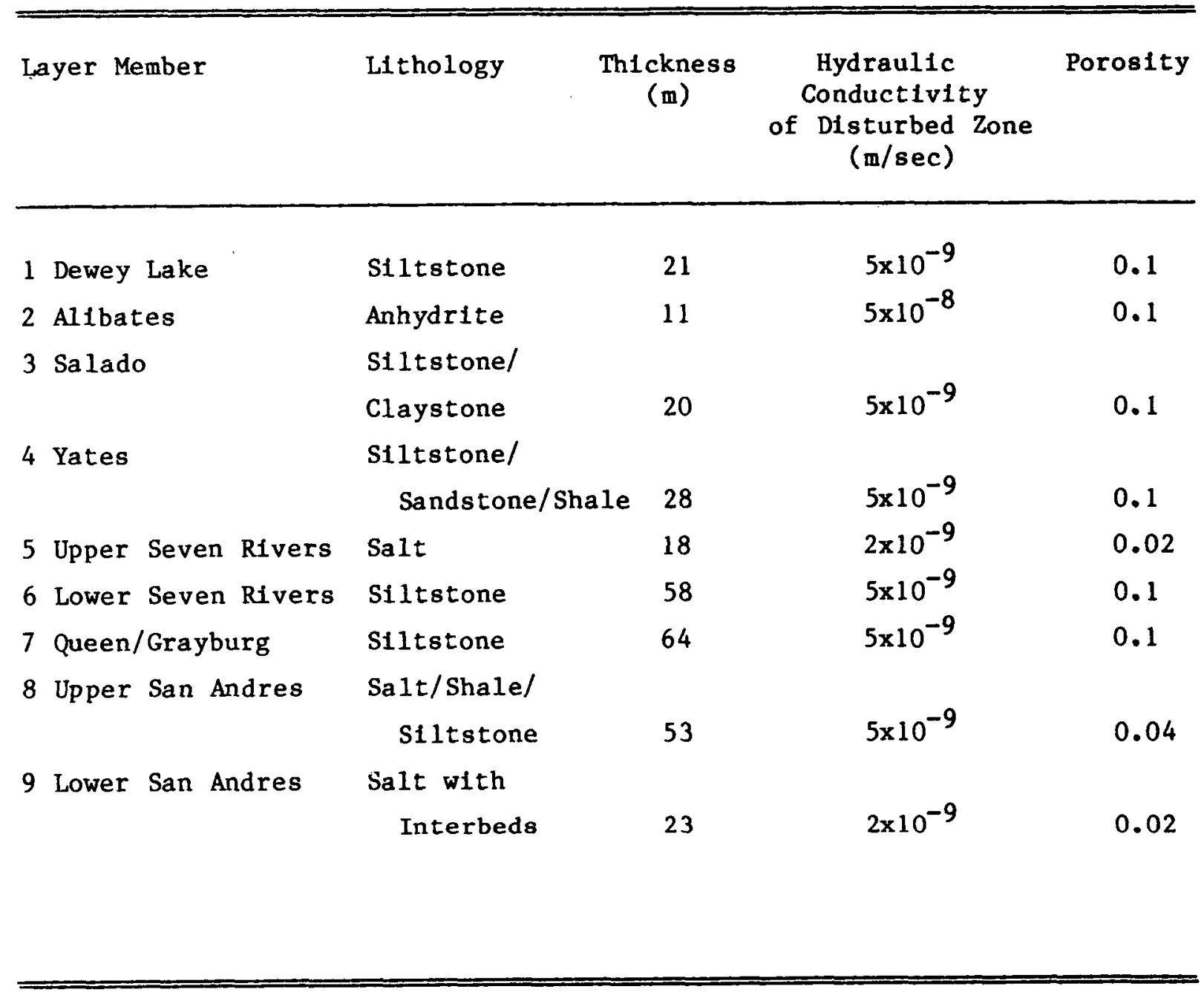

(a) Upper aquifer system is composed of Ogallala and Dockum units. Hydrostatic head at top of the Dewey Lake member is $390 \mathrm{~m}$. Representation is from Stone \& Webster (1983). 
Table 6-6. Hydrogeologic Description of Undisturbed Paradox Basin Formation for Infiltration Analysis ${ }^{(a)}$

\begin{tabular}{|c|c|c|c|c|}
\hline Layer Member & \multirow{2}{*}{$\begin{array}{l}\text { Lithology } \\
\text { Limestone }\end{array}$} & \multirow{2}{*}{$\begin{array}{l}\text { Thickness } \\
\text { (m) } \\
60\end{array}$} & \multirow{2}{*}{$\begin{array}{c}\begin{array}{c}\text { Hydraulic } \\
\text { Conductivity } \\
\text { of Disturbed Zone } \\
(\mathrm{m} / \mathrm{sec})\end{array} \\
5 \times 10^{-8}\end{array}$} & \multirow{2}{*}{$\begin{array}{r}\text { Porosity } \\
0.025\end{array}$} \\
\hline 1 Honaker Trail & & & & \\
\hline 2 Honaker Tra 11 & Limestone/Dolomite & & & \\
\hline & Siltstone & 15 & $5 \times 10^{-8}$ & 0.025 \\
\hline 3 Honaker Tra1l & Limestone/Clayey & & & \\
\hline & Siltstone & 168 & $2 \times 10^{-8}$ & 0.05 \\
\hline 4 Honaker Trail & Siltstone/Limestone & 45 & $2 \times 10^{-8}$ & 0.05 \\
\hline \multirow[t]{2}{*}{5 Honaker Trail } & Clay/Halite/ & & & \\
\hline & & 122 & $2 \times 10^{-8}$ & 0.06 \\
\hline 6 Honaker Trail & Anhydrite/Dolomite & 8 & $5 \times 10^{-8}$ & 0.05 \\
\hline 7 Honaker Tra11 & Anhydrite & 38 & $5 \times 10^{-8}$ & 0.1 \\
\hline 8 Paradox & Salt & 24 & $2 \times 10^{-9}$ & 0.02 \\
\hline
\end{tabular}

(a) Upper aquifer system is the Elephant Canyon unit. Hydrostatic head at the top of the Honaker Trail is $152 \mathrm{~m}$. Representation is from Woodward-Clyde Consultants (1982). 
Table 6-7. Hydrogeologic Description of Undisturbed Richton Dome Formation for Infiltration Analysis ${ }^{(a)}$

\begin{tabular}{llccc}
\hline \hline Layer Member & Lithology & $\begin{array}{c}\text { Thickness } \\
(\mathrm{m})\end{array}$ & $\begin{array}{c}\text { Hydraulic } \\
\text { Conductivity } \\
\text { (m/sec) }\end{array}$ & Porosity \\
\hline 1 Richton Dome & Salt & 355 & $2.0 \mathrm{E}-9$ & 0.02 \\
\hline
\end{tabular}

(a) Upper aquifer system is composed of the Hattiesburg and Catahoula units. The dome caprock is considered to be permeable here and is formally included as part of the aquifer system. The hydrostatic head at the top of the dome salt is $235 \mathrm{~m}$. Representation is from Law Engineering Testing Company (1982). 
Table 6-8. Estlmate of Water Influx Through Shaft Disturbed Zone

\begin{tabular}{|c|c|c|c|}
\hline Flow Variable & Palo Duro & Paradox & Richton \\
\hline $\begin{array}{l}\text { Transit time through } \\
\text { disturbed zone (yr) }\end{array}$ & 79.9 & 18.7 & 43.9 \\
\hline Influx rates $\left(\mathrm{m}^{3} / \mathrm{yr}\right)$ & 5.0 & 14.2 & 2.3 \\
\hline $\begin{array}{l}\text { Time of repository creep } \\
\text { closure }(y r)\end{array}$ & 23.6 & 22.1 & 69.3 \\
\hline $\begin{array}{l}\text { Water accumulation } \\
\text { to saturation }\left(\mathrm{m}^{3}\right)\end{array}$ & 0 & 48.3 & 77.3 \\
\hline $\begin{array}{l}\text { Water accumulation if disturbed } \\
\text { zone is initially saturated }\left(\mathrm{m}^{3}\right)\end{array}$ & 117 & 314 & 159 \\
\hline
\end{tabular}


The sum extends over all layers in the column and the permeabllity of the repository is neglected. The calculated influx rates are given in Table 6-8. The calculated inflow rates in all three cases are very low, less than $15 \mathrm{~m}^{3} /$ year. The calculated rate for the Richton Dome is lowest reflecting the thick section of salt in this case. Of the two bedded salt sites, the inflow rate for the Palo Duro case is lower because of greater quantity of low-conductivity siltstone and salt that has been assumed in this case.

As indicated schematically in Figure 2-3, saturation would occur roughly when the inflow volume and the repository void volume are equal. The time to saturate can be estimated from the rates calculated by the methods described in this and the previous section on creep closure.

The accumulated influx at the time of saturation calculated based on these rates is also 11sted in Table 6-8. No accumulation is given for the Palo Duro site because closure occurs before the water reaches the repository. Although the flow rate is lower in the Richton Dome case than in the Paradox case, this factor is compensated by the longer delay predicted for closure of rooms in the salt dome. Consequent1y, the predicted accumulation is actually larger. The volumes in these cases however are quite sma11, less than $100 \mathrm{~m}^{3}$ total accumulation.

These estimates depend on the parameters assumed, of course. If the porosities assumed were an order of magnitude smaller, the wetting times would decrease by an order of magnitude, for example. In addition, it has been assumed that the water content of the disturbed zone at the time of shaft sealing is zero. If the disturbed zone is instead assumed to be saturated at this time, the delay before water reaches the repository is decreased. The volume of water that would accumulate in the repository in this case is given in Table 6-8. The total volume of brine predicted in this case is roughly 100 to $300 \mathrm{~m}^{3}$.

In comparison to the total vold volume of the repository $\left(10^{6}\right.$ to $\left.10^{7} \mathrm{~m}^{3}\right)$, such fluid volumes are quite small. Furthermore, one would expect that the 
fluid would be distributed over a significant portion of the repository volume so that creep closure would tend to isolate much of the fluid from a point of intrusion. Additionally, the effects of engineering measures to seal the disturbed zone and the effects of potential healing of fractures in the salt units due to reconsolidation have been neglected.

\subsubsection{Migration of Brine Inclusions}

Another source of potential infiltration is connate water residing in the formation that could be induced to migrate to the repository. One of these sources is expected to be the migration of brine inclusions in the salt toward the regions of higher temperature in the vicinity of the waste packages (C1aiborne et a1, 1980).

Recent predictions of such brine migration have been made for the reference repository designs and waste packages in the three sites (See Appendix F). These predictions are summarized in Table 6-9. These rates are based on an assumed brine content of the host salt of 5 percent by volume for the Palo Duro and Paradox sites and 0.5 percent by volume for the Richton Dome.

It is assumed that this water flows into the emplacement boreholes and then, as the boreholes fill, into the repository. The interaction of this water with the waste packages in the emplacement hole or other components of the engineered system is not considered. Temperatures in the vicinity of the waste package could be high enough to affect the flow and phase behavior of the water; however, it is assumed that any water that boils or evaporates simply recondenses in a cooler portion of the repository.

The maximum amount of water in the repository can be estimated just as in the previous section for the inflow through the shaft disturbed zone: the influx of brine continues at the estimated rates until saturation occurs. The predicted volumes of water on this basis are summarized in Table 6-10.

The total inflow in this model is about the same for both bedded salt sites since the temperature gradients and assumed water content of the host salt are similar in these two cases. The inflow rate for the Richton Dome is 
Table 6-9. Brine Migration at Sa1t Sites ${ }^{(a)}$

\begin{tabular}{|c|c|c|c|c|c|c|c|c|}
\hline \multirow[t]{2}{*}{ Site } & \multirow{2}{*}{$\begin{array}{l}\text { Waste } \\
\text { Package }\end{array}$} & \multicolumn{2}{|r|}{ Total } & Inflow & \multicolumn{2}{|c|}{ Per Package $\left(\mathrm{m}^{3}\right)$} & \multirow[b]{2}{*}{$50 \mathrm{yr}$} & \multirow[b]{2}{*}{$75 \mathrm{yr}$} \\
\hline & & $5 \mathrm{yr}$ & $10 \mathrm{yr}$ & $15 \mathrm{yr}$ & $20 \mathrm{yr}$ & $25 \mathrm{yr}$ & & \\
\hline \multirow[t]{2}{*}{ Palo Duro } & $\mathrm{SF}$ & 0.037 & 0.070 & 0.099 & 0.124 & 0.146 & -- & -- \\
\hline & CHLW & 0.220 & 0.36 & 0.46 & 0.53 & 0.58 & - & -- \\
\hline \multirow[t]{2}{*}{ Paradox } & $\mathrm{SF}$ & 0.043 & 0.080 & 0.11 & 0.14 & 0.17 & -- & - \\
\hline & CHLW & 0.26 & 0.43 & 0.54 & 0.61 & 0.67 & -- & -- \\
\hline \multirow[t]{2}{*}{ Richton } & $\mathrm{SF}$ & 0.0080 & 0.015 & 0.021 & 0.026 & 0.030 & 0.045 & 0.055 \\
\hline & CHLW & 0.042 & 0.066 & 0.082 & 0.095 & 0.10 & 0.13 & 0.14 \\
\hline
\end{tabular}

(a) See Appendix F. 
Table 6-10. Estimate of Total Water Influx to Repository $\left(\mathrm{m}^{3}\right)$

\begin{tabular}{llcc}
\hline Source & Palo Duro & Paradox & Richton \\
\hline $\begin{array}{l}\text { Heat-induced brine } \\
\text { migration }\end{array}$ & 3,320 & 3,100 & 930 \\
$\begin{array}{l}\text { Infiltration from shaft } \\
\text { disturbed zone }\end{array}$ & 120 & 310 & 160 \\
Total & 3,440 & 3,810 & 1,090 \\
\hline
\end{tabular}


an order of magnitude lower because the assumed water content is lower by this factor. The total inflow is not smaller by an order of magnitude, however|, because the time over which water inflow is perinitted is much longer.

As in the previous case of infiltration through the shaft disturbed zone, the total inflow from brine migration is quite small in comparison to the total void volume of the repository $\left(10^{6}\right.$ to $\left.10^{7} \mathrm{~m}^{3}\right)$. Furthermore, considering the nature of the flow, one would expect that the fluid would be distributed over an even larger portion of the repository than in the previous case so that creep closure would tend to isolate much of the fluid from a point of intrusion.

\subsubsection{Other Sources of Water}

Other sources of water in the formation may also be considered in the assessments. Some water could reside in 1nterbeds in saturated clays. Trace amounts of water could exist as water of crystallization in some of the minerals (e.g., polyhydrate, carnallite, bloedite) in the formation. The quantities would almost certainly be less than the amount in brine inclusions considered in the previous section (Claiborne et al, 1980), however.

Pockets of connate brine can exist in some salt formations and associated evaporate units. For example, small pockets (a few $\mathrm{m}^{3}$ or less) exist in the margins near the flanks of the Richton Dome. Further, relatively large brine pockets have been discovered in zones of high porosity in the anhydrite interbeds at the WIPP site. Brine pockets, however, are not expected to present a problem for two reasons. First, any brine pockets intersecting repository rooms will be drained when the rooms are excavated. Simflarly, if a brine pocket under a significant pressure has any hydraulic communication with a repository room, most flow should occur before engineered closure when gradients are largest. Second, creep closure and the low permeability of the salt should prevent signiflcant quantities of flow from entering the repository room in the time period between engineered closure and creep closure. 
6.3 RELEASE OF BRINE FROM THE REPOSITORY

The mechanisms considered for fluid inflow into the repository also may be considered as posstble release mechanisms for removing fluid from the repository. One such mechanism is flow through the interconnected porosity by near lithostatic fluid pressures within the repository. However, the low permeability of salt would present a formidable barrier to such flow.

Another is flow through the shaft seal system. As indicated previously, some flow through the shaft disturbed zone might be possible (see Table 6-8). During release, such flows likely would occur near or just prior to creep closure (20 to 70 years) at which time the repository backfill and the shaft disturbed zone would have sufficient permeability, due to incomplete consolidation, to permit such a release. In this case, however, just as in the previous case, fluid release would occur so soon after emplacement that the waste packages with expected life times of 10,000 years should prevent any contamination of the fluid.

Another possibility is that any fluid trapped within the repository by creep closure would, after contamination, migrate as a brine inclusion. The point of significance here, however, is that, since the driving mechanism is the thermal gradient, the repository heat would tend to contain such fluid, thereby preventing release.

Among the human intrusion events would be those of exploratory drilling and solution mining. However because of passive controls, such as widely distributed records and permanent markers, any inadvertent penetration would be unlikely.

\subsection{CONCLUSIONS FROM PRESSURE-RELEASE ANALYSES}

Based on the analyses presented above, the pressure release scenario is not a credible scenario. Several limiting factors underlie this assessment. Creep closure of the repository allows only 20 to 70 years for inflow and releases through the shaft disturbed zone. For such flows this time period is insufficient to permit degradation of the waste package and contamination of the fluld. Creep closure would hydraulically isolate a possible point of 


\section{CONCLUSIONS AND RECOMMENDATIONS FROM PRELIMINARY HUMAN INTERFERENCE SCENARIO ANALYSES}

Conclusions of the scenario analyses are discussed at the end of each of the sections describing these analyses. The conclusions for the U-Tub Connection Scenario, for example, are discussed in Section 4.4. The analyses for this scenario indicated negligible releases, six to eight orders of magnitude below the regulatory standards, for the conditions assumed. No uncertainty analysis has been performed; however, it can be concluded from the analyses that the calculated releases would be higher if the hydraulic conductivity in the flow tube were higher than the value assumed.

The conclusions from the analysis of the Single Borehole Intrusion Scenario are discussed in Section 5.5. The analyses of this scenario also indicated releases well below the proposed regulatory standards, even for the extreme conditions assumed. Again, no uncertainty analyses have yet been performed.

The conclusions that can presently be drawn from analysis of the Pressure Release Scenario are presented in Section 6.4. The conclusions note the preponderance of barriers and other limiting factors, which appear to render this scenario incredible. Consequently, no release rates are given.

In summary, in all the analyses of these human interference scenarios conducted to the present, no releases exceeding proposed regulatory standards were predicted. Furthermore, the analyses have been made using conservative assumptions such that more realistic models will likely predict smaller consequences or even preclude some of the scenarios altogether.

An important need of these assessments is the sensitivity and uncertainty analysis indicated above. From the conservative approach used, it is not likely that consideration of the range of uncertainty in properties and processes will result in any different conclusion than that already drawn; however, such analyses will be required in the licensing process and will provide further insight into repository performance. 
Such uncertainty analyses require data regarding the range of uncertainty in material properties and rates of relevant processes. From the perspective of the analyses that have already been conducted, information will be required to evaluate local flow conditions, thermal and thermomechanical conditions, salt dissolution rates, and the impact of insoluble materials freed from the rock in the course of dissolution. Specific data needs include:

- Local Flow Conditions - Data are needed to evaluate regional flow conditions and water avallability; local varlation in properties must be evaluated and continuity of lower transmissive units, including ability to recelve water, must be evaluated.

- Thermal and Thermomechanical Conditions - Average and local varlability in thermal properties of the formation should be evaluated; constitutive relations and in situ stresses should be appraised; because of the importance of creep closure to the conclusions reached for the Pressure Release Scenario, displacement rates for openings at depth should be observed; and reconsolidation data for crushed salt in these openings should be obtained.

- Salt Dissolution Rates - Dependence of these rates on flow rate, boundary layer conditions, and salt concentration should be measured and evaluated; preferential dissolution in repository openings due to increased surface area and other phenomena should be determined; effects of increased temperature in the repository should also be evaluated.

Another important need of these analyses is to take into account the performance of the waste package. This evaluation has not yet been conducted for two reasons. First, the evaluations of waste package performance made to date have taken into account only so-called expected conditions and have not explicitly considered conditions such as those discussed here resulting from unexpected human intrusion. Second, future licensing activities may well require evaluations of system performance which do not account for the performance of the waste package. Nevertheless, at some point a complete system analysis that takes into account the containment by the waste package 
human intrusion. Also, the unmeasurably small permeability of the intact salt severely limits inflows and releases through interconnected porosity within the salt.

Further, the movement of brine inclusions toward the repository heat source is insufficient to permit significant amounts of fluid to migrate into the repository prior to creep closure, and the direction of such movement would not permit contaminated inclusions to leave the repository region. The expected lifetime of the waste package (greater than 10,000 years) provides yet another barrier to the release of radioactive fluid from the repository. Finally, active and passive controls at the site make both inflows prior to creep closure and releases following such closure a highly unlikely event. 
and the impact of the waste package on the processes that might occur will have to be made. These updated analyses will still take into account waste form leach rates and solubility of the waste form constituents and the radionuclides; but, in addition, release of radionuclides to the water will Involve degradation rates for the waste package as well as the rate of release of radionuclides from the waste package subsystem.

Another requirement for the complete assessment of these scenarios is to evaluate the probability for the occurrence of the events leading to the scenarios and for some of the processes which have been assumed to take place within the scenario. These evaluations will include the estimations of the probability for drilling at the site to the depth required for the scenario. The impact of markers and other passive controls, including widely distributed records, upon such activities will need to be evaluated.

Finally, some scenarios have not yet been evaluated. Such scenarios include the "Direct Hit" Scenario, in which drilling makes direct contact with a waste package and brings its contents to the surface. This scenario has not been evaluated in these analyses because the probability of the event apparently dominates all analyses of this scenario. Future assessments that take into account these probabilities will be able to include evaluation of such scenarios. 
Battelle's Pacific Northwest Laboratories, 1979. Technology for Commercial Radioactive Waste Management, DOE/ET-0028, prepared for U.S. Department of Energy, Washington, DC.

Berry, Warren E., 1983. Durability of Marker Materials for Nuclear Waste Isolation Sites, ONWI-474, prepared by Battelle Columbus Laboratories for Office of Nuclear Waste Isolation, Battelle Memorial Institute, Columbus, $\mathrm{OH}$.

Bingham, F. W., and G. E. Barr, 1979. Scenarios for Long Term Release of Radionuclides from a Nuclear-Waste Repository in the Los Medanos Region of New Mexico, SAND78-1730, Sandia National Laboratories, Albuquerque, NM.

Bradshaw, N. L., and W. C. McClain, Eds., 1971. Project Salt Vault: A Demonstration of Disposal of High-Activity Solidified Waste in Underground Salt Mines, ORNL-4555, Oak Ridge National Laboratory, Union Carbide Corporation, Oak Ridge, TN.

Burkholder, H. C., 1983. Englneered Components for Radioactive Waste Isolation Systems--Are They Technically Justified?, ONWI-286, Office of Nuclear Waste Isolation, Battelle Memorial Institute, Columbus, $\mathrm{OH}$.

Claiborne, H. C., 1974. Potential Contalnment Failure Mechanisms and Their Consequences at a Radioactive Waste Repository In Bedded Sa1t in New Mexico, ORNL/TM-4639, Oak Ridge National Laboratory, Union Carbide Corporation, Oak Ridge, TN.

Claiborne, H. C., L. D. Rickertsen, and R. F. Graham, 1980. Expected Environments in High-Level Nuclear Waste and Spent Fuel Repositories in Salt, ORNL/TM-7201, Oak Ridge National Laboratory, Union Carbide Corporation, Oak Ridge, TN.

Cloninger, M. O., and C. R. Cole, 1981. A Reference Analysis on the Use of Engineered Barriers for Isolation of Spent Nuclear Fuel in Granite and Basalt, PNL-3530, Pacific Northwest Laboratory, Battelle Memorial Institute, Richland, WA. 
Cloninger, M. 0., C. R. Cole, and J. F. Washburn, 1980, An Analysis on the Use of Engineered Barriers for Geologic Isolation of Spent Fuel in a Reference

Salt Site Repository, PNL-3356, prepared for U.S. Department of Energy by Pacific Northwest Laboratory, Battelle Memorial Institute, Richland, WA.

Cranwell, R. M., R. L. Iman, J. E. Campbel1, J. C. Helton, D. E. Longsine, N. R. Ortiz, G. E. Runkle, and M. J. Shortencarier, 1982a. Risk Methodology for Geologic Disposal of Radioactive Wastes: Fina1 Report, SAND81-2573, NUREG/CR-2452, Sandia National Laboratories, Albuquerque, NM.

Cranwe11, R. M., J. E. Campbe11, and S. E. Stuckwisch, 1982b. Risk Methodology for Geologic Disposal of Radioactive Waste: The DNET 'Computer Code User's Manua1, NUREG/CR-2343 or SAND81-1663, Sandia National

Laboratories, Albuquerque, NM.

DOE, see U.S. Department of Energy.

Durie, R. W., and F. W. Jessen, 1964. "Mechanism of the Dissolution of Salt In the Formation of Underground Salt Cavities," Society of Petroleum Engineers Journal, AIME, Vol. 231, p. 183.

Durie, R. W., 1963. "The Boundary Region in the Salt Dissolution Process," Ph.D. Thesis, University of Texas, Austin, TX.

Fournier, R. 0., and J. J. Rowe, 1977. "The Solubility of Amorphous Silica in Water at High Temperatures and High Pressures," American Mineralogist No. 62, p. 1052 .

Gevantman, L. H., Ed., 1981. Physical Properties Data for Rock Salt, National Bureau of Standards Monograph 167, Washington, DC.

Gulffre, M. S., M. F. Kaplan, D. A. Ensminger, S. G. Oston, and J. Y. Nalbandian, 1980. Bedded-Salt Repository Analysis: Final Report, UCRL-15236, prepared by the Analytic Sciences Corporation for Lawrence Livermore Laboratory, University of California, Livermore, CA. 
Gureghian, A. B., L. A. Scott, and G. E. Raines, 1983. Performance Assessment of a Shaft Seals System in an HLW Repository in the Gibson Dome Area, ONWI494, Office of Nuclear Waste Isolation, Battelle Memorial Institute, Columbus, $\mathrm{OH}$.

Harwe11, Mark A., Albin Brandstetter, Gary L. Benson, John R. Raymond, Don J. Bradley, R. Jeff Serne, Joseph K. Soldat, Charles R. Cole, William J. Deutsch, Sumant K. Gupta, Christine C. Harwe11, Bruce A. Napier, Andrew E. Reisenauer, Leigh S. Prater, C. Steve Simmons, Dennis L. Strenge, Jeffrey F. Washburn, and John T. Zellmer, 1982. Reference Site Initial Assessment for a Sa1t Dome Repository, PNL-2955, prepared for U.S. Department of Energy by Pacific Northwest Laboratory, Battelle Memorial Institute, Richland, WA.

Hohlfelder, Jacque J., 1980. Salt Block II: Description and Results, SAND792228, Sandia National Laboratories, Albuquerque, NM.

INTERA Environmental Consultants, Inc., 1983a. VISCOT: A Two-Dimenstonal and Axisymmetric Nonlinear Transient Thermoviscoelastic and Thermoviscoplastic Finite-Element Code for Modeling Time-Dependent Viscous Mechanical Behavior of a Rock Mass, ONWI-437, prepared for Office of Nuclear Waste Isolation, Battelle Memorial Institute, Columbus, OH.

INTERA Environmental Consultants, Inc., 1983b. SWENT: A Three-Dimensional Fintte-Difference Code for the Simulation of Fluid, Energy and Solute Radionuclide Transport, ONWI-457, prepared for Office of Nuclear Waste Isolation, Battelle Memorial Institute, Columbus, $\mathrm{OH}$.

INTERA Environmental Consultants, Inc., 1984a. First Status Report on Reglonal Ground-Water Flow Modeling for the Palo Duro Basin, Texas, ONWI-504, prepared for Office of Nuclear Waste Isolation, Battelle Memorial Institute, Columbus, $\mathrm{OH}$.

INTERA Environmental Consultants, Inc., 1984b. First Status Report on Regional Ground-Water Flow Modeling for Paradox Basin, Utah, ONWI-503, prepared for office of Nuclear Waste Isolation, Battelle Memorial Institute, Columbus, $\mathrm{OH}$. 
INTERA Environmental Consultants, Inc., 1984c. First Status Report on Regional and Local Ground-Water Flow Modeling for Richton Dome, Mississippi, ONWI-502, prepared for Office of Nuclear Waste Isolation, Battelle Memorial Institute, Columbus, $\mathrm{OH}$.

INTERA Environmenta1 Consultants, Inc., 1984d. BORHOL: A Computer Code to Evaluate Dissolution, Precipitation, Creep, and Temperature Effects in Boreholes in Salt, BMI/ONWI-547, prepared for Office of Nuclear Waste Isolation, Battelle Memorial Institute, Columbus, $\mathrm{OH}$.

Jessen, F. W., 1971. "Total Solution Mechanism," Transactions of the Society of Mining Englneers, AIME, Vo1. 250, p. 298.

Katayama, Y. B., D. J. Bradley, and C. 0. Harvey, 1980. Status Report on LWR Spent Fuel IAEA Leach Rates, PNL-3173, prepared for U.S. Department of Energy by Pacific Northwest Laboratory, Battelle Memorial Institute, Richland, WA.

Kelsall, P. C., J. B. Case, W. E. Coons, J. G. Franzone, and D. Meyer, 1985. Schematic Designs for Penetration Seals for a Repository in the Permian Basin, BMI/ONWI-564, prepared by D'Appolonia Consulting Engineers, Inc., for Office of Nuclear Waste Isolation, Battelle Memorial Institute, Columbus, $\mathrm{OH}$.

Lanner, D., 1983. "Can yonlands or No-Man's Land? A Proposed Nuclear Waste Dump Threatens the Park", Sierra, Vol. 68, No. 4, pp. 17-20.

Law Englneering Testing Company, 1982. Gulf Coast Salt Domes Geologic Area Characterization Report, Mississippi Study Area, Vols. VI and VII, ONWI-120, prepared for Office of Nuclear Waste Isolation, Battelle Memorial Institute, Columbus, $\mathrm{OH}$.

McCleary, Jeff, Tom Rogers, and Richard Ely, 1983. Stratigraphy, Structure, and Lithofacies Relationships of Devonian Through Permian Sedimentary Rocks: Paradox Basin and Adjacent Areas - Southeastern Utah, ONWI-485, prepared by Woodward-Clyde Consultants for Office of Nuclear Waste Isolation, Battelle Memorial Institute, Columbus, $\mathrm{OH}$. 
Means, R. E., and T. V. Parcher, 1963. Physical Properties of Solls, Charles E. Merrill Books, Inc., Columbus, $\mathrm{OH}$.

Mende1, J. E., 1978. The Storage and Disposal of Radioactive Waste as Glass in Canisters, PNL-2764, Pacific Northwest Laboratory, Battelle Memorial Institute, Richland, WA.

Muller, A. B., N. C. Finley, and F. J. Pearson, Jr., 1981. Geochemical Parameters Used in the Bedded Salt Reference Repository Risk Assessment Methodology, NUREG/CR-1996, Sandia National Laboratories, Albuquerque, NM.

NRC, see U.S. Nuclear Regulatory Commission.

Pepping, R. E., M. S. Y. Chu, K. K. Wahi, and N. R. Ortiz, 1983. Risk Analysis Methodology for Spent Fuel Repositories in Bedded Salt: Final Report, NUREG/CR-2402, SAND81-2409, Sandia National Laboratories, Albuquerque, NM.

Pfeifle, Tom. W., Kirby D. Mellegard, and Paul E. Senseny, 1981. Constitutive Properties of Salt from Four Sites, ONWI-314, prepared by RE/SPEC Inc. for office of Nuclear Waste Isolation, Battelle Memorial Institute, Columbus, $\mathrm{OH}$.

Richards, L. A., 1931. "Capillary Conduction of Liquids through Porous Media", Physics, Vol. 1, pp. 318-333.

Saberian, Ahmed, and A.L. Podio, 1976. "A Numerical Model for Development of Solution Mined Cavities", Proceedings of Symposium on Salt Dome Utilization and Environmental Considerations, Louisiana State University, Nov. 22-24, 1976, Joseph D. Martinez and Robert L. Thoms, Eds., Institute for Environmental Studies, Louisiana State University, Baton Rouge, LA.

Snow, R. H., and D. C. Chang, 1975. Prediction of Cavity Growth by Solution of Salt Around Boreholes, IITRI C6313-14, IIT Research Institute, Chicago, IL.

Stone \& Webster Engineering Corporation, 1983. Area Geological Characterization Report for Palo Duro and Dalhart Basin Texas, DOE/CH/10140-1, 
prepared for Office of Civilian Radioactive Waste Management, U.S. Department of Energy, Washington, DC.

Tien, Pei-lin, F. B. Nimick, A. B. Muller, P. A. Davis, R. V. Guzowski, L. E. Duda, and R. L. Hunter, 1983. Repository Site Data and Information in Bedded Sa1t: Palo Duro Basin, Texas, NUREG/CR-3129, prepared for U.S. Nuclear Regulatory Commission by Sandia National Laboratories, Albuquerque, NM.

Touloukian, U. S., W. R. Judd, and R. F. Roy, 1981. Physical Properties of Rocks and Mines, McGraw Hi11/CINDAS Data Service on Materia1 Properties, McGraw-Hi11 Book Company, New York, NY.

U.S. Department of Energy, 1980. Final Environmental Impact Statement, Management of Commercially Generated Radioactive Waste, DOE/EIS-0046F, Washington, DC.

U.S. Department of Energy, 1983. Waste Isolation P1lot Plant Safety Analysis Report, Albuquerque Operations office, Albuquerque, NM.

U.S. Environmental Protection Agency, 1982. "Environmental Standards for the Management and Disposal of Spent Nuclear Fuel, High-Level and Transuranic Radioactive Wastes" (40 CFR Part 191), Federal Register (47 FR 58196), Washington, DC, December 29.

U.S. Nuclear Regulatory Commission, 1983. "Disposal of High-Level Radioactive Wastes in Geologic Repositories; Technical Criteria" (10 CFR Part 60), Final Rule, Federal Register (48 FR 28194), Washington, DC, June 21.

Wagner, R. A., 1980. Preliminary Investigation of the Thermal and Structural Influence of Crushed-Sa1t Backfill on Repository Disposal Rooms, ONWI-138, prepared by RE/SPEC Inc. for Office of Nuclear Waste Isolation, Battelle Memorial Institute, Columbus, $\mathrm{OH}$.

Wagner, Ralph A., Marc C. Loken, and Hans Y. Tammemagi, 1985. Preliminary Thermomechanical Analyses of a Conceptual Nuclear Waste Repository at Four Salt Sites, BMI/ONWI-512, prepared by RE/SPEC Inc. for Office of Nuclear Waste 
APPENDIX A

DETAILS OF LOCAL MODELS

\section{A.1 PALO DURO BASIN REPRESENTATION}

The representation for this site used in the local ground-water flow modeling has been described in Sections 4.1.1 and 5.1.1. The location of the model and the local grid used to represent the site are given in these sections (Figures $4-3$ and 5-2). Not specified in these discussions are the pressure boundary conditions. The conditions used are given here in Table A-1. This table gives the pressure at the top of the aquifers inferred from the regional modeling of the basin (INTERA, 1984a)* for the edges of the local model.

\section{A.2 PARADOX BASIN LOCAL REPRESENTATION}

The local representation for the Paradox Basin has been discussed in Section 4.1 .2 and 5.1.2. In those sections it is mentioned that variation in thickness and elevation in the various layers are taken into account. The specific variation in the geometry used in the analyses is given here.

In the representation used in the analysis, the vertical section is composed of seven layers. The top two layers vary in thickness. The thickness of layers 3 and 4 are fixed at 244 and $122 \mathrm{~m}$, respectively. The fifth layer has variable thickness, while the sixth layer has a constant thickness of $22.9 \mathrm{~m}$. The last layer represents the repository and is chosen at $6.4 \mathrm{~m}$ in thickness. The thickness of layers 1,2 , and 5 is given in Table A. 2. Also given in Table A-2 is the elevation of the surface (top of layer 1). From this information, the vertical discretization throughout the local regime can be completely specified. The relevant grid blocks are shown in Figure 4-6.

The pressures at the boundaries of the local model utilized in the analyses are given in Table A-3. The pressures in Table A-3 are the values at the top of the aquifers and have been inferred from the regional modeling of these units in the Paradox Basin (INTERA, 1984b). 
Table A-1. Pressure Boundary Conditions for Palo Duro Basin Loca1 Ground-Water F1ow Modeling

Location Relative to

Center of Grid

$x(m) \quad y(m)$
Pressure (MPa) at Top of Unit

Ogallala

Dockum

Wolf camp

$\begin{array}{rr}-9,656 & -5,230 \\ -9,656 & -3,018 \\ -9,656 & -1,408 \\ -9,656 & -503 \\ -9,656 & 0 \\ -9,656 & 503 \\ -9,656 & 1,408 \\ -9,656 & 3,018 \\ -9,656 & 5,230 \\ 9,656 & -5,230 \\ 9,656 & -3,018 \\ 9,656 & -1,408 \\ 9,656 & -503 \\ 9,656 & 0 \\ 9,656 & 503 \\ 9,656 & 1,408 \\ 9,656 & 3,018 \\ 9,656 & 5,230 \\ -8,046 & -9,656 \\ -5,230 & -9,656 \\ -3,018 & -9,656 \\ -1,408 & -9,656 \\ -503 & -9,656\end{array}$

$\begin{array}{rll}0 & 1.046 & 13.630 \\ -0.006 & 1.040 & 13.636 \\ -0.012 & 1.034 & 13.641 \\ -0.015 & 1.031 & 13.642 \\ -0.015 & 1.031 & 13.644 \\ -0.018 & 1.028 & 13.644 \\ -0.021 & 1.025 & 13.646 \\ -0.030 & 1.016 & 13.656 \\ -0.039 & 1.007 & 13.678 \\ -0.293 & 0.753 & 13.145 \\ -0.296 & 0.750 & 13.142 \\ -0.302 & 0.744 & 13.138 \\ -0.305 & 0.741 & 13.138 \\ -0.305 & 0.741 & 13.136 \\ -0.308 & 0.738 & 13.135 \\ -0.311 & 0.735 & 13.133 \\ -0.320 & 0.726 & 13.129 \\ -0.332 & 0.714 & 13.124 \\ -0.009 & 1.037 & 13.573 \\ -0.045 & 1.001 & 13.484 \\ -0.072 & 0.974 & 13.452 \\ -0.093 & 0.953 & 13.415 \\ -0.105 & 0.941 & 13.390\end{array}$


Location Relative to

$\frac{\text { Center of Grid }}{x(m)}$

$\begin{array}{rr}0 & -9,656 \\ 503 & -9,656 \\ 1,408 & -9,656 \\ 3,018 & -9,656 \\ 5,230 & -9,656 \\ 8,046 & -9,656 \\ -8,046 & 9,656 \\ -5,230 & 9,656 \\ -3,018 & 9,656 \\ -1,408 & 9,656 \\ -503 & 9,656 \\ 0 & 9,656 \\ 503 & 9,656 \\ 1,408 & 9,656 \\ 3,018 & 9,656 \\ 5,230 & 9,656 \\ 8,046 & 9,656\end{array}$

Pressure (MPa) at Top of Unit

Ogallala

Dockum

Wolf camp
$-0.111$

$-0.120$

$-0.135$

$-0.165$

$-0.203$

$-0.251$

$-0.078$

$-0.081$

$-0.108$

$-0.156$

$-0.168$

$-0.174$

$-0.183$

$-0.200$

$-0.230$

$-0.272$

$-0.326$
0.935

0.926

0.911

0.881

0.842

0.795

0.968

0.964

0.938

0.890

0.878

0.872

0.863

0.845

0.815

0.774

0.720
13.378

13.368

13.350

13.311

13.259

13.190

13.678

13.579

13.508

14.461

13.434

13.417

13.402

13. 373

13.325

13.260

13.175 
Table A-2. Thickness of Layers in Paradox Site Mode1

\begin{tabular}{|c|c|c|c|c|c|}
\hline \multirow{2}{*}{$\begin{array}{l}X-D i \text { rection } \\
\text { Grid Blocks }\end{array}$} & Y-Direction & \multirow{2}{*}{$\begin{array}{l}\text { Surface Elevation } \\
\text { (m) }\end{array}$} & \multicolumn{3}{|c|}{ Layer Thickness (m) } \\
\hline & Grid Blocks & & Layer 1 & Layer 2 & Layer 5 \\
\hline 1 & $1-3$ & 1,710 & 107 & 229 & 99 \\
\hline 2 & $1-3$ & 1,680 & 152 & 213 & 99 \\
\hline 3 & 1 & 1,650 & 152 & 244 & 99 \\
\hline 3 & 2 & 1,740 & 244 & 244 & 99 \\
\hline 3 & 3 & 1,650 & 152 & 244 & 99 \\
\hline $4-6$ & $1-3$ & 1,650 & 152 & 244 & 99 \\
\hline 7 & 1 & 1,650 & 152 & 244 & 99 \\
\hline $8-9$ & 1 & 1,550 & 61 & 244 & 99 \\
\hline $10-12$ & 1 & 1,650 & 198 & 229 & 99 \\
\hline $7-11$ & $2-3$ & 1,580 & 137 & 229 & 114 \\
\hline 12 & $2-3$ & 1,650 & 198 & 244 & 108 \\
\hline 13 & 1 & 1,650 & 198 & 244 & 108 \\
\hline 13 & 2 & 1,620 & 168 & 244 & 108 \\
\hline 13 & 3 & 1,650 & 198 & 244 & 108 \\
\hline 14 & $1-3$ & 1,580 & 183 & 244 & 114 \\
\hline 15 & $1-2$ & 1,710 & 305 & 244 & 114 \\
\hline 15 & 3 & 1,580 & 183 & 244 & 114 \\
\hline 1 & $4-8$ & 1,680 & 114 & 221 & 99 \\
\hline 2 & $4-8$ & 1,630 & 130 & 213 & 9.9 \\
\hline $3-8$ & $4-8$ & 1,590 & 122 & 244 & 99 \\
\hline $9-13$ & $4-8$ & 1,590 & 152 & 236 & 130 \\
\hline $14-15$ & $4-8$ & 1,590 & 198 & 244 & 107 \\
\hline 1 & 9 & 1,650 & 122 & 274 & 99 \\
\hline 2 & 9 & 1,580 & 107 & 213 & 99 \\
\hline $3-6$ & 9 & 1,550 & 107 & 229 & 99 \\
\hline $7-9$ & 9 & 1,550 & 107 & 229 & 114 \\
\hline $10-12$ & 9 & 1,520 & 114 & 236 & 99 \\
\hline
\end{tabular}


Table A-2 (Continued)

\begin{tabular}{llcl}
\hline X-Direction & Y-Direction & Surface Elevation & \multicolumn{2}{c}{ Layer Thickness (m) } \\
Grid Blocks & Grid Blocks & (m) & Layer 1 Layer 2 Layer 5 \\
\hline
\end{tabular}

$\begin{array}{llrrrr}13 & 9 & 1,510 & 99 & 236 & 99 \\ 14-15 & 9 & 1,550 & 183 & 244 & 99 \\ 1 & 10 & 1,580 & 107 & 198 & 130 \\ 2 & 10 & 1,580 & 137 & 198 & 160 \\ 3 & 10 & 1,550 & 137 & 198 & 160 \\ 4-8 & 10 & 1,580 & 168 & 198 & 160 \\ 9-12 & 10 & 1,550 & 168 & 229 & 130 \\ 13 & 10 & 1,490 & 107 & 229 & 130 \\ 14-15 & 10 & 1,520 & 168 & 259 & 99 \\ 1 & 11 & 1,520 & 91 & 183 & 160 \\ 2 & 11 & 1,520 & 107 & 213 & 160 \\ 3-6 & 11 & 1,520 & 122 & 244 & 145 \\ 7-8 & 11 & 1,490 & 91 & 243 & 145 \\ 9-11 & 11 & 1,490 & 122 & 259 & 130 \\ 12 & 11 & 1,460 & 91 & 259 & 130 \\ 13-15 & 11 & 1,520 & 183 & 274 & 114\end{array}$


Table A-3. Pressure Boundary Conditions for Paradox Basin Local Ground-Water Flow Modeling

Location Relative to Center of Grid

$x(m) \quad y(m)$
Pressure (MPa) at Top of Unit

Elephant Honaker Pinkerton Molas Canyon Trail Trail Leadville

$\begin{array}{rrrrrr}-5,334 & -3,429 & 0.501 & 2.749 & 9.195 & 10.690 \\ -5,334 & -2,865 & 0.397 & 2.646 & 9.177 & 10.672 \\ -5,334 & -2,591 & 0.720 & 2.896 & 9.468 & 10.963 \\ -5,334 & -2,317 & 0.670 & 2.846 & 9.459 & 10.954 \\ -5,334 & -1,753 & 0.566 & 2.743 & 9.442 & 10.937 \\ -5,334 & -610 & 0.729 & 2.835 & 10.303 & 11.798 \\ -5,334 & 1,219 & 0.844 & 2.799 & 10.849 & 12.344 \\ 5,334 & -3,429 & 2.960 & 5.356 & 11.979 & 13.473 \\ 5,334 & -2,865 & 2.897 & 5.292 & 11.961 & 13.455 \\ 5,334 & -2,591 & 3.015 & 5.410 & 13.074 & 14.567 \\ 5,334 & -2,317 & 2.984 & 5.379 & 13.065 & 14.558 \\ 5,334 & -1,753 & 2.921 & 5.315 & 13.047 & 14.540 \\ 5,334 & -610 & 2.941 & 5.334 & 14.131 & 15.624 \\ 5,334 & 1,219 & 2.870 & 5.408 & 15.572 & 17.065 \\ -4,153 & -5,334 & 0.877 & 3.120 & 9.286 & 10.781 \\ -2,057 & -5,334 & 1.669 & 3.762 & 10.239 & 11.734 \\ -686 & -5,334 & 1.997 & 4.389 & 11.173 & 12.668 \\ 0 & -5,334 & 2.012 & 4.404 & 11.192 & 12.687 \\ 351 & -5,334 & 2.030 & 4.422 & 11.198 & 12.693 \\ 716 & -5,334 & 2.048 & 4.441 & 11.205 & 12.700 \\ 1,448 & -5,334 & 2.084 & 4.478 & 11.219 & 12.714 \\ 2,180 & -5,334 & 2.569 & 4.814 & 11.532 & 13.027 \\ 2,545 & -5,334 & 2.588 & 4.833 & 11.539 & 13.034\end{array}$


Table A-3 (Continued)

Location Relative to $\frac{\text { Center of Grid }}{\mathrm{x}(\mathrm{m})}$
Pressure (MPa) at Top of Unit

Elephant Honaker Pinkerton Molas

Canyon Trail Trail Leadville

\begin{tabular}{rrrrrr}
\hline 2,858 & $-5,334$ & 2.603 & 4.998 & 11.844 & 13.339 \\
3,429 & $-5,334$ & 3.080 & 5.476 & 12.004 & 13.499 \\
4,572 & $-5,334$ & 3.137 & 5.534 & 12.026 & 13.521 \\
$-4,153$ & 5,334 & 0.495 & 2.301 & 11.365 & 12.860 \\
$-2,057$ & 5,334 & 0.551 & 2.684 & 12.614 & 14.109 \\
-686 & 5,334 & 0.640 & 3.089 & 13.844 & 15.339 \\
0 & 5,334 & 0.610 & 3.068 & 13.862 & 15.357 \\
351 & 5,334 & 0.695 & 3.147 & 13.868 & 15.363 \\
716 & 5,334 & 0.783 & 3.230 & 13.875 & 15.370 \\
1,448 & 5,334 & 1.259 & 3.845 & 14.487 & 15.982 \\
2,180 & 5,334 & 1.436 & 4.011 & 14.501 & 15.996 \\
2,545 & 5,334 & 1.525 & 4.094 & 14.508 & 16.003 \\
2,850 & 5,334 & 1.601 & 4.165 & 14.514 & 16.009 \\
3,429 & 5,334 & 2.038 & 4.743 & 15.123 & 16.618 \\
4,572 & 5,334 & 2.315 & 5.003 & 15.145 & 16.640 \\
\hline
\end{tabular}




\section{A.3 RICHTON DOME LOCAL REPRESENTATION}

The representation for this site is discussed in Section 4.1.3. As described there, the thicknesses of the subsurface layers in the vertical representation are assumed to be constant. These thicknesses are given in Figure 4-10. However, the surface elevation and the thickness of the top layer vary over the local regime. When these two parameters are specified, the entire vertical representation is determined. The dip in the slope of the subsurface layers is specified in INTERA (1984c) as $6 \mathrm{~m} / \mathrm{km}$ going from north to south. Th1s variation is used to specify the elevation of all subsurface units. The surface elevation corresponds to the phreatic surface, and this is given in Figure A-1. The pressure boundary conditions used in the local modeling are given in Table A-4. These are pressures at the top of the respective units as inferred from the reglonal modeling. 


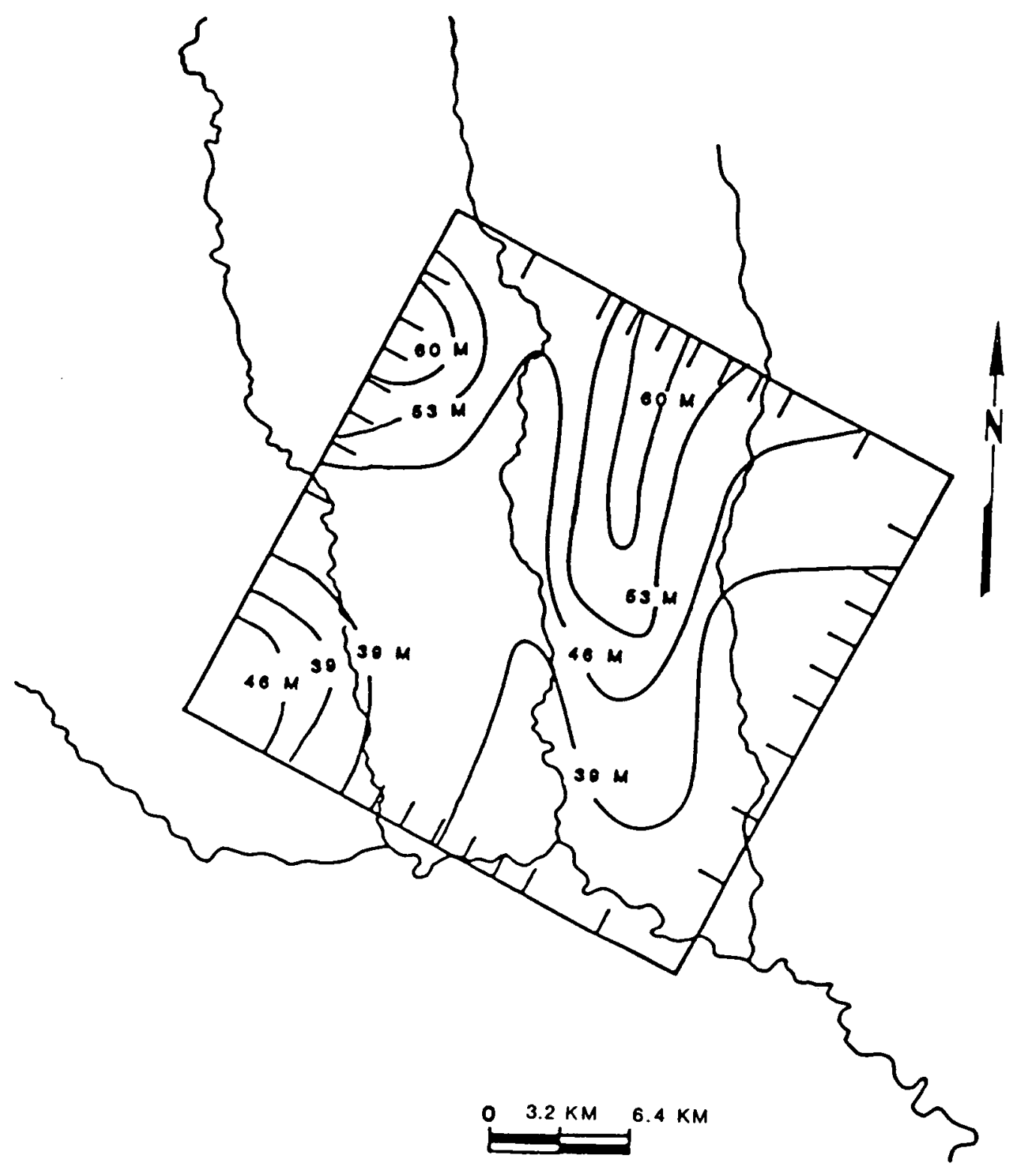

Figure A-1. Phreatic Surface for Local Model of Richton Site 
Table A-4. Pressure Boundary Conditions for R1chton Dome

Loca1 Ground-Water Flow Modeling

\section{Location Relative to Grid Center} $x(m)$ $y(m)$

Pressure (MPa) at Top of Unit

Hattiesburg

Catahoula

0.494

1.316

0.494

1.316

$-12,875$

$-6,840$

0.494

1.316

$-2,414$

0.554

1.376

$-805$

805

2,414

4,023

6,840

10,863

$-10,863$

$-6,840$

$-4,023$

$-2,414$

$-805$

805

2,414

4,023

6,840

10,863

$-12,875$

$-12,875$

0.613

1.436

0.643

1.466

0.643

1.466

0.554

1.376

0.494

1.316

0.524

1.346

1.606

2.428

1.606

2.428

1.606

2.428

1.651

2.473

1.680

2.503

1.725

2.548

1.725

2.548

1.680

2.503

1.651

2.473

1.815

2.637

0.627

1.450

0.699

1.522

0.763

1.585

0.826 
Isolation, Battelle Memorial Institute, Columbus, $\mathrm{OH}$.

Walters, R. F., 1975. Salt Dissolution In 0il and Gas Test Holes In Central Kansas, ORNL/SUB-75/38283/1, Walters Drilling Company, prepared for Oak Ridge Nationa1 Laboratory, Union Carbide Corporation, Oak Ridge, TN.

Waste Isolation Pilot P1ant, 1983. Brine Reservoirs in the Castile Formation - Waste Isolation P1lot Plant (WIPP) Project - Southeastern New Mexico, TME3153, U.S. Department of Energy, Waste Isolation Pllot Plant, Albuquerque, NM. Weast, Robert C., Ed., 1973. Handbook of Chemistry and Physics, CRC Press, The Chemica1 Rubber Company, Cleveland, $\mathrm{OH}$.

Wiley, J. R., 1979. "Leach Rates of High Activity Waste from Borosilicate Glass", Nuclear Technology, No. 43, p. 268.

Woodward-Clyde Consultants, 1982. Geologic Characterization Report for the Paradox Basin Study Region Utah Study Areas, ONWI-290, prepared for Office of Nuclear Waste Isolation, Battelle Memorial Institute, Columbus $\mathrm{OH}$. 
Table A-4 (Continued)

Location Relative to Grid Center

$\overline{x(m)} y(m)$

$-1,609$

$-12,875$

$-402$

3,217

6,437

$-8,449$

$-6,437$

$-4,828$

$-3,219$

$-1,609$

$-402$

3,217

6,437
$-12,875$

$-12,875$

$-12,875$

12,875

12,875

12,875

12,875

12,875

12,875

12,875

12,875
Pressure (MPa) at Top of Unit

Hattiesburg

Catahoula

0.905

1.727

1.022

1.844

1.185

2.007

1.447

2.264

0.807

1.629

0.983

1.806

1.017

1.839

1.021

1.843

1.054

1.877

1.171

1.993

1.260

2.082

1.432

2.254 
APPENDIX B

A SIMPLE MODEL FOR THE U-TUBE FLOW

A simple, one-dimensional model for the U-Tube is indicated in Figure $B-1$.

The flow in the upper aquifer is represented by the flow in resistances $R_{1}$ and $R_{2}$. The resistance in the $U$-Tube is indicated as $R_{3}$. Dissolution of salt in the U-Tube is assumed to occur near the entrance of the U-Tube and is indicated by the mass flux, $M_{b}$. Likewise, instantaneous dilution of the $\mathrm{U}$-Tube flow is assumed to occur at the exit, as indicated by the flux, $\mathrm{M}_{c}$. Momentum conservation at the entrance and exit of the U-Tube gives:

$$
\begin{aligned}
& v_{1}+M_{b} / \rho_{s}=v_{3} \\
& v_{2}+M_{c} / \rho_{s}=v_{3}
\end{aligned}
$$

In this case, $\rho_{s}$ is an effective density of the salt in solution, and $V$ is the volumetric flux.

Mass conservation at the nodes gives:

$$
\begin{aligned}
& \rho_{1} v_{1}+M_{b}=\rho_{3} V_{3} \\
& \rho_{2} v_{2}+M_{c}=\rho_{3} v_{3}
\end{aligned}
$$

where $\rho_{i}$ is the density in leg 1 . Elimination of the salt source and sinks results in:

$$
\begin{aligned}
& v_{1}=v_{3}\left(\rho_{s} \rho_{3}\right) /\left(\rho_{s} \rho_{1}\right) \\
& v_{2}=v_{3}\left(\rho_{s} \rho_{3}\right) /\left(\rho_{s} \rho_{2}\right)
\end{aligned}
$$




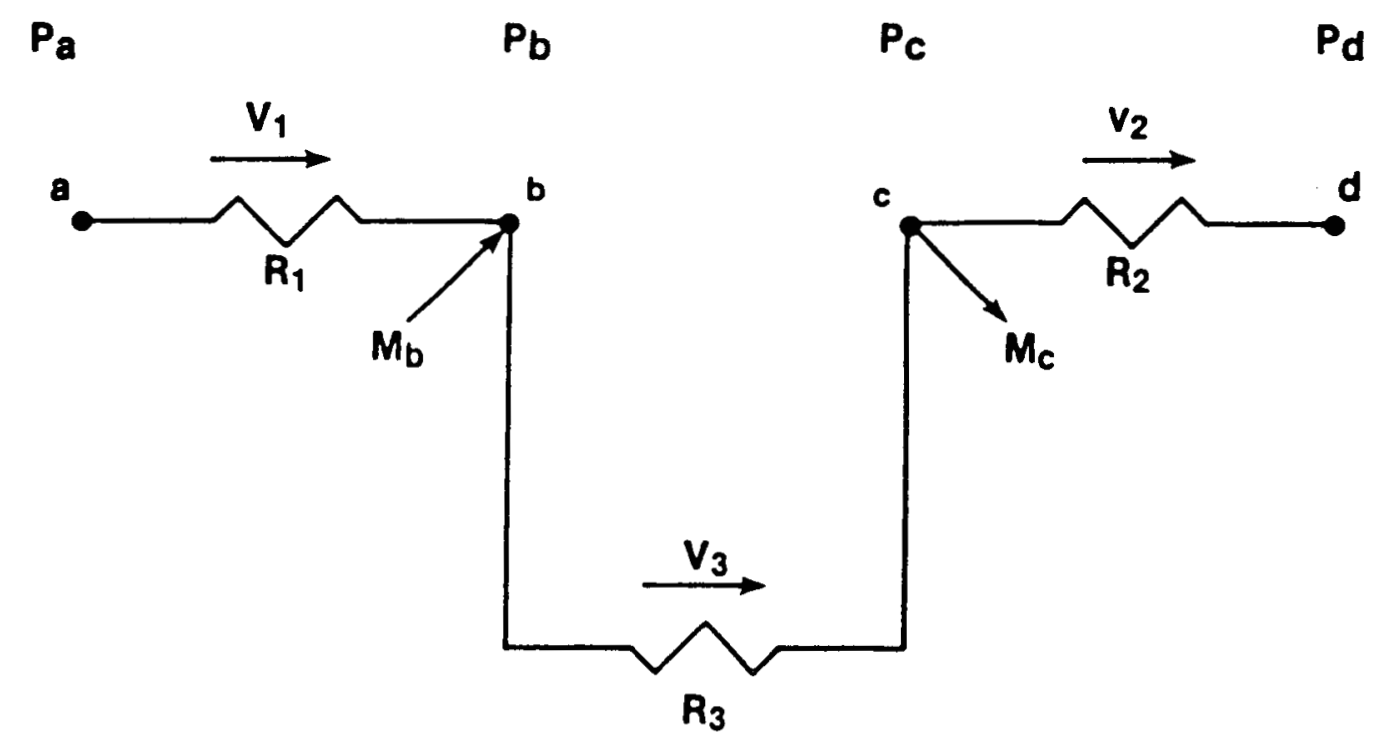

F1gure B-1. Schematic of Simple U-Tube F1ow Model 
By Darcy's Law:

$$
\begin{aligned}
& P_{b}=P_{a}-R_{1} V_{1} \\
& P_{c}=P_{d}+R_{2} V_{2}
\end{aligned}
$$

where $\mathrm{P}_{\alpha}$ is the pressure at the $\alpha$ node. Since

$$
V_{3} R_{3}=P_{b}-P_{c}
$$

the velocity in the U-Tube can be evaluated from

$$
\begin{aligned}
& V_{3} R_{3}=P_{a}-P_{d}-V_{1} R_{1}-V_{2} R_{2} \\
& =\Delta P-R_{1} V_{3}\left(\rho_{s} \rho_{3}\right) /\left(\rho_{s} \rho_{1}\right)-R_{2} V_{3}\left(\rho_{s}-\rho_{3}\right) /\left(\rho_{s}-\rho_{2}\right)
\end{aligned}
$$

where $\Delta P$ is the total pressure drop in the system. The expression for the specific discharge through the U-Tube is

$$
v_{3}=\Delta \mathrm{P} /\left[\mathrm{R}_{3}+\left(\rho_{s} p_{3}\right)\right]\left[\mathrm{R}_{1} /\left(\rho_{s} p_{1}\right)+\mathrm{R}_{2} /\left(\rho_{s} p_{2}\right)\right]
$$

Setting the aquifer densities equal

$$
\rho_{1}=\rho_{2}=\rho_{0}
$$

and setting

$$
R_{0}=R_{1}+R_{2}
$$

the discharge becomes

$$
v_{3}=\Delta P /\left[R_{3}+R_{0}\left(p_{s} p_{3}\right)\right] /\left(p_{s} p_{0}\right)
$$


For the case where the U-Tube resistance is large relative to the aquifer resistance, the $U$-Tube flow satisfies

$$
V_{3} \simeq \Delta P / R_{3}
$$

The volumetric flow is essentially independent of the density in the U-Tube and is inversely proportional to the resistance (1.e., depends linearly on the permeablity). The mass flow rate is:

$$
\rho_{3} V_{3} \simeq \Delta \mathrm{P}_{3} / \mathrm{R}_{3}
$$

and is proportional to the density. If the U-Tube resistance is negligible relative to the aquifer resistance,

$$
V_{3} \simeq \Delta P\left(p_{s}-\rho_{0}\right) / R_{0}\left(\rho_{s}-p_{3}\right)
$$

In this case, the volumetric flow does not depend on the U-Tube resistance (open-U-Tube condition) but on the density. The mass flow rate is given by:

$$
\rho_{3} V_{3} \simeq \Delta p_{3}\left(\rho_{s} \rho_{0}\right) / R_{0}\left(\rho_{s} \rho_{3}\right)
$$


APPENDIX C

DESCRIPTION OF BOREHOL SCENARIO CODE

The BORHOL code has been developed to assist in the asessments of scenarios involving dissolution of salt at the repository horizon (INTERA, 1984d).

A simple approach to the problem is tllustrated in Figure C-1. In this model, it is assumed that dissolution occurs uniformly in all salt layers preceding and including the repository horizon. Furthermore, it is assumed that this dissolution saturates the flow. The dissolution rate at the repository horizon is determined by the amount of salt in the formation, the borehole flow rate, the salinity in the incoming water, and the solubility of the salt.

This crude model ignores many phenomena that can affect the dissolution rate dramatically. Some of these are illustrated in the sketch in Figure C-2. For example, most of the salt dissolution will occur in the salt layers initially encountered by the flow. As the water becomes saturated downstream, less dissolution occurs. The dissolution at the repository horizon may therefore be substantially reduced below the crude estimate in the simple model. The evaluation of the waste exposure rate requires calculation of the degree of salt saturation of the water at the repository horizon and, therefore, an explicit evaluation of the dissolution occurring all along the borehole. This evaluation is complicated by the fact that solubility of salt is temperature-dependent so that the natural geothermal conditions and temperature changes induced by the repository waste heat must be taken into account.

Another effect that must be considered is the creep property of the salt, particularly in the deep units. The increase in borehole radius due to salt dissolution may be compensated by creep closure of these salt layers. If the hole closes due to creep, the flow will decrease or cease altogether, effectively closing off release in this scenario.

In the following, the model used to estimate these effects and to evaluate realistic repository dissolution and waste exposure rates is discussed.

* References to this appendix are listed in Chapter 8. 


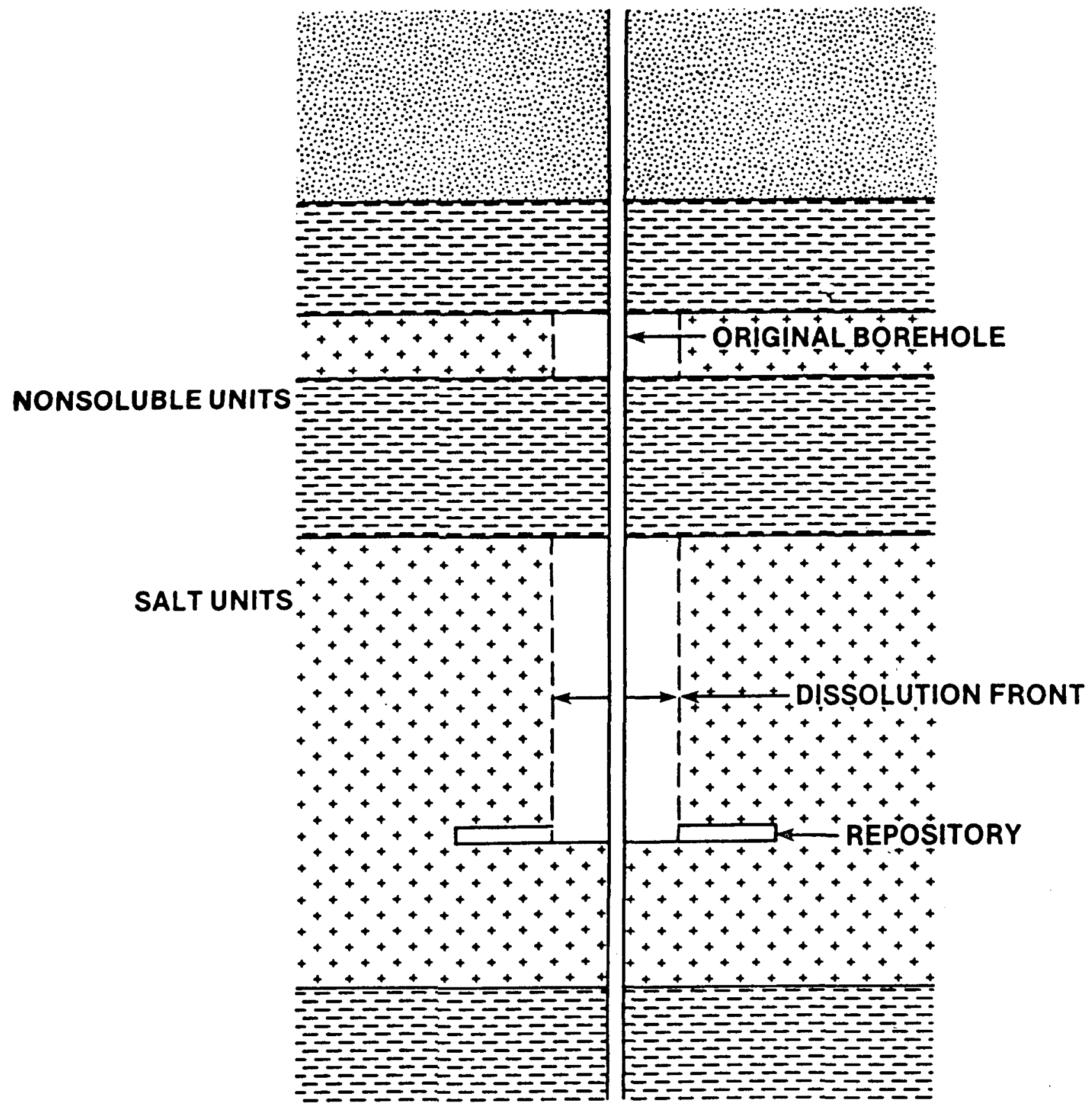

Figure C-1. Simple Model of Salt Dissolution by Borehole Flow Based on Untform Dissolution Versus Depth 


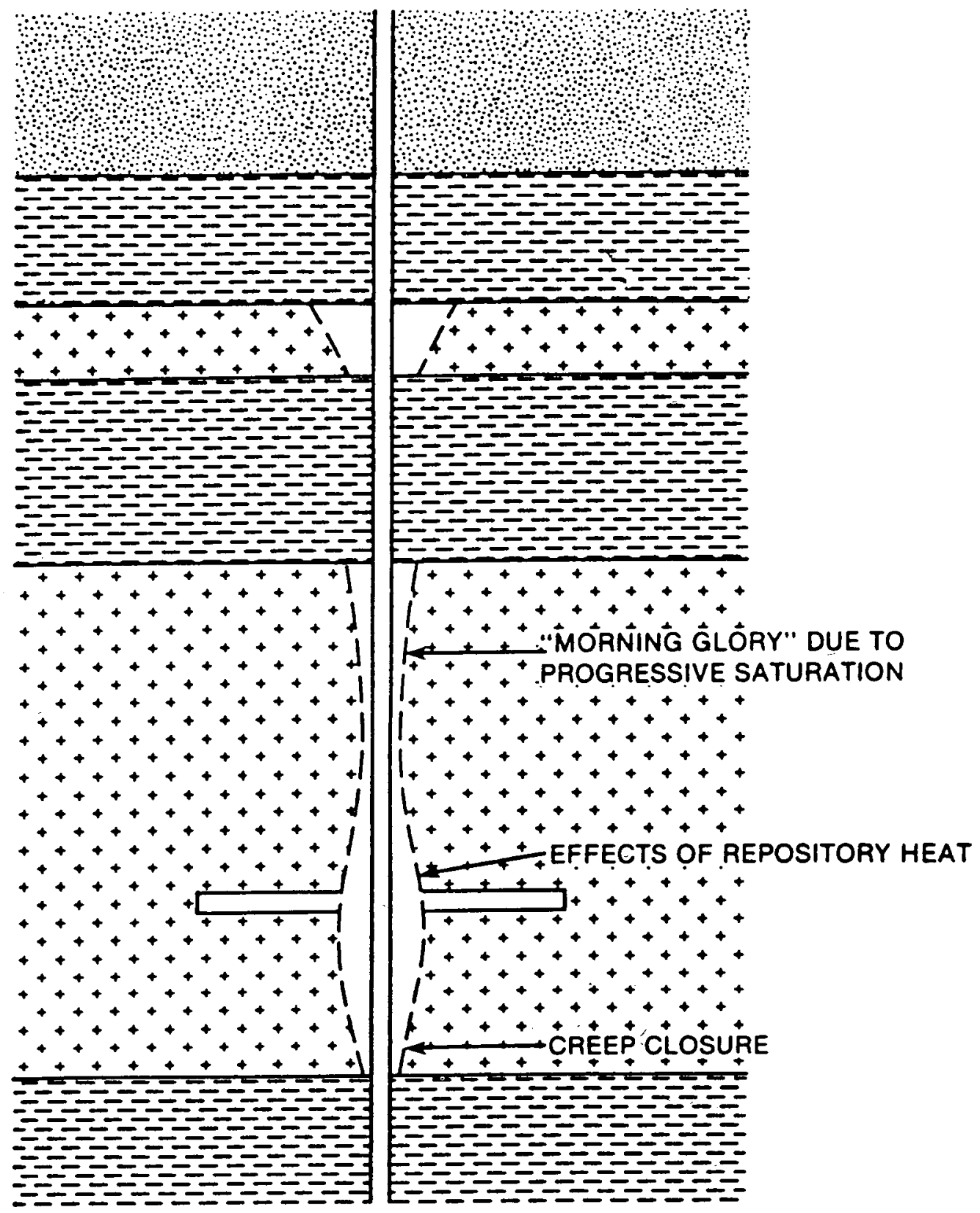

Figure C-2. Improved Model of Salt D1ssolution by Borelole Flow Cons1dering Progressive Saturation of Borehole Flow, Thermal, and Creep Effects 
A two-step approach is used to evaluate the temperature environments. The rock temperatures are estimated in a simple, semi-analytic scheme taking into account both in situ temperatures and the conduction of heat generated by the radioactivity of the emplaced waste. This scheme is described here. The fluid temperatures are evaluated from the heat transfer into the fluid from the rock and convective transport of heat with the borehole flow. This latter evaluation is described in Section C.3.

The partial differential equation governing the transient conduction of heat in the rock is given by:

$$
\rho_{r} C_{p r} \frac{\partial T_{r}}{\partial t}=\nabla \cdot k_{r} \cdot \nabla T_{r}=q_{r}
$$

where:

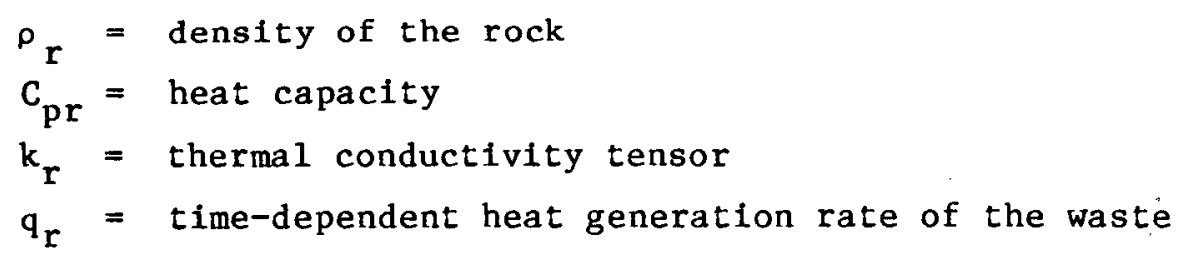

Spatial and temperature dependences of the rock properties are neglected. Also, for temperatures sufficiently far from the repository, the repository heat source can be approximated as a thin, rectangular sheet. Describing the formation as a semi-infinite, homogeneous medium with a fixed temperature at the surface of the earth and finite temperature at infinity, the solution for the induced temperature $\mathrm{T}_{\mathrm{r}}$ is:

$$
\begin{aligned}
T_{r}=T_{r o}(z) & +\frac{1}{4 p_{r} c_{p r}} \int_{0}^{t} \frac{Q\left(t^{\prime}\right) d t^{\prime}}{\sqrt{4 \pi \phi_{z}\left(t-t^{\prime}\right)}} \\
& \star\left[\exp \frac{-(z-d)^{2}}{\sqrt{4 \phi_{z}\left(t-t^{\prime}\right)}}-\exp \frac{-(z+d)^{2}}{\sqrt{4 \phi_{z}\left(t-t^{\prime}\right)}}\right] \\
& *\left[\operatorname{erf} \frac{-(x-x b)}{\sqrt{4 \phi_{x}\left(t-t^{\prime}\right)}}-\operatorname{erf} \frac{-(x-x a)}{\sqrt{4 \phi_{x}\left(t-t^{\prime}\right)}}\right.
\end{aligned}
$$




$$
\star\left[\operatorname{erf} \frac{-(y-y b)}{\sqrt{4 \phi_{y}\left(t-t^{\prime}\right)}}-\operatorname{erf} \frac{-(y-y a)}{\sqrt{4 \phi_{y}\left(t-t^{\prime}\right)}}\right]
$$

where:

$$
\begin{aligned}
\mathrm{T}_{\mathrm{ro}} & =\text { ambient in situ temperature } \\
\mathrm{Q} & =\text { areal heat generation rate of the repository } \\
\mathrm{xa}, \mathrm{xb}, \mathrm{ya}, \mathrm{yb} & =\text { boundaries of the repository } \\
\mathrm{d} & =\text { depth of the repository below the surface } \\
\phi_{1} & =\text { thermal diffusivity in the } i \text { direction }
\end{aligned}
$$

In this expression $x b$ - $x a$ and $y b$ - ya are the widths of the heat-generating region of the repository, $d$ is the depth below the surface of the earth and $Q$ is the areal thermal loading of the repository. The thermal diffusivity is defined:

$$
\phi_{i}=\mathrm{k}_{\mathrm{ri}} / \rho_{\mathrm{r}} \mathrm{C}_{\mathrm{pr}}
$$

The scheme approximates the geologic mass as a homogeneous medium with an effective, uniform conductivity. While the formation is composed of heterogeneous rock with thermal properties displaying some dependence on temperature, these variations do not produce large thermal effects relative to the in situ temperature. An exception that might be considered is salt which generally displays a strong decrease in thermal conductivity with temperature. However, for the elevated temperatures in the vicinity of the waste, the conductivity of salt is not significantly different from that of other rocks; and the linear representation for the repository thermal effects has been used in the past. It appears to be adequate for the bedded salt sites (C1aiborne, et a1, 1980).

\section{C.2 SALT CREEP}

The dissolution of salt along the borehole may be offset by salt creep. This process is evaluated by assuming a steady-state creep expression:

$$
\dot{\varepsilon}_{\text {ss }}=A \exp \left[-\gamma /\left(T_{r}+273.2\right)\right](\Delta \sigma)^{m_{C}}
$$


where:

$$
\begin{aligned}
& \dot{\varepsilon}_{\text {ss }}=\text { steady-state creep strain rate } \\
& \mathrm{A}, \gamma, \mathrm{m}_{\mathrm{C}}=\text { secondary creep law parameters } \\
& \Delta \sigma \quad=\text { deviatoric stress. }
\end{aligned}
$$

The creep rate can be incorporated into a representation of the formation and the borehole to determine the creep closure rate. The approach here, however, is to approximate the borehole as a hole in an infinite, homogeneous, isotropic medium. In this case, the closure rate is:

$$
\frac{1}{r} \frac{d r}{d t}=-\Lambda_{C} / 2
$$

where:

$$
\Lambda_{C}=\sqrt{3} A \exp \left[-\gamma /\left(T_{r}+273.2\right)\right]\left(\sqrt{3} \Delta \sigma / m_{C}\right)^{m_{C}}
$$

is the fractional change in volume due only to creep.

The deviatoric stress, $\Delta \sigma$, in this case is assumed to be the difference between the in situ lithostatic stress and the hydrostatic pressure in the :cehole.

\section{:.3 INTEGRATED MODEL FOR BOREHOLE TEMPERATURE, CREEP, AND SALT DISSOLUTION}

The calculational model for the borehole is suggested in Figure C-3. The borehole is represented as a sequence of discrete cells. The difference equations for mass, energy, and momentum transport are solved for each cell. These equations involve couplings between the cells due to transport across the top and bottom cell faces and source terms within each cell due, for example, to salt dissolution within the cell. Therefore, a coupled set of difference equations must be solved.

A simplification is to treat the transport as a one-dimensional problem. This approximation will be adequate if the vertical discretization is fine enough. The representation for a single cell is shown in Figure C-4. In each cell, the one-dimensional equations for mass and energy transport are given with source terms representing the lateral transfer of heat and mass from the walls of the cell. 


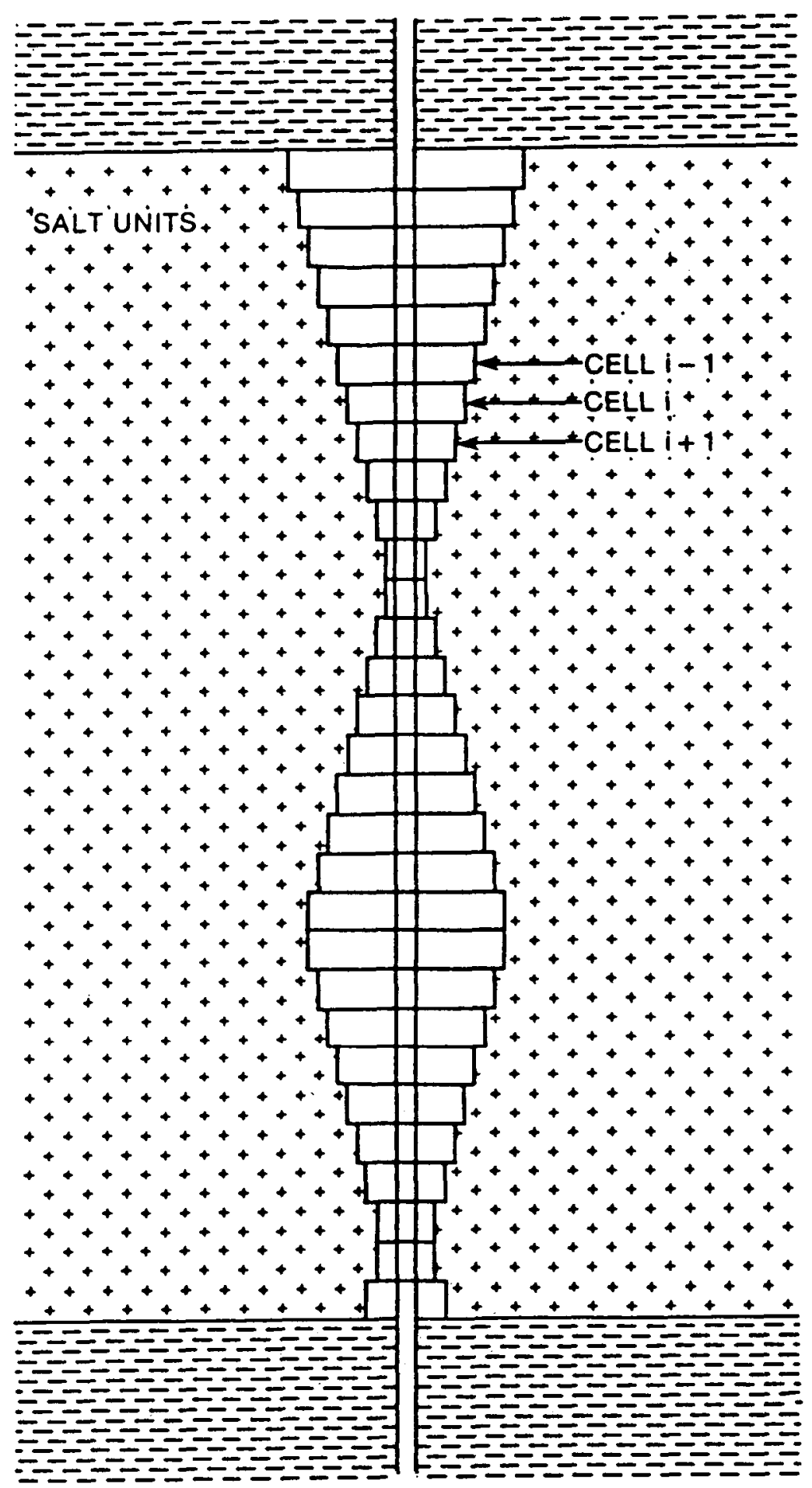

Figure C-3. Conceptual Model for Borehole Dissolution and Creep Analyses 
MASS IN: ENERGY IN:

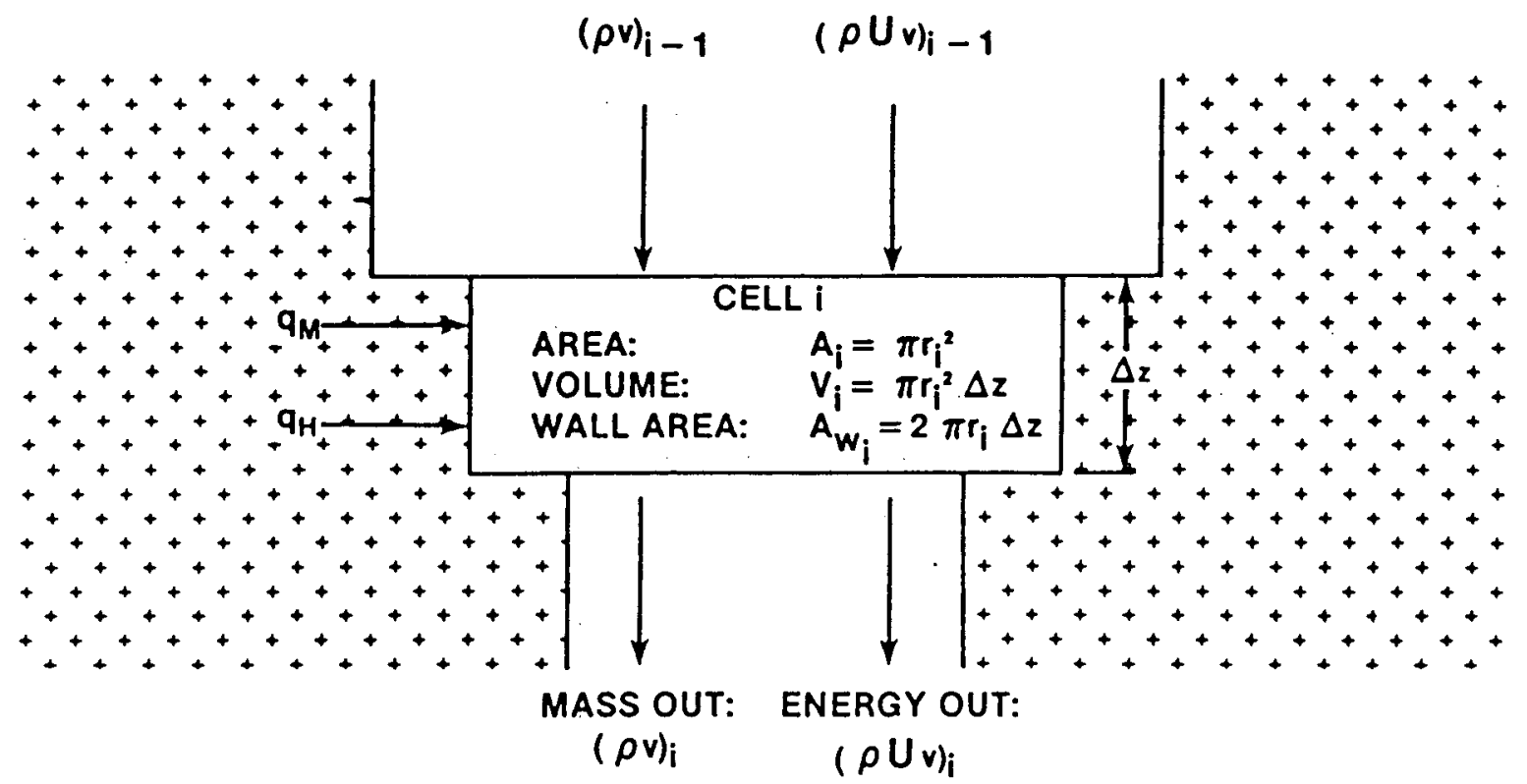

Figure C-4. Conceptual Mode1 for Borehole Cell 
A second simplification is to assume that two different types of flow exist within the borehole. One is externally induced by the potentiometric boundary conditions of the transmitting and receiving aquifers. The other (see INTERA, 1984d) is internally induced by salt dissolution, precipitation, and creep processes, which alter the volume available for fluid flow within the borehole. Time-dependent changes in hydraulic conductivity due to siltation of the borehole are not considered.

The governing equations are then:

$$
\begin{aligned}
& \text { Mass } \\
& \text { Conservation: }
\end{aligned} \begin{aligned}
& \frac{\partial \rho_{f}}{\partial t}=-\frac{\partial}{\partial z}\left(\rho_{f} F / A\right)+q_{M} \\
& \text { Energy } \\
& \text { Conservation: }
\end{aligned}
$$

where:

$$
\begin{aligned}
& \rho_{\mathrm{f}}=\text { fluid density } \\
& \mathrm{U}_{\mathrm{f}}=\text { mass-specific internal energy of the fluid } \\
& \mathrm{F}=\text { total volumetric flow rate } \\
& \mathrm{A}=\text { cross-sectional area of the borehole } \\
& \mathrm{q}_{\mathrm{M}}=\text { density source term } \\
& \mathrm{q}_{\mathrm{H}}=\text { heat transfer from energy source term. }
\end{aligned}
$$

The internal energy for the fluid is defined by:

$$
U_{f}=\int_{T_{0}}^{T} C_{p f} d T
$$

Here:

$$
C_{p f}=\text { specific heat of the fluid. }
$$

The density source term, $q_{M}$, in Equation (c-7) is a sum of contributions:

$$
q_{M}=q_{M D}+q_{M T}+q_{M P}+q_{M V}
$$

where:

$$
\begin{aligned}
& q_{M D}=\text { contribution from dissolution from the wall of the borehole } \\
& q_{M T}=\text { contribution from thermal expansion of the fluid }
\end{aligned}
$$




$$
\begin{aligned}
\mathrm{q}_{\mathrm{MP}}= & \text { contribution from precipitation of salt from the fluid under } \\
& \text { super-saturated conditions } \\
\mathrm{q}_{\mathrm{MV}}= & \text { contribution from volumetric changes within the borehole. }
\end{aligned}
$$

The formulation of each of these terms is presented in INTERA (1984d).

Similarly, the energy source term, $q_{H}$, in Equation $(C-8)$ is also a sum of contributions:

$$
\mathrm{q}_{\mathrm{H}}=\mathrm{q}_{\mathrm{HK}}+\mathrm{q}_{\mathrm{HD}}+\mathrm{q}_{\mathrm{HP}}+\mathrm{q}_{\mathrm{HV}}
$$

where:

$$
\begin{aligned}
q_{H K}= & \text { rate of convective heat transfer from the walls of the } \\
& \text { borehole } \\
q_{H D}= & \text { rate of transfer of the internal energy of dissolved salt to } \\
& \text { the fluid } \\
q_{H P}= & \text { rate of transfer of the internal energy of the fluid to the } \\
& \text { precipitated salt } \\
q_{H V}= & \text { rate of the energy concentration or dilution arising from } \\
& \text { changes in the borehole volume. }
\end{aligned}
$$

The formulation of each of these terms is also presented in INTERA (1984d).

For the case of mass conservation, the implicit finite-difference equation is:

$$
\frac{\delta \rho}{\Delta t}=q_{M i}^{n+\alpha}+\left(F_{i-1 / 2}^{n+\alpha} \rho_{i-1}^{n+\alpha}-F_{i+1 / 2}^{n+\alpha} \rho_{i}^{n+\alpha}\right) / v_{i}^{n+\alpha}
$$

where:

$$
\begin{aligned}
& \Delta t=\text { time step } \\
& \delta \rho=\text { change in density during time step }
\end{aligned}
$$

In Equation (C-12) subscripts and superscripts denote the cell $i$, its interfaces $1 \pm 1 / 2$ with neighboring cells, and the time step $n$. The parameter $\alpha$ must satisfy

$$
0.5<\alpha<1
$$


APPENDIX D

SALT DISSOLUTION AND BRINE PROPERTIES

Properties of salt dissolution and of brine are needed to evaluate salt dissolution. The literature regarding these properties was reviewed by $\mathrm{H}$. $\mathrm{C}$. Clalborne and R. J. Vedder (see Appendix G) of Oak Ridge National Laboratory under contract to the office of Nuclear Waste Isolation. Their description of salt dissolution is adequate for the purposes of the present analysis; and their review of relevant salt dissolution and brine properties is given below in Sections D. 1 and D.2 with only minor editorial changes. Because the work of Claiborne and Vedder is oriented to analysis of a salt mine flooded before permanent closure, these sections reflect that focus; but the information presented is relevant to the case of postclosure scenario analysis as well.

\section{1 SALT SOLUTIONING}

Water intrusion into a radioactive waste repository in salt will quickly become a saturated brine. The kinetics of solutioning will vary depending on salt surface area, temperature, initial salt concentration of the intruding water, and transport mechanisms of both solute and solvent that give rise to an effective mass transfer coefficient.

Modeling the kinetics of salt dissolution in a radioactive waste repository during a flooding incident is an obviously difficult task because of the number of parameters involved and their variations with spatial position, flow regime, and time. The effective mass transfer coefficient for the solutioning process is the single most 1mportant parameter and the most difficult to ascertain for the variable conditions of a flooded repository. However: except for the Improbable case of large flow rates through a repository, it appears that the kinetics of solution mining in salt have similarity to solutioning in a flooded repository during the initial or isothermal phase. The potential errors involved in using models developed for solution mining can be large when used to estimate dissolution rates in salt repositories. Fortunately, the results obtained show that the time scale involved in the approach to saturation of intruding fresh water is very small 
compared to the time scale involved in analyzing the consequences of flooding. Consequently, an error of an order of magnitude or two in the effective mass transfer coefficient for dissolution becomes unimportant.

Two models having application to the preheating or isothermal phase in the saturation of intruding water have been identified in the studies pertaining to the solution mining of salt. These models describe dissolution by natural convection and by turbulent forced convection. In a flooding repository, after an initial period, the brine velocities will be sufficiently low as to cause the boundary layer to control the dissolution rates. Turbulent forced convection and the higher dissolution rates it engenders would be important only in limited regions around the entrance and exit. Although a vast literature exists on solution mining and the resulting salt dissolution mechanisms, the studies by Durie and Jessen (1964)* and by Jessen (1971) seem most appropriate to the problem at hand, and the following discussion of the isothermal phase is taken from their publications, particularly that by Durie and Jessen.

\section{D.1.1 Natural Convection}

In the solution mining process, natural convection effects are of prime importance because of the generally small lineal velocities near the saltbrine interface. Salt dissolution causes the brine density near the saltbrine interface to increase. The more dense brine sinks and creates a laminar boundary layer between the salt surface and the bulk 1iquid. The laminar boundary can eventually become turbulent. However, this turbulence and laminar flow in the bulk of the liquid will not significantly change the dissolution rates unless the turbulence extends throughout the system (Durie and Jessen, 1964; Jessen, 1971).

By analogy to heat transfer, Durie and Jessen (1964) generated a solution to the boundary layer problem for salt dissolution from a smooth vertical surface in a quiescent body of water.

The equation developed was

$$
M=0.0977\left(C_{s}-C\right)^{5 / 4} D^{3 / 4} \mu-1 / 4 H^{-1 / 4}
$$

* References for this appendix are listed in Chapter 8 . 
where:

$$
\begin{aligned}
\mathrm{H} & =\text { height of exposed salt surface, } \mathrm{cm} \\
\mathrm{D} & =\text { average diffusion coefficient for salt, } \mathrm{cm}^{2} / \mathrm{sec} \\
\mathrm{C}_{\mathrm{S}} & =\text { saturation concentration, } \mathrm{mol} / \mathrm{L} \\
\mathrm{C} & =\text { concentration in bulk fluid, } \mathrm{mol} / \mathrm{L} \\
\mu & =\text { average kinematic viscosity, } \mathrm{cm}^{2} / \mathrm{sec} \\
M & =\text { mass salt flux from surface, } \mathrm{g} / \mathrm{cm}^{2} \mathrm{sec}
\end{aligned}
$$

Experiments made to verify Equation (D-1) produced dissolution rates which were much greater than those predicted by the equation. Th1s was due to irregularities that developed on the salt surface. An empirical factor, A, was developed that, when used as a multiplier of Equation (D-1), produced good agreement between experiment and theory when

$$
A=1.7+0.26\left(C_{s}-C\right)
$$

Studies of inclined surfaces by Durie (Saberian and Podio, 1976) showed the mass flux from a horizontal surface to be higher than that predicted by the empirically corrected Equation (D-1) when the salt overlies the water (ceiling) and to approach zero for a horizontal surface when the water overlies the salt (floor). The different rates are due to the varying salt concentration throughout the brine. Brine near the floor is more dense (more nearly saturated) than brine near the celling. In the application to a repository, the brine will probably be nearly saturated by the time the liquid rises to the celling and the angle of inclination of the salt surface 18 of no consequence. In the case of an unbackfilled room, however, salt dissolution on the floor could occur by a different diffusional process with the relative importance of the dissolution mechanisms being a function of the water flow rate.

\section{D.1.2 Turbulent Forced Convection}

As previously mentioned, turbulence in the boundary layer will not greatly affect the salt dissolution provided that the turbulence does not 
extend throughout the bulk fluid. For this latter condition, forcedconvection turbulence can distort the boundary layer and greatly increase salt dissolution rates.

Durie and Jessen (1964) performed experiments on dissolutioning in the turbulent regime by pumping water at high rates through circular holes in salt blocks. For the range of velocities and block size tested, they found that the rate of salt removal was 10 to 20 times that observed using laminar flow rates in the same geometries. However, this experiment represents confined flow in pipes and is not a good model for solution mining or flow through a repository. Jessen (1971) later simulated a turbulent free-convection system by mechanical stirring of brine of various concentrations in contact with crystalline salt of various shapes and sizes. The type and shape of the salt crystals had little effect on the rate of salt dissolution. An increase of about $10 \%$ in the dissolution rate for the smaller crystals occurred in comparison with the larger ones.

An approximate fit to the data for the turbulent conditions of the Jessen (1971) experiments is given by

$$
M=3.9 \times 10^{-4}\left(C_{s}-C\right)
$$

Making a similar fit to the Durie and Jessen (1964) data fur free convection with no turbulence results in

$$
M=1.5 \times 10^{-4}\left(C_{s}-C\right)
$$

The ratio of Equation (D-3) to Equation (D-4) is only 2.6. Since Equation (D-3) is based on a simulation of turbulent conditions in solution mining or flow through a repository, it would seem that a factor of 3 increase is more likely due to turbulence rather than a factor of 10 or more.

\section{D.2 PHYSICAL PROPERTIES FOR BRINE}

The following equations correlating brine properties with temperature and concentration are taken from Cranwell, et al (1982b), where the derivation of these equations is outlined: 


$$
\begin{aligned}
W= & 26.218+7.2 \times 10^{-3} \mathrm{~T}+1.06 \times 10^{-4} \mathrm{~T}^{2} \\
\rho= & 1.0+0.1877 \mathrm{SAT}-3.168 \times 10^{-4}(\mathrm{~T}-20) \\
& -2.56 \times 10^{-6}(\mathrm{~T}-20) \\
\mu= & \mu_{0}(1.0+0.0219 \mathrm{WSAT}) \exp \left[\mathrm{B} \frac{\mathrm{T}_{0}-\mathrm{T}^{\prime}}{\mathrm{T}^{\prime} \mathrm{T}_{0}}\right]
\end{aligned}
$$

where:

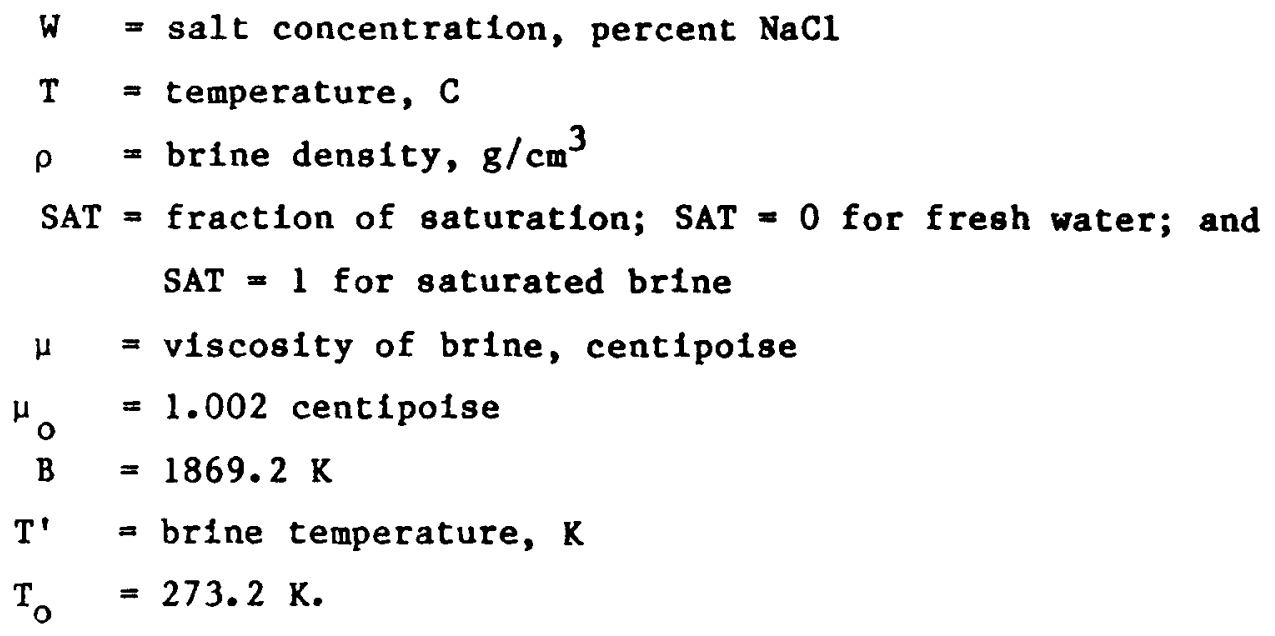

The following equations for rock salt (halite) density and heat capacity as a function of temperature are taken from Gevantman (1981):

$$
\begin{gathered}
\rho=2.2372-2.543(T+273.2) \\
C p=47.495-0.01356(T+273.2)
\end{gathered}
$$

where $C_{p}=$ heat capactity, $\mathrm{J} / \mathrm{mol} \mathrm{R}$.

The tabulated values in Gevantman (1981) for the thermal conductivity of halite were fitted to within $\pm 3 \%$ for temperatures between 20 and $250^{\circ} \mathrm{C}$ with the following equation:

$$
k=3310(T+273)^{-1.091}
$$

where $k=$ thermal conductivity, $W / m K$. 
D. 3 DISSOLUTION OF SALT FROM A NONVERTICAL SURFACE

The Information in Section D.1, by Claiborne and Vedder (see Appendix G) alludes to the dependence on the angle from the vertical of the salt surface. This dependence was revlewed by Saberian and Podto (1976). They concluded that Durle's analysis (Durie, 1963) adequately describes the effect of inclined surfaces overlain by water. The dependence given by Durle is:

$$
M=M o(\cos \theta)^{1 / 2}
$$

where:

$$
\begin{aligned}
& M=\text { mass flux from surface } \\
& M o=\text { flux from vertical surface } \\
& \theta=\text { angle with vertical. }
\end{aligned}
$$

\section{4 CONCENTRATIVE PROPERTY OF SODIUM CHLORIDE}

The displacement of dissolved salt in water is different than solid salt because of the lonic nature of the solution. The variation can affect the concentration of the fluid in the borehole as the salt is dissolved. The dependence can be determined from standard tables for the concentrative properties of sodlum chlorlde ( $\mathrm{NaC1}$ ) (Weast, 1973). The dependence is given by:

$$
\eta=0.628+0.206 \mathrm{SAT}-0.0523 \mathrm{SAT}^{2}
$$

Where $\eta$ is the reduction in displacement and SAT is the salinity of the brine. 
MINIMUM CONSEQUENTIAL BRINE VOLUMES FOR SALT REPOSITORIES

This appendix presents the radionuclide releases for the saturated volumes predicted for the repository. These estimates are compared with the regulatory criteria for releases to evaluate repository performance. The inverse problem is to use these criteria to evaluate the volume of saturated brine in the repository that precisely meets these standards. These volumes for the radionuclides are given in Tables E-1 and E-2.

Table E-l gives the volumes needed to exceed a fractional release rate of 1.E-5 $\mathrm{yr}^{-1}$ based on the inventories in Tables 3-3 and 3-4. The minimum volume in tinis case is about $1.0 \mathrm{E}+4 \mathrm{~m}^{3}$.

Table E-2 gives the volumes that could dissolve enough radionuclides to exceed the EPA standards. This evaluation has been based on the standards for likely release which may not be applicable to the scenario. If the applicable standard is that for unlikely release, the volume of water in the repository would have to be an order of magnitude larger than that in Table E-2 before the release standard could possibly be exceeded. 
Table E-1. Minimum Brine Volumes to Satisfy 1.E-5 per Year Fractional

Release Criterion

\begin{tabular}{ll}
\hline Radionuclide & Volume $\left(\mathrm{m}^{3}\right)$ \\
$93 \mathrm{Zr}$ & 9,800 \\
$93 \mathrm{~m}_{\mathrm{Nb}}$ & 9,800 \\
$99{ }^{\mathrm{Tc}}$ & 9,800 \\
$239 \mathrm{~Np}$ & 9,800 \\
$239 \mathrm{Pu}$ & 20,200 \\
$240 \mathrm{Pu}$ & 20,200 \\
$242 \mathrm{Pu}$ & 20,200 \\
$241 \mathrm{Am}$ & 17,200 \\
$243 \mathrm{Am}$ & 10,400 \\
& \\
\hline
\end{tabular}


Table E-2. Minimum Brine Volumes to Satisfy EPA Criterion for Release to Accessible Environment

\begin{tabular}{lllll}
\hline Radionuclide & $\begin{array}{c}\text { EPA Release Limit } \\
(\mathrm{Ci})\end{array}$ & $\begin{array}{c}\text { Solubility } \\
(\mathrm{kg})\end{array}$ & $\begin{array}{c}\text { Brine Volume } \\
(\mathrm{ppm})\end{array}$ \\
\hline $239 \mathrm{Pu}$ & $7.2 \mathrm{E}+3$ & 120 & $9.0 \mathrm{E}-2$ & $1.5 \mathrm{E}+6$ \\
$240 \mathrm{Pu}$ & $7.2 \mathrm{E}+3$ & 32 & $3.6 \mathrm{E}-2$ & $1.0 \mathrm{E}+6$ \\
$241_{\mathrm{Am}}$ & $7.2 \mathrm{E}+2$ & 0.21 & $4.8 \mathrm{E}+3$ & $5.1 \mathrm{E}+4$ \\
& & & & \\
\hline
\end{tabular}


and is used to select the implicit scheme. For example, $\alpha=0.5$ corresponds to a Crank-Nicholson approach, and $\alpha=1$ gives the classical implicit scheme. The superscript $n+\alpha$ implies evaluation at time level $t_{n}+\alpha \Delta$. The difference equation for the temperature follows analogously. Since the source terms $q_{M}$ and $q_{H}$, and the Internally induced flow components of $F$ depend nonlinearly upon density and temperature, an iteration (m) must be performed for each time step. Convergence 1s defined for each cell by:

$$
\frac{\rho^{(m+1)}}{\rho^{(m)}}<C
$$

where $C$ is a prescribed tolerance. Similarly, convergence is tested for the temperature and volume of the borehole cells.

When the governing equations are solved at a given time, the borehole growth rate can be calculated from the contributions for dissolution and creep:

$$
\frac{1}{v} \frac{d V}{d t}=\Lambda_{V}
$$

Here the fractional rate of volume change 1s:

$$
\Lambda_{V}=\left(M_{D}-M_{p} f_{p}\right) a_{w} / p_{s}-\Lambda_{C}
$$

where:

$$
\begin{aligned}
M_{D} a_{w} / \rho & =\begin{array}{l}
\text { fractional change in volume due to dissolution } \\
\text { from walls }
\end{array} \\
M_{P} f_{P}{ }^{a}{ }_{w} / \rho & \text { fractional change in volume due to preclpitation } \\
& \text { on walls }
\end{aligned}
$$

The finite-difference equation in this case 1s:

$$
\frac{\delta v_{i}}{\Delta t}=\Lambda_{V i} v_{i}^{n+\alpha}
$$

where:

$$
\delta V=\text { change in volume occurring during time-step } \Delta t .
$$




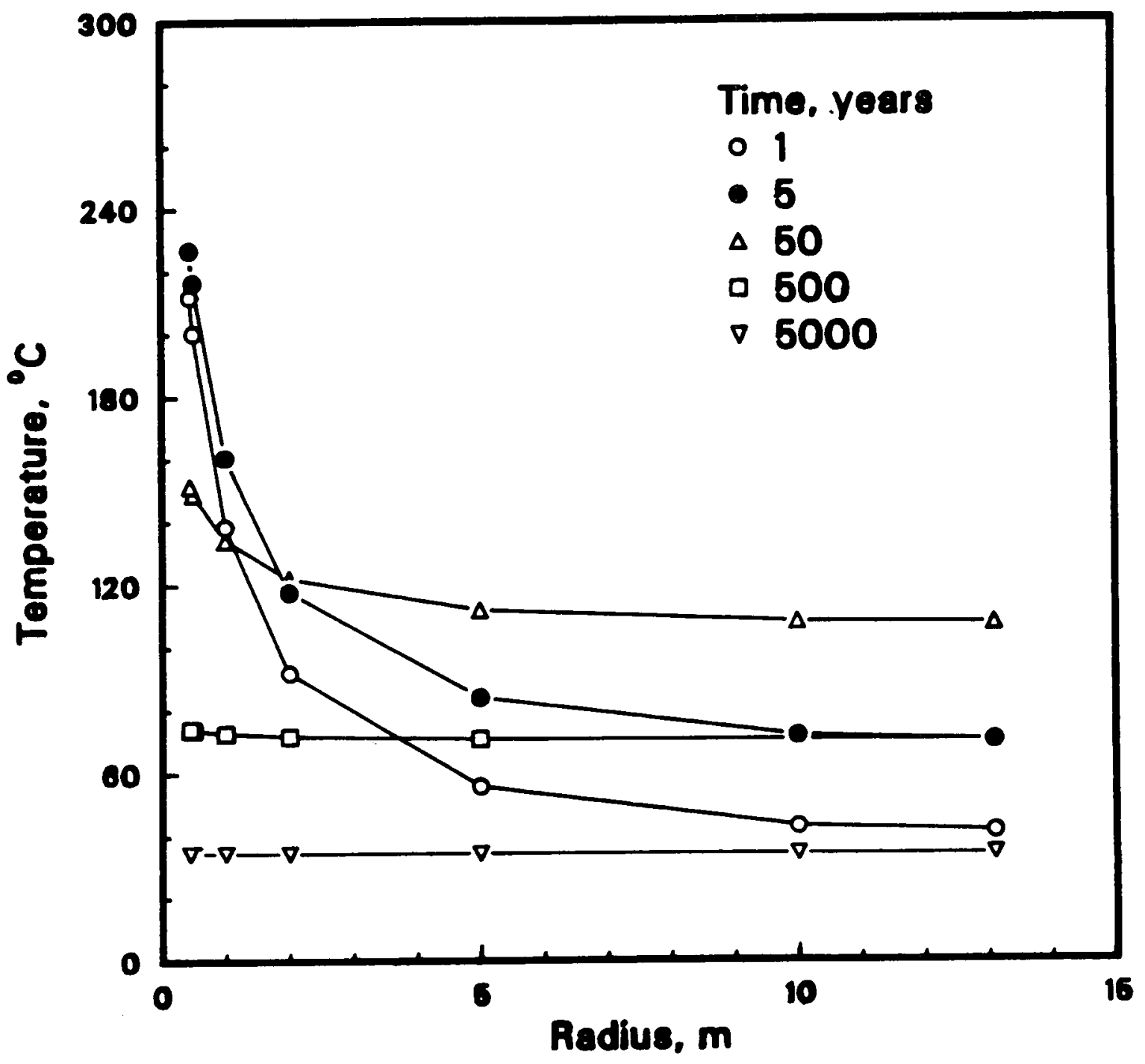

Temperetures Around CHLW Weste Packeas at Deaf Smith

Figure F-1 


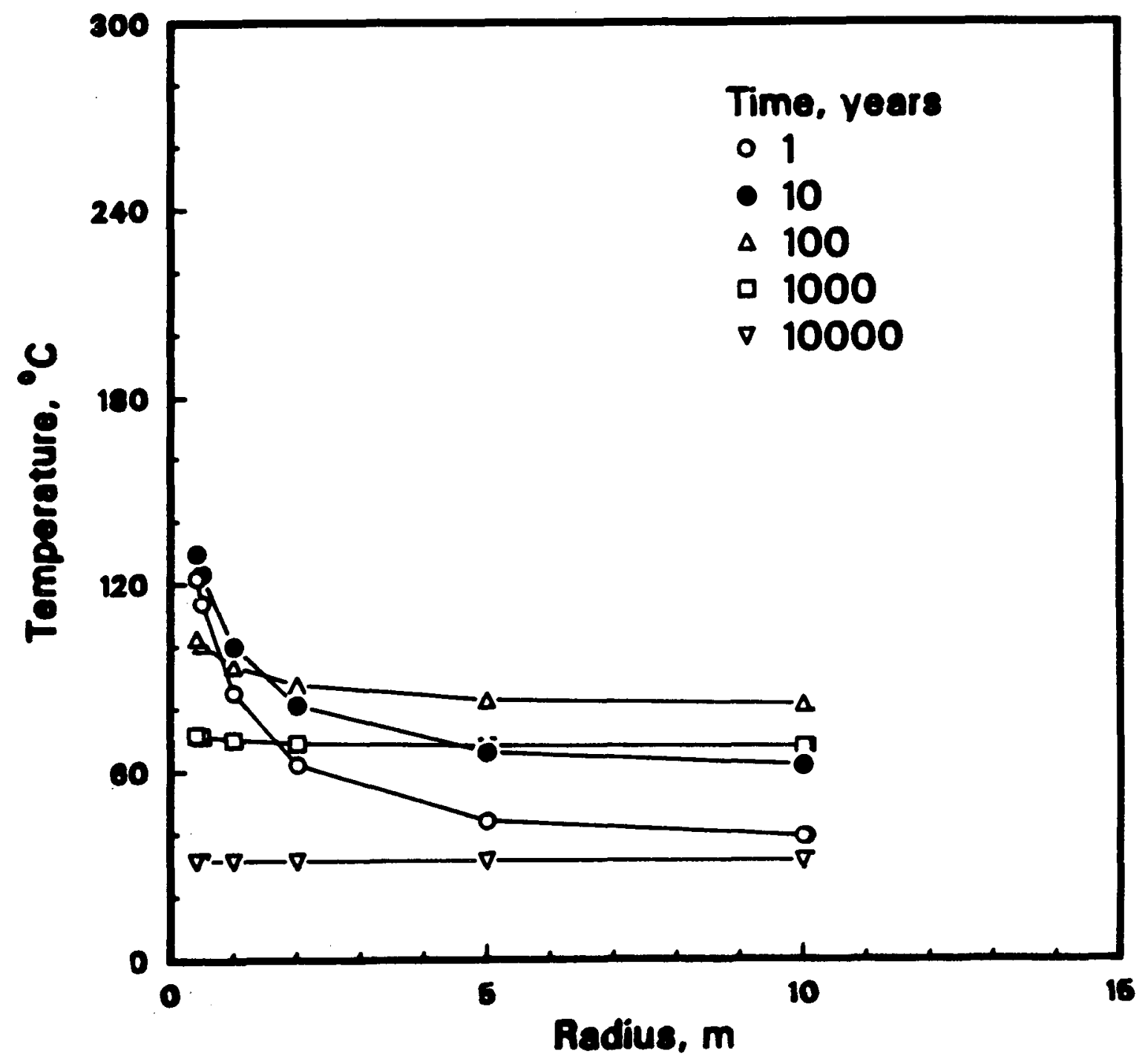

Tomporatures Around SFPWR

Weote Packeape at

Doef Smith

Figure F-2 


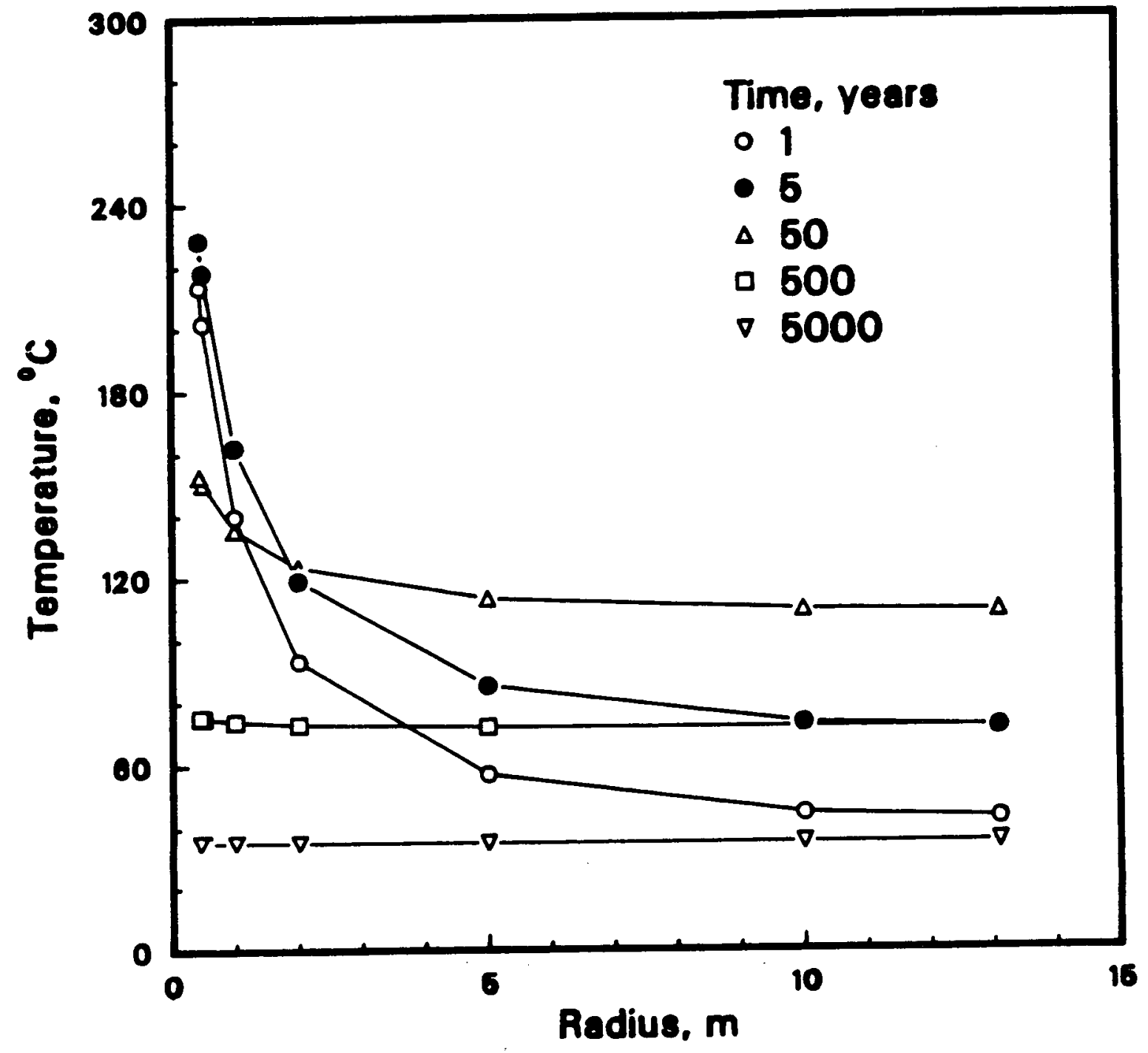

Temperatures Around CHLW

Weste Packege at Swishor

Figure F-3 


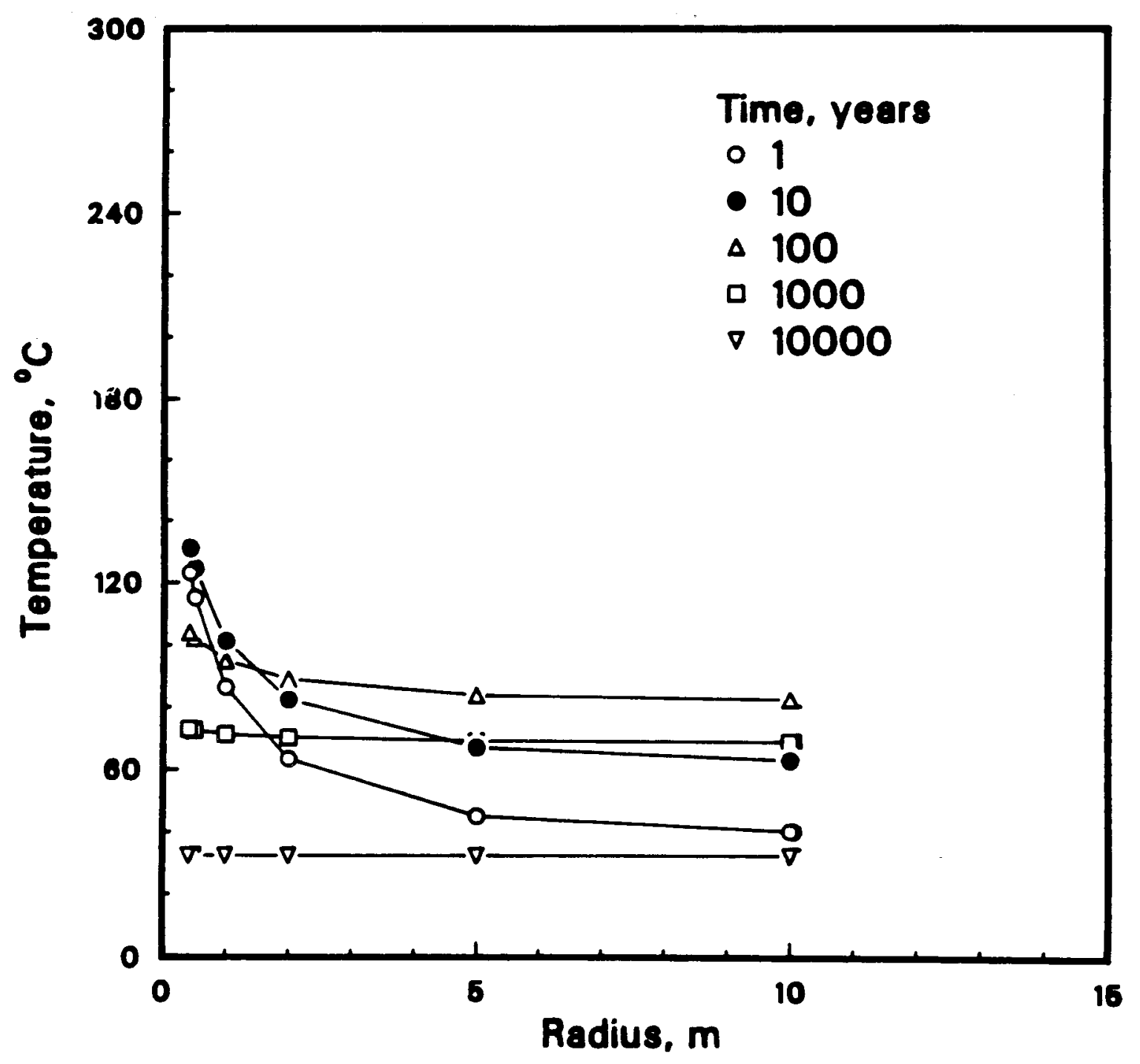

Temperatures Around SFPWR

Waste Package at Swisher

Figure F-4 


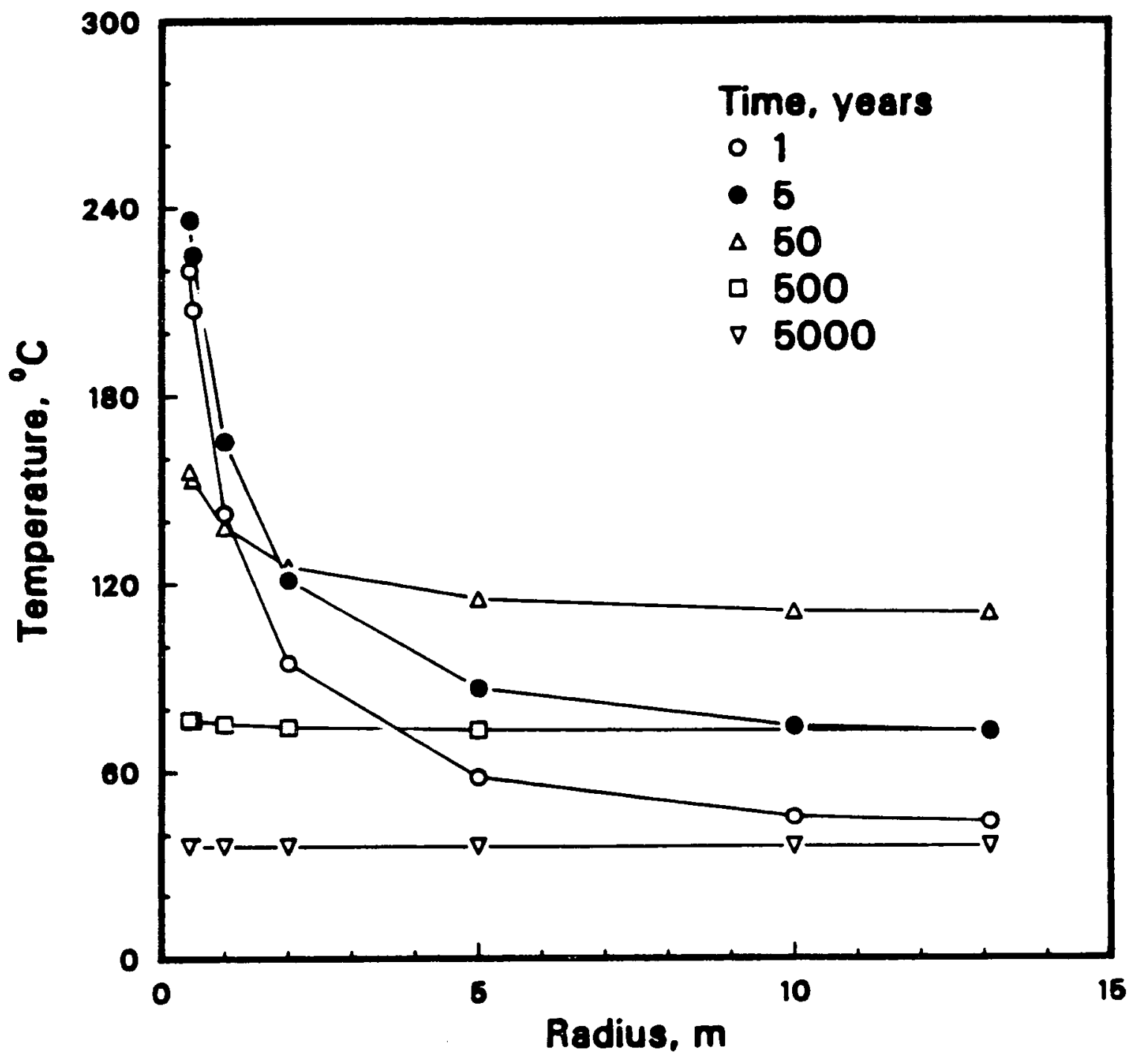

Tomporatures Around CHLW Weste Packags at

Davis Canyon

Figure F-5 


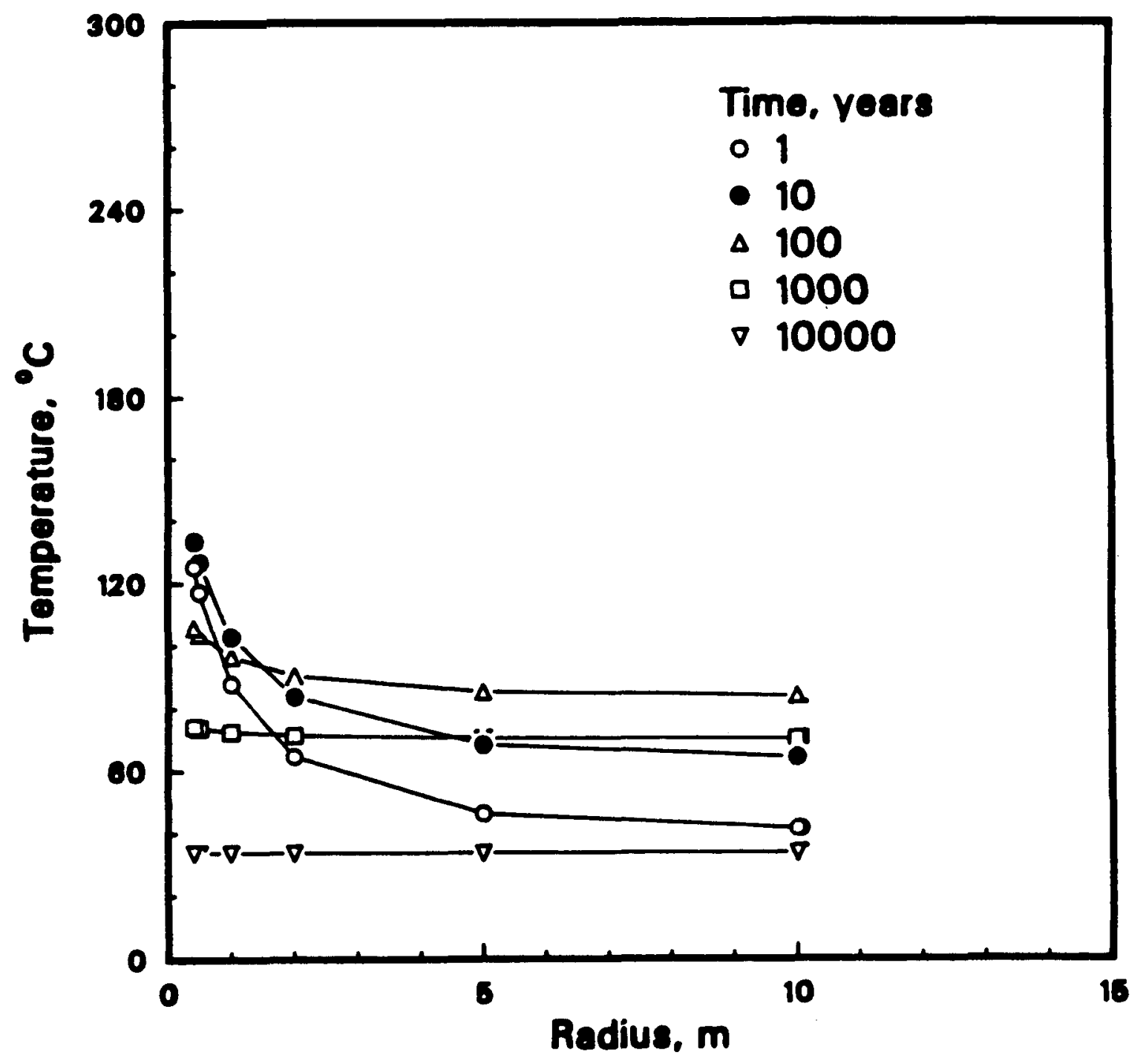

Tomperatures Around SFPWR

Wave Packaes ot

Devis Canyon

Figure F-6 


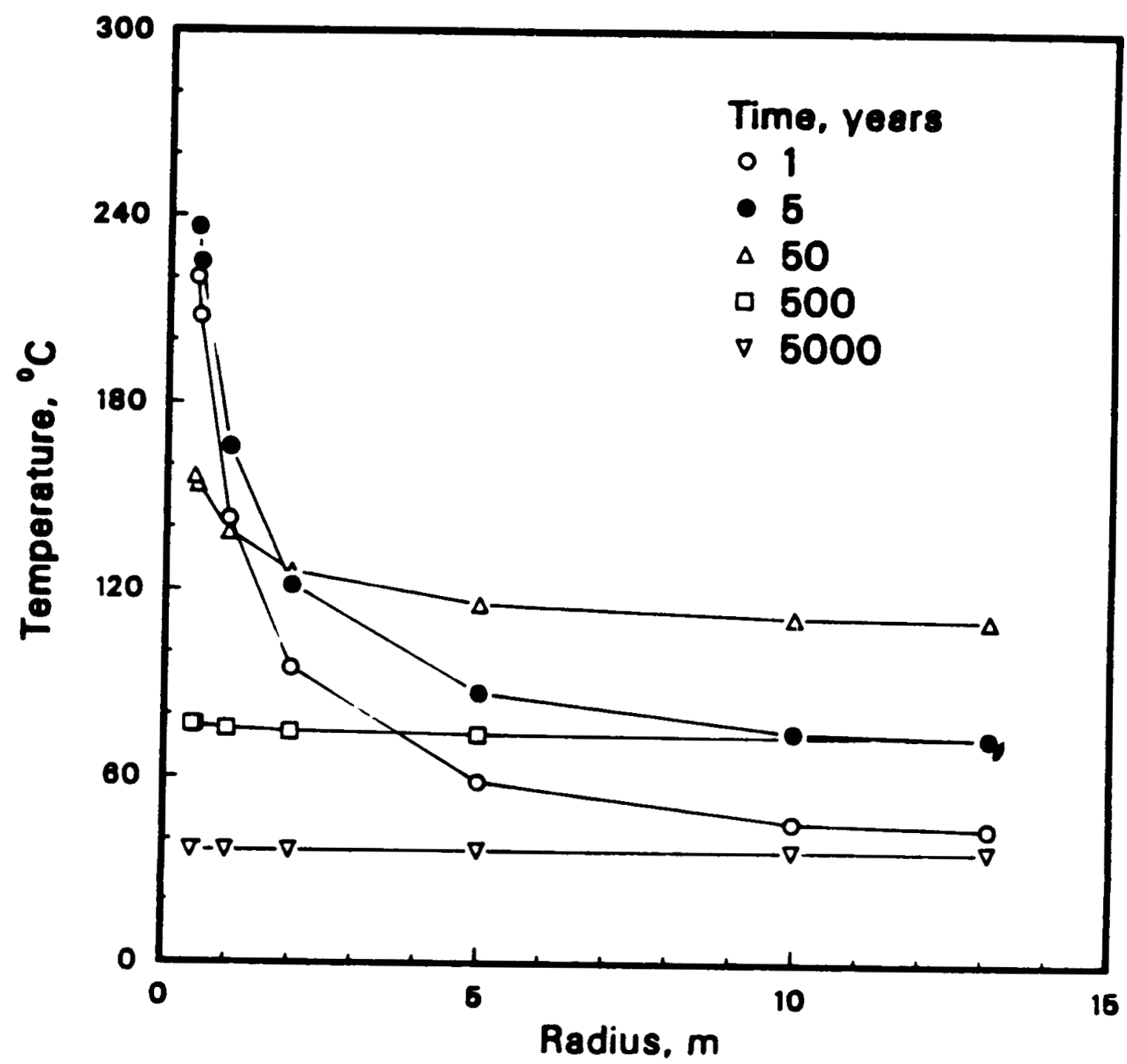

Temporatures Around CHLW Weste Packape at

Lavender Canyon 


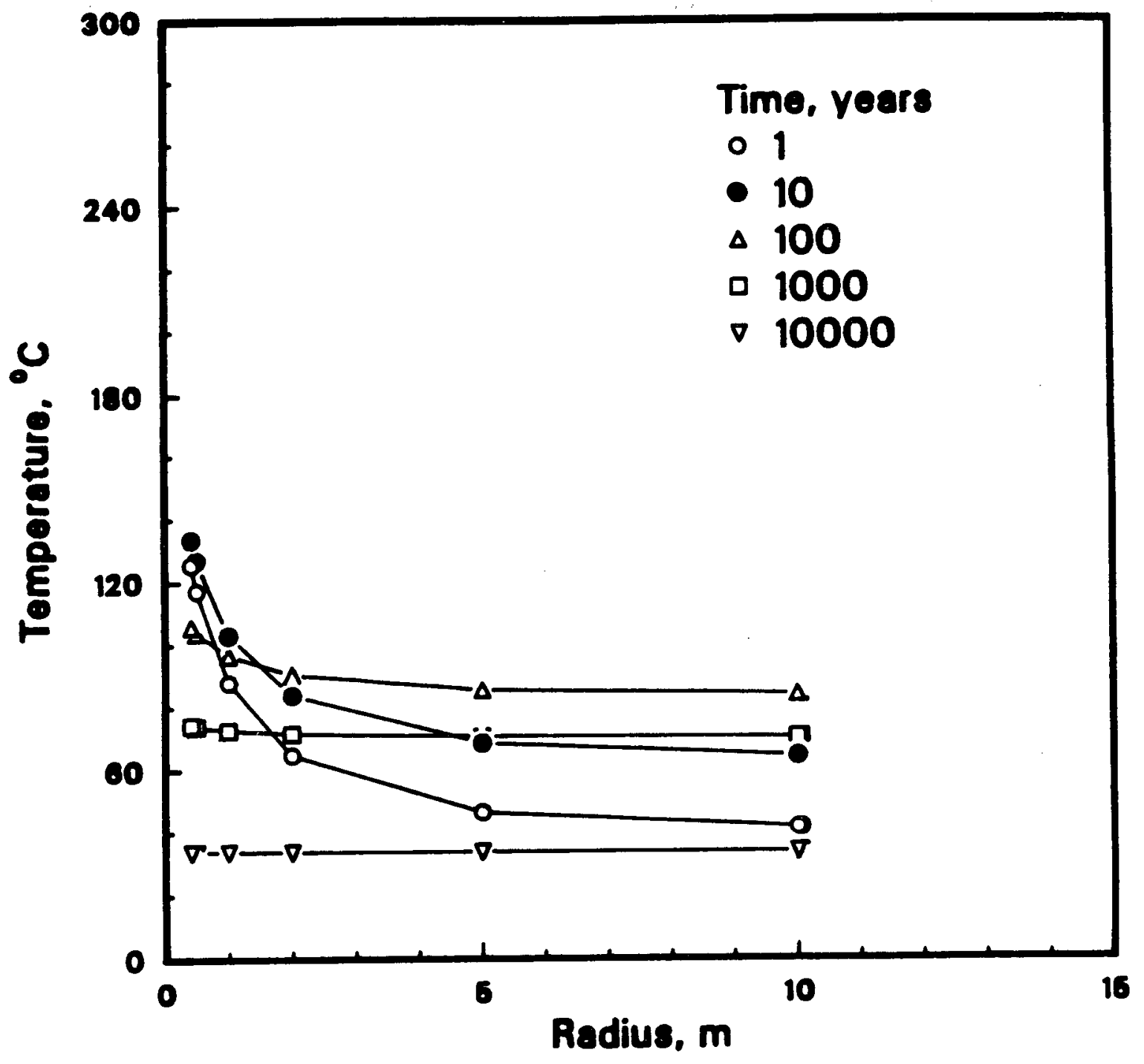

Temperatures Around SFPWR

Weato Packegs at

Lavonder Canyon

Figure F-8 


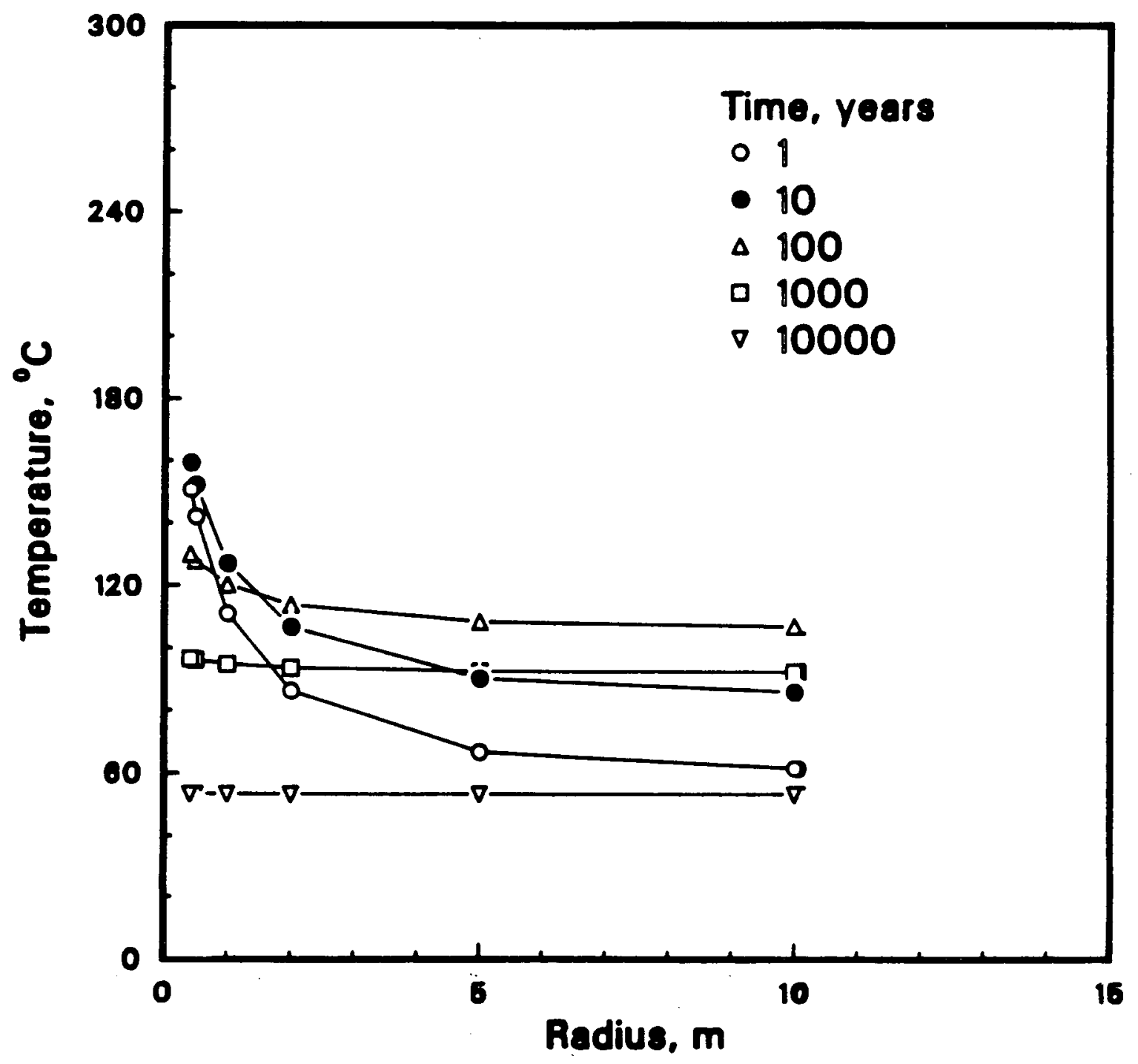

Temperatures Around SFPWR

Werto Package at

Cypress Creek Dome

Figure F-9 


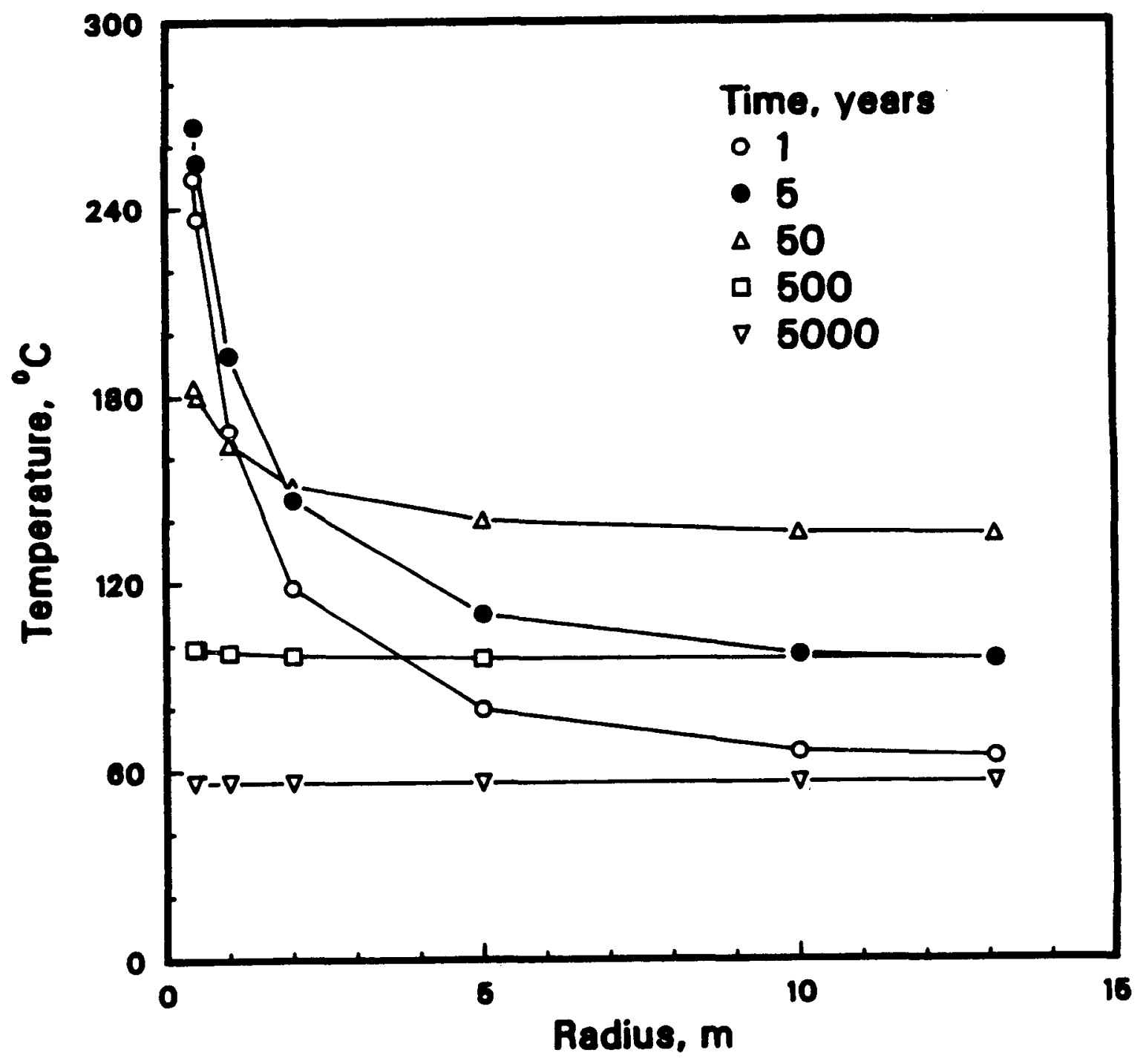

Tomperatures Around CHLW

Werto Packene at

Cyprese Creak Dome

Figure F:10 


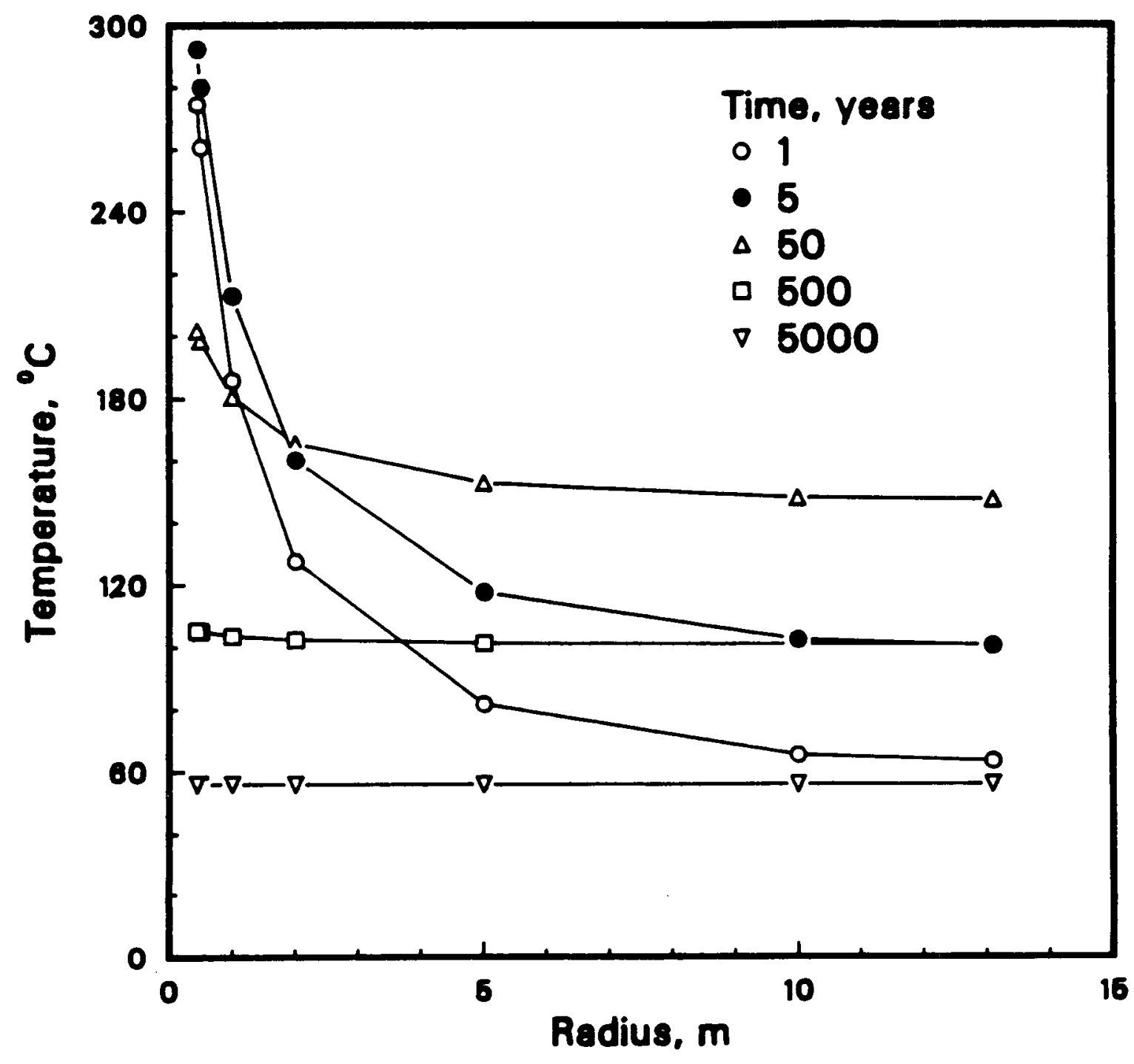

Tomperatures Around CHLW

Wastu Package at

Richton Doms

Figure F-11 


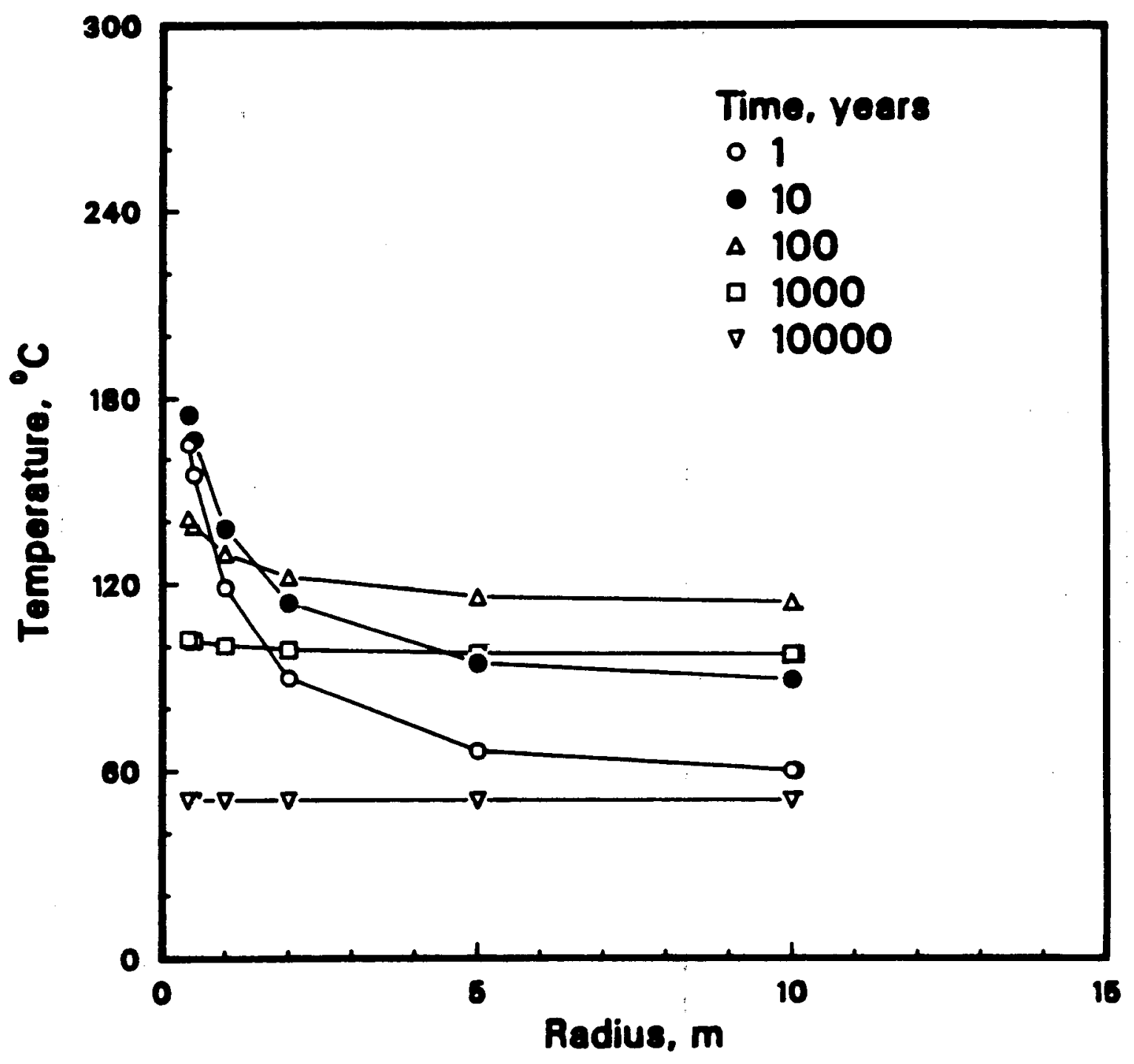

Temperatures Around SFPWR Weste Puckeges at

Plchton Dome

Figure F-12 


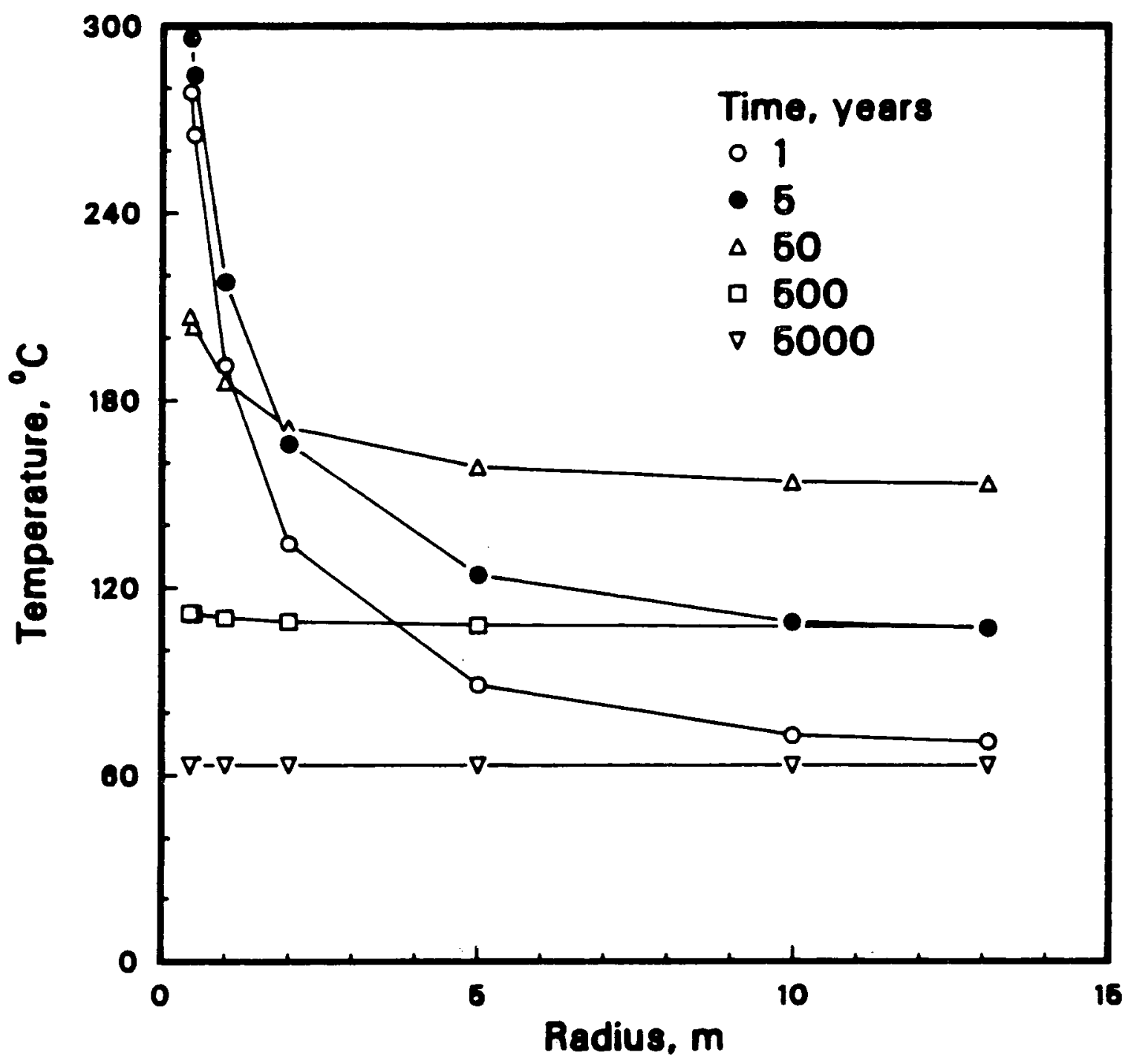

Temperatures Around CHLW Westo Fackege at Vechorie Domo

Figure F-13 


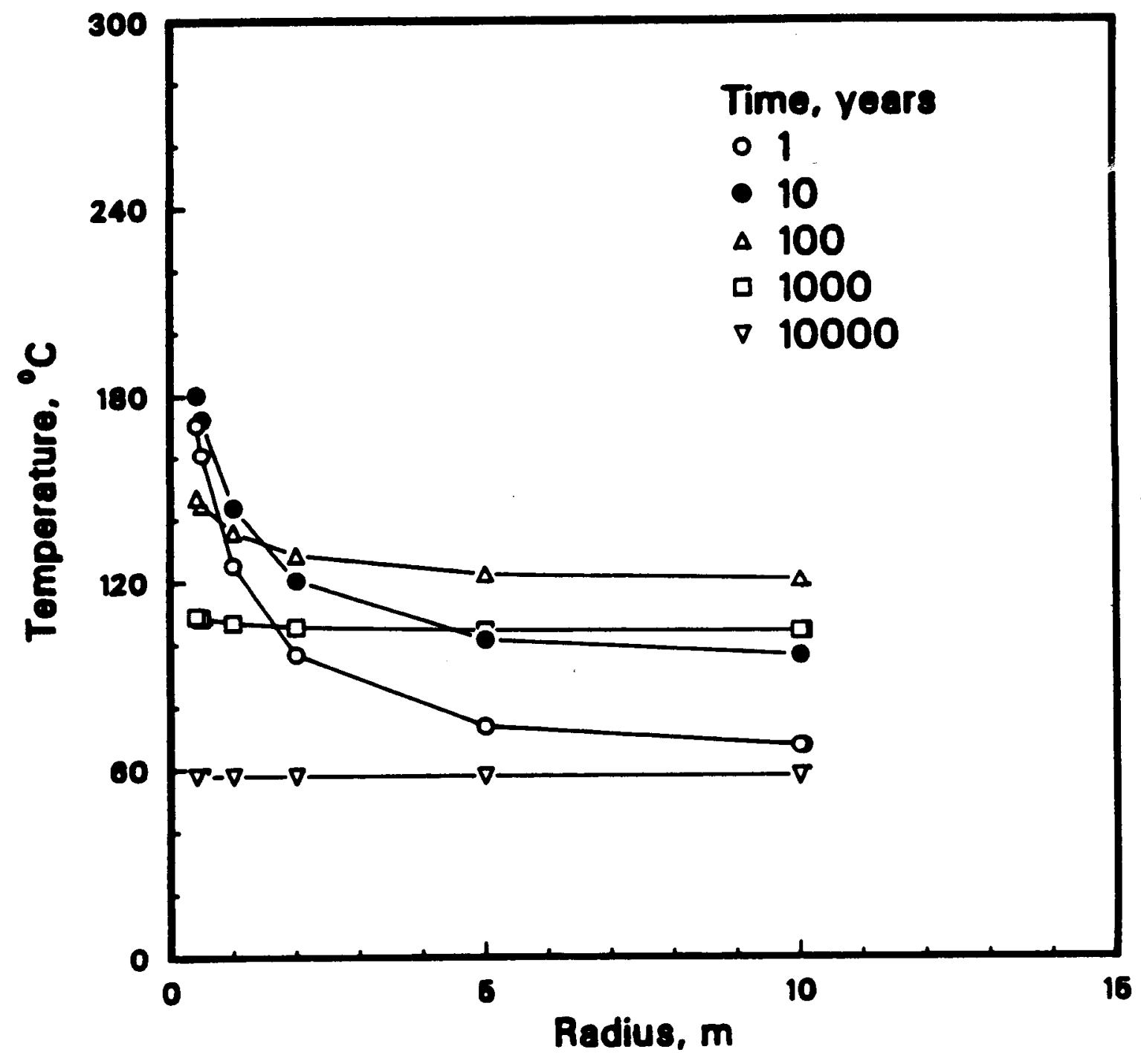

Temparatures Around SFPWR Waste Packses at Vacherio Domo 


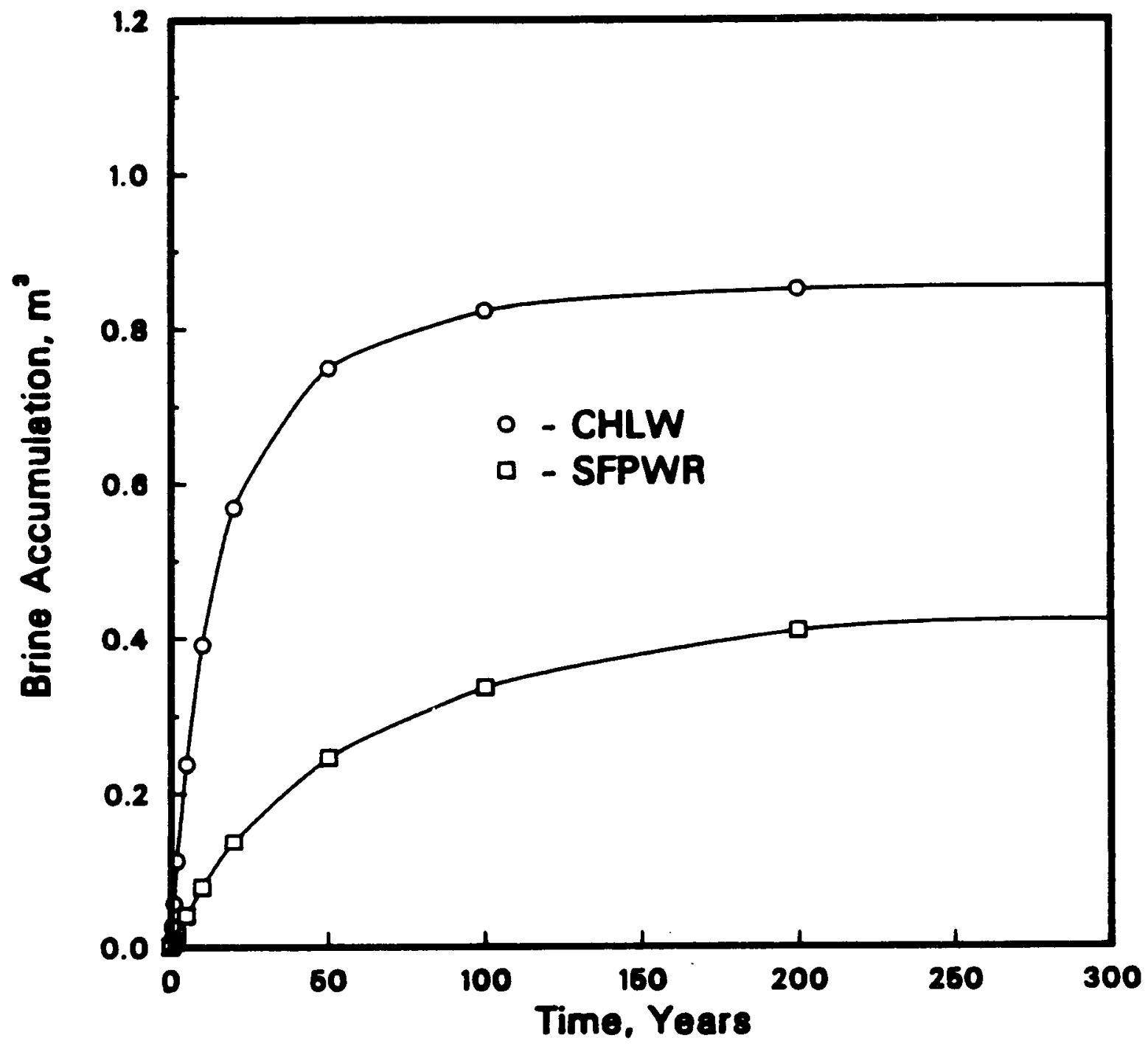

Brime Accumulation at Weste Package with Time and Threahold Gradient of $0.125^{\circ} \mathrm{C} / \mathrm{cm}$ for Deaf Smith

Figure F-15 


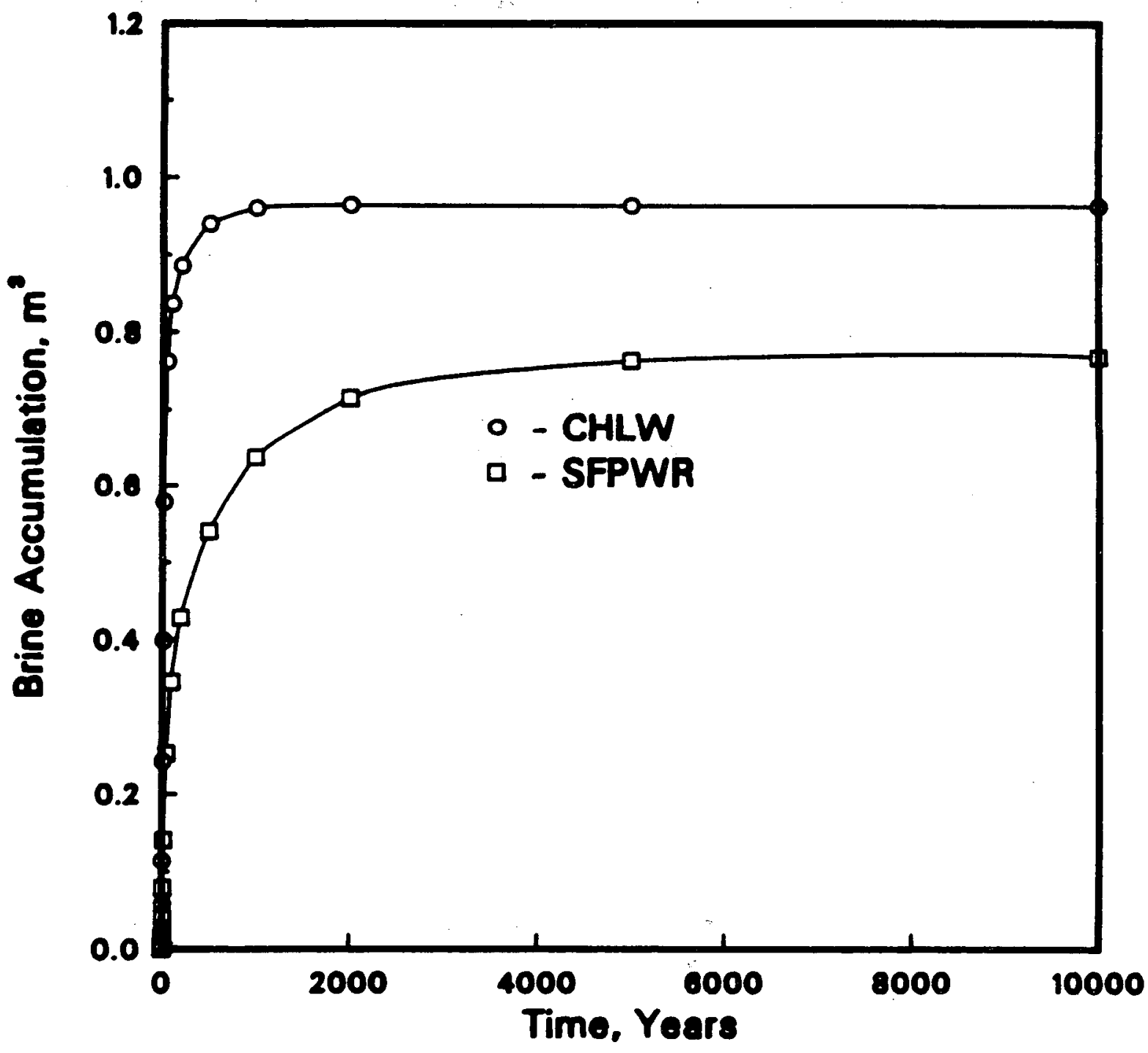

Brine Accumulation at Waste Package with Time and Zaro Threahold Gradient for Doef Smith

Figure F-16 


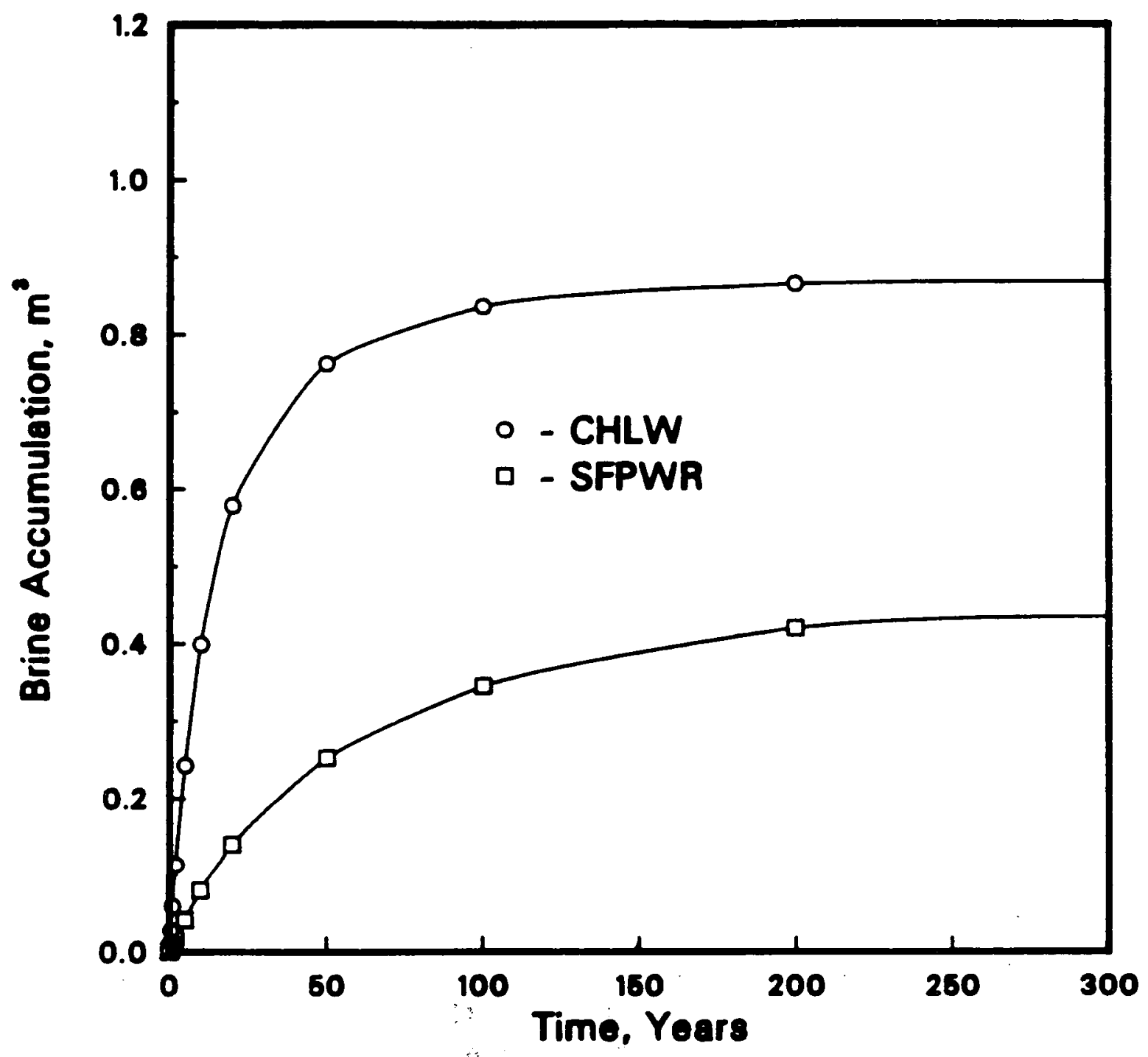

Brine Accumulation at Waste Package with Time and Threshold Gradient of $0.125^{\circ} \mathrm{C} / \mathrm{cm}$ for Swisher

Figure F-17 


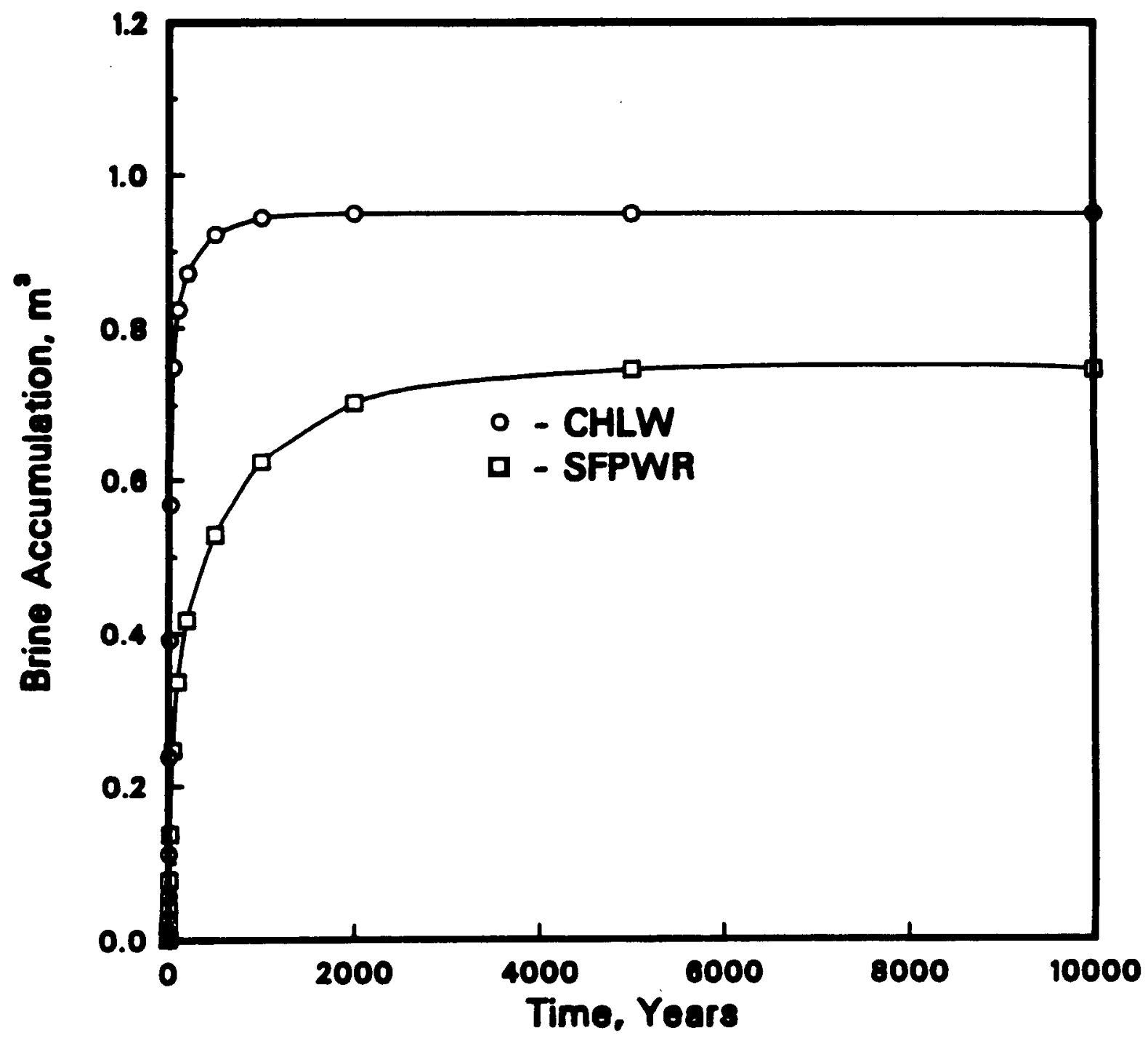

Brine Accumulation at Waste Packens with Time and Zero Threshold Gredient for Swisher

Figure F-18 


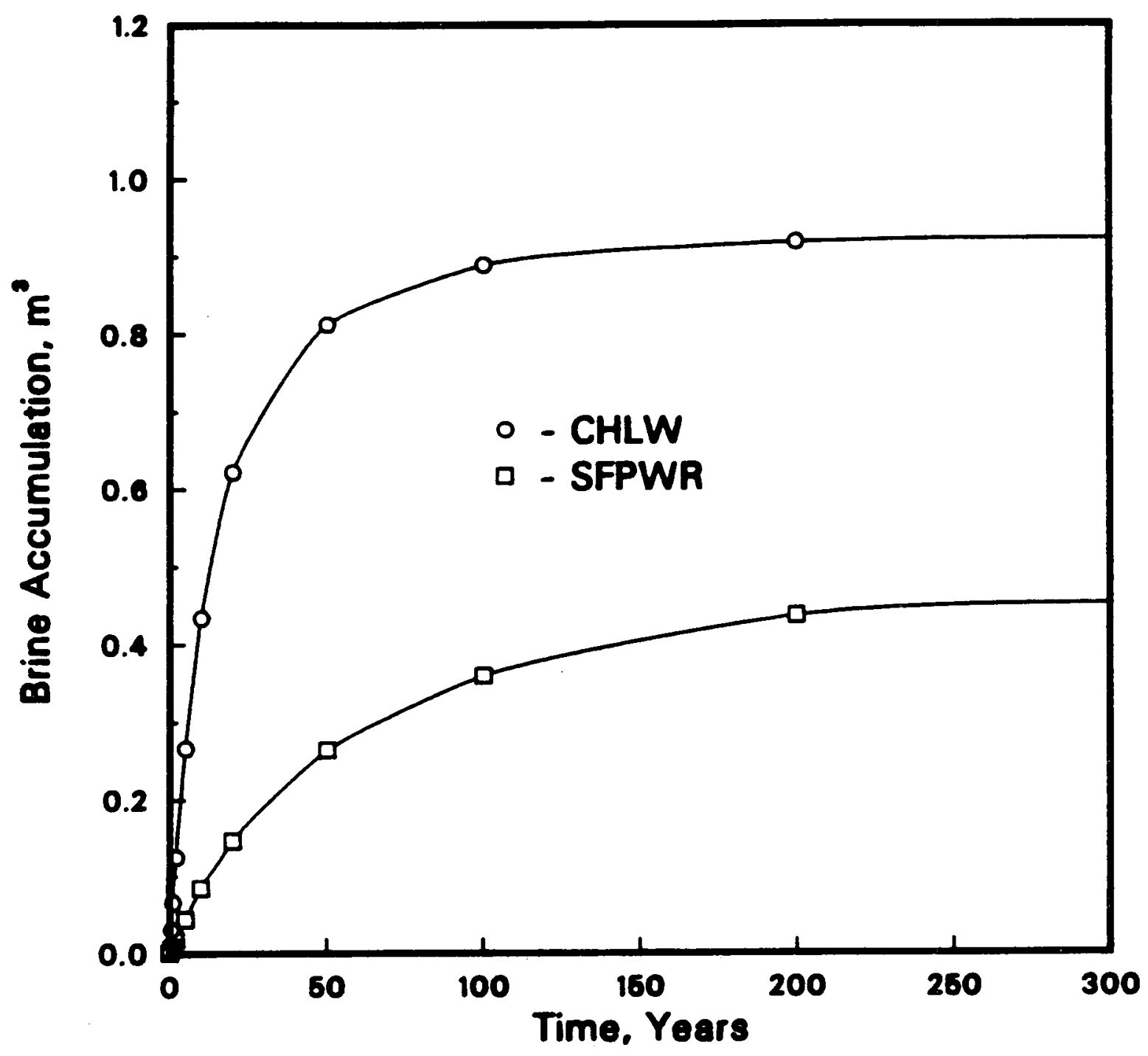

Brine Accumulation at Weate Packere with Time and Threahold Gradient of $0.125{ }^{\circ} \mathrm{C} / \mathrm{em}$ for Davis Canyon

Figure F-19 


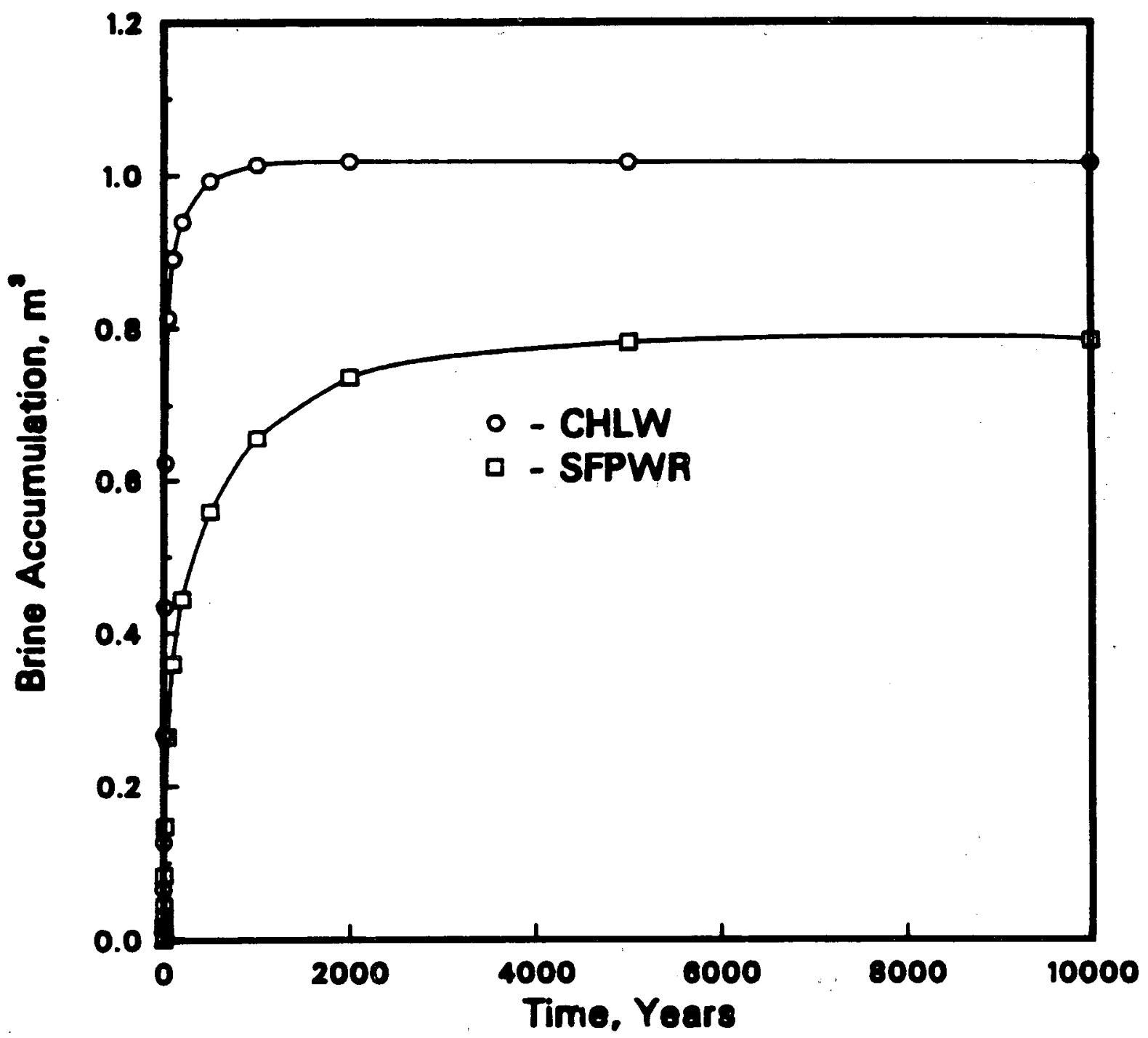

Brine Accumulation at Werto Package with Time and Zoro Threchold Gradiont for Davis Canyon

Figure F-20 


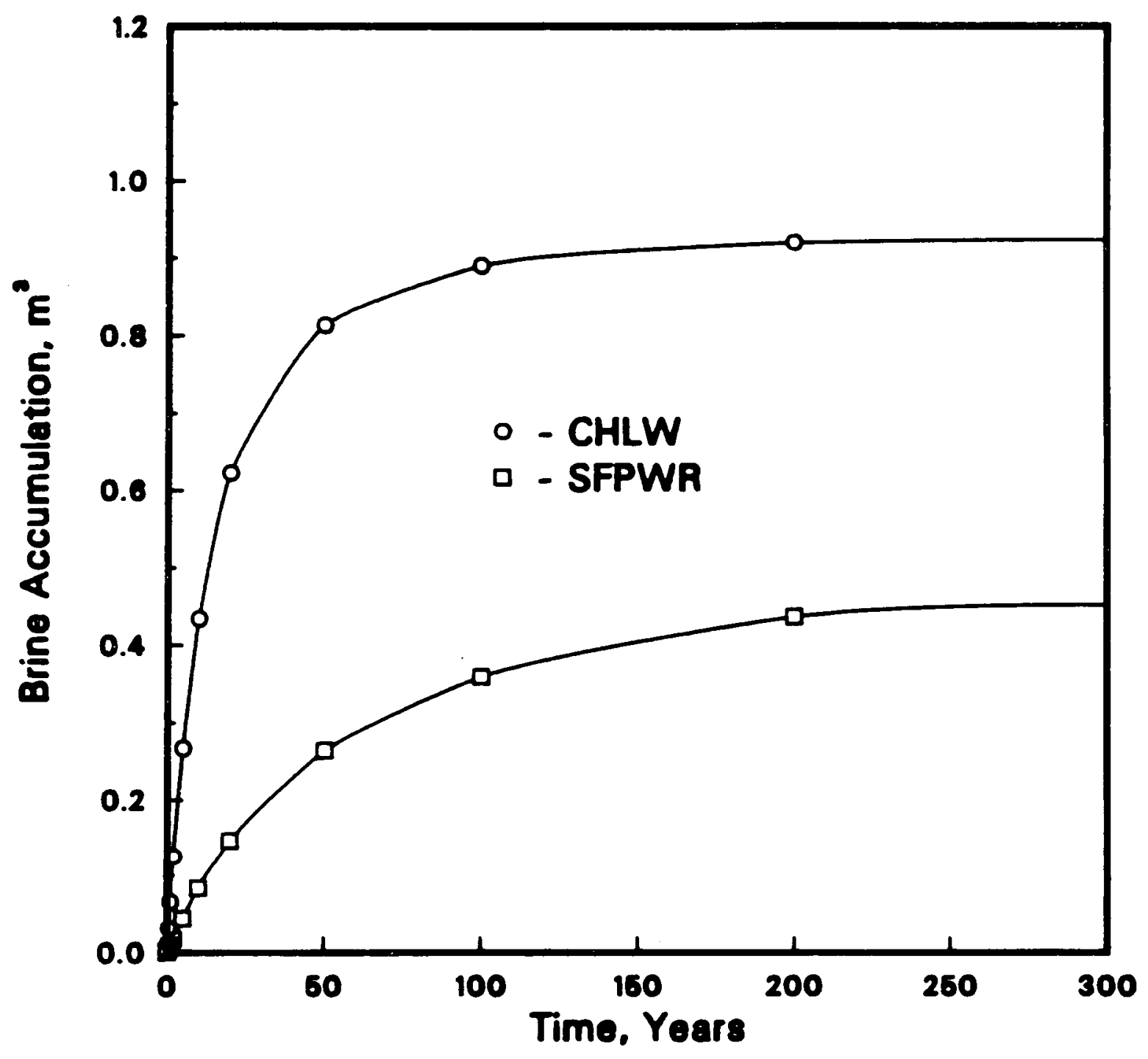

Brine Accumulation at Weate Package with Time and Threshold Gredient of $0.125{ }^{\circ} \mathrm{C} / \mathrm{cm}$ for Lavender Canyon 


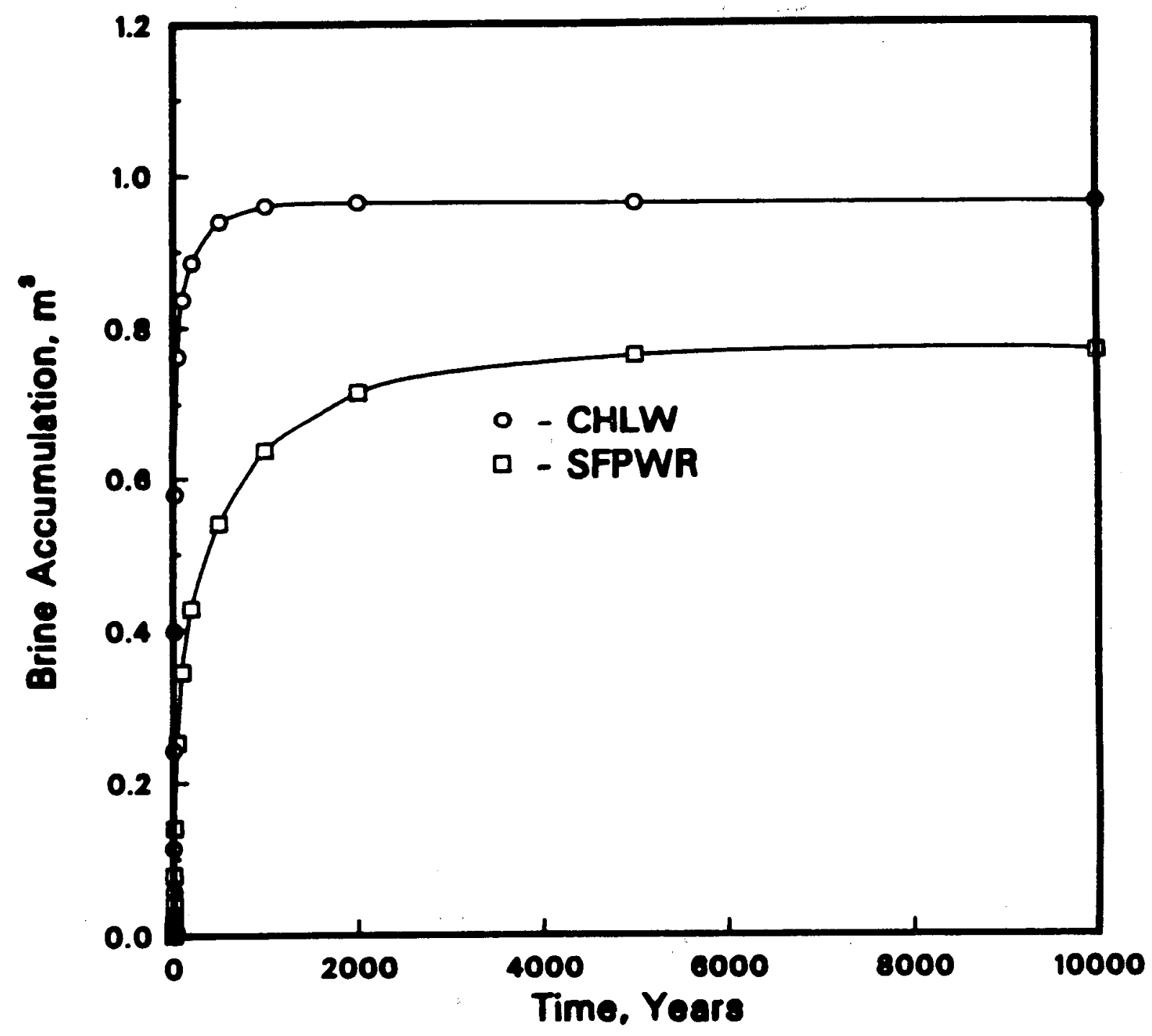

Brine Accumulation at Waste Package with Time and Zaro Threshold Gradient for Davis Canyon

Figure F-22 


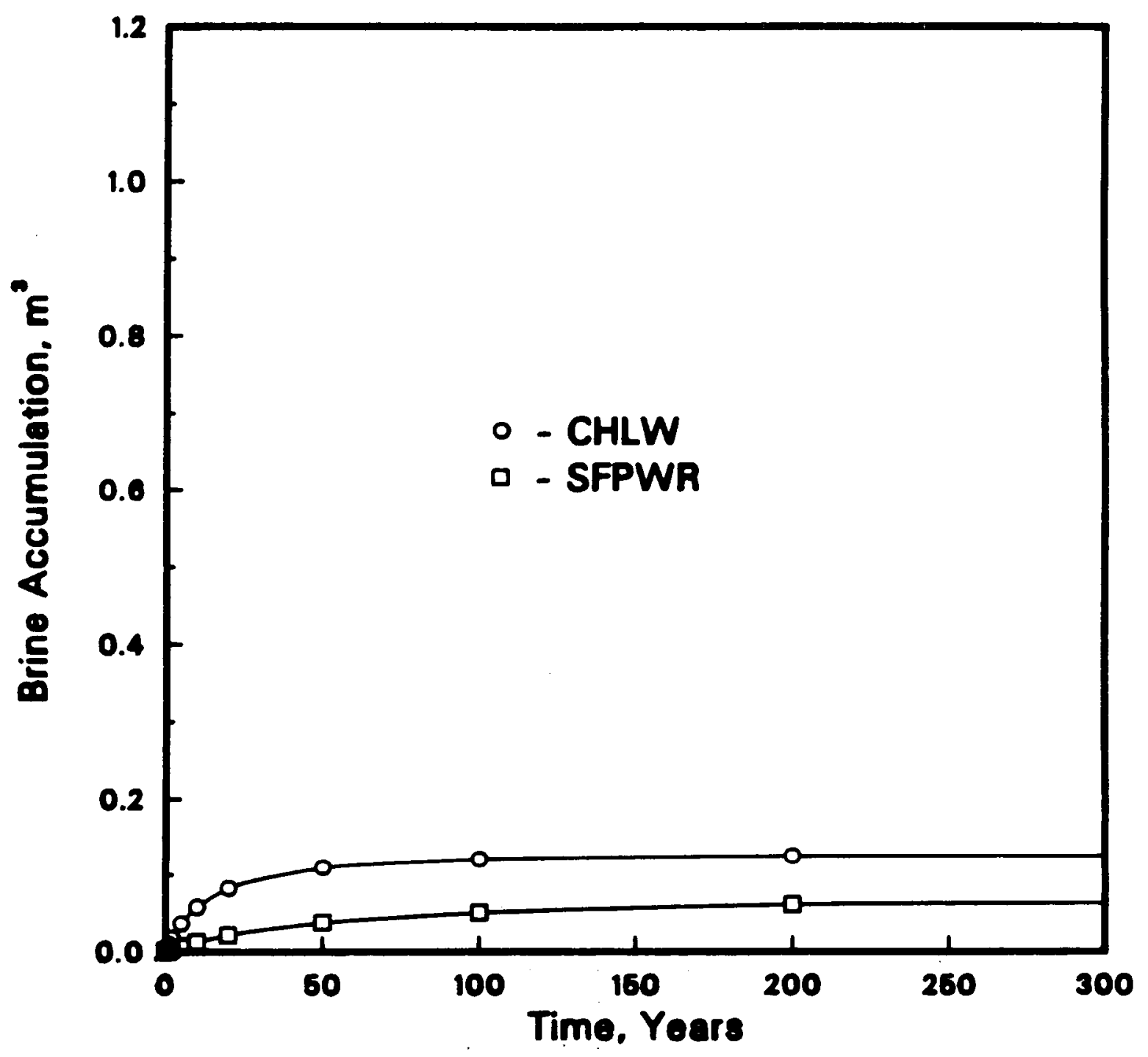

Brine Accumulation at Westo Packeos with Time and Threshold Gradient of $0.125^{\circ} \mathrm{C} / \mathrm{m}$ for Cypress Creak Dome 


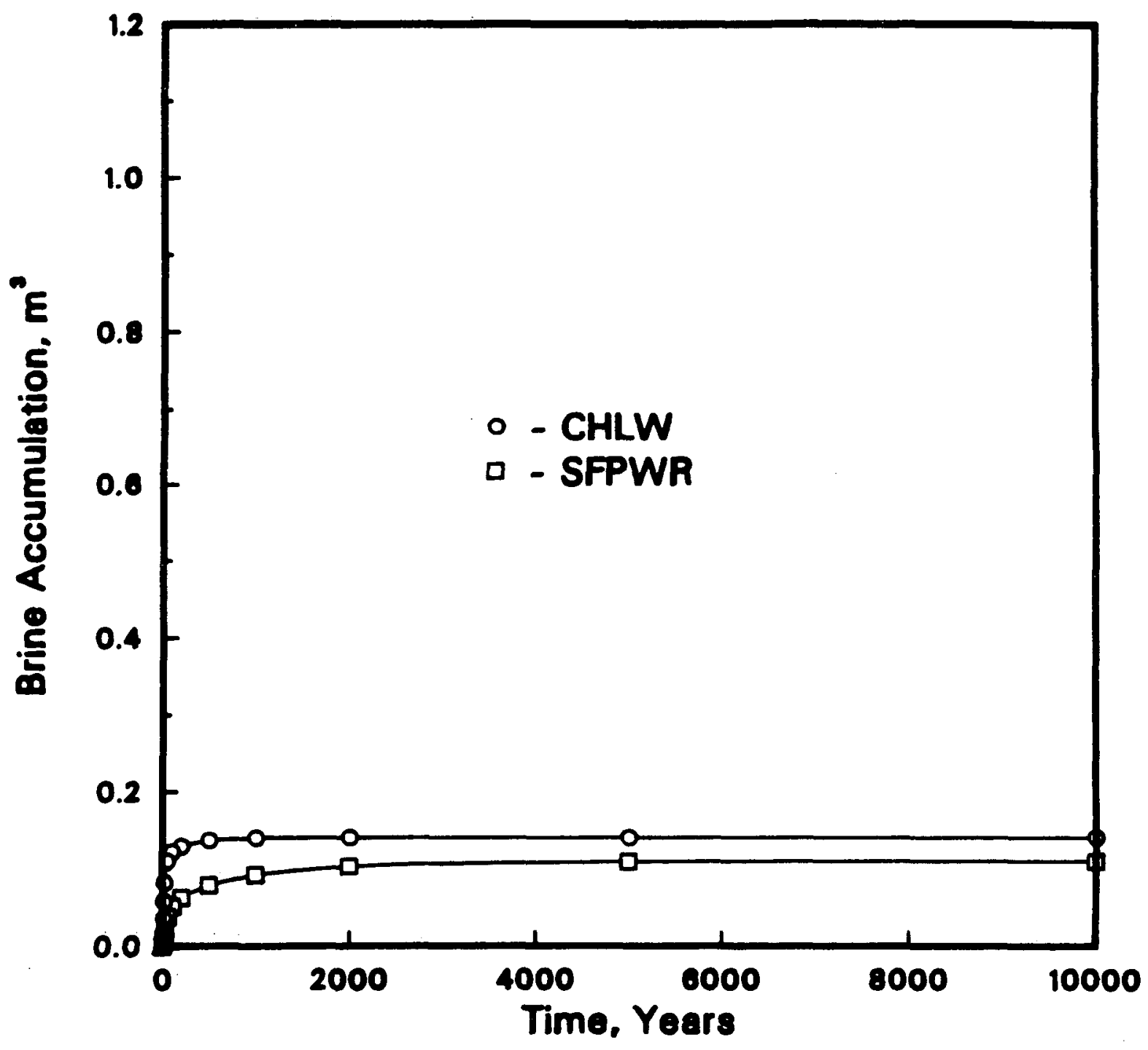

Brine Accumulation at Weste Packege with Time and Zoro Threehold Gredient for Cypress Creak Dome 


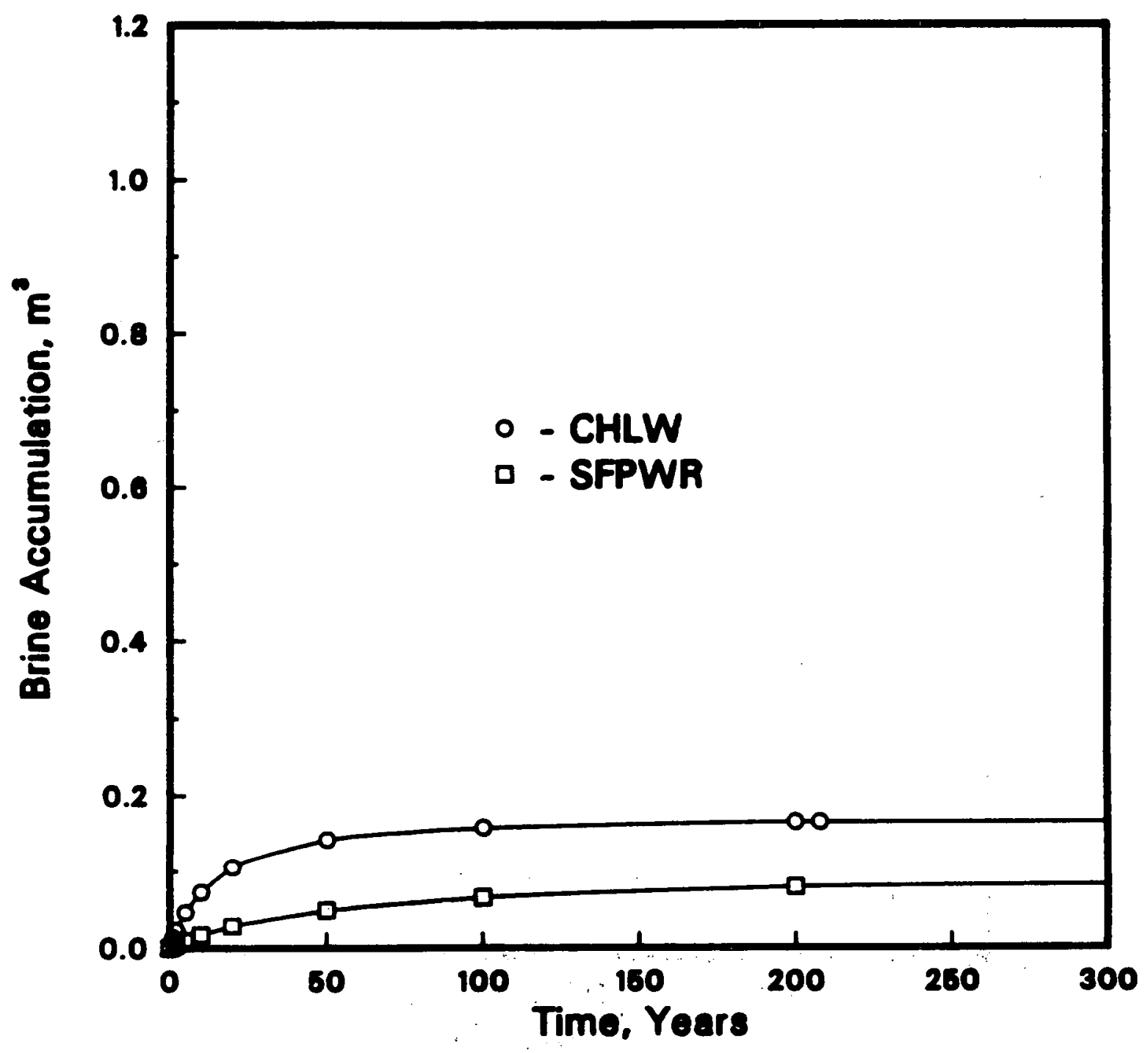

Brine Accumulation at Weoto Packese with Time and Threahold Gradient of $0.125^{\circ} \mathrm{C} / \mathrm{m}$ for Alecteon Doms 


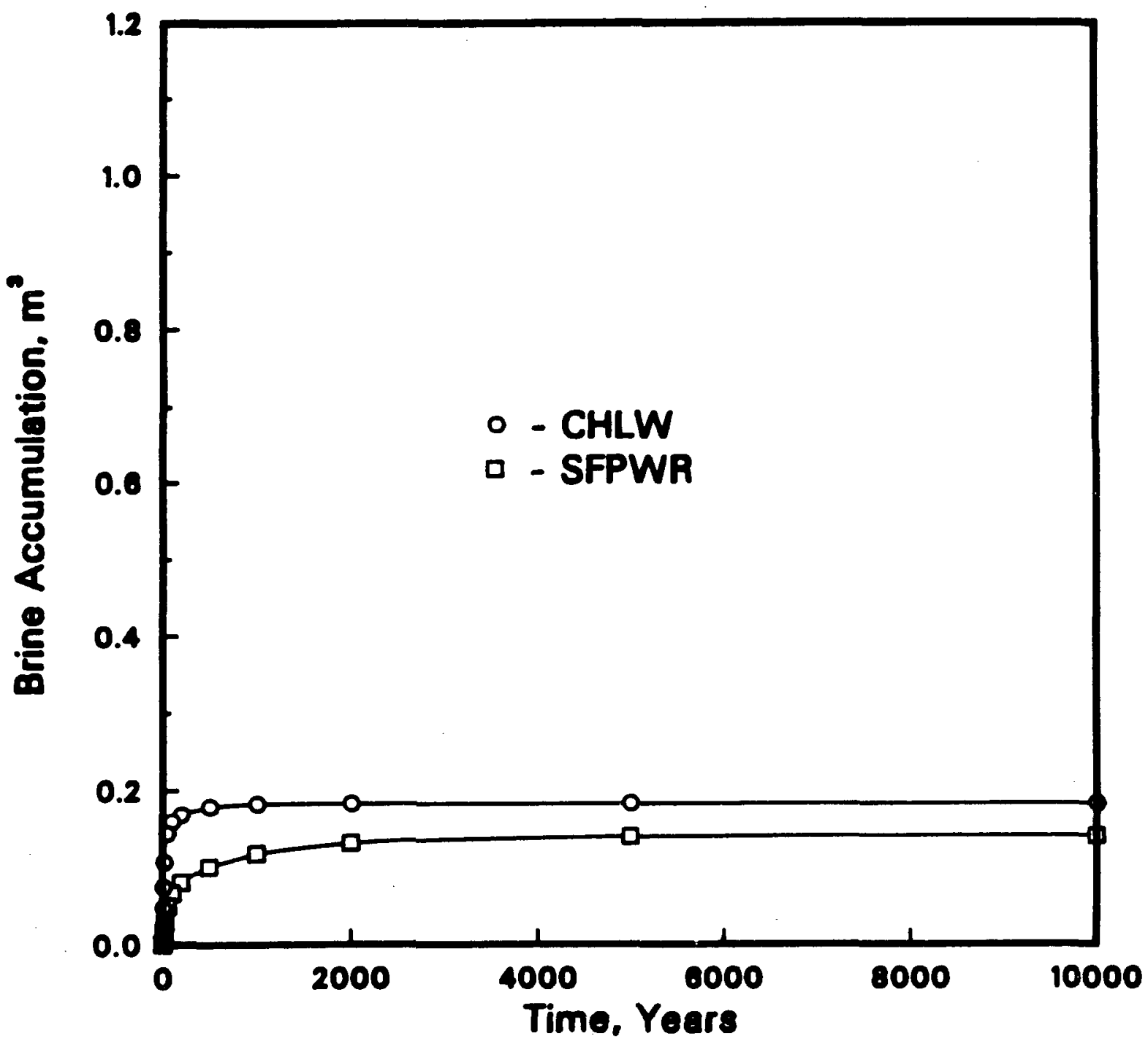

Brino Accumulation at Wastu Packago with Time and Zero Threshold Gredient for Richton Dome

Figure F.26 


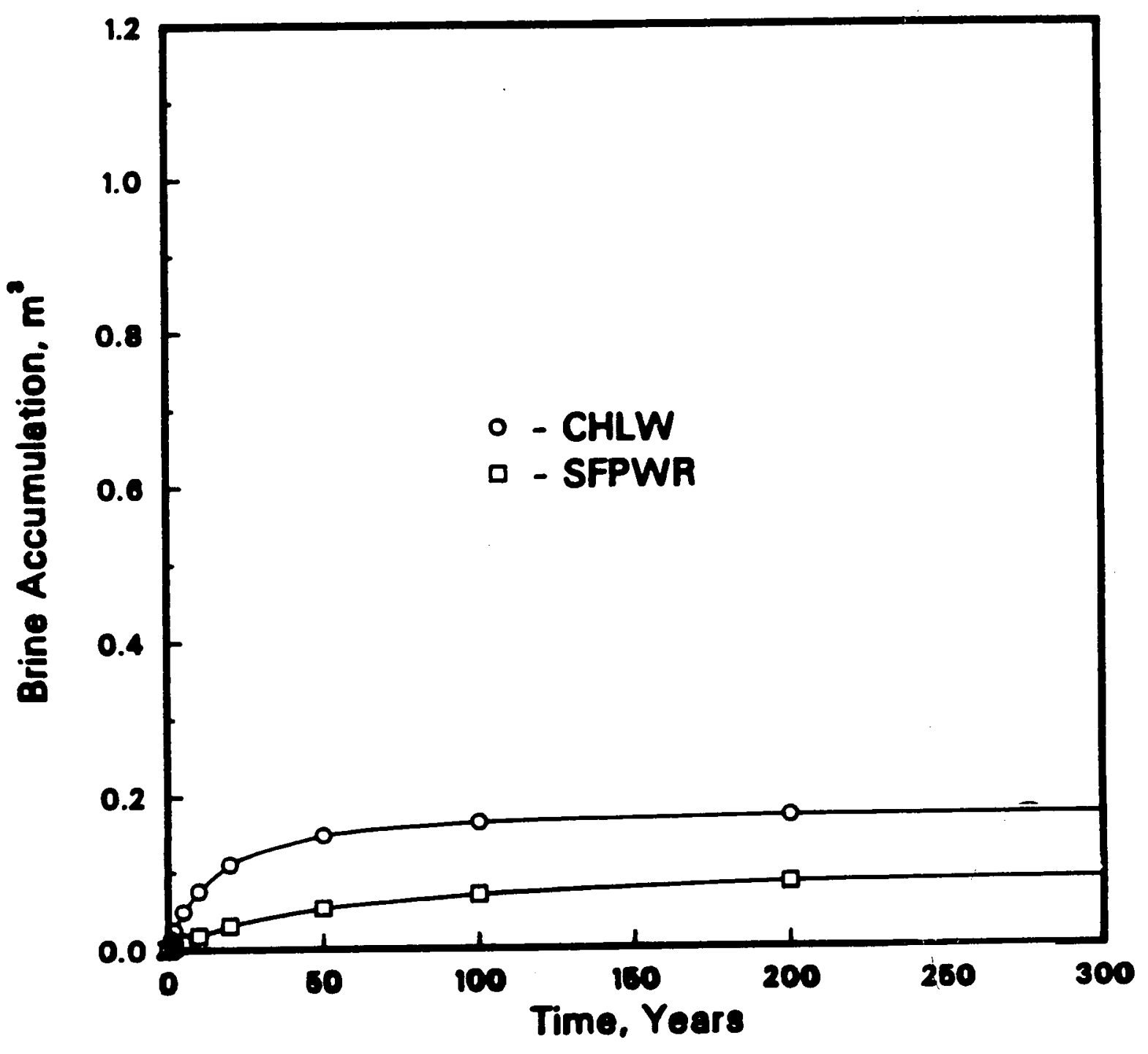

Brine Accumulation et Werte Packago with Time and Throshold Gradient of $0.125^{\circ} \mathrm{C} / \mathrm{m}$ for Vacherie Dome

Figure F-27 


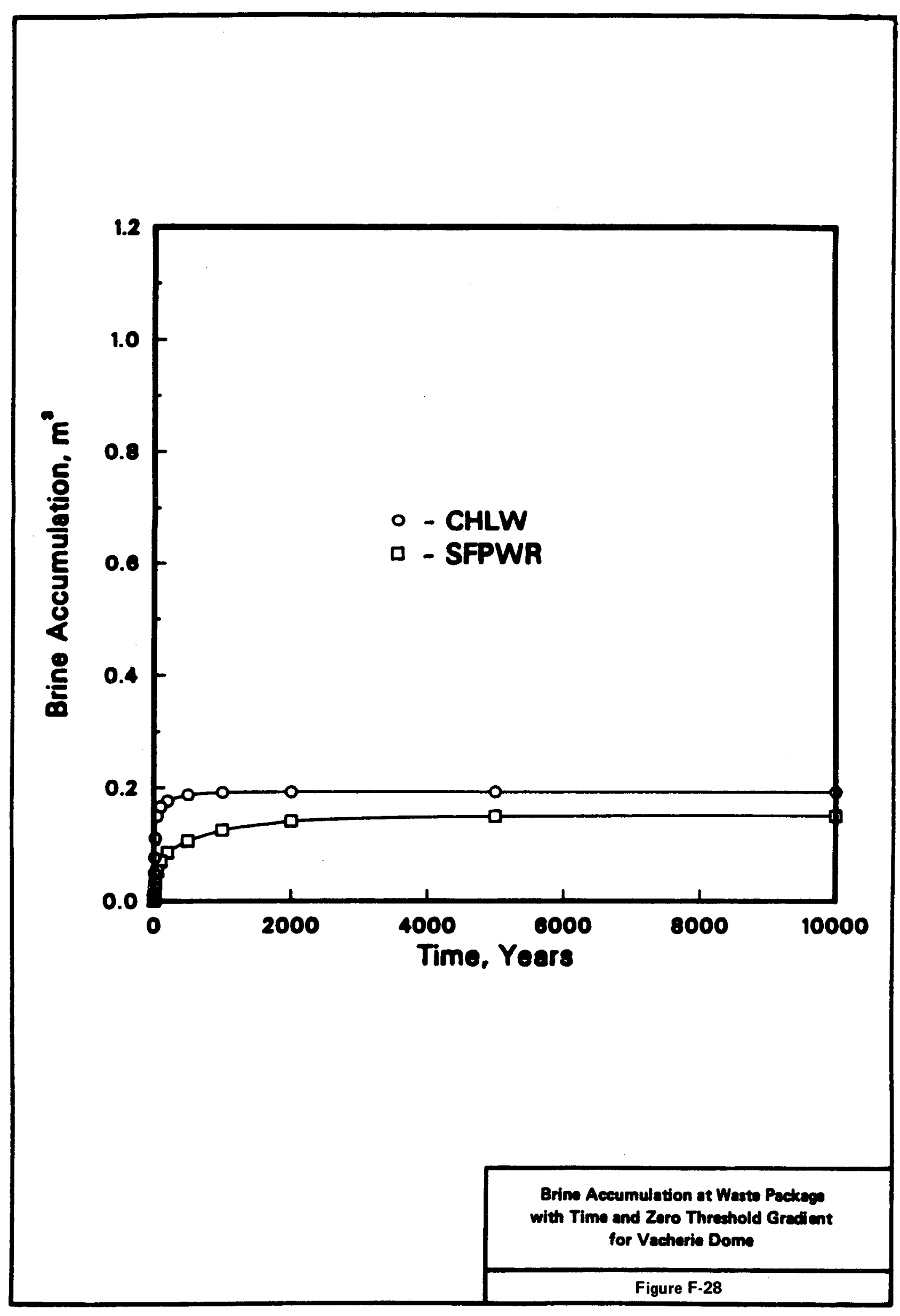




\section{APPENDIX F}

LETTER REPORT FROM E. G. MCNULTY TO S. K. GUPTA

Office of

BATTELLE Project Management Division

Date December 18, 1984

To S. K. Gupta

From

Subject
E. G. McNulty $\varepsilon$ \& $M$

Brine Migration at Potential Salt Sites in Palo Duro, Paradox, and the Gulf Coast
Project Number
Internal Distribution

EG McNulty/LB

SATD File

See enclosed draft figures which give approximate temperatures and brine volumes with time for seven potential salt sites. I calculated the temperatures using the TEMP code and the brine volumes using the BRINEMIG2.

The attached figures that show brine accumulation at the waste package based on a threshold gradient of $0.125^{\circ} \mathrm{C} / \mathrm{cm}$ confirm the approximate correctness of the data given in Table 6-9 of the INTERA report.

$E G M: f k$

Attachment 
APPENDIX G

\section{EVALUATION OF PARAMETERS INVOLVED IN A FLOODED RADIOACTIVE WASTE REPOSITORY IN SALT}

H. C. Claiborne

R. J. Vedder

August 1982 


\title{
EVALUATION OF PARAMETERS INVOLVED IN A FLOODED RADIOACTIVE WASTE REPOSITORY IN SALT
}

\author{
H. C. Claiborne
}

R. J. Vedder

\begin{abstract}
The primary objective is to make a preliminary report on the evaluation of the parameters that are involved in analyzing the consequences of an intrusion of water into a radioactive waste repository.

It was readily apparent that a repository in salt represented a more difficult analysis task than in other geologic media because of salt dissolutioning and mine closure resulting from salt creep. Since the parameters were frequently interrelated for these complex mechanisms, the parameter evaluation was broadened to include examination of potential models for these phenomena that are peculiar to salt.

In this report a discussion of the potential models and required parameters is given for salt dissolutioning, crushed salt permeability as a function of time, disposal room closure, and waste form leaching. Some recommendations are made for application to a flooded repository in salt and some recommended equations for physical properties as functions of temperature and salt concentration are given.
\end{abstract}

\subsection{INTRODUCTION}

The objective of the project was to make available information needed in developing the methodology and appropriate computer codes for analyzing the effects of water intrusion into a radioactive waste repository which is applicable for salt and other geologic media.

As part of this project, the parameters involved required evaluation with respect to their availability and uncertainties. The primary objective here is to make a preliminary report on the parameter evaluation.

It was readily apparent that a repository in salt represented a more difficult analysis task than in other geologic media because of salt dissolutioning and mine closure resulting from salt creep. Since the parameters were 
frequently interrelated for these complex mechanisms, the parameter evaluation was broadened to include examination of potential models for these phenomena that are peculiar to salt.

In the following sections of this report a discussion of the potential models and required parameters is given for salt dissolutioning, crushed salt permeability as a function of time, disposal room closure, and waste form leaching. This is followed by recommended equations for physical properties as functions of temperature and salt concentration.

\subsection{SALT SOLUTIONING}

Water intruding into a radioactive waste repository in salt will quickly become a saturated brine. The kinetics of solutioning will vary depending on salt surface area, temperature, initial salt concentration of the intruding water, and transport mechanisms of both solute and solvent that give rise to an effective mass transfer coefficient. In any event it seems that the solutioning process can be divided into two phases that are fairly distinguishable even though some flow conditions can blur the boundary. In the first or preheating phase, dissolution of the salt would occur at essentially the temperature of the intruding water (probably in the range of 15 to $30^{\circ} \mathrm{C}$ ). The dissolution process is endothermic but the heat transferred into the solution will tend to maintain an isothermal state in the initial phase. The second phase will occur when the temperature of the essentially saturated brine begins to rise as heat is transferred from the surrounding rock salt. Salt will preferentially dissolve from the warm surfaces and be transported by natural convection to cooler regions of the repository where it will precipitate out. This process of dissolution in the warm regions and precipitation in the cooler regions will continue until the brine reaches uniform temperature.

Modeling the kinetics of salt dissolution in a radioactive waste repository during a flooding incident is an obviously difficult task because of the number of parameters involved and their variations with spatial position, flow regime, and time. The effectiveness mass transfer coefficient for the solutioning process is the single most important parameter and the most 
difficult to ascertain for the variable conditions of a flooded repository. However, except for the improbable case of large flow rates through a repository, it appears that the kinetics of solution mining in salt have similarity to solutioning in a flooded repository during the initial or isothermal phase. The potential errors involved in using models developed for solution mining can be large when used to estimate dissolution ranges in salt repositories. Fortunately, the results obtained show that the time scale involved in the approach to saturation of intruding fresh water is very small compared to the time scale involved in analyzing the consequences of flooding. Consequently, an order of magnitude or two error in the effective mass transfer coefficient for dissolution becomes unimportant.

When the saturated brine begins to heat up, additional salt will dissolve and mass transport by thermal convection will occur. This heat up phase has been examined by Jung and Delislel and their conclusions and results are applied here.

In the following sections, the models developed for both the isothermal and heat up salt dissolution phases are discussed and the application to a flooded repository is made.

\subsection{Pre-heating Phase}

Two models having application to the pre-heating or isothermal dissolution phase in the saturation of intruding water have been identified in the studies pertaining to the solution mining of salt. These models describe dissolution by natural convection and by turbulent forced convection. In a flooding repository, after an initial period, the brine velocities will be sufficiently low as to cause the boundary layer to control the dissolution rates. Turbulent forced convection and the higher dissolution rates it engenders would be important only in limited regions around the entrance and exit. Although a vast literature exists on solution mining and the resulting salt dissolution mechanisms, the studies by Durie and Jessen ${ }^{2}$ and by Jessen ${ }^{3}$ seem most appropriate to the problem being examined and the following discussion of the isothermal phase is taken from their publications, particularly that by Durie and Jessen. 


\subsubsection{Natural convection}

In the solution mining process, natural convection effects are of prime importance because of the generally small lineal velocities near the saltbrine interface. Salt dissolution causes the brine density near the saltbrine interface to increase. The more dense brine sinks and creates a laminar boundary layer between the salt surface and the bulk liquid. The laminar boundary can eventually become turbulent. However, this turbulence and laminar flow in the bulk of the liquid will not significantly change the dissolution rates unless the turbulence extends throughout the system.1,2

By analogy to heat transfer, Durie and Jessen ${ }^{2}$ generated a solution to the boundary layer problem for salt dissolution from a smooth vertical surface in a quiescent body of water.

The equation developed was

$$
M=0.0977\left(C_{s}-C\right)^{5 / 4} D^{3 / 4} u^{-1 / 4} H^{-1 / 4}
$$

where

$H=$ height of exposed salt surface, cm

$D=$ average diffusion coefficient for salt, $\mathrm{cm}^{2} / \mathrm{sec}$

$\mathrm{C}_{\mathrm{S}}=$ saturation concentration, $\mathrm{mol} / \mathrm{L}$

$\mathrm{C}=$ concentration in bulk fluid, $\mathrm{mol} / \mathrm{L}$

$U=$ average kinematic viscosity, $\mathrm{cm}^{2} / \mathrm{sec}$

$M=$ mass salt flux from surface, $\mathrm{g} / \mathrm{cm}^{2} \mathrm{sec}$

Experiments made to verify Eq. (1) produced dissolution rates which were much greater than those predicted by the equation. This was due to irregularities that developed on the salt surface. An empirical factor, A, was developed that when used as a multiplier of Eq. (1) produced good agreement between experiment and theory when

$$
A=1.7+0.26\left(C_{S}-C\right)
$$

Later studies of inclined surfaces by Jessen ${ }^{3}$ showed the mass flux from a horizontal surface to be higher than that predicted by the empirically corrected $\mathrm{Eq}$. (1) when the salt overlies the water (ceiling) and approaches zero 
for a horizontal surface when the water overlies the salt (floor). The different rates are due to the varying salt concentration throughout the brine. Brine near the floor is more dense (more nearly saturated) than brine near the ceiling. In the application to a repository, the brine will probably be nearly saturated by the time the liquid rises to the ceiling and the angle inclination of the salt surface is of no consequence. In the case of an unbackfilled room, however, salt dissolution on the floor could occur by a different diffusional process with the relative importance of the dissolution mechanisms being a function of the water flow rate. This is discussed in more detail in sect. 2.1.3.

\subsubsection{Turbulent forced convection}

As previously mentioned, turbulence in the boundary layer will not greatly affect the salt dissolution provided that the turbulence does not extend throughout the bulk fluid. For this latter condition, forcedconvection turbulence will distort the boundary layer and greatly increase salt dissolution rates.

Durie and Jessen ${ }^{2}$ performed experiments on dissolutioning in the turbulent regime by pumping water at high rates through circular holes in salt blocks. For the range of velocities and block size tested, they found that rate of salt removal was 10 to 20 times that observed using laminar flow rates in the same geometries. This experiment represented confined flow in pipes and is not a good model for solution mining or flow through a repository. Jessen ${ }^{3}$ later simulated a turbulent free-convection system by mechanical stirring of brine of various concentrations in contact with crystalline salt of various shapes and sizes. The type and shape of the salt crystals had little effect on the rate of salt dissolution. An increase of about $10 \%$ in the dissolution rate for the smaller crystals occurred in comparison with the larger ones.

An approximate fit to the data for the turbulent conditions of the Jessen experiments is given by

$$
M=3.9 \times 10^{-4}\left(C_{s}-C\right)
$$


Making a similar fit to the Durie and Jessen data for free convection with no turbulence results in

$$
M=1.5 \times 10^{-4}\left(C_{s}-C\right)
$$

The ratio of Eq. (3) to Eq. (4) is only 2.6. Since Eq. (3) is based on a better simulation of turbulent conditions in solution mining or flow through a repository, it would seem that a factor of 3 increase is more likely due to turbulence rather than a factor of 10 or more.

\subsubsection{Salt dissolution in a repository not backfilled with crushed salt}

Flooding of a repository during the operational period or in some retrievable unbackfilled mode does not seem to be a credible possibility because of site selection criteria and mine maintenance procedures. If the unlikely event does occur, the most important consideration would be potential exposure of the waste canisters. Another consideration is the speed of saturation of the inflowing water.

As previously mentioned in Sect. 2.1.1, the work by Jessen ${ }^{3}$ demonstrated that different mechanisms of dissolution can exist at the vertical and horizontal surfaces.

The horizontal surface of salt overlying the solution (repository ceiling) experiences the greatest dissolution rate because of cellular flow, a free-convection phenomenon that occurs because the denser solution at the salt-water interface falls through the less dense saline solution below and is constantly replaced by the latter. This develops a free-convection flow field with a cellular structure. The boundary layer theory for vertical walls as exemplified by Eq. (1) also involves free convection due to density differences, but the boundary acts as a restriction to the convection mechanism that limits the dissolution rate to lower values.

The dissolution rate of a horizontal salt surface underlying the solution (repository floor) is substantially less than that of the other surfaces because protection is provided by a layer of nearly saturated brine, and the 
dissolution process becomes diffusion 1 imited. In an actual repository additional protection to the floor would be provided by insoluble residues.

In addition to the work by Durie and Jessen, ${ }^{2}$ Jung and Delisle 1 also found that low dissolution rates existed at the floor of a repository model even with a net flow through the room.

A simple calculation shows that a disposal room filled with fresh water would require dissolution of about $0.7 \mathrm{~m}$ from the walls, ceiling, and floor to become saturated if uniform dissolution from all surfaces were assumed. In view of the previous discussion, considerably less salt removal can be expected from the floor. Even if dissolution occurred on the floor alone, only $2.8 \mathrm{~m}$ would be dissolved. Consequently, it seems incredible that a waste canister could be exposed in a flooded repository due to dissolutioning, barring an improbably large and continuous flow through a repository disposal room.

A conservative estimate of the time required for intruding water to reach saturation can be made by applying Eq. (1) to a typical repository room that is completely filled with water at $30^{\circ} \mathrm{C}$. Any turbulence effects or enhanced dissolution rates on the ceiling would decrease the saturation time. In applying Eq. (1) a stepwise procedure was used in which it was assumed that the salt dissolved in a previous time step was completely mixed in determining the physical properties used in the next time step. The results shown in Fig. 1 indicate that the water will be essentially saturated within two weeks after filling a disposal room. Although parameters could be quite different than those that were used and the model is somewhat crude, it seems safe to conclude that saturation would occur in a matter of days and at most, a few weeks after complete flooding.

\subsubsection{Crushed salt backfilling}

A sealed repository in salt will very probably contain disposal rooms that are backfilled with crushed salt. The crushed salt will provide a surface area of about 1,000 to 1,500 times greater than that of the repository walls, ceiling, and floor. Consequently, intruding water will preferentially dissolve the crushed salt and will quickly become saturated. Assuming that the mass transfer rate can be estimated by Eq. (4), simpi a calculations for a 
ORNL DWG 82-1206

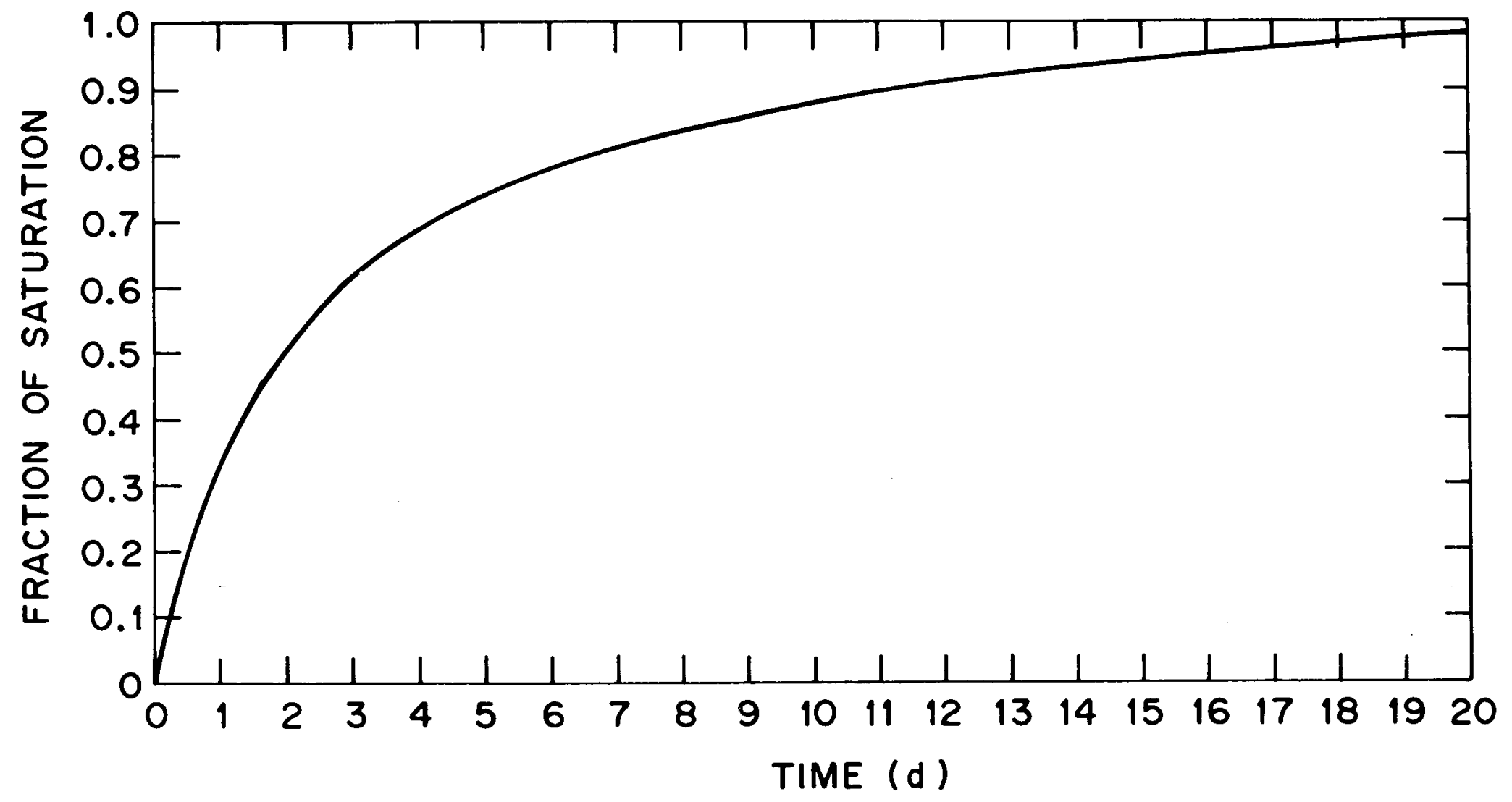

Figure 1. Approach to Saturation for Salt Dissolutioning by Natural Convection 
reasonable range of fresh water flow rates show that the water will be saturated within a few meters of contacting the backfill.

When a room becomes completely flooded and no further flow occurs, the height of the bed of crushed salt that remains will depend on the salt concentration of the intruding water, final temperature, and void fraction in the crushed salt. Based on material balances for the salt and water, the following equation (see appendix Derivation l) can be used to estimate the height of the remaining bed of salt:

$$
\frac{h}{H}=\frac{\rho_{s} f_{i}+\rho_{f} \psi}{\rho_{s} f_{s}+\rho_{f} f_{f} \psi}
$$

where

$$
\begin{aligned}
& h=\text { height of remaining crushed salt, } m \\
& H=\text { height of room, } m \\
& \rho=\text { density of saturated solution or solid salt, } \mathrm{g} / \mathrm{cm}^{3} \\
& f=\text { fraction of solid salt in crushed salt } \\
& \psi=\frac{F_{s i}}{F_{w i}}-F_{s f} \\
& F=\text { wt. fraction of salt or water in solution } \\
& \quad \text { and s:bscripts } \\
& \text { s refers to solid salt, } \\
& i \text { refers to initial condition, and } \\
& f \text { refers to final condition and saturated solution, } \\
& w \text { refers to water. }
\end{aligned}
$$

\subsection{Heatup phase}

It is necessary to examine this only if flooding occurs while the package is still emitting heat during the first couple of centuries.

In the flooding of a salt mine, saturation would be complete shortly after flooding and equilibrium would prevail. However, in a waste repository, heating of the saturated brine by the waste packages would cause additional 
salt to enter into solution. This aspect of salt dissolution was thoroughly examined by Jung and Delisle ${ }^{1}$ for an unbackfilled room and their results are utilized in this report. They identified two distinct processes: solubility increase due to the temperature rise and salt transport as the result of convective heat transport.

The additional salt dissolution from repository surfaces or salt backfill due to temperature $r$ ise of the solution is of little significance since the solubility of salt is not a sensitive function of the temperature. The salt transport mechanisms can be important, however, and two types were identified and examined by Jung and Delisle. One involves any net flow of brine that will cause dissolved salt to be transported from the heated regions to the cooler regions of the repository where salt will be precipitated. The other transport mechanism involves the concept of diffusion of salt from a solid surface across a stagnant temperature and diffusion boundary layer into a perfectly mixed (infinite thermal conductivity and diffusion coefficient) body of saturated brine. The transport of salt across the boundary layers was treated similarly to migration of brine inclusions up a thermal gradient in rock salt, which was first analyzed by Anthony and $\mathrm{Cline}{ }^{4}$ and thoroughly examined by Jenks and Claiborne. 5 During this migration phenomenon salt is dissolved on the hot side of the brine inclusion, undergoes both concentration gradient and thermal diffusion through the brine, and precipitates on the cold side. In the development by Jung and Delislel the salt surface of the cold side is considered replaced by the perfectly mixed body of saturated brine, and salt diffuses across the stagnant boundary layers between the salt surface and the edge of the bulk fluid in accordance with the Anthony and Cline treatment. The following equation was derived (see appendix Derivation 2) that relates the mass flux to the heat flux from the salt surface.

$$
\frac{M}{q}=\left(\frac{D}{K}\right)\left[\left(\frac{d C}{d t}\right) L e^{n}+S C_{b}\right]
$$

where

$$
\begin{aligned}
& M=\text { mass flux of salt }, \mathrm{g} / \mathrm{cm}^{2} \mathrm{sec} \\
& q=\text { heat flux, } \mathrm{W} / \mathrm{cm}^{2} \\
& D=\text { diffusion coefficient }, \mathrm{cm}^{2} / \mathrm{sec}
\end{aligned}
$$




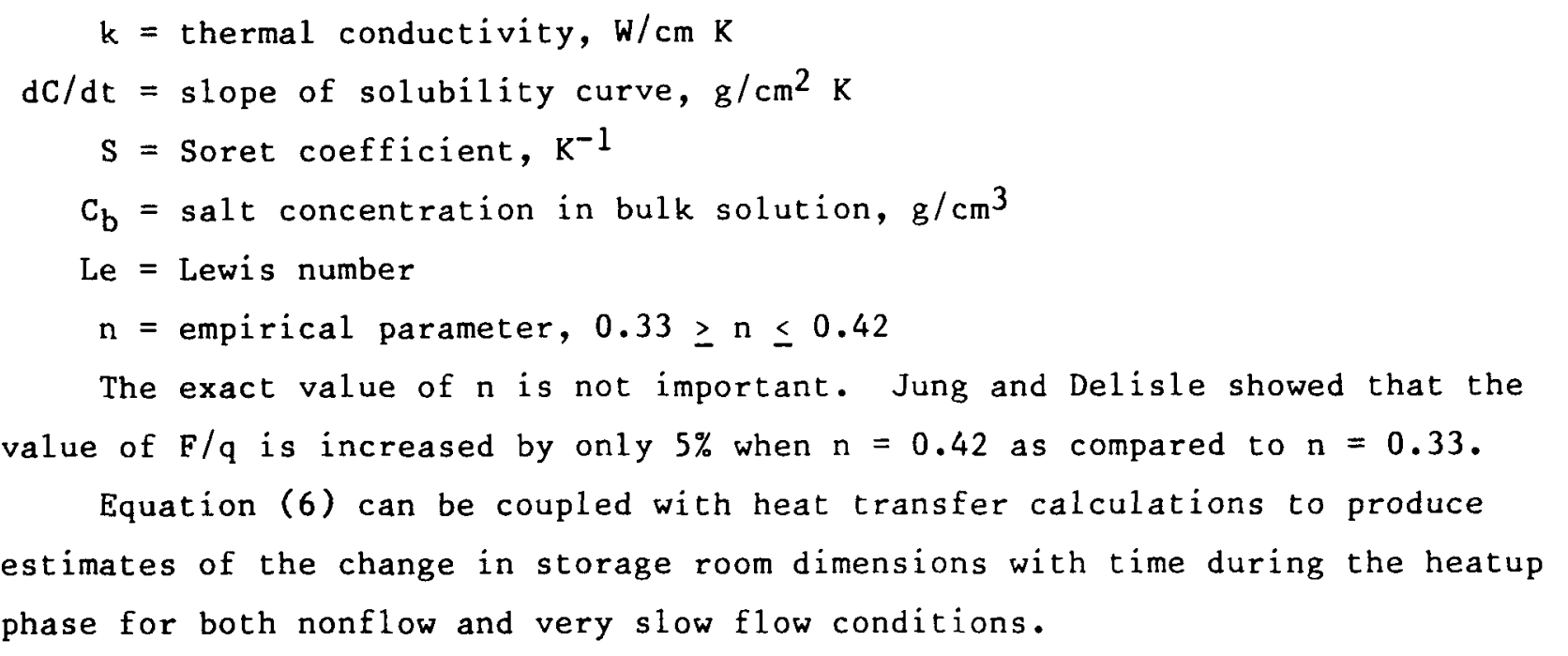

\subsection{CRUSHED SALT PERMEABILITY AS A FUNCTION OF TIME}

Crushed salt in bulk lots will slowly reconsolidate by plastic deformation and recrystallization and consequently lower the permeability to fluid transport. This rate of permeability decrease is a function of stress, temperature, particle size distribution, void fraction, and the amount of water present. All of the variables affecting permeability will change with time under the conditions of a flooded repository. In the following sections each of these parameters and the empirical equation developed from experimental data by Shor et al. 6 that correlates the permeability as a function of these parameters are examined with respect to application in a radioactive waste repository.

\subsection{Stress}

It is well-known that any column of crushed material consisting of random size particles will decrease in height to an irreducible minimum void fraction when tamped or vibrated because of rearrangement of the particles into their most stable configuration. In the case of salt which undergoes plastic flow when stressed, it is theoretically possible to squeeze out all fluids when sufficient stress is supplied and create a solid mass of salt with essentially no void space. 
In a flooded repository the stress on the salt would eventually equal the lithostatic pressure because of mine closure due to salt creep. However, as long as the mine roof is not in contact with the remaining crushed salt, the crushed salt would not be stressed significantly since the liquid above and within the salt bed will transmit the stress uniformly in all directions. When the roof of the disposal room contacts the salt bed, the stress will start increasing until lithostatic pressure is obtained, which may take hundreds to thousands of years. This rate of mine closure and stress increase depends on mine depth, temperature, creep properties of the rock salt, extraction ratio for the mine, and net liquid exclusion rate after contact of the roof with the salt bed.

\subsection{Temperature}

Temperature affects the plasticity and creep rate of salt. After flooding occurs, the crushed-salt bed will be close to the temperature of the intruding water if the flooding is rapid. Otherwise the temperature of the crushed salt becomes a function of the flooding rate. In either case the temperature will begin to rise (assuming flooding within the first few hundred years) by heat transfer from the boundaries of the disposal room. Eventually the temperature will begin to decrease.

\subsection{Particle Size Distribution and Void Fraction}

The particle size distribution will affect the void fraction and rate of dissolutioning when flooding occurs. The smaller particles have a larger surface area per unit weight or per unit volume when the void fraction is the same as the larger particles. Consequently, flooding with fresh water will preferentially dissolve the finer particles and change the initial particle size distribution. Dissolution of the finer particles will increase the void fraction and the average particle size. After the mine is completely flooded, the particle size distribution could still change because of solutioning/crystallization caused by thermal gradients. This latter phenomenon would increase the void fraction and permeability in the hotter region and decrease 
the void fraction and permeability (or even cause complete plugging) in the cooler region.

\subsection{Amount of Water Present}

Any fresh water intruding into disposal rooms backfilled with salt will saturate within days to weeks. Consequently, any significant consolidation of the crushed salt (other than volume reduction by solutioning) would only occur when the liquid phase is saturated brine. A continuous flow of water through a repository as the result of a sink that develops will, of course, eventually dissolve all the crushed salt.

\subsection{Equation for Permeability.}

Shor et al. 6 developed an empirical equation that relates the permeability at time $t$ to the average particle size and void fraction existing at time $t$.

The equation is:

$$
\ln \left(\mu / z^{2}\right)=21+6 \ln B
$$

where

$$
\begin{aligned}
& \mu=\text { permeability, Darcy } \\
& z=\text { average particle size, } \mathrm{cm} \\
& \beta=\text { void fraction at time } t
\end{aligned}
$$

The following semi-empirical equation based on a sintering theory was fitted to the experimental data to relate the void fraction, $\beta$ at any time, to the stress, temperature, initial average particle size, time, and the initial void fraction.

$$
\beta=\beta O-(A / B) \ln \left(1+\frac{B t}{z^{3}}\right)
$$


where

$$
\begin{aligned}
\text { Bo } & =\text { initial void fraction } \\
t & =\text { time, minutes } \\
z & =\text { initial average particle size, } \mathrm{cm} \\
A & =\mathrm{fit} \text { parameter to data } \\
B & =\mathrm{fit} \text { parameter to data }
\end{aligned}
$$

The experimental values for the fit parameters along with the estimated standard deviations were:

$$
\begin{aligned}
& A=10^{-9}[(8.63 \pm 0.59)+(0.0393 \pm 0.0029) \sigma] \exp \left[D\left(\frac{1}{T}-\frac{1}{293}\right)\right] \\
& B=10^{-7}(3.18 \pm 0.23) \exp \left[D\left(\frac{1}{T}-\frac{1}{293}\right)\right]
\end{aligned}
$$

where

$$
\begin{aligned}
& \sigma=\text { average stress, bar } \\
& \mathrm{T}=\text { absolute temperature, } \mathrm{K} \\
& \mathrm{D}=-5130 \pm 320
\end{aligned}
$$

\subsection{Effects of Fit Constant Deviations and Correlating Parameters}

The potential uncertainties in calculated permeabilities as a function of time based on the use of the higher and lower limits to the fit constants are demonstrated in Fig. 2 for the probable range of stress from zero at mine closure to the lithostatic of $14.4 \mathrm{MPa}$ ( $140 \mathrm{bar}$ ), which is to be expected at a depth of $610 \mathrm{~m}(2,000 \mathrm{ft})$. At $100 \mathrm{y}$, the uncertainty spread is around a factor of 3 for all stresses. But at 1,000 y this increases to a factor of 5 for zero stress to 3 orders of magnitude for the lithostatic stress.

The effects from variation of two other parameters, initial void fraction and average particle size, that will be difficult to predict after a flooding incident are illustrated in Figs. 3 and 4, respectively.

The figures demonstrate that large changes in the permeability with relatively small changes in the parameters can occur in some expected range: of the parameters. This follows from the form of Eq. (8). As the second term on the right-hand side of $\mathrm{Eq}$. (8) approaches the initial void fraction (Bo) 
ORNL DWG 82-1207

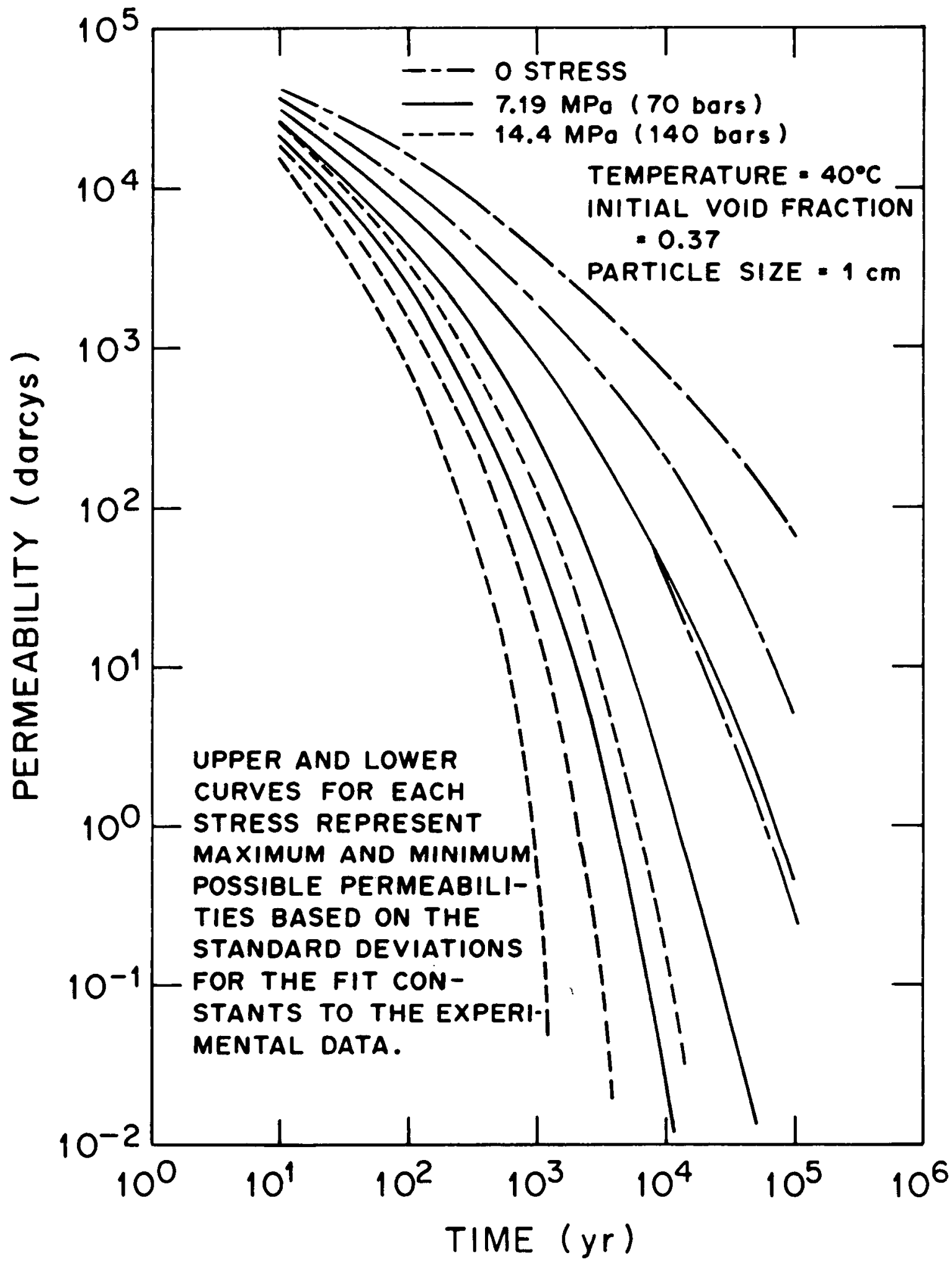

Figure 2. Variation and Potential Spread of Permeabilities of Crushed Salt with Time for Several Stresses 


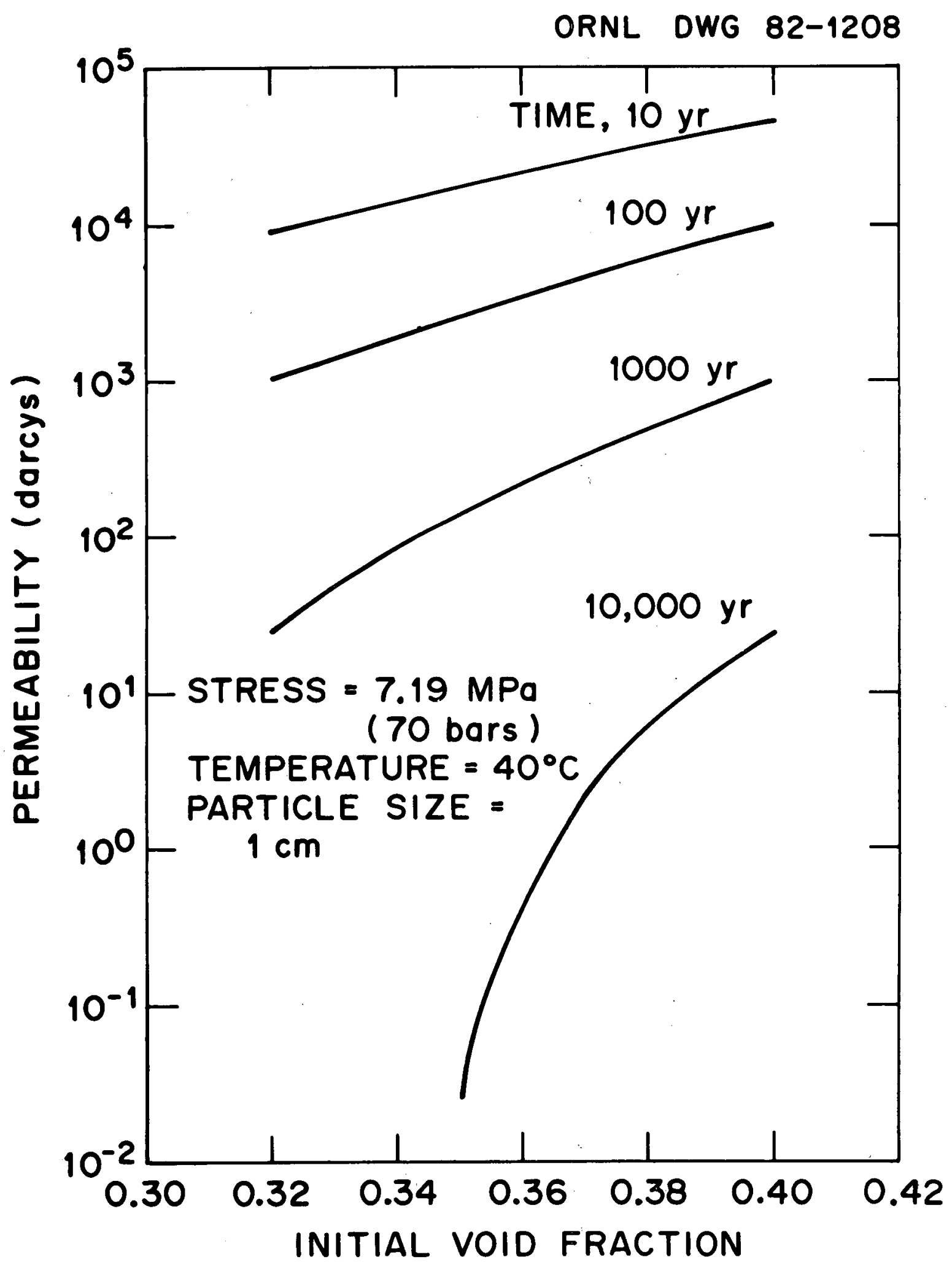

Figure 3. Variation of permeability of Crushed Salt with Initial Void Fraction for Several Times 
ORNL DWG 82-1209

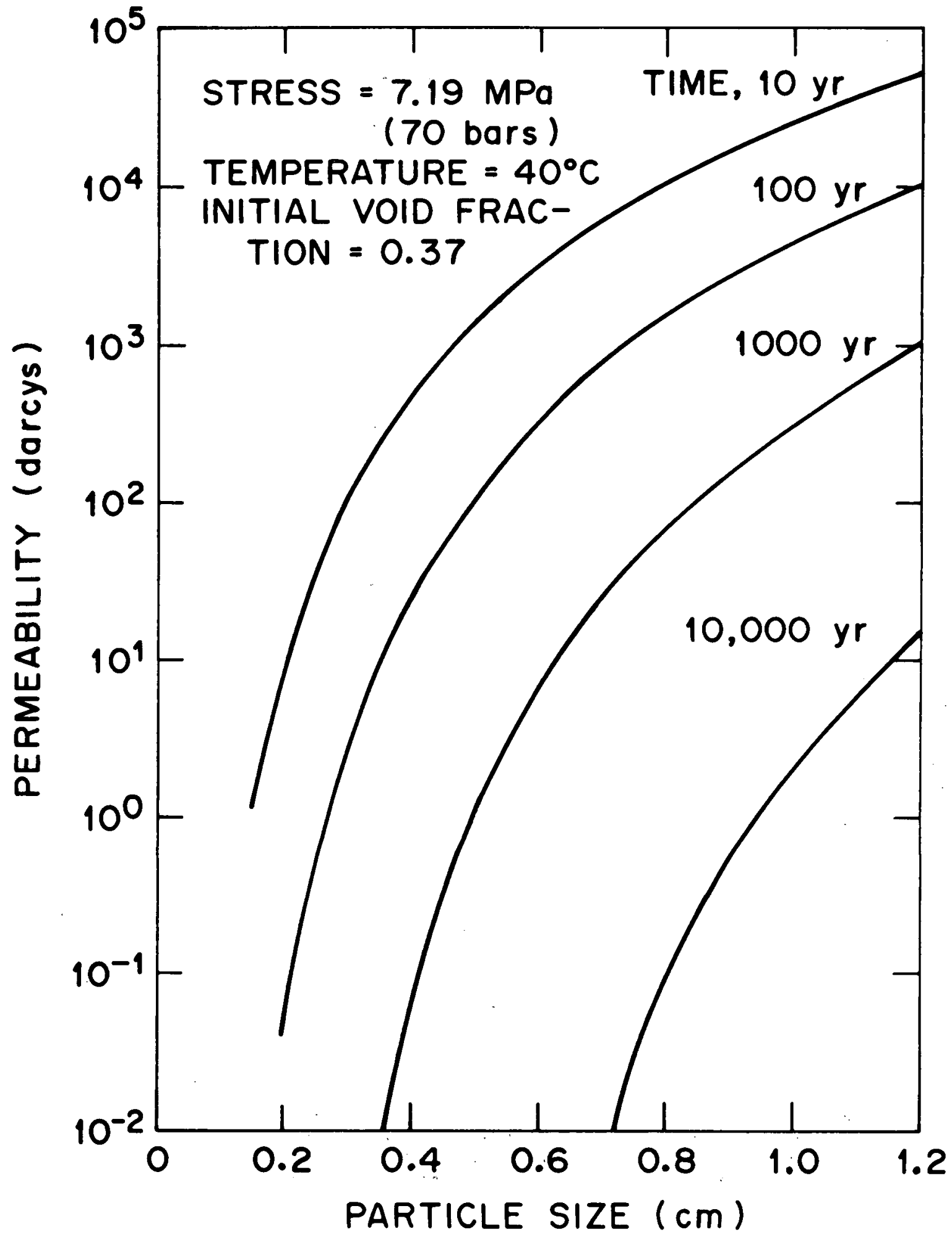

Figure 4. Variation of Permeability of Crushed Salt with Average Particle Size for Several Times 
regardless of which parameter is driving the term, the $\ln \beta$ of Eq. (7) approaches minus infinity with ever increasing steepness causing a concomitant rapid decrease in the permeability as it approaches zero. Consequently, in this region an error of a few percent in the estimated initial void fraction can create an error of several orders of magnitude in the calculated permeability.

\subsection{Extrapolation of Laboratory Data to a Repository}

The laboratory study covered the probable range that will occur in a repository for the following parameters: temperature $\left(20\right.$ to $\left.85^{\circ} \mathrm{C}\right)$, stress $(20$ to 155 bars), and initial void fraction ( 0.25 to 0.4$)$. The greatest extrapolation will be in time and to a smaller extent, the average particle size. Most of the experimental run time was for around seven days, a few for a couple of weeks, and one for almost five months. The range of the average particle size was 0.01 to $0.034 \mathrm{~cm}$.

Evaluation of the consequences of a flooded repository scenario will involve hundreds to thousands of years which is an extreme extrapolation of the experimental time. However, it seems probable that a calculated permeability based on the extrapolation in time of the laboratory data would be conservative (high) because of additional creep of the salt that would not be included in the experimental data.

It would be desirable to backfill with very finely ground salt from the viewpoint of prompting rapid consolidation of the salt. Milling the rock salt to an average particle size in the range of 0.01 to $0.03 \mathrm{~cm}$ will involve higher costs than for normal milling practice. It seems possible that the average particle size used in backfilling could exceed $0.03 \mathrm{~cm}$ significantly. The most common practice ${ }^{7}$ in the rock salt industry is to grind the salt in three steps to reduce excessive fines and produce material with a particle size of $<1 / 2$ in. A typical sieve analysis indicates an average particle size of $0.5 \mathrm{~cm}$ with the very fine material or dust removed. The ground salt is usually separated into four commercial size classifications with the finest designated FC. The typical sieve analysis shows that the FC cut is about $30 \%$ of the production with an average particle size of $0.11 \mathrm{~cm}$. 
The minimum void fraction and permeability obtained in the experiments were 0.06 and $500 \mu \mathrm{D}$ respectively. Using Eq. (8) to extrapolate significantly below these values is probably not justified.

In addition, these experiments were made under isothermal conditions with CP sodium chloride. Thermal gradients will exist in a repository and the temperature will change with time, which will cause solutioning/precipitation reactions. The impurities present in rock salt, particularly along the grain boundaries, could also significantly affect the consolidation rate.

\subsection{Additional Experiments}

It is quite possible that conservative use of Eq. (8) in analyzing the behavior of a flooded repository is adequate for all reasonable scenarios. However, in view of the emphasis being placed on developing a data base with minimized uncertainties, additional experimental data will be necessary to achieve such a goal.

Some permeability measurements covering the range of Eq. (8) should be repeated using crushed halite (both bedded and domal) with varying particle size distributions. Preferably, the samples should come from the commercial production of the various size classifications with and without the addition of the rejected fines. If possible, the experiments should be extended into lower ranges of the final void fraction and permeability.

A set of sample "beaker experiments" could be made to determine the probable void fraction and particle size distribution after a flooding incident. Samples of various particle size distributions of crushed halite from several sources could be placed in large beakers and sufficient fresh water added to produce the same water/crushed salt ratio to be expected in a repository. After standing long enough to come to equilibrium and saturate the water, a wet sieve analysis could be made.

\subsection{DISPOSAL ROOM CLOSURE}

Al1 deep cavities in rocks are subjected to pressures that produce a resultant closure force. Hard rocks can resist these forces but salt, being a 
viscous material, creeps under stress. Consequently, the disposal rooms of a salt repository will slowly close and squeeze out brine until the crushed salt backfill consolidates into a solid mass or the brine exit becomes plugged. Room closure calculations are complex and are of a very nonlinear type, which makes extrapolation of existing information a dubious procedure for the flooded repository conditions. In addition, such calculations are very specific for the repository design and the local geology. For example, the constitutive law, which governs the creep rate, can be quite different for different salt formations.

The calculations made in the past for room closure have been for open rooms. In a flooded repository, room closure would be resisted by the hydrostatic head and even greater resistance would be encountered when the crushed salt is compressed into an increasingly smaller volume.

Although calculations are not available for room closures for flooded mine conditions and prospective thermal loadings for a commercial waste repository, a parametric study by Wagner ${ }^{8}$ involving thermo/viscoelastic analyses of a room and pillar configuration can be used to obtain a rough and conservative (with respect to squeezing out brine) estimate for closure rates for unbackfilled rooms. Table 1 lists the results of the study. The most sensitive parameter with respect to room deformation was the repository depth. An increase in depth of $500 \mathrm{ft}$ increased the roof-to-floor closure by approximately a factor of two. The three thermal loads produced a linear relationship between the temperature fields, and the plots of the deformations versus thermal loading appeared 1 inear. It must be emphasized that the total roofto-floor closure (roof sag plus floor heave) at the centerline represents a maximum value. The walls will also buckle in and contribute to the closure. Consequently, the proper measure of room closure for liquid displacement purposes is the volume change, which takes into consideration the curvature of the boundaries of the deformed walls, floor, and roof. The report by Wagner does show vector displacements of the walls (or ribs), roof, and floor from which it is theoretically possible to estimate the volume change. If it is required, the computer code can be altered to do the required numerical integration and output the volume change.

Another point to be made is that it is not possible to model room closure all the way to completion in an open room because of rock failure. The rubble 
Table 1

Maximum roof-floor closures in $25-y r$ for unbackfilled disposal rooms

\begin{tabular}{|c|c|c|c|c|c|}
\hline \multirow[b]{2}{*}{$\begin{array}{l}\text { Depth } \\
(\mathrm{ft})\end{array}$} & \multirow{2}{*}{$\begin{array}{c}\text { Pillar height } \\
\text { to width } \\
\text { ratio }\end{array}$} & \multirow{2}{*}{$\begin{array}{c}\text { Extraction } \\
\text { ratio } \\
(\%)\end{array}$} & \multicolumn{3}{|c|}{ Thermal load, $\mathrm{kW} /$ acre } \\
\hline & & & $\begin{array}{c}30 \\
\text { Total }\end{array}$ & $\begin{array}{r}36 \\
\text { closure }\end{array}$ & $25-y r$, in. \\
\hline 1,500 & $1: 3$ & 24 & 5.1 & 5.7 & 6.6 \\
\hline 1,500 & $1: 4$ & 20 & 4.9 & 5.5 & 6.5 \\
\hline 1,500 & $1: 5$ & 16 & 5.0 & 5.7 & 6.8 \\
\hline 2,000 & $1: 3$ & 24 & 11.5 & 12.5 & 14.2 \\
\hline 2,000 & $1: 4$ & 20 & 10.1 & 11.1 & 12.7 \\
\hline 2,000 & $1: 5$ & 16 & 9.5 & 10.7 & 12.4 \\
\hline 2,500 & $1: 3$ & 24 & 23.2 & 25.2 & 28.2 \\
\hline 2,500 & $1: 4$ & 20 & 19.9 & 21.6 & 24.4 \\
\hline 2,500 & $1: 5$ & 16 & 18.5 & 20.2 & 22.9 \\
\hline
\end{tabular}

a Data from Ref. 8 .

b Roof sag plus floor heave at centerline for 25-yr. after waste emplacement. 
that collects will actually inhibit complete closure; consequently, calculated closure rates using a model with intact boundaries that undergo no step function changes should be conservative after the boundaries contact the rubble, providing that the creep model is reasonably accurate. In a water-filled room exerting hydrostatic pressure, and in particular with a crushed-salt backfill, the resistance by these materials will tend to prevent rock failure, which makes calculations of complete room closure more realistic for greater closure.

Bearing in mind the previous discussion on limitations of the calculations and the problems with extrapolation, the data of Table 1 will be used to estimate an average room closure rate that seems conservative; that is, the room closure rate is higher and the contaminated brine is squeezed into an aquifer or onto the surface at a higher rate than probable. The assumptions made are:

1. The effective stress for closure calculations is obtained by subtracting the hydrostatic pressure from the 1 ithostatic pressure; that is, a flooded repository at a depth of $2,000 \mathrm{ft}$ is equivalent to an unflooded one at 1,000 ft. Actually, initially the effective stress would involve the state of stress after room excavation and would approach the lithostatic stress only after a long period of time.

2. Deformations for higher thermal loadings can be obtained by linear extrapolation.

3. The average yearly rate of roof-floor closure is uniform and is $1 / 25$ of the values in Table 1 .

4. The crushed salt has no effect. Assumptions 1 and 2 are not conservative but seem to be a reasonable approximation for the purpose intended. Assumptions 3 and 4 are definitely very conservative. Averaging the creep rate over 25 years gives too great an importance to the contribution by the initial creep rate, which can be much greater than the steady-state creep that follows after some closure.

From Table 1 the maximum value for roof-floor closure in 25 years at a depth of $1,500 \mathrm{ft}$ is $6.8 \mathrm{in}$. Since each $500 \mathrm{ft}$ increases the closure rate by approximately a factor of 2 , the closure rate at $1,000 \mathrm{ft}$ is estimated to be $3.4 \mathrm{in.}$ Extrapolating linearly for a $100 \mathrm{~kW} /$ acre thermal loading gives 
$7.6 \mathrm{in.}$, which is an average of $0.30 \mathrm{in.}$ per year. With this closure rate, a repository with $18-\mathrm{ft}$ high rooms will take 710 years to close. In view of the assumptions made, this value represents only a rough estimate. However, it does give credence to the belief that rooms will close within a few hundred years.

\subsection{LEACHING OF WASTE GLASSES AND SPENT FUEL}

In an early review by Mendel ${ }^{9}$ of leaching of radioactive wastes, he pointed out that it was an extremely complex process which was complicated by the lack of standardization of leaching tests and the general concern of predicting the long-term dissolution rates from short-term laboratory data. Mendel found the time law expression which was most widely used as an approximation of the leaching behavior to glass was:

$$
Q=a t^{1 / 2}+b t
$$

where $Q$ is the cumulative quantity leached and $a$ and $b$ are empirically fitted constants to the data. Application of diffusion theory will produce the square root of time term and uniform dissolution on the surface (akin to uniform corrosion) produces the second term. Consequently, leach data that can be correlated with Eq. (11) implies that in the early stages leaching is controlled by the diffusion rate of a nuclide into the leaching solution and in the later stages, the corrosion mechanism controls.

Such empirical models represented by Eq. (11) are useful but the prediction of long-term dissolution rates from short-term laboratory data was of concern at the time of Mendel's review and still is today after much data accumulation and model synthesizing.

In the following sections phenomena are discussed that complicate the leaching process along with the application to an actual flooded repository. Some models and data are also examined and recommendations for use are made. 


\subsection{Mechanisms of Chemical Dissolution}

The mechanisms involved in the dissolution of glasses have been a subje of study for many years in and out of the nuclear industry. Whereas such studies for spent fuel are of more recent origin and less is known on the su ject but can be described with empirical equations similar in form to that o glasses.

\section{1 .1 Glasses}

An excellent and recent review of the mechanisms that control leaching radioactive waste glass was made by Simmons et al.10 The following discussi is excerpted from that review.

In earlier work it was established that the attack of water on glass starts with alkali cations being preferentially leached by a diffusive proce from the surface layers which results in the formation of a porous, highsilica, dealkalized layer. The thickening of this layer slows the diffusior process until silica dissolution at the dealkalized layer-solution interface begins to control the rate of attack. Eventually equilibrium between the tw processes is reached and a dealkalized layer of fixed thickness and composition moves into the bulk glass at a constant rate. More recent experiments show that the dissolution process is far more complex than described above when polyvalent ions are present in the glass matrix.

Simmons et al. 10 point out that a number of additional processes or events can occur during the layer formation period that can drastically alte the long-term leaching rate and lists some of them as follows:

1. Layer disintegration from wet-dry cycling of the glass surface.

2. Changes in solution $\mathrm{pH}$ from accumulation of corrosion products in $t$ bath or fluid around a canister.

3. Variations in dissolution mechanisms with different flow conditions

4. Effects of $\mathrm{pH}$ buffer depletion in solution.

5. Solution and groundwater saturation effects.

6. Precipitation of corrosion products or reacted solution components with leached components. 
7. Temperature effects.

8. Radiation effects on both the waste form and the repository fluid.

\subsubsection{Spent Fue1}

In an early study by Katayamall on leach tests on PWR fuel pellet fragments using deionized water, building water, and typical Hanford ground water, he found that the relative leachability of the elements decrease in the order of

$\mathrm{Cs}>\mathrm{Sb}>\mathrm{Sr}+\mathrm{Y}>\mathrm{Pu}>\mathrm{Cm}$.

The data were fitted to an equation in the form of

$\mathrm{F}=\mathrm{Bt} \mathrm{t}^{\mathrm{n}}$

where

$F=$ fraction leached

$\mathrm{t}=\mathrm{time}$, days

$\mathrm{B}$ and $\mathrm{n}=\mathrm{fit}$ constants.

For Hanford ground water the long-term leach mechanisms seemed near identical since the average exponents of Eq. (12) were about the same, averaging 0.07 . The average for deionized water was 0.31 and the exponent for the building water varied from 0.06 to 0.35 , indicating different leach mechanisms for building water. This wide variation was attributed to the varying quality of the building distilled water and the subsequent variation in the ionic concentration. Since an exponent of 0.5 would indicate a diffusion mechanism with a constant coefficient of diffusion, Katayama concluded that the 0.07 exponent reflected the major role of dissolved chemicals in suppressing leach rates and the 0.31 exponent probably reflected the inverse relationship of the diffusion coefficient for the radioisotope with its ionic concentration in the leachant.

Wang and Katayama 12 in a later study made a number of experiments with $\mathrm{UO}_{2}$ single crystals and spent fuel in an attempt to develop a clearer understanding of the leaching mechanism. They concluded that: 
The oxidation and dissolution mechanisms for $\mathrm{UO}_{2}$ and spent fuel will be quite similar based on this preliminary work with electrochemical leaching of $\mathrm{UO}_{2}$ and spent fuel. In solutions containing oxygen or other oxidizing species, the $\mathrm{UO}_{2}$ surface will be rapidly oxidized and dissolved following the transformation of uranium from $U(I V)$ to $U(V I)$. The hydrolysis of dissolved uranyl ions forms solid $\mathrm{UO}_{3}$ hydrates or related complex compounds deposited onto the $\mathrm{UO}_{2}$ surface, or other surfaces, as thin or thick coatings. Depending on the $\mathrm{pH}$, temperature and time, the various kinds of porosity and the mechanical properties of the hydrate coatings will control the dissolution rate. The effects of radiation in terms of generation of $\mathrm{H}_{2} \mathrm{O}_{2}$ will enhance the dissolution kinetics.

Mitchell et al.13 examined the leaching of declad, irradiated fuel samples in a borate solution. The effects of temperature and fuel fragment size on the leach rate and released fraction of several fission products were examined. Some of the conclusions reached, after 250 days of leaching, were:

1. The relative order of the rate of leaching is $\mathrm{Sb}>\mathrm{I}>3^{3}>\mathrm{Cs}>\mathrm{Sr}>\mathrm{Ru}, \mathrm{Ce}, \mathrm{Eu}, \mathrm{U}>\mathrm{Pu}$.

2. Data fit to an equation of the form of Eq. (12) gave values for the exponent which varied from 0.01 to 0.59 , depending upon the leachate and the leaching conditions.

3. No significant difference in leach rates was found at $100^{\circ} \mathrm{C}$ and at $85^{\circ} \mathrm{C}$.

4. The leach rates (in units of $\mathrm{g} f u e l / \mathrm{cm}^{2} \cdot \mathrm{d}$ ) were higher for the larger particle sizes.

5. The fractional releases (in units of fraction of the substance in inventory) were smaller for the larger particle sizes.

The results of the study determined fractional releases and relative leaching rates for the various $f$ ission products which were in general agreement with those obtained by Katayama. Differences between the studies may be attributed to the longer leaching time of the Mitchell et al. study ( 40 weeks vs 20 weeks) and the difference in leachants (borate solution vs distilled water). 


\subsection{Leach Tests}

There are many leach tests that have been used in the past and have been proposed for use. These include the International Atomic Energy Agency (IAEA) test, two International Standards Organization (ISO) tests, at least five Materials Characterization Center (MCC) tests, 14 and the Paige test 11 that has been used for spent fuel. Each of these tests was developed based on various needs and ultimate use of the results.

The leach data can be quite different depending on the test procedure. For example, in an intercomparison of leach-testing methods for potential use in the Canadian Program, Harvey and Jensen 15 found that for a particular glass, the apparent leach rate determined by a static (nonreplenished leach solution) test can be an order of magnitude higher than that from a test involving leachant replenishment. An apparent anomaly where the leach rate of a number of sodium borosilicate glasses under static leaching conditions was observed to rise after declining for a few days and then fall, was explained in terms of a $\mathrm{pH}$ change in the leachant which was a function of the glass composition.

In an effort to develop standard tests for the characterization of the components of a waste package, a Nuclear Waste Materials Characterization Center (MCC) was established at the Pacific Northwest Laboratory. Five related leach tests 14 have been proposed by the Center to study time-dependent leaching of waste forms. Three of these tests are static and two are dynamic. Under the conditions of a flooded repository, any leaching that takes place could be essentially static or with low flow rates, which relate to the MCC-1 and MCC-4 tests, respectively. The MCC-1 Static Low Temperature Test has been in use for some time; the standard prescribes the surface area of the sample and the sample to solution volume ratio. The MCC-4 Low Flow Test will simulate repository conditions when a net flow rate exists around the waste canister. In comparison tests, 15 it was found the MCC-1 tests yielded leach rates which were lower than those produced by the MCC-4 tests by a factor of two for silicon and 200 for strontium. Using the MCC-4 tests to determine the leach rate for the waste in a flooded repository should be very conservative. 


\subsection{Leaching Models}

The need to extrapolate short-term laboratory data to long-term leaching of radioactive waste in a repository has led to the development of models for the process.

\subsubsection{Analytical models}

A model that has a good theoretical basis and is normalized to experimental data would seem to have the best chance of success. Along this line, Godbee et al.16 have reviewed the application of mass transport theory and also developed additional equations involving diffusion from the solid matrix and dissolution at the boundary (corrosion). Although the developed equations can be used to correlate the experimental data quite well in some cases, application to repository presents difficulties because of the uncertainties in the basic parameters due to time dependency and other factors. However, similar problems develop with any model, which is a strong impetus for use of simple but conservative models.

\subsubsection{Flow model based on silica dissolution}

A model proposed by Macedo et al, 17 which is still under development, calculates the rate of fractional mass transport from a solid under all possible flow conditions. Basically, this model relates silica dissolution in a laboratory leach test to that in a repository by the number of volume changes of solution per unit of time in the test and in the waste canister (as determined by the void space and flow rate). The greater the flow rate expected in the repository, the greater the number of volume changes required in the leach test. The data show that silica concentration equilibrates in the test after a few days at concentrations dependent on the surface/volume ratio and flow rate equivalent (solution volume rate of change). This model represents a rational approach for leaching when significant flow is present and the application seems straightforward. The necessary assumptions when applied to a repository seem very conservative. 


\subsubsection{Phantom Dissolution Leach Model}

Another model that is empirical, but has a relation to theory, is the Phantom Dissolution Leach Model developed by Richardson. 18 In this model, the leached constituents are assumed to have been dissolved from the surface of a phantom solid whose dimensions decrease uniformly with time as leaching proceeds. The calculated depth of penetration (d) to the phantom surface at any time $(t)$ is given by

$$
d=k_{0}+k_{1} t^{0.5}+k_{2} t
$$

where $k_{0}, k_{1}$, and $k_{2}$ are $f i t$ constants that are related to an initial surface washoff, diffusion rate, and corrosion rate constants, respectively. The penetration depth used in calculating the fit constants is calculated from leach data according to

$$
F=1-\frac{V}{V_{0}}=1-\frac{(a-2 d)(b-2 d)(c-2 d)}{a b c}
$$

where $F$ is the cumulative fraction leached at time $t, V$ is the volume of the phantom solid at time $t, V_{O}$ is the initial geometric volume of the solid; and $a, b$, and $c$ are characteristic dimensions of the original solid. The righthand side of Eq. (14) as written represents a parallelepiped. This reduces to $\mathrm{d} / \mathrm{a}$ for an infinite slab of thickness a. For a cylinder of radius a and halfheight $b$, the right-hand side of Eq. (14) becomes

$$
1-\frac{(a-d)^{2}(c-d)}{a^{2} c}
$$

Actually, this model is effectively very similar to that described by Eq. (11) with an addition of a washoff constant. 


\subsubsection{Diffusion and corrosion models}

One of the simplest models is that represented by either the first term (diffusion) or the second term (corrosion) of Eq. (11). Ewest 19 pointed out that in most cases the actual release rate lies between that predicted by diffusion alone or corrosion alone. Consequently, when Eq. (12) is used to fit long-term leach data, the exponent $n$ usually can be expected to 1 ie between 0.5 and 1.0 and that values $n$ in the range of $2 / 3$ to $3 / 4$ are frequently found.

\subsubsection{Silica saturated model}

A recent study by Hughes et al. 20 pointed out that a number of investigators, in which they are in agreement, concluded that flow rates in hard rock repositories will be so small that the rate of removal of material will be 1 imited by the saturation solubility of the glass matrix in the available water. Consequently, leach rates measured with frequently changed water is not representative of repository conditions. They propose that an effective leach rate be used that is defined as the leach rate which would give the same rate of mass 1 oss in the same circumstances.

Since it is obviously impossible to closely simulate in the laboratory the leaching phenomena that would exist in an actual repository, they suggest using the saturation solubility of silica as a limit; that is, any flow in contact with the waste glass would dissolve sufficient glass along with the other constituents to become saturated with silicon dioxide. This model represents a limiting case of the flow model discussed in sect. 5.3.2 and should be conservative.

\subsection{Application of Leach Models in a Repository}

A scenario that envisions intimate contact with a relatively large amount of flowing water and the waste itself seems incredible. The most credible scenario in a flooded repository in salt is that the waste canister may be exposed to saturated brine that seeps into the disposal hole leaving any backfilling and shielding plugs or materials essentially intact. Contact with the waste will take more time and probably will begin in only very 1 imited areas 
through corrosion pits and/or cracks in the canister. This, along with cracks in the glass, make the active surface a difficult parameter to ascertain along with an effective leach rate.

In view of the difficulties with regard to characterizing the leaching process, it seems that a rational and conservative method for calculating the dissolution of waste glasses for small flows would be to apply the Hughes et al. 20 model (Sect. 5.3.5) that assumes leaching is controlled by the available water. In some leach tests cesium and strontium have been known to leach at greater rates than that calculated on the basis of glass corrosion. This should be of no concern since these isotopes will have decayed away by the time any significant leaching begins.

Silica solubility of a waste glass sample could be determined with the MCC-3 solubility test 14 using as a leachant solutions of varying salt concentrations up to a saturated brine made from cores taken at a proposed site. If some unlikely scenario is developed that involves larger flows, the flow model based on silica dissolution (Sect. 5.3.2) seems most appropriate.

A similar saturation model may be possible for spent fuel but it has not been developed yet. Consequently, a simple power law model (Sect. 5.1.2)

seems appropriate.

\subsection{SOME PHYSICAL PROPERTY DATA}

The following equations correlating brine properties with temperature and concentration are taken from Ref. 21 where the derivations of these equations are outlined.

$$
\begin{aligned}
W= & 26.218+7.2 \times 10^{-3} \mathrm{~T}+1.06 \times 10^{-4} \mathrm{~T}^{2} \\
\rho= & 1.0+0.1877 \mathrm{f}-3.168 \times 10^{-4}(\mathrm{~T}-20) \\
& -2.56 \times 10^{-6}(\mathrm{~T}-20) \\
\mu= & \mu_{0}(1.0+0.0219 \mathrm{~W} \rho \mathrm{f}) \exp \left[\mathrm{B} \frac{\mathrm{T}_{0}-\mathrm{T}}{\mathrm{T}^{\prime} \mathrm{T}_{0}}\right]
\end{aligned}
$$


where

$$
\begin{aligned}
W= & \text { salt concentration, } \% \mathrm{NaCl} \\
\mathrm{T}= & \text { temperature, }{ }^{\circ} \mathrm{C} \\
\rho & =\text { brine density, } \mathrm{g} / \mathrm{cc} \\
\mathrm{f}= & \text { fraction of saturation; } \mathrm{f}=0 \text { for fresh water and } \\
& \mathrm{f}=1 \text { for saturated brine } \\
\mu= & \text { viscosity of brine, } \mathrm{Cp} \\
\mu_{\mathrm{O}}= & 1.002 \mathrm{Cp} \\
\mathrm{B}= & 1869.2 \mathrm{~K} \\
\mathrm{~T}^{\prime}= & \text { brine temperature, } \mathrm{K} \\
\mathrm{T}_{\mathrm{O}}= & 293.15 \mathrm{~K}
\end{aligned}
$$

The following equations correlating rock salt (halite) density and heat capacity as a function of temperature are taken from Ref. 21:

$$
\begin{gathered}
\rho=2.2372-2.543(\mathrm{~T}+273) \\
C_{p}=47.495-0.01356(\mathrm{~T}+273)
\end{gathered}
$$

where

$$
\mathrm{C}_{\mathrm{p}}=\text { heat capacity, } \mathrm{J} / \mathrm{mol} \mathrm{K}
$$

The tabulated values in Ref. 22 for the thermal conductivity of halite were fitted to within $\pm 3 \%$ for temperatures between 20 and $250^{\circ} \mathrm{C}$ with the following equation:

$$
k=331(T+273)^{-1.091}
$$

where

$$
\mathrm{k}=\text { thermal conductivity, } \mathrm{W} / \mathrm{mK}
$$




\subsection{REFERENCES}

1. Jung, R., and G. Delisle, 1978. Investigations on the Delineation of Safety Risks Involved in the Flooding of a Final Disposal Mine Repository for Radioactive Wastes, Progress Report on Project St. Sch. 506, Geophysical Investigations of Salt Formations with Reference to the Final Disposal of High-Level Radioactive Wastes in Geologic Bodies, Archive No. 80112 and OLS-79-203 (translated from the German), Bundesanstalt für Geowissenschaften und Rohstoffe (Federal Institute for Geosciences and Raw Materials), Hannover, FRG.

2. Durie, R. W., and F. W. Jessen, 1964. "Mechanism of the Dissolution of Salt in the Formation of Underground Salt Cavities," Society of Petroleum Engineers Journal, June.

3. Jessen, F. W., 1971. "Total Solution Mechanism," Transactions of the Society of Mining Engineers of AIME, Vol. 250, p 298.

4. Anthony, T. R., and H. E. C1ine, 1971. "Thermal Migration of Liquid Droplets Through Solids," Journal of Applied Physics, Vol . 42, p. 3380.

5. Jenks, G. H., and H. C. Claiborne, 1981. Brine Migration in Salt and Its Implications in the Geologic Disposal of Nuclear Waste, ORNL-5818, Oak Ridge National Laboratory, Union Carbide Corporation, Oak Ridge, TN.

6. Shor, A. J., C. F. Baes, Jr., and C. M. Canonico, 1981. Consolidation and Permeability of Salt in Brine, ORNL-5744, Oak Ridge Laboratory, Union Carbide Corporation, Oak Ridge, TN.

7. Kaufman, D. W., Ed., 1960. Sodium Chloride, Reinhold, New York, NY, pp. 127-135.

8. Wagner, R. A., 1980. Parametric Study Involving Thermo/Viscoelastic Analyses of A Room and Pillar Configuration, ONWI-115, prepared by RE/SPEC Inc. for Office of Nuclear Waste Isolation, Battelle Memorial Institute, Columbus, $\mathrm{OH}$.

9. Mende1, J. E., 1973. A Review of the Leaching Test Methods and the Leachability of Various Solid Media Containing Radioactive Wastes, BNWL-1765, Battelle Pacific Northwest Laboratories, Battelle Memorial Institute, Richland, WA.

10. Simmons, J. H., A. Barkatt, and P. B. Macedo, 1982. "Mechanisms that Control Aqueous Leaching of Nuclear Waste Glass," Nuclear Technology, No. 56 , p. 265.

11. Katayama, Y. B., 1976. Leaching of Irradiated LWR Fuel Pellets in Deionized Water and Typical Ground Water, BNWL-2057, Battelle Pacific Northwest Laboratories, Battelle Memorial Institute, Richland, WA. 
12. Wang, R., and Y. B. Katayama, 1981. "Probable Leaching Mechanisms for $\mathrm{UO}_{2}$ and Spent Fuel," Scientific Bases for Nuclear Waste Management, Vol. 3, J. G. Moore, Ed., Plenum Press, New York, NY, p. 379.

13. Mitchel1, A. O., J. H. Goode, and V.C.A. Vaughen, 1981. Leaching of Irradiated Light-Water-Reactor Fuel in Simulated Post-Accident Environment, ORNL/TM-7546, Oak Ridge National Laboratory, Union Carbide Corporation, Oak Ridge, TN.

14. Strachan, D. M., B. O. Barnes, and R. P. Turcotte, 1981. "Standard Leach Tests for Nuclear Materials," Scientific Basis for Nuclear Waste Management, Vol. 3, J. G. Moore, Ed., Plenum Press, New York, NY, p. 347.

15. Harvey, K. B., and C. D. Jensen, 1982. "An Intercomparison of LeachTesting Methods and the Effects of Waste-Form Composition on Test Type and Ducation," Nuclear and Chemical Waste Management, Vol. 3, p. 43.

16. Godbee, H. W., E. L. Compere, D. S. Joy, A. H. Kibbey, J. G. Moore, C. W. Nestor, Jr., O. U. Anders, and R. M. Neilson, Jr., 1980. "Application of Mass Transport Theory to the Leaching of Radionuclides from Waste Solids," Nuclear and Chemical Waste Management, Vol. 1, p. 29.

17. Macedo, P. B., Aaron Barkatt, and J. H. Simmons, 1982. "A Flow Model for the Kinetics of Dissolution of Nuclear Waste Glasses," Nuclear and Chemical Waste Management, Vol. 3, p. 13.

18. Richardson, G. L., 1981. "The Phantom Dissolution Leach Model," Nuclear and Chemical Waste Management, Vo1. 2, p. 237.

19. Ewest, E., 1979. "Calculations of Radioactivity Release Due to Leaching of Vitrified High Level Waste," Scientific Bases for Nuclear Waste Management, Vol. 1, G. J. McCarthy, Ed., Plenum Press, New York, NY, p. 161 .

20. Hughes, A. E., J.A.C. Marples, and A. M. Stoneham, 1981. The Significance of Leach Rates in Determining the Release of Radioactivity from Vitrified Nuclear Waste, AERE-R-10190, United Kingdom Atomic Energy Authority, Harwell, Oxfordshire, England.

21. Cranwell, R. M., J. E. Campbe11, and S. E. Stuckwisch, 1982. Risk Methodology for Geologic Disposal of Radioactive Waste: The DNET Computer Code User's Manual, NUREG/CR-2343 and SAND-81-1663, prepared by Sandia National Laboratories for U.S. Nuclear Regulatory Commission, Washington, DC.

22. Gevantman, L. H., Ed., 1981. Physical Properties Data for Rock Salt, NBS Monograph 167. 
TABLE OF CONTENTS

Page

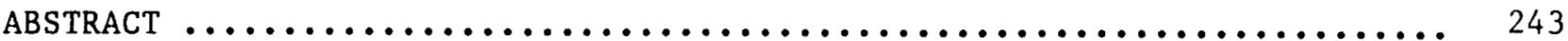

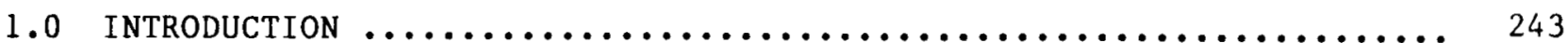

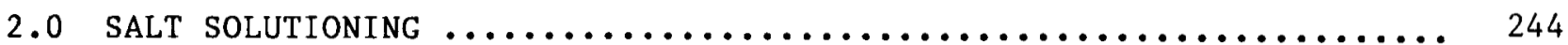

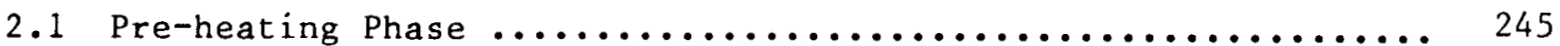

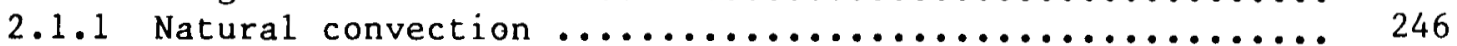

2.1.2 Turbulent forced convection .................... 247

2.1.3 Salt dissolution in a repository

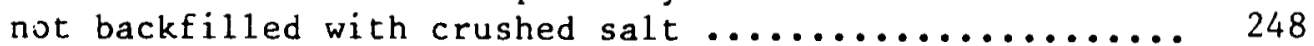

2.1 .4 Crushed salt backfilling ........................ 249

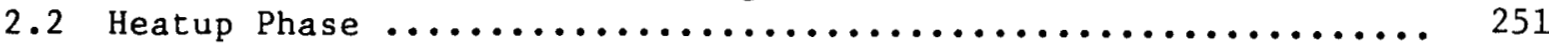

3.0 CRUSHED SALT PERMEABILITY AS A FUNCTION OF TIME $\ldots \ldots \ldots \ldots \ldots \ldots \ldots \ldots \ldots$

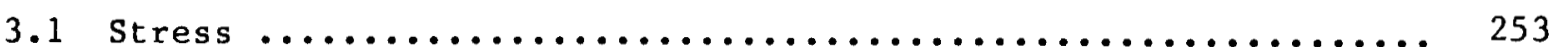

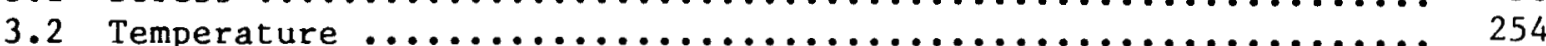

3.3 Particle Size Distribution and Void Fraction ................. 254

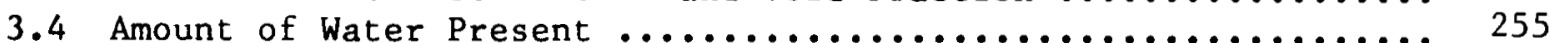

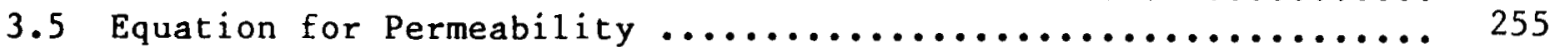

3.6 Effects of Fit Constant Deviations and Correlating Parameters .............................. 256

3.7 Extrapolation of Laboratory Data to a Repository ............ 260

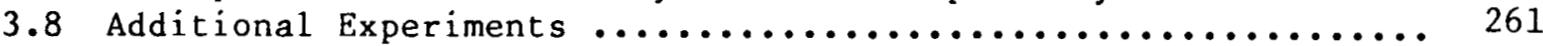

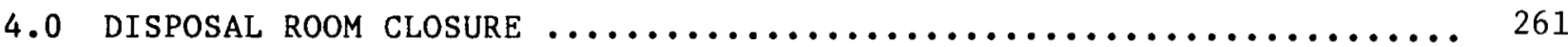

5.0 LEACHING OF WASTE GLASSES AND SPENT FUEL $\ldots \ldots \ldots \ldots \ldots \ldots \ldots \ldots \ldots \ldots \ldots$

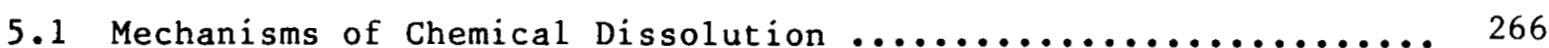

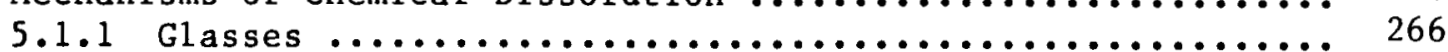

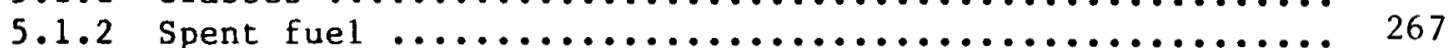

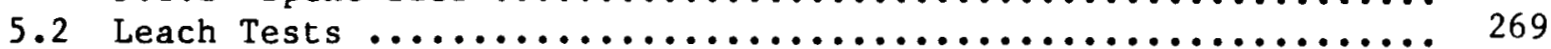

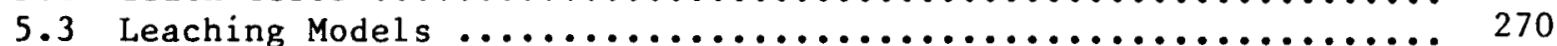

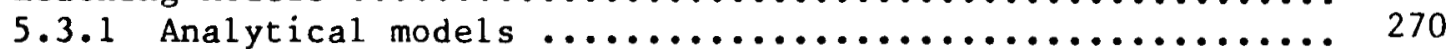

5.3.2 Flow model based on silica dissolution .............. 270

5.3.3 Phantom dissolution leach model ................... 271

5.3.4 Diffusion and corrosion models ................... 272

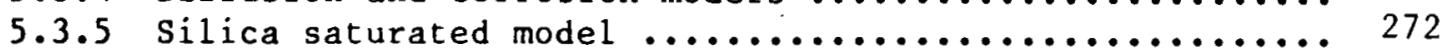

5.4 Application of Leach Models in a Repository .............. 272

6.0 SOME PHYSICAL PROPERTY DATA $\ldots \ldots \ldots \ldots \ldots \ldots \ldots \ldots \ldots \ldots \ldots \ldots \ldots \ldots \ldots$

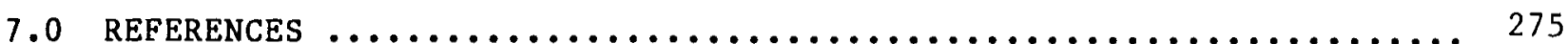


DERIVATION 1

$\ominus$ 
DERIVATION 1: DERIVATION OF EQUATIONS FOR HEIGHT OF CRUSHED SALT REMAINING AFTER WATER INFLUX

Water intruding into a disposal room will dissolve some of the crushed salt; the amount depends on the salt concentration of the intruding water. The derivation of the equation for the remaining height of crushed salt after saturation obtains is given below.

Salt Balance:

Salt in intruding water + initial crushed salt = salt in sat. soln. above crushed salt + salt in sat. soln. crushed salt interstices + remaining crushed salt.

Expressing as an equation, this becomes

$$
M F_{S i}+H W L f_{i} \rho_{S}=(H-h) W L \rho_{f} F_{S f}+h W L \rho_{f} F_{S f}\left(1-f_{f}\right)+h W L \rho_{s} f_{f}
$$

where

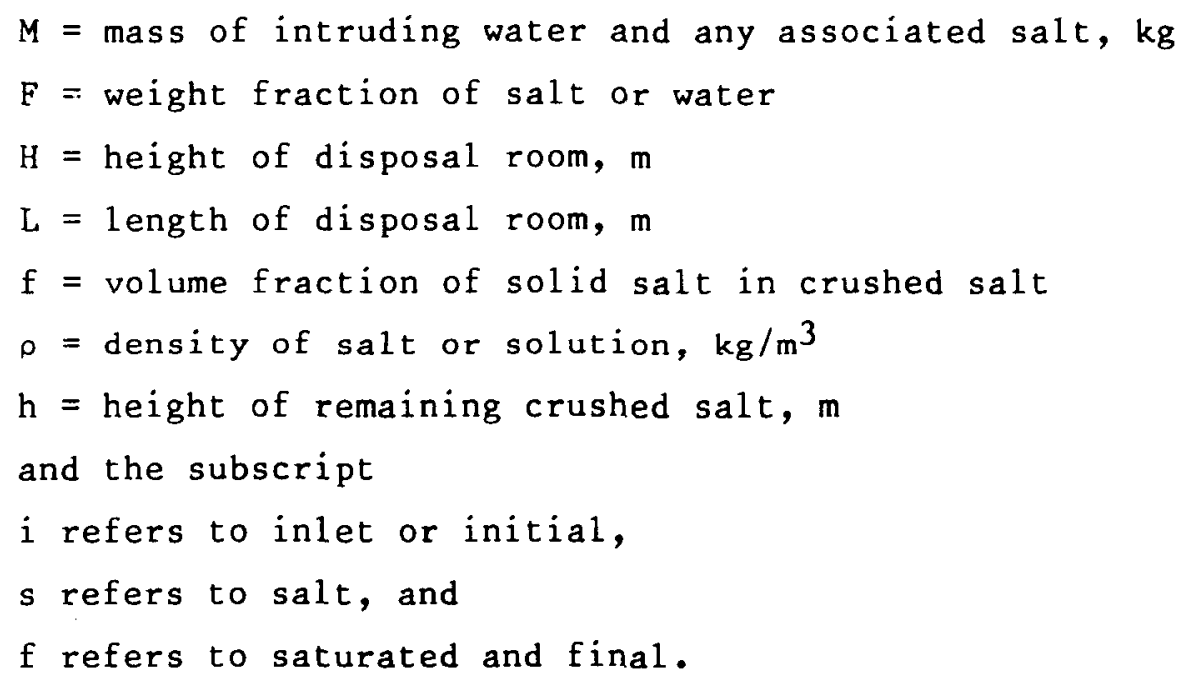

\section{Water Balance:}

Intruding water (minus any salt) $=$ water above crushed salt + water in interstices of remaining crushed salt.

Expressing as an equation, this becomes

$$
M F_{w i}=(H-h) \rho_{f} F_{w f}+h W L \rho_{f}\left(1-f_{f}\right) F_{w f}
$$

where subscript $w$ refers to water. 
Eliminating $M$ by substituting Eq. (A2) into ( $A 1$ ) and rearranging, we get

$$
\frac{F s i}{F_{w i}}\left(H-h f_{f}\right) \rho_{f} F_{w f}+H \rho_{s} f_{i}=\left(H-h f_{f}\right) \rho_{f} F_{s f}+h \rho_{s} f_{f}
$$

Solving Eq. (A3) for the height of the remaining crushed salt gives

$$
\frac{h}{H}=\frac{\rho_{s} f_{i}+\rho_{f} \Psi}{\rho_{s} f_{f}+\rho_{f} f_{f} \Psi}
$$

where

$$
\Psi=\frac{F_{s i} F_{w f}}{F_{w i}}-F_{s f}
$$


DERIVATION 2: DERIVATION OF SIMULTANEOUS MASS AND HEAT TRANSFER EQUATION

In this appendix the derivation by Jung and Delisle $e^{1}$ is outlined for salt dissolution due to heatup of saturated brine in a flooded, unbackfilled repository.

The basic assumptions are that a stagnant boundary layer exists next to a salt surface across which heat is conducted and that salt diffuses into the main bulk of saturated solution that is perfectly mixed (infinite thermal conductivity and diffusion coefficient) that the concentration and thermal gradients are linear within this boundary layer, and the solution at the boundaries is saturated with respect to the existing temperatures. With these assumptions, the Anthony and $\mathrm{Cl}_{\text {ine }} 4$ treatment for migration of brine inclusions applies. The mass flux of salt into and out of the boundary later is the sum of concentration and thermal diffusion components and is described by

$$
\phi=D \nabla C+D S C \nabla T
$$

where

$$
\begin{aligned}
\phi & =\text { mass flux, } \mathrm{g} / \mathrm{cm}^{2} \mathrm{sec} \\
\mathrm{D} & =\text { diffusion coefficient, } \mathrm{cm}^{2} / \mathrm{sec} \\
\nabla \mathrm{C} & =\text { concentration gradient }, \mathrm{g} / \mathrm{cm}^{4} \\
\mathrm{~S} & =\text { Soret coefficient }, \mathrm{K}^{-1} \\
\nabla \mathrm{T} & =\text { temperature gradient }, \mathrm{K} / \mathrm{cm} \\
\mathrm{C} & =\text { concentration, } \mathrm{g} / \mathrm{cm}^{3}
\end{aligned}
$$

The heat flux is

$$
\mathrm{q}=\mathrm{k} \nabla \mathrm{T}
$$

where

$$
\begin{aligned}
& \mathrm{q}=\text { heat } \mathrm{flux}, \mathrm{W} / \mathrm{cm}^{2} \\
& \mathrm{k}=\text { thermal conductivity, W/cm K}
\end{aligned}
$$$$
\text { Assume that the thickness of the diffusion and thermal boundary layers }
$$
are $\delta_{d}$ and $\delta_{t}$ respectively. Therefore for linear gradients 


$$
\begin{aligned}
& \nabla T=\frac{T_{w}-T_{b}}{\delta_{t}} \\
& \nabla C=\frac{C_{w}-C_{b}}{\delta_{d}}
\end{aligned}
$$

where the subscripts $w$ and $b$ refer to the wall and bulk fluid respectively. Dividing Eq. (1B) by (2B), utilizing Eq. (3B) and (4B), and rearranging,

$$
\frac{\Phi}{q}=\frac{D}{k}\left[\left(\frac{C_{w}-C_{b}}{T_{w}-T_{b}}\right)\left(\frac{\delta_{t}}{\delta_{d}}\right)+s C\right]
$$

The ratio of the boundary layer thickness can be expressed as a function of the Lewis number, Le. The Lewis number is a ratio of the thermal diffusivity and the diffusion coefficient. Jung and Delisle ${ }^{1}$ assume that

$$
\delta_{t} / \delta_{d}=\operatorname{Le}^{\mathrm{n}}
$$

where, based on experimental work,

$$
0.3 \leq \mathrm{n} \leq 0.42
$$

As a good approximation,

$$
\frac{C_{w}-C_{b}}{T_{w}-T_{b}}=\frac{d C}{d T}
$$

where $\mathrm{dC} / \mathrm{dT}$ is the slope of the solubility curve at the average temperature. The concentration, $\mathrm{C}$, in $\mathrm{Eq}$. ( $5 \mathrm{~B}$ ) should be the average concentration. Jung and Delisle use $C_{b}$. However, the difference is of no practical significance.

Combining Eq. (5B), (6B), and (7B) and using the bulk fluid concentration, the final equation is obtained:

$$
\frac{\Phi}{q}=\left(\frac{D}{k}\right)\left(L e^{n} \frac{d C}{d T}+S C_{b}\right)
$$




\section{DISTRIBUTION LIST}

ACRES INTERNATIONAL CORPORATION STEWART N. THOMPSON

AEROSPACE CORP

PETER J. ALEXANDRO

LAWRENCE P. BOESCH, PH.D.

BARRETT R. FRITZ

R. L. JOHNSON

KENNETH W. STEPHENS

ALABAMA STATE GEOLOGICAL SURVEY

THORNTON L. NEATHERY

AMERICAN ROCK WRITING RESEARCH JOHN NOXON

APPLIED RESEARCH ASSOCIATES STEVEN WOOLFOLK

ARGONNE NATIONAL LABORATORY

DOUGLAS F. HAMBLEY

WYMAN HARRISON

MARTIN SEITZ

MARTIN J. STEINDLER

STEVE Y. TSAI

ARIZONA NUCLEAR POWER PROJECT HENRY W. RILEY, JR.

ARIZONA STATE UNIVERSITY PAUL KNAUTH

ARKANSAS GEOLOGICAL COMMISSION WILLIAM V. BUSH

ARTHUR D. LITTLE INC CHARLES R. HADLOCK

ATKINS RESEARCH \& DEVELOPMENT-UNITED KINGDOM

T. W. BROYD

ATOMIC ENERCY CONSULTANTS DONALD G. ANDERSON

ATOMIC ENERGY OF CANADA LTD SIEGRUN MEYER

ATOMIC ENERGY RESEARCH ESTABLISHMENTUNITED KINGDOM D. P. HODGKINSON

AUSTRALIAN ATOMIC ENERGY COMMISSION

BATTELLE MEMORIAL INSTITUTE

JAMES DUGUID

JOHN T. MCGINNIS

JEFFREY L. MEANS

STEPHEN NICOLOSI

CARL SPILKER

BATTELLE-INSTITUT E.V. UDO T. POHL

BECHTEL NATIONAL INC BEVERLY S. AUSMUS LESLIE J. JARDINE

WILLIAM LI

T. R. MONGAN

BENDIX FIELD ENGINEERING CORP

LARRY M. FUKUI

CHARLES A. JONES

ANTHONY ZAIKOWSKI

BERKELEY GEOSCIENCES/HYDROTECHNIQUE

ASSOCIATES

BRIAN KANEHIRO

BHABHA ATOMIC RESEARCH CENTRE-INDIA V. SUKUMORAN

BILOXI PUBLIC LIBRARY

BLACK \& VEATCH

M. JOHN ROBINSON

BRENK SYSTEMPLANUNG-W. GERMANY

H. D. BRENK

BRIGHAM YOUNG UNIVERSITY

WILLIAM M. TIMMINS

BRITISH GEOLOGICAL SURVEY

DAVID MICHAEL MCCANN
BROOKHAVEN NATIONAL LABORATORY M. S. DAVIS

BROOME COMMUNITY COLLEGE BRUCE OLDFIELD

BUNDESANSTALT FUR GEOWISSENSCHAFTEN

UND ROHSTOFFE-W. GERMANY

MICHAEL LANGER

HELMUT VENZLAFF

BUREAU DE RECHERCHES GEOLOGIQUES ET

MINIERES-FRANCE

BERNARD FEUGA

PIERRE F. PEAUDECERF

BUTLER UNIVERSITY

PAUL VAN DER HEIJDE

BUTTES GAS \& OIL COMPANY ROBERT NORMAN

CALIFORNIA DEPT OF CONSERVATION PERRY AMIMITO

CANVIRO CONSULTANTS DOUG METCALFE

CAPITAL AREA GROUND WATER

CONSERVATION COMMISSION GEORCE T. CARDWELL

CELSIUS ENERGY COMPANY NICK THOMAIDIS

CENTER FOR ENVIRONMENTAL HEALTH CAMERON MCDONALD VOWELL

CENTER FOR INTERDISCIPUINARY STUDIES DAVID M. ARMSTRONG

CHEM NUCLEAR SYSTEMS INC W. VON BLACK

CHEVRON OIL FIELD RESEARCH COMPANY BJORN PAULSSON

CITIZENS AGAINST NUCLEAR DISPOSAL INC STANLEY D. FLINT

CLARK UNIVERSITY JEANNE X. KASPERSON

CLIFFS ENGINEERING INC GARY D. AHO

COLBY COLLEGE BRUCE F. RUEGER

COLORADO GEOLOGIC INC MIKE E. BRAZIE

COLORADO GEOLOGICAL SURVEY JOHN W. ROLD

COLORADO SCHOOL OF MINES W. HUSTRULID

COLUMBIA UNIVERSITY

M. ASHRAF MAHTAB

COPPEJFR! LUIZ OLIVEIRA

CORNELL UNIVERSITY ARTHUR L. BLOOM DUANE CHAPMAN FRED H. KULHAWY ROBERT POHL

CORSTAR RESEARCH INC DOUGLAS K. VOGT

COUNCIL OF ENERGY RESOURCE TRIBES WYATT M. ROGERS, JR.

D.R.E. KARL J. ANANIA

DAMES \& MOORE RON KEAR CHARLES R. LEWIS LES SKOSKI

DEAF SMITH COUNTY LIBRARY

DEPT OF ENERGY, MINES AND RESOURCES CANADA
A. S. JUDGE

DESERET NEWS JOSEPH BAUMAN

DEUTSCHE GESELLSCHAFT ZUM BAU UND

BETRIEB VON ENDLAGERN FUR GERNOT GRUBLER

DISPOSAL SAFETY INC BENJAMIN ROSS

DMGA, IPT-BRAZIL C. DINIS DA GAMA

DUNN GEOSCIENCE CORP WILLIAM E. CUTCLIFFE

DYNATECH RESEARCH/DEVELOPMENT COMPANY STEPHEN E. SMITH

E.I. DU PONT DE NEMOURS \& CO ANN L. P. LINDNER

E.R. JOHNSON ASSOCIATES INC E. R. JOHNSON C. L. JOHNSON

EARTH RESOURCE ASSOCIATES INC SERGE GONZALES

EARTH SCIENCE AND ENGINEERING INC LOU BLANCK

EARTH SCIENCES CONSULTANTS INC HARRY L. CROUSE

ECOLOGY \& ENVIRONMENT INC MICHAEL BENNER

ECOLOCY CENTER OF LOUISIANA ROSS VINCENT

EDS NUCLEAR INC C. SUNDARARAJAN

EG \& G IDAHO INC BRENT F. RUSSELL

ELEKTRIZITAETS-GES. LAUFENBURG -

SWITZERLAND H. N. PATAK

ELSAM-DENMARK ARNE PEDERSEN

ENERGY FUELS NUCLEAR INC DON M. PILLMORE

ENERGY RESEARCH GROUP INC MARC GOLDSMITH

ENGINEERING ANALYSIS INC WILLIAM MULLEN

ENGINEERS INTERNATIONAL INC LIBRARY V. RAIARAM

ENVIRONMENTAL DEFENSE FUND JAMES B. MARTIN

ENVIRONMENTAL POLICY INSTITUTE DAVID M. BERICK

ENVIROSPHERE COMPANY ROGER G. ANDERSON

DXXON COMPANY MICHAEL. FARRELL

F.J. SCHLUMBERGER PETER ALEXANDER

FENIX \& SCISSON INC CHARLENE U. SPARKMAN

FERRIS STATE COLLEGE MICHAEL E. ELLS

FINNISH CENTRE FOR RADIATION AND NUCLEAR SAFETY KAI IAKOBSSON

FLORIDA INSTITUTE OF TECHNOLOGY JOSEPH A. ANGELO, IR.

FLORIDA STATE UNIVERSITY JOSEPH F. DONOGHUE

FLUOR TECHNOLOCY INC WILLIAM LEE (F2X) THOMAS O. MALLONEE, JR (F2X) 
FOUR CORNERS COMMUNITY MENTAL HEALTH CENTER BOB GREENBERG

FREIE UNIVERSITAET BERLIN HANSKARL BRUEHL

FRIENDS OF THE EARTH JEAN BROCKLEBANK RENEE PARSONS

FUTURE RESOURCES ASSOCIATES INC ROBERT I. BUDNITZ

GA TECHNOLOGIES INC ROBERT M. BURGOYNE MICHAEL STAMATELATOS

GARTNER LEE ASSOCIATES LTD-CANADA ROBERT E. J. LEECH

GEOLOGICAL SURVEY OF CANADA JEFFREY HUME LIBRARY

GEOLOGICAL SURVEY OF NORWAY SIGURD HUSEBY

GEOMIN INC STANLEY R. SPICER

GEORGIA INSTITUTE OF TECHNOLOGY GEOFFREY C. EICHHOLZ ALFRED SCHNEIDER CHARLES E. WEAVER

GEOSTOCK-FRANCE CATHERINE GOUGNAUD

GEOSYSTEMS RESEARCH INC RANDY L. BASSETT

GEOTHERMAL ENERGY INSTITUTE DONALD F. X. FINN

GEOTRANS INC JAMES MERCER

GESELLSCHAFT F. STRAHLEN U. UMWELTFORSCHUNG M.B.H.W. GERMANY WOLFGANG BODE HANS W. LEVI H. MOSER

GI.SFT/COMMONWEALTH JERRY L. ELLIS

GOLDER ASSOCIATES MELISSA MATSON J. W. VOSS

GOLDER ASSOCIATES-CANADA CLEMENT M. K. YUEN

GRIMCO DONALD H. KUPFER

GRUPPE OKOLOGIE (COK) JURGEN KREUSCH

GULF INTERSTATE ENGINEERING THOMAS I. HILL

GULF STATES UTILITIES COMPANY JOHN E. BARRY

GUSTAVSON ASSOCIATES RICHARD M. WINAR

$H$ \& R TECHNICAL ASSOCIATES INC WILLIAM R. RHYNE

H. LAWROSKI \& ASSOCIATES P.A. HARRY LAWROSKI

H-TECH LABORATORIES INC BRUCE HARTENBAUM

HANFORD OVERSIGHT COMMITTEE LARRY CALDWELL

HART-CROWSER AND ASSOCIATES MICHAEL BAILEY

HARVARD UNIVERSITY CHARLES W. BURNHAM DADE W. MOELLER RAYMOND SIEVER

HARZA ENGINEERING COMPANY PETER CONROY
HATTIESBURG PUBLIC LIBRARY

HIGH LEVEL NUCLEAR WASTE OFFICE PATRICK D. SPURGIN (20)

HIGH PLAINS WATER DISTRICT DON MCREYNOLDS A. WAYNE WYATT

HITACHI WORKS, HITACHI LTD MAKOTO KIKUCHI

HOUGH-NORWOOD HEALTH CARE CENTER GEORGE H. BROWN, M.D.

ILLINOIS DEPT OF NUCLEAR SAFETY JOHN COOPER TERRY R. LASH

ILL!NO STATE GEOLOGICAL SURVEY KEISOS CARTWRIGHT MORRIS W. LEIGHTON E. DONALD MCKAY, III

IMPERIAL COLLEGE OF SCIENCE AND TECHNOLOGY-ENGLAND B. K. ATKINSON

INDIANA GEOLOGICAL SURVEY MAURICE BICGS

INDIANA UNIVERSITY CHARLES J. VITALIANO

INSTITUT FUR GEOGRAPHIE ECKHARD GRIMMEL

INSTITUT FUR TIEFLAGERUNG-W. GERMANY WERNT BREWITZ H. GIES E. R. SOLTER

INSTITUTE OF GEOLOGICAL SCIENCESENGLAND STEPHEN THOMAS HORSEMAN

INTER/FACE ASSOCIATES INC RON CINGERICH

INTERA TECHNOLOGIES INC JAMES E. CAMPBELI F. I. PEARSON, JR. JOHN F. PICKENS

INTERNATIONAL ENGINEERING COMPANY INC MAX ZASLAWSKY

INTERNATIONAL RESEARCH AND EVALUATION R. DANFORD

INTERNATIONAL SALT COMPANY JOHN VOIGT

IOWA STATE COMMERCE COMMISSION

IOWA STATE UNIVERSITY BERNARD I. SPINRAD

IRAD-GAGE

R. BOYD MONTCOMERY

ISHIKAWAIIMA-HARIMA HEAVY INDUSTRIES COMPANY LTD YOZO ISOGAI

ISTITUTO SPERIMENTALE MODELII E STRUTTURE

S.P.A.-ITALY FERRUCCIO GERA

IT CORP

MORRIS BALDERMAN

PETER C. KELSALL

LIBRARY

CARL E. SCHUBERT

ITASCA CONSULTING GROUP INC CHARLES FAIRHURST ROGER HART

J.F.T. AGAPITO \& ASSOCIATES INC MICHAEL P. HARDY CHRISTOPHER M. ST. JOHN

I.L. MAGRUDER \& ASSOCIATES J. L. MAGRUDER

IACOBY \& COMPANY CHARLES H. JACOBY

IAY L. SMITH COMPANY INC JAY L. SMITH
IGC CORPORATION-JAPAN MASAHIKO MAKINO

JOHNS HOPKINS UNIVERSITY IARED L. COHON

KALAMAZOO COLLEGE RALPH M. DEAL

KANSAS DEPT OF HEALTH AND ENVIRONMENT GERALD W. ALLEN

KANSAS STATE GEOLOGICAL SURVEY WILLIAM W. HAMBLETON

KELLER WREATH ASSOCIATES FRANK WREATH

KERNFORSCHUNCSZENTRUM KARLSRUHE GMBH-W. GERMANY K. D. CLOSS

KERNFORSCHUNGSZENTRUM UND

UNIVERSITAT-W. GERMANY STEFAN GAHLERT

KETTERING FOUNDATION ESTUS SMITH

KIERSCH ASSOCIATES GEOSCIENCES/RESOURCES CONSULTANTS INC GEORGE A. KIERSCH, PH.D.

KIHN ASSOCIATES HARRY KIHN

KLM ENGINEERING INC B. GEORGE KNIAZEWYCZ

KUTA RADIO

KUTV-TV ROBERT LOY

LACHEL HANSEN \& ASSOCIATES INC DOUGLAS E. HANSEN

LAKE SUPERIOR REGION RADIOACTIVE WASTE PROJECT C. DIXON

LAWRENCE BERKELEY LABORATORY

JOHN A. APPS

EUGENE BINNALL

NORMAN M. EDELSTEIN

M. S. KING

E. MAIER

CHIN FU TSANG

J. WANG

LAWRENCE LIVERMORE NATIONAL

LABORATORY

EDNA M. DIDWELL

HUGH HEARD

FRANCOIS E. HEUZE

NAI-HSIEN MAO

LAWRENCE MCKAGUE

THOMAS E. MCKONE

WILLIAM J. OCONNELL

ABELARDO RAMIREZ

LAWRENCE D. RAMSPOTT (2)

TECHNICAL INFORMATION DEPARTMENT JESSE L. YOW, JR.

LEAGUE OF WOMEN VOTERS OF UTAH SANDY PECK

LEAGUE OPPOSING SITE SELECTION LINDA S. TAYLOR

LEGISLATIVE COMMISSION ON SCIENCE \& TECHNOLOGY DALE M. VOLKER

LEIGHTON AND ASSOCIATES INC BRUCE R. CLARK

LIBRARY OF MICHIGAN RICHARD J. HATHAWAY

IOCKHEED ENGINEERING \& MANAGEMENT COMPANY STEVE NACHT

LOS ALAMOS NATIONAL LABORATORY ERNEST A. BRYANT

B. CROWE 
AREND MEIJER

C. W. MYERS

DONALD T. OAKLEY

LOUISIANA DEPT OF ENVIRONMENTAL

QUALITY

L. HALL BOHLINGER (3)

LOUISIANA GEOLOCICAL SURVEY

RENWICK P. DEVILLE

JAMES J. FRILOUX

SYED HAQUE

LOUISIANA STATE UNIVERSITY JEFFREY S. HANOR

LOUISIANA TECHNICAL UNIVERSITY

R. H. THOMPSON

LUMMUS CREST INC

JOHN PIRRO

LYLE FRANCIS MINING COMPANY LYLE FRANCIS

M.J. OCONNOR \& ASSOCIATES ITD M. J. OCONNOR

MARYLAND DEPT OF HEALTH \& MENTAL HYGIENE

WILLIAM M. EICHBAUM

MAX EISENBERG

MASSACHUSETTS INSTITUTE OF TECHNOLOGY

RICHARD K. LESTER

DANIEL METLAY

MCDERMOTT INTERNATIONAL KAREN L. FURLOW

MCMASTER UNIVERSITY-CANADA L. W. SHEMILT

MELLEN GEOLOGICAL ASSOCIATES INC FREDERIC F. MELLEN

MEMBERS OF THE GENERAL PUBLIC

L. ROBERT ANDERSON

PAUL L. ARCHER

ROGER H. BROOKS

LAWRENCE CHASE, PH.D.

TOM \& SUSAN CLAWSON

STEVE CONEWAY

ROBERT H. CURTIS

GHISLAIN DEMARSILY

GERALD A. DRAKE, M.D.

ROBERT EINZIGER

WARREN EISTER

CARL A. GIESE

DONALD GILLIS

KENNETH GUSCOTT

MICHAEL T. HARRIS

MICHAEL R. HELFERT

JOSEPH M. HENNIGAN

B. IEANINE HULL

CHARLES B. HUNT

HAROLD L. JAMES

KENNETH S. JOHNSON

LINDA LEHMAN

CLIVE MACKAY

DUANE MATLOCK

W. D. MCDOUGALD

MAX MCDOWELL

A. ALAN MOGHISSI

TONY MORGAN

CAROLINE PETT

L. M. PIERSON

RUS PURCELL

PETER J. SABATINI, JR.

ZUBAIR SALEEM

OWEN SEVERANCE

LEWIS K. SHUMWAY

HARRY W. SMEDES

P. E. STRALEY-GREGA

M. J. SZULINSKI

SUSAN D. WILTSHIRE
MERRIMAN AND BARBER CONSULTINC

ENGINEERS INC

GENE R. BARBER

MESA VERDE GAS \& OIL COMPANY ELLIOTT A. RIGGS

MICHIGAN DEPT OF PUBLIC HEALTH ARTHUR W. BLOOMER ERIC SCHWING

MICHIGAN DISTRICT. HEALTH DEPT NO. 4 EDGAR KREFT

MICHIGAN ENVIRONMENTAL COUNCIL ROOM 305

MICHIGAN GEOLOGICAL SURVEY ROBERT C. REED

MICHIGAN TECHNOLOGICAL UNIVERSITY DAE S. YOUNG

MICHIGAN UNITED CONSERVATION CLUBS WAYNE SCHMIDT

MIDDLETON LIBRARY

M. S. BOLNER

MINE CRAFT INC NORBERT PAAS

MINNESOTA GEOLOGICAL SURVEY MATT S. WALTON

MISSISSIPPI ATTORNEY GENERALS OFFICE MACK CAMERON

MISSISSIPPI BUREAU OF GEOLOGY MICHAEL B. E. BOGRAD

MISSISSIPPI DEPT OF ENERGY AND

TRANSPORTATION RONALD |. FORSYTHE (3) KELLY HAGGARD

MISSISSIPPI DEPT OF NATURAL RESOURCES ALVIN R. BICKER, JR. CHARLES L. BLALOCK

MISSISSIPPI DEPT OF WILOLIFE CONSERVATION KENNETH L. GORDON

MISSISSIPPI LIBRARY COMMISSION SARA TUBB

MISSISSIPPI MINERAL RESOURCES INSTITUTE

MISSISSIPPI STATE DEPT OF HEALTH EDDIE S. FUENTE GUY R. WILSON

MISSISSIPPI STATE UNIVERSITY TROY J. LASWELL VICTOR L. ZITTA

MITRE CORP LESTER A. ETTLINGER

MONTICELLO NUCLEAR WASTE INFORMATION OFFICE CARL-EISEMANN (2)

MORRISON-KNUDSEN COMPANY INC MICHELLE L. PAURLEY

MURPHY OIL USA INC RANDALL L MAUD

NAGRA-SWITZERLAND CHARLES MCCOMBIE

NATIONAL ACADEMY OF SCIENCES JOHN T. HOLLOWAY

NATIONAL BOARD FOR SPENT NUCLEAR FUEL, KARNBRANSLENAMDEN-SWEDEN NILS RYDELL

NATIONAL HYDROLOGY RESEARCH

INSTITUTE-CANADA DENNIS J. BOTTOMLEY

K. U. WEYER

NATIONAL PARK SERVICE

CECIL D. LEWIS, JR.

L. L. MINTZMEYER

PETER L. PARRY

NATIONAL PARKS \& CONSERVATION ASSOCIATION TERRI MARTIN
NATIONAL SCIENCE FOUNDATION ROYAL E. ROSTENBACH

NATIONAL WATER WELL ASSOCIATION VALERIE ORR

NEW HAMPSHIRE HOUSE OF REPRESENTATIVES M. ARNOLD WICHT, IR.

NEW MEXICO BUREAU OF GEOLOCY BILL HATCHELL

NEW MEXICO ENVIRONMENTAL EVALUATION GROUP

ROBERT H. NEILL

NEW MEXICO INSTITUTE OF MINING AND TECHNOLOCY IOHN L. WILSON

NEW YORK ENERGY RESEARCH \&

DEVELOPMENT AUTHORITY JOHN P. SPATH (8)

NEW YORK STATE ASSEMBLY WILLIAM B. HOYT

NEW YORK STATE DEPT OF ENVIRONMENTAL CONSERVATION PAUL MERGES

NEW YORK STATE GEOLOGICAL SURVEY IAMES R. ALBANESE ROBERT H. FICKIES

NEW YORK STATE HEALTH DEPT JOHN MATUSZEK

NEW YORK STATE PUBLIC SERVICE COMMISSION FRED HAAG

NEYER, TISEO, \& HINDO LTD KAL. R. HINDO

NORTH CAROLINA STATE UNIVERSITY M. KIMBERLEY

NORTH DAKOTA GEOLOGICAL SURVEY DON L. HALVORSON

NORTHWEST REGIONAL PLANNING COMMISSION MARK J. MUELLER

NORTHWESTERN UNIVERSITY BERNARD J. WOOD

NUCLEAIRE HYDRO LTD JOHN WILLIAM KENNEY, III

NUCLEAR ASSURANCE CORP JOHN V. HOUSTON

NUCLEAR ENERGY AGENCY/OECD-FRANCE ANTHONY MULLER

NUCLEAR REGULATORY COMMISSION BANAD N. JAGANNATH

NUCLEAR SAFETY RESEARCH ASSOCIATION HIDETAKA ISHIKAWA

NUCLEAR WASTE CONSULTANTS ADRIAN BROWN

NUS CORP

W. G. BELTER DOUGLAS D. ORVIS

NWT CORP W. L. PEARL

OAK RIDGE NATIONAL LABORATORY J. O. BLOMEKE

H. C. CLAIBORNE

ALLEN G. CROFF

DAVID C. KOCHER

T. F. LOMENICK

E. M. OBLOW

FRANCOIS G. PIN

ELLEN D. SMITH SUSAN K. WHATLEY

OHIO DEPT OF HEALTH ROBERT M. QUILLIN

OKLAHOMA STATE DEPT OF HEALTH R. L. CRAIC 
ONTARIO DEPT OF CIVIL ENGINEERING F. SYKES

ONTARIO HYDRO-CANADA

$$
\text { K. A. CORNELL }
$$

C. F. LEE

ONWI

JAMES R. SCHORNHORST

ORANGE COUNTY COMMUNITY COLLEGE LAWRENCE E. OBRIEN

ORECON DEPT OF ENERGY

DAVID A. STEWART-SMITH

PACIFIC NORTHWEST LABORATORY

DON I. BRADLEY

H. C. BURKHOLDER

CHARLES R. COLE

HARVEY DOVE

FLOYD N. HODGES

CHARLES T. KINCAID

I. M. LATKOVICH

J. M. RUSIN

R. JEFF SERNE

STEVEN C. SNEIDER

R. E. WESTERMAN

PARSONS BRINCKERHOFF QUADE \& DOUGLAS INC

T. R. KUESEL

ROBERT PRIETO

PARSONS BRINCKERHOFF/PB-KBB

J. R. SCHMEDEMAN

PARSONS-REDPATH

KRISHNA SHRIYASTAVA

GLEN A. STAFFORD

PB-KBB INC

JUDITH G. HACKNEY

PENNSYLVANIA STATE UNIVERSITY

MICHAEL GRUTZECK

DELLA M. ROY

WILLIAM B. WHITE

PERMIAN BASIN REGIONAL PLANNING

COMMISSION

E. W. CRAWFORD

PERRY COUNTY CITIZENS AGAINST NUCLEAR

WASTE DISPOSAL

DOROTHY G. COLE

DURLEY HANSEN

PHYSIKALISCH-TECHNISCHE BUNDESANSTALT-

W. GERMANY

PETER BRENNECKE

POTASH CORPORATION OF SASKATCHEWAN -

CANADA

GRAEME C. STRATHDEE

POTASH CORPORATION OF SASKATCHEWAN

MINING LIMITED

PARVIZ MOTTAHED

POWER REACTOR AND NUCLEAR FUEL

DEVELOPMENT CORP-JAPAN

PRESEARCH INC

MARTIN S. MARKOWICZ

PROGRAM REVIEW COMMITTEE THOMAS H. LANGEVIN

R.J. SHLEMON AND ASSOCIATES INC R. J. SHLEMON

RANDALL COUNTY UBRARY

RAYMOND KAISER ENGINEERS

W. J. DODSON

RESSPEC INC

GARY D. CALLAHAN

PAUL F. GNIRK

RENSSELAER POIYTECHNIC INSTITUTE BRIAN BAYLY

RHODE ISLAND OFFICE OF STATE PLANNING BRUCE VILD
RISO NATIONAL LABORATORY-DENMARK LARS CARLSEN

ROCKWELL HANFORD OPERATIONS

RONALD C. ARNETT

HARRY BABAD

G. S. BARNEY

KUNSOO KIM

KARL M. LA RUE

MICHAEL J. SMITH

ROCKWELL INTERNATIONAL ENERGY SYSTEMS GROUP

ROGERS \& ASSOCIATES ENGINEERING CORP ARTHUR A. SUTHERLAND ROBERT WILEMS

ROY F. WESTON INC

DAVID F. FENSTER

MARTIN HANSON

VIC MONTENYOHL

SAM PANNO

JILL RUSP!

LAWRENCE A. WHITE

ROYAL INSTITUTE OF TECHNOLOGY-SWEDEN IVARS NERETNIEKS ROGER THUNVIK

ROYCES ELECTRONICS INC ROYCE HENNINGSON

S.E. LOGAN \& ASSOCIATES INC STANLEY E. LOGAN

SALT LAKE CITY TRIBUNE JIM WOOLF

SAN JUAN RECORD JOYCE MARTIN

SANDIA NATIONAL LABORATORIES

JOY BEMESDERFER

MARCARET S. CHU

ROBERT M. CRANWELL

IOE A. FERNANDEZ

ROBERT CUZOWSK!

THOMAS O. HUNTER

A. R. LAPPIN

RUDOLPH V. MATALUCCI

MARTIN A. MOLECKE

IAMES T. NEAL

E. I. NOWAK

SCOTT SINNOCK

LYNN D. TYLER

SARGENT \& LUNDY ENGINEERS LAWRENCE L. HOLISH

SAVANNAH RIVER LABORATORY

$$
\text { E. J. HENNELLY }
$$

CAROL JANTZEN

SCIENCE APPLICATIONS INTERNATIONAL CORP MARY LOU BROWN

BARRY DIAL

JAMES E. HAMMELMAN

ROBERT R. JACKSON

DEAN C. KAUL

DAVID H. LESTER

JOHN E. MOSIER

DOUGLAS A. OUTLAW

HOWARD PRATT

MICHAEL E. SPAETH

ROBERT T. STULA

M. D. VOEGELE

KRISHAN K. WAHI

SENECA COUNTY DEPT OF PLANNING \&

DEVELOPMENT

SHAFER EXPLORATION COMPANY WILLIAM E. SHAFER

SHANNON \& WILSON INC

HARVEY W. PARKER

FRANK S. SHURI
SHELL OIL COMPANY PHILIP BERGER

SHIMIZU CONSTRUCTION COMPANY

LTD-IAPAN

TAKASHI ISHII

SIERRA CLUB

MARVIN RESNIKOFF

BROOKS YEAGER

SIERRA CLUB-COLORADO OPEN SPACE

COUNCIL

ROY YOUNC

SIERRA CLUB-MISSISSIPPI CHAPTER

SIERRA CLUB LEGAL. DEFENSE FUND H. ANTHONY RUCKEL

SIMECSOL CONSULTING ENGINEERS-FRANCE MATTHEW LEONARD

SKBF/KBS-SWEDEN

C. THEGERSTROM

SOGO TECHNOLOCY INC TIO C. CHEN

SOUTH CAROLINA GOVERNORS OFFICE JOHN J. STUCKER

SOUTH DAKOTA GEOLOGICAL SURVEY MERLIN I. TIPTON

SOUTH DAKOTA OFFICE OF ENERCY POLICY STEVEN M. WEGMAN

SOUTHERN CALIFORNIA EDISON CO JOHN LADESICH

SOUTHWEST RESEARCH AND INFORMATION CENTER DON HANCOCK

SPRING CREEK RANCH DALTON RED BRANGUS

SRI INTERNATIONAL (PS 285) DIGBY MACDONALD

ST \& E TECHNICAL SERVICES INC STANLEY M. KLAINER

STANFORD UNIVERSITY KONRAD B. KRAUSKOPF

GEORGE A. PARKS IRWIN REMSON

STATE PLANNING AGENCY GREGG LARSON

STATE UNIVERSITY OF NEW YORK AT CORTLAND

JAMES E. BUGH

STONE \& WEBSTER ENGINEERING CORP JOHN PECK EVERETT M. WASHER

STUDIO GEOLOGICO FOMAR-ITALY A. MARTORANA

STUDSVIK ENERGITEKNIK AB-SWEDEN ROLF SJOBLOM

SWEDISH GEOLOGICAL LEIF CARLSSON

SWISHER COUNTY UIBRARY

SYRACUSE UNIVERSITY WALTER MEYER I. E. ROBINSON

SYSTEMS SCIENCE AND SOFTWARE PETER LACUS

TECHNICAL INFORMATION PROJECT DONALD PAY

TERRA TEK INC DANIEL D. BUSH

TERRAFORM ENGINEERS INC FRANCIS S. KENDORSKI

TEXAS A \& M UNIVERSITY JOHN HANDIN JAMES E. RUSSELL

TEXAS BUREAU OF ECONOMIC GEOLOGY WILLIAM L. FISHER 
AS DEPT OF HEALTH

DAVID K. LACKER

TEXAS DEPT OF WATER RESOURCES

W. KLEMT

T. KNOWLES

TEXAS GOVERNORS OFFICE STEVE FRISHMAN

TEXAS STATE HOUSE OF REPRESENTATIVES JULIE CARUTHERS

TEXAS WORLD OPERATIONS INC DAVID JEFFERY

THE ANALYTIC SCIENCES CORP JOHN W. BARTLETT CHARLES M. KOPLIK

THE BENHAM GROUP KEN SENOUR

THE DAILY SENTINEL JIM SULLIVAN

THE EARTH TECHNOLOGY CORP FRED A. DONATH (2)

DAN MELCHIOR

IAMES R. MILLER

FIA VITAR

MATT WERNER

KENNETH L. WILSON

THOMSEN ASSOCIATES

C. T. GAYNOR, II

TIMES.PICAYUNE MARK SCHLEIFSTEIN

TIOGA COUNTY PLANNING BOARD THOMAS A. COOKINGHAM

TRINITY EPISCOPAL CHURCH BENIAMIN F. BELL

U.H.D.E.-W. GERMANY FRANK STEINBRUNN

U.S. ARMY CORPS OF ENGINEERS DON BANKS ALAN BUCK ANDY OBROCHTA

U.S. BUREAU OF LAND MANAGEMENT GENE NODINE EDWARD R. SCHERICK GREGORY F. THAYN

U.S. BUREAU OF MINES ANTHONY IANNACCHIONE

U.S. BUREAU OF RECLAMATION ATTN:

JOHN BROWN AL R. JONEZ

U.S. DEPT OF COMMERCE PETER A. RONA

U.S. DEPT OF ENERGY RICHARD BLANEY REBECCA BOYD R. COOPERSTEIN NEAL DUNCAN JIM FIORE LAWRENCE H. HARMON D. L. HARTMAN MICHAELENE PENDLETON (2) PUBLIC READING ROOM JANIE SHAHEEN

U.S. DEPT OF ENERGY-ALBUQUERQUE OPERATIONS OFFICE LORETTA HELLINC

U.S. DEPT OF ENERCY-CHICACO OPERATIONS OFFICE

ERIC J. MOTZ

PUBLIC READINC ROOM R. SELBY DEPT OF ENERGY-DALLAS SUPPORT FFICE CURTIS E. CARLSON, JR.
U.S. DEPT OF ENERGY-ENGINEERING AND LICENSINC DIVISION RALPH STEIN

U.S. DEPT OF ENERGY-IDAHO OPERATIONS OFFICE

JAMES F. LEONARD

PUBLIC READING ROOM

U.5. DEPT OF ENERGY - OAK RIOCE

OPERATIONS OFFICE PUBLIC READING ROOM

U.S. DEPT OF ENERGY-OFFICE OF ENERGY RESEARCH

FRANK I. WOBBER

U.S. DEPT OF ENERGY-OSTI (317)

U.S. DEPT OF ENERGY-REGION VIII SIGRID HIGDON

U.S. DEPT OF ENERGY-RICHLAND OPERATIONS OFFICE

D. H. DAHLEM

U.S. DEPT OF ENERGY-SALT REPOSITORY

PROJECT OFFICE I. O. NEFF

U.S. DEPT OF ENERGY - SAN FRANCISCO OPERATIONS OFFICE PUBLIC READING ROOM

U.S. DEPT OF ENERCY-WIPP ARLEN HUNT

U.S. DEPT OF LABOR KELVIN K. WU

U.S. DEPT OF THE INTERIOR MATTHEW IAMES DEMARCO

F. L. DOYLE PAUL A. HSIEH

U.S. ENVIRONMENTAL PROTECTION AGENCY IAMES NEIHEISEL

U.S. ENVIRONMENTAL PROTECTION AGENCYDENVER REGION VIII PHIL NYBERC

U.S. ENVIRONMENTAL PROTECTION AGENCY REGION II JOYCE FELDMAN

U.S. FOREST SERVICE JOSEPH E. CLAYTON

U.S. GEOLOGICAL SURVEY GEORGE A. DINWIDDIE VIRGINIA M. GLANZMAN DARWIN KNOCHENMUS GERHARD W. LEO EDWIN ROEDDER JACOB RUBIN RAYMOND D. WATTS

U.S. GEOLOGICAL SURVEY-COLUMBUS A. M. LA SALA, JR.

U.S. GEOLOCICAL SURVEY-DENVER M. S. BEDINGER JESS $M$. CLEVELAND ROBERT J. HITE FREDERICK L. PAILLET WILLIAM WILSON

U.S. GEOLOGICAL SURVEY-IACKSON GARALD C. PARKER, JR.

U.S. GEOLOGICAL SURVEY-MENLO PARK MICHAEL CLYNNE

U.S. GEOLOGICAL SURVEY-RESTON I-MING CHOU NEIL PLUMMER EUGENE H. ROSEBOOM, JR. DAVID B. STEWART NEWELL J. TRASK, JR.

U.S. GEOLOGICAL SURVEY-WATER RESOURCES DIVISION PETER DAVIES
U.S. NUCLEAR REGULATORY COMMISSION

R. BOYLE

EILEEN CHEN

F. ROBERT COOK

DOCKET CONTROL CENTER

GEOSCIENCES BRANCH

CLYDE JUPITER

PHILIP S. JUSTUS

WALTON R. KELLY

KYO KIM

H. E. LEFEVRE

WILLIAM D. LILLEY

JOHN C. MCKINLEY

EOWARD OCONNELL

SYLVIE L. OLNEY

JEROME R. PEARRING

IACOB PHILIP

DAVID M. ROHRER

FREDERICK W. ROSS

R. JOHN STARMER

JOHN TRAPP

TILAK R. VERMA

MICHAEL WEBER

U.S. SENATE

CARL LEVIN

UINTAH COUNTY LIBRARY

UNION CARBIDE CORP JOHN D. SHERMAN

UNION OF CONCERNED SCIENTISTS MICHAEL FADEN

UNION OIL COMPANY OF CALIFORNIA BRAD GOVREAU

UNITED KINGDOM ATOMIC ENERGY

AUTHORITY

A. B. LIDIARD

UNITED KINGDOM DEPT OF THE

ENVIRONMENT

F. S. FEATES

UNIVERSITY OF ALBERTA-CANADA

F. W. SCHWARTZ

UNIVERSITY OF ARIZONA

JAAK DAEMEN

STANLEY N. DAVIS

I. W. FARMER

KITTITEP FUENKAJORN

AMITAVA GHOSH

JAMES G. MCCRAY

SHLOMO P. NEUMAN

ROY G. POST

UNIVERSITY OF BRITISH COLUMBIA - CANADA R. ALLAN FREEZE

UNIVERSITY OF CALIFORNIA AT LOS ANGELES D. OKRENT

UNIVERSITY OF CALIFORNIA AT RIVERSIDE LEWIS COHEN

UNIVERSITY OF DELAWARE FRANK A. KULACKI

UNIVERSITY OF FLORIDA DOLORES C. JENKINS

UNIVERSITY OF ILLINOIS AT URBANA-

CHAMPAIGN

ALBERT I. MACHIELS

MAGDI RAGHEB

UNIVERSITY OF LOWELL JAMES R. SHEFF

UNIVERSITY OF MARYLAND AMERICAN NUCLEAR SOCIETY LUKE L. Y. CHUANG

UNIVERSITY OF MASSACHUSETTS GEORGE MCGILL

UNIVERSITY OF MISSOURI AT COLUMBIA W. D. KELLER 
UNIVERSITY OF MISSOURI AT KANSAS CITY EDWIN D. GOEBEL SYED E. HASAN

UNIVERSITY OF MISSOURI AT ROLLA ALLEN W. HATHEWAY ARVIND KUMAR

UNIVERSITY OF NEVADA AT RENO BECKY WEIMER-MCMILLION

UNIVERSITY OF NEW MEXICO - HAROLD M. ANDERSON DOUGLAS G. BROOKINS RODNEY C. EWING

UNIVERSITY OF NORTH CAROLINA STEPHEN B. HARPER

UNIVERSITY OF RHODE ISLAND EDWARD P. LAINE

UNIVERSITY OF ROCHESTER DAVID ELMORE

UNIVERSITY OF SOUTHERN MISSISSIPPI CHARLES R. BRENT GEORGE F. HEPNER DANIEL A. SUNDEEN

UNIVERSITY OF TEXAS AT AUSTIN BUREAU OF ECONOMIC GEOLOGY CAROLYN E. CONDON EARNEST F. GLOYNA MARTIN P. A. JACKSON IOE O. LEDBETTER PRISCILLA P. NELSON JOHN M. SHARP, JR.

UNIVERSITY OF TEXAS AT SAN ANTONIO DONALD R. LEWIS

UNIVERSITY OF TOLEDO DON STIERMAN

UNIVERSITY OF UTAH THURE CERLING STEVEN I. MANNINC MARRIOTT LIBRARY JAMES A. PROCARIONE GARY M. SANDQUIST LEE STOKES

UNIVERSITY OF UTAH RESEARCH INSTITUTE LIBRARY DUNCAN FOLEY HOWARD P. ROSS

UNIVERSITY OF WISCONSIN B. C. HAIMSON

UNIVERSITY OF WISCONSIN-MILWAUKEE HOWARD PINCUS

UNIVERSITY OF WYOMING PETER HUNTOON
UNIVERSITY OF WASHINGTON DAVID BODANSKY M. A. ROBKIN

UNIVERSITY OF WESTERN AUSTRALIA LLOYD R. TOWNLEY

URS//OHN A. BLUME \& ASSOCIATES, ENGINEERS ANDREW B. CUNNINGHAM

UTAH DEPT OF NATURAL RESOURCES \& ENERGY MARK P. PACE

UTAH DEPT OF TRANSPORTATION DAVID LLOYD

UTAH DIVISION OF PARKS \& RECREATION EDGE OF THE CEDARS STATE GORDON W. TOPHAM

UTAH DIVISION OF WATER RESOURCES BARRY C. SAUNDERS

UTAH ENERCY OFFICE ROD MILLAR

UTAH GEOLOGICAL AND MINERAL SURVEY MAGE YONETANI

UTAH MULTIPLE USE ADVISORY COUNCIL JOHN M. GARR

UTAH SOUTHEASTERN DISTRICT HEALTH

DEPARTMENT ROBERT L. FURLOW

UTAH STATE GEOLOGIC TASK FORCE DAVID D. TILLSON

UTAH STATE UNIVERSITY DEPT OF GEOLOCY 07 IACK T. SPENCE

VANDERBILT UNIVERSITY FRANK L. PARKER

VERMONT STATE NUCLEAR ADVISORY PANEL VIRGINIA CALLAN

VIRGINIA DEPT OF HEALTH ROBERT G. WICKLINE

VIRGINIA POWER COMPANY B. H. WAKEMAN

WASHINGTON HOUSE OF REPRESENTATIVES RAY ISAACSON

WASHINGTON STATE DEPT OF ECOLOGY DAVID W. STEVENS

WASHINGTON STATE UNIVERSITY NACHHATTER S. BRAR

WATTLAB BOB E. WATT

WEST VALLEY NUCLEAR SERVICES COMPANY INC

LARRY R. EISENSTATT
WESTERN MICHIGAN UNIVERSITY ROBERT KAUFMAN W. THOMAS STRAW

WESTERN STATE COLLEGE FRED R. PECK

WESTINGHOUSE ELECTRIC CORP JAMES H. SALING WIPP PROJECT

WESTINGHOUSE IDAHO NUCLEAR COMPANY INC NATHAN A. CHIPMAN

WESTON GEOPHYSICAL CORPORATION JOHN P. IMSE

WILLIAMS AND ASSOCIATES INC GERRY WINTER

WILLIAMS BROTHERS ENGINEERING COMPANY MICHAEL CONROY

WISCONSIN DEPT OF NATURAL RESOURCES DUWAYNE F. GEBKEN

WISCONSIN STATE SENATE JOSEPH STROHL

WITHERSPOON, AIKEN AND LANGLEY RICHARD FORREST

WOODWARD-CLYDE CONSULTANTS TERRY A. GRANT

A. M. HIRSCH

RANDALL L. LENTELL

ASHOK PATWARDHAN

GARY ROBBINS WESTERN REGION LIBRARY

YALE UNIVERSITY

G. R. HOLEMAN BRIAN SKINNER

YORK COLLEGE OF PENNSYLVANIA JERI LEE JONES 
281

DERIVATION 2

0 